\title{
MONOGRAPHS
}

innsbruck university press

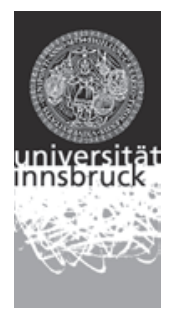



Franz Mathis

\section{Mit der Großstadt aus der Armut Industrialisierung im globalen Vergleich}




\section{Franz Mathis}

Institut für Geschichtswissenschaften und Europäische Ethnologie, Universität Innsbruck

Gedruckt mit Unterstützung des Vizerektorats für Forschung der Universität Innsbruck, der Industriellenvereinigung Tirol, der Industriellenvereinigung Wien, des Landes Vorarlberg, Abteilung Wissenschaft und Weiterbildung, der Linz Textil Holding AG, der voestalpine AG und der Wirtschaftskammer Vorarlberg, Sparte Industrie

(C) innsbruck university press, 2015

Universität Innsbruck

1. Auflage

Alle Rechte vorbehalten.

Umschlagbild: Carol Kofler

www.uibk.ac.at/iup

ISBN 978-3-902936-78-3 
Für Pia und Christine 



\section{Inhaltsverzeichnis}

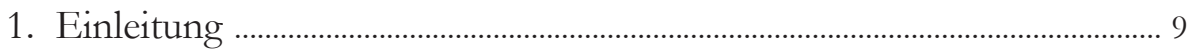

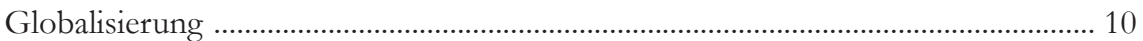

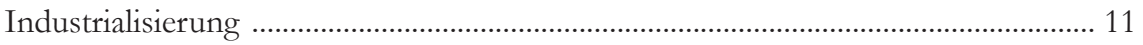

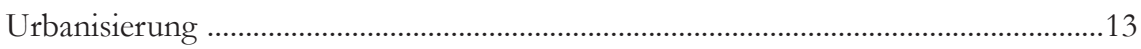

Ohne Urbanisierung keine Industrialisierung ............................................................ 15

Globale Verflechtungen ......................................................................................... 20

Traditionelle Erklärungen ....................................................................................... 24

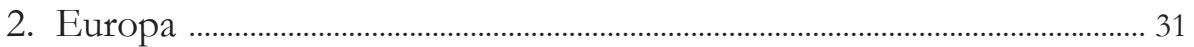

Urbanisierung in der Antike ................................................................................ 31

Urbanisierung im Mittelalter und in der frühen Neuzeit ............................................ 33

Urbanisierung und Industrialisierung im späten 18. und

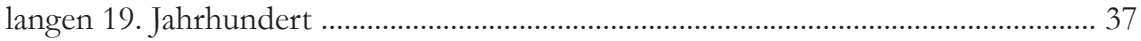

Industrialisierung im 20. Jahrhundert ....................................................................... 49

Von der Industrie- zur urbanen Dienstleistungsgesellschaft ...................................... 61

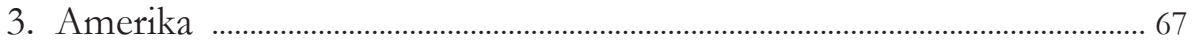

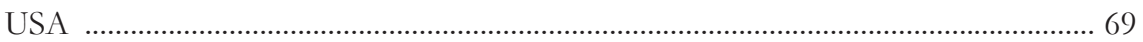

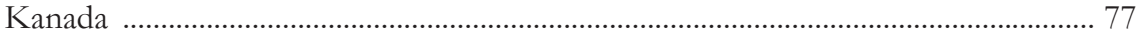

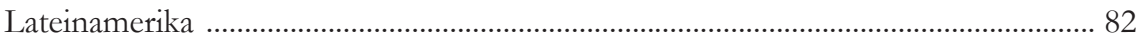

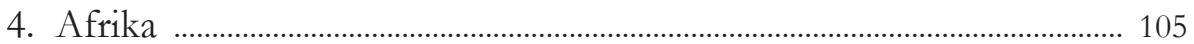

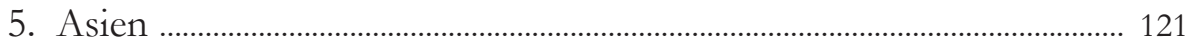

Nord- und Zentralasien .......................................................................................... 122

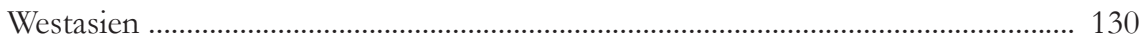

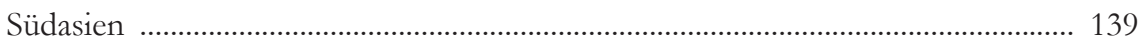

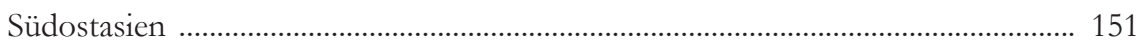

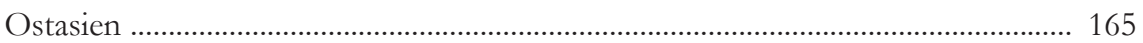

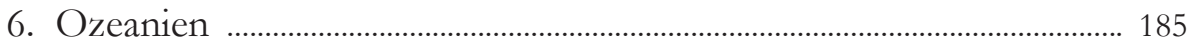

Australien und Neuseeland ..................................................................................... 185 


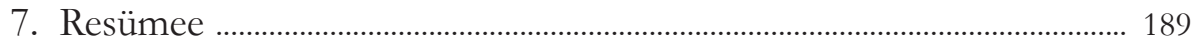

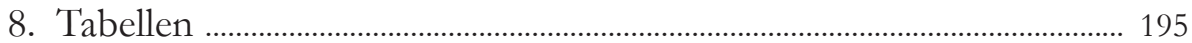

9. Bibliographie ……………………………………………………………..... 223

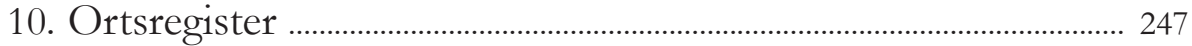




\section{Einleitung}

Arme Länder - reiche Länder, Erste Welt - Dritte Welt, Ausbeutung, Landflucht, Slumbildung. All dies sind Begriffe, über die im Zusammenhang mit globaler wirtschaftlicher Entwicklung fast täglich zu lesen ist. Noch immer sind die durchschnittlichen, kaufkraftbereinigten Pro-Kopf-Einkommen in den USA rund 13 Mal so hoch wie in Indien, in der Schweiz mehr als 40 Mal so hoch wie in Mali. ${ }^{1}$ Noch immer wird behauptet, dass die Erste Welt ihren Wohlstand in hohem Maße der Ausbeutung der Dritten Welt verdanke. Tausende arme Menschen verlassen tagtäglich ihre ländliche Umgebung in der Hoffnung, in den wachsenden Megastädten Arbeit und Einkommen zu finden. Die meisten von ihnen finden sich vorerst in den Elendsvierteln oder Slums wieder, während sich gleichzeitig auch die Wohnviertel der mittleren und oberen Schichten weiter ausbreiten.

Seit Jahren wird versucht, solche und andere Zusammenbänge wirtschaftlicher Entwicklung zu erklären. Eine auch nur ansatzweise Zusammenfassung der Erklärungsversuche, die von Legionen von Wissenschaftlern verschiedener Disziplinen unternommen wurden, würde allein ein ganzes Buch füllen. ${ }^{2}$ Sie sind nicht nur in zahllosen wissenschaftlichen Untersuchungen dargelegt worden, sondern haben vielfach Eingang in die öffentliche Wahrnehmung gefunden. Sie können als allgemein bekannt vorausgesetzt werden und brauchen daher in der Folge weder breit ausgeführt noch im Detail auf ihr Zustandekommen hin analysiert werden. Dennoch sollen die wichtigsten unter ihnen am Ende dieser Einleitung noch einmal kurz vorgestellt und diskutiert werden. Schon hier jedoch sei daraufhin gewiesen, dass die bisherigen Erklärungsversuche einer genaueren Prüfung nicht standhalten. Für die Beispiele, die zu ihrer Untermauerung vorgebracht werden, lassen sich zu viele Gegenbeispiele anführen, um ihre Richtigkeit aufrecht erhalten zu können. Dazu zählt unter anderem die nach wie vor vertretene Meinung, dass der Reichtum der Ersten Welt auf der Armut der Dritten Welt beruhe und umgekehrt. Auch die Behauptungen, dass eigene Rohstoffe für eine erfolgreiche Industrialisierung unabdingbar seien,

1 Schätzungen des Internationalen Währungsfonds für 2013 nach Liste der Länder (Bruttoinlandsprodukt).

2 Einer der ersten, die sich mit dieser Frage auseinandersetzten, war David S. Landes in Landes (1969), dessen zentrale Überlegungen 30 Jahre später noch einmal in Landes (1998) dargelegt wurden. Stellvertretend für jüngere Darstellungen - neben den unten genannten - etwa Broadberry/O'Rourke (2010),Cameron/Neal (2003), Clark (2007), Diamond (1998), Maddison (2001), Maddison (2007), Berend (2006). 
dass bestimmte Religionen oder Mentalitäten eher Industrieunternehmer hervorbrächten als andere, dass klimatische oder andere, speziell in Europa zu beobachtende Bedingungen ausschlaggebend gewesen seien, erweisen sich - wie weiter unten gezeigt wird - bei genauerem Hinsehen als nicht zutreffend. Wo tatsächlich die Gründe für eine günstigere und vor allem breite wirtschaftliche Entwicklung zu suchen sind und warum eine solche bis heute nur relativ wenigen Ländern vorbehalten blieb, wird Gegenstand der folgenden Analyse sein. Sie kreist um die Begriffe Globalisierung, Industrialisierung und Urbanisierung, die es daher zunächst etwas genauer zu beschreiben und auf ihre gegenseitige Interferenz hin zu erläutern gilt.

\section{Globalisierung}

Über Globalisierung ist in den letzten Jahren viel geschrieben worden. Ob es sich bei ihr - wie viele meinen - um ein junges Phänomen handelt oder ob von Globalisierung auch schon in früheren Jahrhunderten gesprochen werden kann, hängt von der Intensität und der Vielfalt der globalen Verflechtungen ab, die man als essentiell für Globalisierung ansieht. Es besteht kein Zweifel, dass die Regionen, Länder und Kontinente heute viel stärker miteinander verknüpft sind als dies zur Zeit von Christoph Kolumbus um 1500 der Fall war. Und doch macht es Sinn, Globalisierung mit den zahlreichen Entdeckungsfahrten seit dem Ende des 15. Jahrhunderts beginnen zu lassen. Sie rückten ständig weitere Teile der Welt in das zuvor auf Europa, Nordafrika und Asien beschränkte Gesichtsfeld der Europäer und ließen umgekehrt auch die Menschen in Amerika, in weiten Teilen Afrikas und in Ozeanien über die ihnen bis dahin bekannte Welt hinausblicken. Die Entdeckungsfahrten erweiterten die Handelsbeziehungen der Europäer über Asien und den Mittelmeerraum hinaus, auch wenn ihr Volumen noch lange Zeit weit hinter dem innereuropäischen Handel zurückblieb. Sie legten aber auch die Basis für die Eroberung vieler außereuropäischer Gebiete durch europäische Kolonialmächte, die sie unterschiedlich lange politisch und zum Teil auch wirtschaftlich beherrschten.

500 Jahre Globalisierung werfen eine Reihe von Fragen auf: Welche Rolle spielten die von außerhalb Europas bezogenen Güter für die wirtschaftliche Entwicklung der europäischen Länder? Inwiefern dienten die außereuropäischen Länder als Absatzmärkte für europäische Waren? In welchem Ausmaß erweiterten die importierten Edelmetalle und die im außereuropäischen Handel erzielten Gewinne den Umfang des in den europäischen Wirtschaften investierten Kapitals? Wie sehr behinderten europäische Exporte 
eine erfolgreiche Industrialisierung außerhalb Europas? Inwiefern wurden den außereuropäischen Ländern Güter entzogen, die sie für die eigene wirtschaftliche Entwicklung benötigt hätten? Wie sehr verhinderten etwaige Kapitalabflüsse nach Europa Investitionen in die eigene Wirtschaft? Wieso konnten sich manche der anfänglich eroberten Gebiete wie die USA, Kanada oder Australien zu hoch entwickelten Volkswirtschaften entwickeln, die meisten anderen aber nicht? Warum erlebten zwei unabhängige, d.h. niemals kolonialisierte Länder wie China und Japan derart unterschiedliche wirtschaftliche Entwicklungen? Wieso verlief auf der anderen Seite die Entwicklung der ersten Kolonialmächte Spanien und Portugal weit weniger dynamisch als die der jüngeren Kolonialmächte England, Frankreich oder der Niederlande? Fragen über Fragen, die mit Globalisierung zu tun haben und denen es im Folgenden nachzugehen gilt.

\section{Industrialisierung}

Ihnen allen ist gemeinsam, dass es um mehr oder weniger Industrialisierung als Schlüssel zum heutigen Wohlstand geht. ${ }^{3}$ Zwar ist es inzwischen auch in anderen Bereichen wie der Landwirtschaft, dem Bank- und Versicherungswesen, in Handel, Verkehr und Tourismus sowie insbesondere im öffentlichen Dienst möglich geworden, hohe Einkommen zu erzielen. Letztlich jedoch wären sie ohne eine erfolgreiche Industrialisierung nicht zu realisieren gewesen. Erst die im Zuge der Industriellen Revolution begonnene, bis heute anhaltende und mit der Verwendung neuer Energieträger verbundene Umstellung von einer manuellen zu einer maschinellen Warenproduktion hatte eine ständige Erhöhung der menschlichen Arbeitsproduktivität zur Folge, und zwar in quantitativer ebenso wie in qualitativer Hinsicht. Dank andauernd effizienter gestalteter Produktionsweisen wurden und werden bis heute nicht nur ständig mehr, sondern auch zunehmend bessere Waren hergestellt als früher. Die wachsende Produktivität erweiterte das pro Kopf und

3 Auf die zentrale Bedeutung der Industrialisierung für die Modernisierung von Wirtschaft und Gesellschaft sowie auf die damit einhergehende Steigerung des jährlich erzeugten Sozialproduktes hat zuletzt auch der bekannte Wirtschaftswissenschaftler Jeffrey D. Sachs, ehemaliger Sonderberater von UNO-Generalsekretär Kofi Annan, hingewiesen. Noch vor 200 Jahren waren die Unterschiede, die in der durchschnittlichen Pro-Kopf-Produktion zwischen einzelnen Ländern und Regionen bestanden, nicht annähernd so groß wie heute. Erst durch die in den einzelnen Ländern zu verschiedenen Zeiten stattgefundene Industrialisierung, die manche Länder in wirtschaftlicher Hinsicht viel rascher wachsen ließ als andere, ging die Schere massiv auseinander. Sachs (2005) auf der Basis der von Angus Maddison errechneten und in Maddison (Per Capita GDP) wiedergegebenen Werte. Dass sich etwa Europa und China, das in den letzten Jahren wieder stärker ins Blickfeld gerückt ist, erst seit dem 19. Jahrhundert auseinander entwickelten, wird unter anderem von Kenneth Pomeranz in Pomeranz (2000) darzulegen versucht. 
Zeiteinheit erzeugte Warenangebot um ein Vielfaches, führte damit tendenziell zu einer Verbilligung der Produkte und erhöhte gleichzeitig die Einkommen der Produzenten. Wo Industrialisierung stattfand, standen den Menschen nicht nur mehr, billigere und vielfach bessere Waren zur Verfügung, sondern sie konnten sich diese dank steigender Einkommen auch leichter leisten. Zwar bedurfte es dazu einer vielfach erst mit Druck erzwungenen, weniger ungleichen Verteilung der höheren Einkommen zwischen Arbeitgebern und Arbeitnehmern, unabdingbare Grundlage steigender Einkommen war jedoch die höhere Produktivität.

Die positive Wirkung steigender Produktivität wurde in der Folge und teilweise parallel zur Mechanisierung und Automatisierung der Produktion über ähnliche Prozesse in anderen Bereichen der Wirtschaft verstärkt. Eisenbahn, Kraftfahrzeuge und Dampfschiffe anstelle von Pferdefuhrwerken und Segelschiffen verbilligten den Transport und erhöhten dank der pro Kopf größeren Transportmengen die Einkommen im Transportgewerbe. Dasselbe gilt für die Landwirtschaft, wo vielseitige Maschinen und Traktoren die Arbeitsproduktivität in die Höhe trieben. Die in diesen und zum Teil auch in anderen Bereichen erzielten Produktivitäts- und Einkommenssteigerungen schufen eine Kaufkraft, die etwa auch dem Tourismus oder dem Bank- und Versicherungswesen zugute kam. Darüber hinaus erlaubten sie die Einhebung von Steuern und Sozialabgaben, mit denen wiederum das Bildungs- und Gesundheitswesen sowie der öffentliche Dienst finanziert werden konnten. Außerdem war es dank steigender Arbeitsproduktivität möglich, all dies mit kürzeren Tages-, Wochen- und Jahresarbeitszeiten zu erreichen. Die Industrialisierung stand aber nicht nur am Anfang moderner wirtschaftlicher Entwicklung, sondern lag ihr auch in der weiteren Folge zugrunde. Erst die Industrialisierung ermöglichte den breiten und im Vergleich zu vorindustriellen Jahrhunderten ungleich höheren Wohlstand, den die Länder der Ersten Welt bereits seit einigen Jahrzehnten, die Länder der Dritten Welt hingegen erst ansatzweise genießen können.

Allerdings zeigt sich bei genauerem Hinsehen, dass die in der Regel auf ganze Länder bezogenen Statistiken und Pro-Kopf-Einkommen die Wirklichkeit nur sehr eingeschränkt und vielfach verzerrt widerspiegeln. Bei genauerer Betrachtung wird deutlich, dass es sich bei der Industrialisierung nicht um eine gesamtstaatliche, nationale Entwicklung handelt, sondern vielmehr um eine regionale Erscheinung. ${ }^{4} \mathrm{Zu}$ groß sind die Unter-

$4 \quad$ Auf die Bedeutung der Regionen im Industrialisierungsprozess hat vor allem Pollard (1981) hingewiesen. Vgl. auch Mathis (2012). 
schiede im Pro-Kopf-Einkommen etwa zwischen Nord- und Süditalien, zwischen Katalonien und Andalusien, zwischen Mecklenburg-Vorpommern und Bayern oder zwischen dem küstennahen China und dem chinesischen Hinterland, um von einer italienischen, spanischen, deutschen oder chinesischen Industrialisierung sprechen zu können. Die gesamtstaatlichen Werte ergeben sich stattdessen aus der Summe mehrerer regionaler Entwicklungen, die ihrerseits auf ähnlichen oder aber unterschiedlichen Strukturen beruhen. Neben stark landwirtschaftlich geprägten, wenig urbanisierten Regionen können sich im selben Staat hoch industrialisierte oder vom Tourismus bestimmte Regionen finden. Ihre jeweilige Entwicklung hat vielfach mehr mit benachbarten Regionen anderer Länder gemeinsam als mit Regionen desselben Landes. Die Existenz von Rohstoffen oder die touristische Attraktivität von Berglandschaften und Küstengebieten sind ebenso ein regionales Phänomen wie die Häufung von Städten oder Fabriken in bestimmten Gebieten. Und wenn Städte - wie noch zu zeigen sein wird - eine unabdingbare Voraussetzung für eine erfolgreiche Industrialisierung darstellten, so entstanden sie vielfach in Ländern, deren Staatsgrenzen früher ganz anders verliefen als heute und sich im Laufe der Geschichte wiederholt verschoben. All diese Beobachtungen und die Tatsache, dass trotz aller wirtschaftspolitischen Bemühungen verschiedener Regierungen noch immer große Unterschiede zwischen einzelnen Regionen bestehen, relativieren auch den Einfluss nationaler Wirtschaftspolitik auf die wirtschaftliche Entwicklung eines Landes. ${ }^{5}$ Es ist daher vielmehr nach den regionalen, sowohl naturräumlichen als auch von den Menschen im Laufe der Zeit geschaffenen, sozioökonomischen Strukturen zu fragen, wenn es darum geht, unterschiedliche wirtschaftliche Entwicklungen zu erklären. Dies gilt in besonderem Maße für den Grad der Urbanisierung.

\section{Urbanisierung}

Unter Urbanisierung soll hier die Entstehung, die Verbreitung und das Wachstum von Städten verstanden werden, die mit einer absoluten und relativen Zunahme der städtischen im Verhältnis zur ländlichen Bevölkerung einhergehen. Allerdings fand Urbanisierung nicht überall in der Welt zur selben Zeit statt. Im Gegenteil, es lassen sich deutliche Unterschiede zwischen einzelnen Regionen feststellen - sowohl was

5 Zur Rolle der in unzähligen Untersuchungen im Vordergrund stehenden Wirtschaftspolitik, die vielfach die an der Basis ablaufenden, eher von Angebot und Nachfrage als von der Wirtschaftspolitik bestimmten Prozesse übersehen oder zumindest unterschätzen, vgl. jüngst Weigl (2011). 
das Ausmaß als auch den Zeitpunkt und das Tempo von Urbanisierung betrifft. Die Unterschiede ergaben sich insbesondere, wenn auch nicht ausschließlich, aus einer unterschiedlichen Bevölkerungsdichte. Je mehr Menschen in einer Region lebten, umso eher war die Entstehung von Städten zu erwarten. Push- und Pull-Faktoren führten dazu, dass Menschen das Land verließen und in Orte zogen, von denen sie sich eine Verbesserung ihrer Lebenschancen erhofften.

Ein wesentlicher Push-Faktor stellte die relative Übervölkerung am Land dar. Sie ergab sich aus einem zunehmenden Missverhältnis zwischen wachsender Bevölkerung auf der einen und verfügbaren Ressourcen bzw. Einkommensquellen auf der anderen Seite. Allerdings genügte der daraus resultierende Abwanderungsdruck allein noch nicht, um eine Landflucht auszulösen. Neben dem Push-Faktor einer relativen Übervölkerung bedurfte es auch eines Pull-Faktors. Er bestand im Wesentlichen in der Hoffnung, anderswo aus nicht-landwirtschaftlicher Tätigkeit die erwünschten Einkommen erzielen zu können. Dazu bedurfte es einer genügend großen Zahl von Menschen, die als Abnehmer für die Güter oder Dienstleistungen in Frage kamen, die von den Abwandernden erzeugt bzw. angeboten wurden. Auch der Pull-Faktor potentieller Kunden war bei einer dichteren Bevölkerung eher gegeben als bei einer weniger dichten.

Eine dichtere Bevölkerung hatte mehr Handel und Verkehr zur Folge und verlangte in zunehmendem Maß nach Verwaltung und Rechtsprechung. Beides konzentrierte sich auf bestimmte, günstig gelegene Orte, die sowohl ständige als auch nur vorübergehende Zuwanderer anzogen. Sobald die Handels- und Verwaltungsmittelpunkte als anfängliche PullFaktoren weiter wuchsen, stellten sie dank ihrer steigenden Einwohnerzahl einen wachsenden Markt mit entsprechenden Einkommenschancen als zusätzlichen Pull-Faktor für potentielle Zuwanderer dar. Beispiele für Handelszentren wären - um nur einige wenige zu nennen - Hamburg, New York, Osaka oder Bombay, Beispiele für Verwaltungsmittelpunkte Städte wie Madrid, Berlin oder Tokio, während Wien, London oder Buenos Aires beide Funktionen, die eines Handels- ebenso wie die eines Verwaltungszentrums, erfüllten.

Welchem der beiden Faktoren, dem Push-Faktor einer relativen Übervölkerung am Land oder dem Pull-Faktor potentieller Kunden, bei der Entstehung nicht-landwirtschaftlicher Siedlungen und späterer Städte mehr Bedeutung zukam, war von Fall zu Fall verschieden. Wo immer in der Welt und wann immer in der Geschichte Städte entstanden, in den allermeisten Fällen lassen sie sich auf die genannten Voraussetzungen und Bedingungen zurückführen. Auch die bewussten Städtegründungen bedurften - sollten sie erfolgreich sein - zumindest einer der beiden Faktoren: der Bereitschaft, das Land zu 
verlassen, und der Chancen, die ein Verkehrs- und/oder Verwaltungsmittelpunkt bot. Da jedoch weder der Abwanderungsdruck noch die Anziehungskraft überall im selben Ausmaß gegeben waren, erlangten die neuen, nicht-ländlichen Siedlungen eine unterschiedliche Größe. Wann, wo und in welcher Größenordnung es in den verschiedenen Teilen der Welt auf diese Weise zur Entstehung und zum Wachstum von Städten kam und wie Urbanisierung mit Industrialisierung und Globalisierung verbunden war, wird im Folgenden zu zeigen sein.

\section{Ohne Urbanisierung keine Industrialisierung}

Erst die Städte schufen Strukturen, die als notwendige Voraussetzung für eine erfolgreiche Industrialisierung angesehen werden können. Während am Land trotz vereinzelter nichtlandwirtschaftlicher Tätigkeiten die Landwirtschaft und mit ihr die Selbstversorgung oder Subsistenzwirtschaft vorherrschend blieben, wurden die Städte, wo und wann immer sie entstanden, zu Zentren von Handel und gewerblicher Produktion. Im arbeitsteiligen städtischen Handwerk, das sowohl die eigene als auch die umliegende ländliche Bevölkerung mit Waren aller Art versorgte und in manchen Fällen auch für überregionale Märkte produzierte, entwickelten sich dank der Spezialisierung die technischen Kenntnisse, die zur erfolgreichen Ausübung eines Gewerbes unerlässlich waren. Solche Kenntnisse sollten die Entwicklung, den Bau und die Bedienung der späteren Maschinen wesentlich erleichtern. Wo immer sie infolge geringer Urbanisierung fehlten, war es deutlich schwieriger, eine nachhaltige Industrialisierung aufzubauen.

Neben den für eine industrielle Fabrikproduktion unverzichtbaren Fachkräften bedurfte es, damit eine solche überhaupt zustande kam, investitionsbereiter Unternehmer. Als Gründer von Fabriken zeichneten sie sich außer durch Risikobereitschaft auch durch ein überdurchschnittlich starkes Streben nach selbständigem Wirtschaften, Gewinn und Prestige aus, das als „Unternehmergeist“ bezeichnet werden könnte. Die gesellschaftliche Gruppe, die in vorindustrieller Zeit am ehesten über diese Eigenschaften und Motivationen verfügte, waren die meist in den Städten ansässigen Kaufleute, und zwar insbesondere die größeren unter ihnen, die sich eher im Fernhandel als im lokalen Detailhandel betätigten. Investitionen in den Fernhandel waren zwar mit höheren Risiken verbunden, versprachen aber dank der geringeren Zahl von Fernhändlern höhere Gewinne und nicht zuletzt dank dieser auch ein höheres Sozialprestige. Auch waren die Fernhändler besser als andere mit den äußeren Märkten vertraut, von wo sie ihre Handelswaren bezogen und auf denen sie diese vertrieben. 
Keine andere Gruppe vorindustrieller Gesellschaften hatte mit den späteren Industrieunternehmern so viel gemein wie die mittleren und größeren Kaufleute. So verfügte der Adel zwar durchaus über das für Investitionen notwendige Kapital, doch ließ er es eher in einen standesgemäßen Konsum als in den Handel oder später in eine Fabrikproduktion fließen. Die Bauern standen - von Ausnahmen abgesehen - einer überregionalen Handelstätigkeit oder einer industriellen Investition aus zumindest zwei Gründen fern: zum einen arbeiteten sie meist für den eigenen Bedarf, waren also wenig marktorientiert und schon gar nicht auf ferne Märkte ausgerichtet; zum anderen unterschied sich die landwirtschaftliche wesentlich von der gewerblichen Produktionsweise. Die Handwerker wiederum, die in dieser Hinsicht der industriellen Produktion am Nächsten standen, orientierten sich in der Regel eher am lokalen Markt, wodurch sie tendenziell weniger „Unternehmergeist“ entwickelten als die Fernhändler, mit denen sie sich allerdings nicht selten zu einer gemeinsamen Fabrikgründung zusammenschlossen.

Regionaler und überregionaler Handel, als deren Nervenzentren die Städte gelten konnten, ${ }^{6}$ bedurfte entsprechender Verkehrswege. Auf diese Weise schuf Urbanisierung ein unterschiedlich dichtes Netz an Land-, Fluss- und Seestraßen. Es konnte eine spätere Industrialisierung, die auf zum Teil von außen bezogene Rohstoffe angewiesen und für den Absatz der Massenproduktion auch auf überlokale Märkte ausgerichtet war, wesentlich erleichtern. Die modernen Transportmittel wie die Eisenbahn, die Dampfschiffe oder das Automobil fanden vielfach erst einige Jahrzehnte nach den Anfängen der Industrialisierung massenhafte Verbreitung, trugen dann allerdings maßgeblich zu ihrer weiteren Verbreitung bei. Und schließlich vollzog sich auch der Wandel von einer Tausch- zu einer Geldwirtschaft - eine weitere unabdingbare Voraussetzung für Industrialisierung - nicht im Rahmen der Subsistenzwirtschaft am Land, sondern in erster Linie in der Marktwirtschaft der Städte.

All dies - arbeitseilige Marktorientierung, handwerkliches Know-how, großhändlerisches Gewinnstreben und Unternehmergeist, ein Netz von Verkehrswegen sowie eine Geld- statt einer Tauschwirtschaft - waren zwar notwendige Voraussetzungen für Industrialisierung, doch reichten sie allein noch nicht aus. Städte gab es bereits in der Antike und im Mittelalter sowie außer in Europa auch in vielen anderen Teilen der Welt, ohne dass es dort und damals bereits zu einer Industrialisierung kam. Dazu bedurfte es einer zweiten Phase von Urbanisierung, die über die bloße Entstehung und Verbreitung von Städten hinausging. Sie setzte in Teilen Europas ab der zweiten Hälfte des 18. Jahrhunderts ein, in

6 Vgl. Lopez (1971), 60. 
Nordamerika und Japan im 19., auf den anderen Kontinenten dagegen vielfach erst in der zweiten Hälfte des 20. Jahrhunderts.

Diese zweite Phase von Urbanisierung war gekennzeichnet durch das Wachstum bereits bestehender Städte zu Großstädten. Anstelle einiger tausend oder einiger zehntausend zählten sie nun mehrere hunderttausend und mehr Einwohner. Es waren die Großstädte wie zunächst London, dann auch Paris, Berlin oder Wien in Europa, New York, Boston, Philadelphia oder Chicago im Nordosten der USA, Tokio und Osaka in Japan oder in jüngster Zeit die jungen Metropolen in der Dritten Welt, die eine weitere und in diesem Fall entscheidende Grundbedingung erfolgreicher Industrialisierung boten. Erst solche und andere Großstädte stellten einen genügend großen und aufnahmefähigen Markt dar, der es sinnvoll und vor allem lohnend erscheinen ließ, gewerbliche Waren nicht mehr nur mit handwerklichen Methoden und in relativ kleinen Stückzahlen, sondern auf maschinelle Weise und in viel größeren Mengen herzustellen. Industrielle Massenproduktion bedurfte eines Massenmarktes, wie er als Folge zum Teil rasch wachsender Bevölkerungen und damit einhergehender Landflucht in den modernen Großstädten entstand. ${ }^{7}$ Erst der

7 Auf die Rolle, die der Nachfrage im Industrialisierungsprozess zukam, wird in der einschlägigen Fachliteratur meist nur am Rande und lediglich neben vielen anderen, höher eingeschätzten Faktoren hingewiesen. Dies gilt sowohl für ältere Studien wie Gilboy (1932), zitiert in Rule (1992), 252, oder Eversley (1967) als auch für jüngere Untersuchungen wie Pollard (1981), Matis (1988), Wallerstein (1989), 6 und 11, Menzel (1993), Buchheim (1994), 61 f, Evans (1996), 115, Pierenkemper (1996), 15 ff, Jones (2002) oder Bayly (2006), 217. Noch weniger wird die Nachfrage mit Städten und so gut wie nie mit der konzentrierten Kaufkraft von Großstädten in Verbindung gebracht. So widmet etwa Bayly (2006), 228-245, den Städten der Welt ein eigenes, großes Kapitel, allerdings ohne jeden Hinweis auf ihre Bedeutung für die Industrialisierung. Ein solcher Hinweis auf die Rolle der Großstädte fehlt auch in Eigner (2011) im jüngst erschienenen, für Studenten, Lehrende und die interessierte Öffentlichkeit bestimmten Sammelband zur Entwicklung der europäischen Wirtschaft in den letzten 1000 Jahren. Bei Ehmer (2011), $140 \mathrm{f}$. und anderen werden die wichtigsten Großstädte samt ihren Einwohnerzahlen zwar genannt, allerdings ohne jeden Bezug zur Industrialisierung. Laut Bairoch (1991), 250 wird Urbanisierung für die Industrielle Revolution von manchen als günstig, nicht jedoch als „,besonders entscheidend“ angesehen, und er selbst hält es in Bairoch (1991), 257 für „sehr unwahrscheinlich, dass sich die Städte zur Erklärung der Industrialisierung in England als nützlich erweisen würden“, obwohl er gleichzeitig mit Nachdruck auf die „Märkte verweist, die Städte für Industriewaren boten.“ Bairoch (1991), 257. Pollard (1981), 211 fgeht noch einen Schritt weiter und schreibt Großstädten zumindest in den europäischen Randgebieten sogar einen negativen Einfluss auf die Industrialisierung zu. Auch Malanima (2010) geht in seinem langen Artikel über Urbanisierung in der Cambridge Economic History of Modern Europe auf Großstädte mit über 100.000 Einwohnern und ihre etwaige Auswirkung auf die Industrialisierung überhaupt nicht ein, sondern konzentriert sich auf die Entwicklung und den innereuropäischen Vergleich von Urbanisierungsraten, gemessen an Städten mit mehr als 10.000 oder mehr als 5.000 Einwohnern. Ähnliches schon früher bei Vries (1984). Eine der wenigen, die anders als Bairoch (1991), 252 und Sachs (2005), 36 Urbanisierung nicht nur als Folge, sondern als mögliche Ursache der Industrialisierung sehen, ist Phyllis Deane, wenn sie in Deane (1998), 49 meint, dass „die Nachfrage der Städter nach Lebensmitteln, Brennstoff und grundlegenden Erzeugnissen ... die Entwicklung von Gewerbe und Industrie stimulierte." Allerdings fehlt auch bei ihr jeglicher Hinweis auf die diesbezüglich besondere Stellung der Großstädte. Dies ist zwar bei North (1961), 166-170 der Fall, wenn er unter den günstigen Voraussetzungen für die Industrialisierung im Nordosten der USA auch das Wachstum großer urbaner Zentren anführt, allerdings bezogen auf die Zeit vor 1815, als die amerikanischen Städte wie in vielen anderen Teilen der Welt noch zu klein waren, um eine industrielle Massenproduktion anzuregen. 
zu erwartende Massenabsatz versprach die Gewinne, deren Erwartung es für potentielle Unternehmer lohnend erscheinen ließ, in relativ teure Maschinen und Fabriken zu investieren. Je größer die Städte wurden, umso mehr Unternehmer entschieden sich zu einer Fabrikgründung, für die sie in den Großstädten nicht nur den Markt, sondern gleichzeitig auch das für ihren Betrieb notwendige, handwerklich-technische Wissen fanden.

Konnte schon der Markt einer einzigen Großstadt einen Anreiz für industrielle Investitionen bieten, so war dies erst recht der Fall, wenn sich mehrere Großstädte in einer nicht allzu weiten Entfernung voneinander befanden. Dank kurzer Distanzen mit entsprechend reduzierten Transportkosten erweiterten sie den potentiellen Markt und lockten noch mehr Fabrikgründer in ihnen selbst und in ihrem Umfeld an. Auf diese Weise ließen sie nicht nur isolierte Industrien in einem ansonsten weitgehend ländlichen Umfeld entstehen, sondern schufen ganze Industrielandschaften, die ihrerseits statt einer nur punktuellen und schmalen eine breite Industrialisierung zur Folge hatten. Beispiele für das eine wie das andere finden sich etwa in Süd- und Norditalien: auf der einen Seite eine lange Zeit auf die Großstadt Neapel und ihr Umland beschränkte Industrialisierung, auf der anderen Seite eine von den Großstädten Mailand, Turin und Genua sowie mehreren mittelgroßen Städten getragene Industrialisierung, die viel mehr Menschen mit einbezog, als es im nach wie vor weitgehend ländlich strukturierten Süden der Fall war. Auch in West- und Mitteleuropa sowie im Nordosten der USA wurde die Industrialisierung außer durch die genannten Großstädte durch ein dichtes Netz weiterer großer und mittelgroßer Städte zusätzlich angeregt und auf eine geographisch breitere Basis gestellt.

Die Massennachfrage der Großstädte und der sich in ihnen und ihrem Umfeld entwickelnden Industrien konnte darüber hinaus auch anderen, zum Teil weiter entfernten Regionen zu einer Industrialisierung verhelfen. Dies waren beispielsweise Regionen, die über die notwendigen Rohstoffe wie etwa Steinkohle oder Eisenerz verfügten. Sie waren Jahrhunderte lang entweder überhaupt nicht oder nur in relativ geringem Umfang abgebaut worden. Erst mit der Massennachfrage der modernen Industrien wurden sie in einem Ausmaß gefördert, dass sie neue Industrieregionen wie etwa das Ruhrgebiet in Deutschland entstehen ließen. Infolge ihrer zwar auf Rohstoffen basierenden, aber letztlich erst durch die Entwicklung von Großstädten und ihre Nachfrage möglich gewordenen Industrialisierung konnten in ihnen neue Großstädte entstehen, die dann ihrerseits dieselben stimulierenden Effekte für eine fortgesetzte Industrialisierung auslösten wie die älteren Großstädte. 
Dass die groß angelegte Förderung von Rohstoffen der Nachfrage durch Großstädte bedarf, wird außer im diachronen auch im synchronen Vergleich sichtbar. Trotz der bereits begonnenen Industrialisierung in Europa oder Nordamerika, die als Modell für andere Regionen der Welt hätte dienen können, blieben deren zum Teil weit größere Rohstoffreserven lange Zeit unerschlossen. Dies änderte sich erst, als zum einen die modernen Verkehrsmittel die Transportkosten auch über größere Distanzen verbilligten und zum anderen auch in ihrer Nähe Großstädte entstanden und eine aus deren Nachfrage resultierende Industrialisierung einsetzte.

Wie manche Regionen über natürliche Rohstoffe verfügten, konnten andere relativ billige Arbeitskräfte anbieten. Für sie gilt dasselbe wie für die Rohstoffe: Sie stellten erst dann für potentielle Unternehmer einen Investitionsanreiz dar, wenn die Chance bestand, die von ihnen produzierten Waren abzusetzen, wofür wiederum die großstädtische Nachfrage gegeben sein musste. Teile der Schweiz oder das benachbarte Vorarlberg verdankten wie andere Regionen ihre Industrialisierung in einem hohen Maß ihrem verhältnismäßig billigen Arbeitskräfteangebot, das seinerseits aus einer relativen Übervölkerung resultierte. Die fehlenden Möglichkeiten, allein aus der Landwirtschaft den Lebensunterhalt zu bestreiten, ließ sie die anfangs sowohl vom Lohn als auch von den Arbeitsbedingungen her wenig attraktive Fabrikarbeit annehmen.

Der in dieser Untersuchung vorgenommene, globale Vergleich wird zeigen, wie sehr die bisher angeführten Ursachen und Bedingungen erfolgreicher Industrialisierung außer bei den „Frühstartern“ in West- und Mitteleuropa später auch in anderen Teilen der Welt für mehr oder weniger Industrialisierung verantwortlich waren. Er soll zeigen, dass es tatsächlich weltweit anzutreffende und in diesem Sinn globale Modelle der Industrialisierung gab und immer noch gibt. Sie werden erlauben, eine allgemein gültige, wenn auch $\mathrm{zu}$ verschiedenen Zeiten realisierte Theorie wirtschaftlicher Entwicklung zu formulieren, die auch gewisse Ausblicke auf die Zukunft erlaubt. Eine solche Theorie versteht Globalisierung nicht als eine gemeinsame globale Entwicklung, bei der die einzelnen Regionen im Rahmen eines Weltsystems miteinander verbunden sind, bei der die einen von den anderen abhängen und sich die Entwicklung der einen auf Kosten der anderen vollzieht. ${ }^{8}$

$8 \quad$ Stellvertretend für viele: Frank (1978), Frank (1978a), Wallerstein (1989), Senghaas (1981), Menzel/Senghaas (1986), Amin (1997a). Eine umfangreiche Bibliographie zu der von ihnen und anderen vertretenen Entwicklungstheorie mit über 3.000 Titeln findet sich bei Menzel (1993). Die Theorie geht von einem Weltsystem miteinander verbundener Länder und Großregionen aus, die in unterschiedlichem Ausmaß voneinander abhängig sind (Dependenztheorie) und sich im Rahmen weltweiter Arbeitsteilung in hoch entwickelte, industrialisierte Metropolen und weniger entwickelte Peripherien und Semiperipherien unterscheiden lassen. Dabei wird den Außenhandelsbeziehun- 
Vielmehr besteht der globale Aspekt einer solchen Theorie darin, dass Ursachen, Verlauf und Ergebnis wirtschaftlicher Entwicklung und insbesondere der Industrialisierung in erster Linie in regionalspezifischen Bedingungen zu suchen sind, die letztlich überall auf der Welt dieselben oder zumindest ähnliche Muster aufwiesen.

\section{Globale Verflechtungen}

Dennoch ist nicht zu leugnen, dass darüber hinaus - und heute mehr denn je - vielfältige wirtschaftliche Beziehungen zwischen den Regionen bestehen. Allerdings ist es notwendig, sie nach Zeit und Region zu gewichten, um nicht zu voreiligen Schlüssen zu gelangen. Dies gilt insbesondere für die häufig vorgebrachte und bereits angesprochene Meinung, dass sich die so genannte Erste Welt auf Kosten und zu Lasten der Dritten Welt entwickelt habe und der Entwicklungsrückstand der Dritten Welt der Ausbeutung durch die Erste Welt geschuldet sei. Für diese weit verbreitete Ansicht werden mehrere Argumente ins Treffen geführt, die allerdings einer genaueren Überprüfung nicht standhalten.

Zunächst einmal wird behauptet, dass die europäischen Kolonien in Übersee als billige Rohstofflieferanten für die Industrialisierung in Europa gedient hätten. ${ }^{9}$ Dies ist in mehrfacher Hinsicht unrichtig. Bei den Gütern, die seit dem 16. Jahrhundert etwa aus Amerika bezogen wurden, handelte es sich zum einen um Nahrungs- und Genussmittel wie Zucker, Kaffee, Tabak und Kakao, zum anderen um Holz und Pelze. Weder die einen noch die anderen waren für die Industrialisierung notwendig, sondern dienten lange Zeit dem gehobenen Konsum relativ schmaler Eliten oder dem Schiffsbau. Die für die Ernährung der europäischen Bevölkerung viel wichtigeren Nahrungsmittel Mais und Kartoffel lernten die Europäer zwar in Amerika kennen, in der Folge wurden sie jedoch in Europa selbst angebaut und waren nicht Gegenstand des transatlantischen Handels.

gen der einzelnen Länder für ihre wirtschaftliche Entwicklung eine weit größere Bedeutung beigemessen als ihren binnenwirtschaftlichen Strukturen, obwohl die Exporte speziell in größeren Ländern nur für einen sehr kleinen Teil der gesamtwirtschaftlichen Wertschöpfung aufkommen; nach O’Brien (1982), 4 machte der Wert der Exporte, die von europäischen Ländern getätigt wurden, gegen Ende des 18. Jahrhunderts nur 4 Prozent des gesamteuropäischen Bruttosozialproduktes aus. Außerdem wird wirtschaftliche Entwicklung in dieser Theorie tendenziell als Folge wirtschaftspolitischer oder gesamtgesellschaftlicher Entscheidungen gesehen und weniger als das Ergebnis tausendfacher Einzelentscheidungen individueller Wirtschaftssubjekte, die mit Ausnahme zentraler Planwirtschaften nur zu einem sehr kleinen Teil von staatlicher Wirtschaftspolitik, zu einem viel größeren hingegen von den Chancen, Herausforderungen und Grenzen des Marktes bestimmt sind.

9 Vgl. neben anderen etwa Frank (2005), 58 oder Senghaas (1982). Kritisch dazu Elsenhans (1982). 
Der einzige nennenswerte und gerade für die frühe Industrialisierung wichtige Rohstoff war die Rohbaumwolle. Sie war zur Deckung des begrenzten vorindustriellen Bedarfes lange Zeit aus der Levante bezogen worden und stammte erst mit der gestiegenen Nachfrage nach Rohbaumwolle, die seit dem Ende des 18. Jahrhunderts von den neuen Spinnmaschinen ausging, größtenteils aus den Südstaaten der seit 1776/83 unabhängigen USA. Obwohl Großbritannien mit Indien über eine Kolonie verfügte, aus der es die Rohbaumwolle hätte beziehen können, entschieden sich die britischen und in der Folge auch die kontinentaleuropäischen Importeure für die billigere amerikanische Baumwolle. Zum niedrigen Preis trug die Ausbeutung der aus Afrika nach Amerika verschleppten Sklaven durch die amerikanischen Plantagenbesitzer zwar zweifellos bei, doch fand eine vergleichbare Ausbeutung auch in der von den britischen Kolonialherren betriebenen Teeproduktion in Indien statt. Letztlich dürften daher die im Vergleich zu Indien niedrigeren Transportkosten der Grund gewesen sein, dass die Baumwolle statt aus der britischen Kolonie in Indien aus den unabhängigen USA eingeführt wurde.

Das Beispiel der Rohbaumwolle verdeutlicht daher ebenso wie gut 100 Jahre später das Beispiel des Mineralöls, dass es für den Bezug notwendiger Rohstoffe keiner Kolonien bedurfte. Die Länder des Nahen Ostens, die bis heute zu den wichtigsten Lieferanten von Rohöl zählen, waren vor dem Ersten Weltkrieg vielfach Teil des Osmanischen Reiches, bevor sie in den folgenden Jahrzehnten ihre Unabhängigkeit erlangten. Ähnliches gilt für andere Öl exportierende Staaten wie das ständige unabhängig Persien oder die seit Beginn des 19. Jahrhunderts unabhängigen Länder Mexiko und Venezuela sowie seit der zweiten Hälfte des 20. Jahrhunderts etwa auch für Nigeria oder Indonesien. Der Welthandel benötigt - wie viele weitere Beispiele zeigen könnten - keine Kolonien. Wirtschaftliche Interessen und Gewinnerwartungen genügen, um zwischen potentiellen Lieferanten und Kunden Geschäftsbeziehungen entstehen zu lassen. Andere wichtige Rohstoffe wie Eisenerz und Kohle, die speziell für die um die Mitte des 19. Jahrhunderts einsetzende, zweite Phase des Industrialisierungsprozesses unentbehrlich waren, wurden bis weit in das 20. Jahrhundert hinein aus den Lagerstätten in Europa selbst bezogen.

Die europäischen Kolonien in Übersee boten aber auch keinen wichtigen oder gar für die Industrialisierung notwendigen Absatzmarkt, wie ebenfalls gerne behauptet wird. Zwar ist es richtig und wurde hier bereits ausführlich dargelegt, dass die Massenproduktion der in Europa entstehenden Industrien einer Massennachfrage bedurfte. Doch fand sich diese, wenn überhaupt, nur zum kleineren Teil in Übersee. Nach einer Untersuchung des irischen Wirtschaftshistorikers Patrick O’Brien wurde gegen Ende des 18. Jahrhun- 
derts nur ein Viertel des europäischen Außenhandels mit anderen Kontinenten abgewickelt, 5 Prozent mit Asien, 10 Prozent mit Nordamerika, 8 Prozent mit Südamerika und 1 Prozent mit Afrika. Der Rest spielte sich zwischen den Ländern innerhalb Europas ab, woran sich auch im 19. Jahrhundert nicht viel ändern sollte. ${ }^{10}$

Zu gering - so lässt sich dieser Befund erklären - waren mit Ausnahme Asiens die Bevölkerungszablen außerhalb Europas: Um 1800 lebten in Amerika, Afrika und Ozeanien zusammen lediglich etwa 128 Millionen Menschen, gegenüber 188 Millionen in Europa selbst. ${ }^{11}$ Außerdem war auch die Kaufkraft der außerhalb Europas lebenden Menschen, die in manchen Kontinenten vielfach noch als Jäger und Sammler oder als sich selbst versorgende Bauern lebten, zu schwach, um in größerer Zahl als Abnehmer für die Waren aus Europa, die durch den damals noch viel kostspieligeren Transport zusätzlich verteuert wurden, in Frage zu kommen. Letzteres gilt auch für den Großteil der asiatischen Bevölkerung, obwohl dort ein Teil der etwa 638 Millionen Menschen wie in Europa bereits in Städten lebte. ${ }^{12}$ Ihr Bedarf an gewerblichen Gütern konnte lange Zeit von ihnen selbst gedeckt werden. Als ihre eigenen Waren im Laufe des 19. Jahrhunderts zum Teil von billigeren, weil maschinell hergestellten Importprodukten verdrängt wurden, machten die Ausfuhren nach Asien nur etwa 10 Prozent der europäischen Gesamtexporte aus. ${ }^{13}$

Auf diese Weise entstanden - zumindest in Summe und unabhängig von den hohen Profiten einzelner Kaufleute und Handelsunternehmen - auch die oft angeführten $G e$ winne weniger aus dem außereuropäischen Handel als vielmehr aus dem umfangreicheren Austausch innerhalb und zwischen den europäischen Ländern. Wenn derartige Gewinne - was keineswegs immer der Fall war - als Kapital für industrielle Investitionen herangezogen wurden, bedurfte es dazu ebenso wenig des außereuropäischen Handels wie des außereuropäischen Marktes.

10 O’Brien (1982), 4 und Fischer (1985), 170. Die Bedeutung der äußeren Märkte ganz allgemein relativierten schon früh etwa Eversley (1967) und später auch Evans (1996), 113; nach Evans ging der britische Außenhandel zwischen 1775 und 1784 sogar um 6 Prozent zurück. Einen Rückgang der britischen Exporte im dritten Viertel des 18. Jahrhunderts konstatiert auch Landes (1973), 64, der aber dennoch dem Außenhandel eine nicht geringe Bedeutung für die Industrialisierung beimisst, was zuletzt auch für Vries (2011), 430-434 gilt, der sich detailliert und sehr reflektiert mit dieser Frage auseinandersetzt. Auch für die USA konnte bereits Lipsey (1972) feststellen, dass etwa 1869 die Exporte nur 6 Prozent der gesamten Produktion ausmachten und die Importe für nur 11 Prozent aller in den USA gekauften Güter aufkamen. Die vielfach zu beobachtende Überschätzung des Außenhandels für die Anfänge der Industrialisierung dürfte aus den später zum Teil höheren Wachstumsraten der Exporte resultieren, die jedoch nichts über das relativ weit größere Volumen des Binnenhandels aussagen. Vgl. etwa Frank (1978), 74-77.

11 Mathieu (2011), 87.

12 Mathieu (2011), 87.

13 Fischer (1985), 170. 
Dasselbe gilt schließlich für das vielfach als Zahlungsmittel verwendete Silber. Zwar gelangte es seit der Mitte des 16. Jahrhunderts in großen Mengen und vor allem aus Potosí im heutigen Bolivien nach Europa, doch wurde es zum Großteil zur Herstellung von Schmuckgegenständen oder als Zahlungsmittel für Gewürze und Luxuswaren aus Asien verwendet. Das Geld, das für industrielle Investitionen eingesetzt wurde, war seit Jahrhunderten in Europa selbst vorhanden, und zwar umso mehr als der anfängliche Kapitalbedarf für die neuen, meist klein beginnenden Fabriken nicht allzu hoch war. ${ }^{14}$

Wenn somit die Voraussetzungen und Gründe der Industrialisierung in Europa zum größten Teil in Europa selbst zu finden sind, liegt auch die lange Zeit ausbleibende und erst seit kurzem in stärkerem Ausmaß einsetzende Industrialisierung in den Ländern der Dritten Welt letztlich in ihnen selbst begründet. Der ihnen zum Teil aufgezwungene, zum Teil von ihren eigenen Eliten aus Eigeninteresse aufgenommene Handel mit Europa hätte ihnen bis heute genügend Rohstoffe belassen, um auf deren Grundlage eigene Industrien aufzubauen. Trotz der vor Ort stattgefundenen Ausbeutung heimischer Arbeitskräfte durch einheimische wie ausländische Unternehmer floss aus dem Export von Nahrungsmitteln oder von Rohöl genug Geld in zumindest manche dieser Länder, das für industrielle Investitionen hätte verwendet werden können. Zwar ist es richtig, dass der Aufbau heimischer Industrien angesichts einer starken Konkurrenz ausländischer Importwaren erschwert wurde. ${ }^{15}$ Länder wie Kanada, die USA, Australien oder Japan zeigen jedoch, dass eine eigene Industrialisierung dennoch möglich war. Wenn industrielle Investitionen ausblieben, lag dies in der Regel nicht am Mangel an Rohstoffen und/oder Kapital, auch nicht an einer übermächtigen ausländischen Konkurrenz, sondern - wie im Einzelnen zu zeigen sein wird - an einer lange Zeit fehlenden Massennachfrage in Form genügend großer Städte. Die mangelnden Anreize, in verarbeitende Industrieunternehmen zu investieren, führten zu fortgesetzten Investitionen in die Produktion agrarischer und mineralischer Rohstoffe für den Export sowie zu einem Kapitalabfluss ins Ausland, wo sowohl aufnahmefähige Märkte als auch profitträchtigere Möglichkeiten der Kapitalverwertung bestanden. Erst in jüngerer Zeit entstand in vielen Ländern der Dritten Welt eine zunehmende Zahl von Groß- und Megastädten, die nunmehr auch in diesen Ländern entsprechende Investitionsanreize für eine industrielle Produktion boten und einen stärkeren Industrialisierungsprozess zur Folge hatten. Noch 1940 befanden sich

14 Vgl. auch Evans (1996), 110.

15 Zur Beschränkung des Binnenmarktes infolge der Überbetonung des Außenhandels vgl. etwa Frank (1978), 92-139, Frank (2005), 65 oder Bayly (2006), 226. 
sämtliche der 5 Megastädte mit mehr als 5 Millionen Einwohnern in der Ersten, 60 Jahre später - an der Wende zum 21. Jahrhundert - lagen 34 von nunmehr 45 solcher Städte bereits in der Dritten Welt. ${ }^{16}$

\section{Traditionelle Erklärungen}

Der in der Folge vorgenommene, globale Vergleich von mehr oder weniger Industrialisierung wird nicht nur ähnliche Ursachen für den Industrialisierungsprozess erkennen lassen, sondern erlaubt auch, die Erklärungen, die bisher für die Unterschiede zwischen den einzelnen Ländern vorgebracht wurden, zu hinterfragen. Die wichtigsten von ihnen sollen in der Folge kurz vorgestellt werden.

Zunächst verleitete die Tatsache, dass der Industrialisierungsprozess gegen Ende des 18. Jahrhunderts in Europa begann, zahlreiche Historiker und Wirtschaftswissenschaftler dazu, nach spezifisch europäischen oder abendländischen Gründen zu suchen. ${ }^{17}$ Ein nur flüchtiger Blick auf die Länder, in denen ein breiter Industrialisierungsprozess stattfand, zeigt, dass schon die Frage als solche verfehlt war. Zum einen gab und gibt es bis heute innerhalb Europas selbst große Unterschiede zwischen stark industrialisierten und wenig industrialisierten Ländern. Es wäre daher, wenn überhaupt, zu fragen, ob es typisch west-, mittel- und nordeuropäische Faktoren gab, die in diesem Teil Europas zu einer breiteren Industrialisierung führten als in den bis heute weniger entwickelten Ländern in Süd- und Osteuropa. Zum anderen lassen die prominenten Beispiele der USA, Kanadas, Australiens oder Japans ebenso wie die jüngeren Industrieländer Südkorea, Taiwan oder Singapur erkennen, dass eine breite Industrialisierung keineswegs auf Europa beschränkt blieb und daher schwerlich als europäisches Phänomen angesehen werden kann. Auch der Hinweis auf die letztlich in ihrer Mehrheit von europäischen Einwanderern abstammende Bevölkerung etwa der USA, Kanadas oder Australiens vermag nicht zu überzeugen, da dasselbe auch für die weniger industrialisierten Länder Lateinamerikas zutrifft.

Ähnliches gilt für die ebenfalls weit verbreitete Meinung, dass bestimmte religiöse Orientierungen den Industrialisierungsprozess stärker begünstigt hätten als andere. Mit Blick auf Großbritannien und die USA wird in Anlehnung an Max Weber eine besondere Spielart der protestantischen Ethik ursächlich mit dem „Geist des Kapitalismus“

16 Bronger (2004), 20.

17 Vgl schon früh Landes (1973), 26-34 und 37-46 sowie in jüngster Zeit stellvertretend für viele Jones (1981), Jones (2002) oder Mitterauer (2003). 
in Verbindung gebracht. ${ }^{18}$ Demnach würde - stark verkürzt - wirtschaftlicher Erfolg und Reichtum im diesseitigen Leben auf eine auserwählte Stellung im Jenseits schließen lassen und daher zu unternehmerischem Tun anregen. Mit dieser These wurde unter anderem die unterschiedliche Entwicklung der eher protestantischen USA und der katholischen Länder Lateinamerikas zu begründen versucht. ${ }^{19}$ Eine solche Theorie lässt nicht nur die vielen nicht-protestantischen Industrieländer, sondern auch die durchaus kapitalistisch denkenden Fernhändler der Zeit vor der Reformation außer Betracht. Zu ersteren zählen etwa Frankreich, Belgien, Oberitalien, Österreich oder diejenigen Teile Deutschlands und der Schweiz, die sich zum Katholizismus bekennen, aber auch das schintoistisch-buddhistische Japan. Letztere hingegen, die Großkaufleute und Bankiers des europäischen Mittelalters wie etwa die Fugger, Medici und viele andere, belegen eindeutig, dass es gewinnorientierte Haltungen und unternehmerisches Handeln schon lange vor der im späten 18. Jahrhundert einsetzenden Industriellen Revolution gab. Es geht daher vielmehr um die Frage, warum die außer in Europa auch in anderen Teilen der Welt anzutreffenden Kaufleute ihre unternehmerische Tätigkeit über Jahrhunderte auf den Handel konzentrierten und ihr Kapital - von Ausnahmen abgesehen - nicht in die gewerbliche Produktion investierten. Lediglich eine relative kleine Gruppe so genannter „Verleger“ organisierten neben dem Fernhandel auch eine gewerbliche Massenproduktion, indem sie eine größere Zahl von dezentral angesiedelten Handwerkern - meist im Textilgewerbe - für sich arbeiten ließen. ${ }^{20}$ Warum aber der durchaus als kapitalistisch zu bezeichnende Fernhandel in der Regel einer ebenso gewinnträchtigen, industriellen Massenproduktion vorgezogen wurde, lässt sich mit religiösen oder sonstigen kulturellen Haltungen nicht erklären. ${ }^{21}$

Kaum anders verhält es sich mit den häufig ins Treffen geführten, klimatischen Bedingungen. ${ }^{22}$ Sie werden vielfach als Erklärung für ein angeblich unterschiedliches Arbeitsethos etwa in den Tropen im Vergleich zu den gemäßigten Klimazonen angeführt. Zwar finden sich auf der Ebene der einzelnen Länder - weniger hingegen auf der Ebene einzelner Regionen - mit Singapur und Taiwan tatsächlich nur wenige Industrieländer in den Tropen, in den Subtropen hingegen mit Japan, Südkorea und Australien durch-

18 Neu aufgelegt: Weber (2006). Vgl. dazu schon früh auch Landes (1973), 35 f.

19 Mehr dazu und durchaus kritisch: Frank (1978), 25-33.

20 Zu dieser in den letzten Jahren unter dem Begriff Proto-Industrialisierung zusammengefassten Produktionsweise vgl. Pollard (1981), 63-78 und jüngst auch Cerman (2011).

21 Ganz anders Grondana (2002).

22 Vgl. Sachs (2002), 60-62. 
aus wichtige Beispiele erfolgreicher Industrialisierung. Umgekehrt weisen die gemäßigten Klimazonen nördlich und südlich davon eine ganze Reihe von wenig industrialisierten Ländern auf. Entscheidender ist jedoch auch in diesem Fall der schwer nachvollziehbare Zusammenhang zwischen Klima und industrieller Produktion. Wenn überhaupt ein Zusammenhang zwischen Klima und wirtschaftlicher Tätigkeit besteht, ist ein solcher eher bei im Freien ausgeführten Tätigkeiten wie etwa in der Landwirtschaft anzunehmen, weniger hingegen bei der in geschlossenen Gebäuden stattfindenden Fabrikarbeit.

Ähnliches lässt sich auch zu den institutionellen Rabmenbedingungen, unter denen wirtschaftliches Tun stattfindet, ins Treffen führen. ${ }^{23}$ Obwohl eine gewisse Rechtssicherheit für eine entsprechende Investitionstätigkeit als unabdingbar angesehen werden muss, gilt dies für jede wirtschaftliche Tätigkeit und keineswegs nur für industrielle Investitionen. Die rechtlichen Rahmenbedingungen spielen daher für die wirtschaftliche Entwicklung als Ganzes zweifelsohne eine große Rolle, insbesondere wenn sie in kriegerischen Auseinandersetzungen oder sonstigen, politisch unruhigen Zeiten beeinträchtigt werden. Für die Erklärung der weltweit ungleichen Verteilung von mehr oder weniger Industrialisierung im Speziellen reichen sie jedoch ebenso wenig aus wie religiös-kulturelle Werthaltungen oder klimatische Bedingungen.

Enger mit Industrialisierung verbunden sind die Rohstoffe. Dass sie eine unentbehrliche Voraussetzung für die Herstellung von Fertigwaren aller Art darstellen, versteht sich von selbst. Allerdings zeigt die Erfahrung, dass sie nicht notwendig in den Ländern vorhanden sein müssen, in denen sie verarbeitet werden. Schon der oft erste Rohstoff, den die industrielle Massenproduktion benötigte, nämlich die Rohbaumwolle, stammte weder aus West- und Mitteleuropa noch aus Kanada, Australien oder Japan, sondern lange Zeit aus der Levante, in großem Ausmaß aus Indien und seit dem Ende des 18. Jahrhunderts insbesondere aus den Südstaaten der USA. Die in den genannten Industrieländern entstehenden Baumwollwarenfabriken waren offenbar in der Lage, den notwendigen Rohstoff von außen zu beziehen. Dasselbe gilt für Eisenerz und Kohle, die beiden wichtigsten Rohstoffe bzw. Energieträger der Eisen- und Stahlindustrie sowie in der weiteren Folge auch vieler eisenverarbeitender Industrien. Zwar waren sie in einigen späteren Industrieländern in großem Umfang vorhanden, nicht jedoch oder nur in Ansätzen in Ländern wie Japan, Südkorea, Taiwan, Italien oder der Schweiz. Auch der später aufkommende und die Kohle zum Teil ablösende Energieträger Erdöl wurde in

23 Stellvertretend: North (1988), North (2005), Acemoglu/Robinson (2014); im Überblick Resch (2011). 
viel größerem Ausmaß von außen bezogen als in den Industrieländern selbst gefördert. Offenbar fanden sich bei einem entsprechenden Bedarf nach Rohstoffen weltweit immer genügend Anbieter, die sie den nachfragenden Unternehmen - falls erforderlich, aus der ganzen Welt - lieferten. Lediglich in den meist aus politischen Gründen geführten Kriegen wurden die Handelswege gelegentlich unterbrochen. Die Existenz von Rohstoffen vor Ort konnte die Industrialisierung begünstigen, notwendig war sie nicht. Umgekehrt zeigen die vielen rohstoffreichen, aber bis heute wenig industrialisierten Länder, dass lokal vorhandene Rohstoffe allein nicht in der Lage waren, eine erfolgreiche Industrialisierung zu stimulieren.

Wie sich die Rohstoffe aus der ganzen Welt beziehen ließen, gab es auch für die weltweite Verbreitung der technischen Errungenschaften in der Regel keine Grenzen - und zwar in den Anfängen im späten 18. Jahrhundert ebenso wenig wie später und bis heute. Wenn investitionswillige Unternehmer nicht selbst über das technische Know-how für ihre industrielle Produktion verfügten, konnten sie es sich über vielfältige Wege von auBen erwerben. An fehlender Technik sollte daher eine etwaige Industrialisierung ebenso wenig scheitern, wie sie umgekehrt für sich allein nicht in der Lage war, eine solche in Gang zu setzen. Dass die technischen Erfindungen für die industrielle Produktion eine ebenso unabdingbare Voraussetzung darstellten wie die Rohstoffe, steht außer Frage, doch reichten sie, wie die vielen bis heute wenig industrialisierten Länder zeigen, nicht aus, eine vor allem breite Industrialisierung auszulösen. ${ }^{24}$

Eine weitere notwendige, aber nicht ausreichende Bedingung für eine breite Industrialisierung war das für Investitionen verfügbare Kapital. Es war in der Regel in den wohlhabenderen Schichten der Bevölkerung vorhanden, die es allerdings auf unterschiedliche Weise nutzten. Die Adeligen und sonstigen grundbesitzenden Oberschichten gaben ihre Einkommen in der Regel zur Finanzierung eines gehobenen Lebensstils aus, während es die Kaufleute tendenziell in ihre Handelstätigkeit reinvestierten. Es stellt sich daher die Frage, welche Bedingungen oder Anreize gegeben sein mussten, um das Kapital stattdessen in industrielle Investitionen fließen zu lassen. Solche Anreize fehlten offenbar in den vorindustriellen Jahrhunderten ebenso wie in den vielen Länder, die aus dem Export von Nahrungsmitteln und/oder Rohstoffen bis heute hohe Erlöse erzielen, diese jedoch nur zum kleineren Teil in der Industrie investieren. Außerdem zeigen die meist relativ

24 Zur Rolle der Technologie vgl. schon früh Landes (1973) und Pollard (1981), 143-148 sowie in jüngerer Zeit neben vielen anderen Sachs (2005), $31 \mathrm{f}$. und sehr ausführlich Weitensfelder (2011) sowie zur Begründung der Industriellen Revolution gerade in England auch Allen (2009). 
bescheidenen Anfänge industrieller Produktion, die erst in weiterer Folge über die Reinvestition der Gewinne und/oder die Aufnahme von Fremdkapital zur Entstehung von Großunternehmen führten, dass der Bedarf an Gründungskapital nicht sehr hoch und daher relativ leicht aufzubringen war. ${ }^{25}$

Neben ausreichendem Gründungskapital bedurfte es für eine erfolgreiche Industrialisierung auch einer entsprechend großen Zahl von Arbeitskräften. Sie dürften in Europa trotz zum Teil gegenteiliger Ansicht ${ }^{26}$ bereits in früheren Jahrhunderten und nicht erst als Folge der beschleunigten Bevölkerungszunahme seit etwa 1750 vorhanden gewesen sein. Dafür sprechen die zahlreichen Menschen, die schon vor der Industriellen Revolution im dezentralen Verlagssystem arbeiteten. Sie hätten wohl ebenso gut in Fabriken beschäftigt werden können. Falls jedoch die vor Ort vorhandene Bevölkerung im Zuge wachsender Produktion nicht mehr ausreichte, waren die Unternehmen durchaus in der Lage, ihre Arbeitskräfte von außen anzuwerben. Als Beispiele kann auf die aus dem Osten des ehemaligen Deutschen Reiches stammenden Arbeiter verwiesen werden, die in die Kohlenreviere des Ruhrgebietes zogen, aber auch auf die von der Vorarlberger Textilindustrie aus dem ehemals österreichischen, heute italienischen Trentino angeworbenen Arbeiterinnen oder in jüngerer Vergangenheit auf die tausenden Gastarbeiter aus dem südlichen Europa, die nach dem Zweiten Weltkrieg für Industrieunternehmen in Deutschland, Österreich oder der Schweiz rekrutiert wurden. Umgekehrt konnte die Existenz billiger, Arbeit suchender Menschen - wie bis heute in vielen Teilen der Welt zu beobachten ist - in einzelnen Regionen potentielle Unternehmer oder bereits bestehende Unternehmen zwar zur Errichtung von Fabriken anregen, allerdings nur, wenn es einen Markt gab, auf denen die von ihnen hergestellten Produkte abgesetzt werden konnten. Dass eine große Zahl potentieller Arbeitskräfte allein nicht ausreicht, um als Anreiz für eine Fabrikgründung zu dienen, wird aus den Millionen von Menschen deutlich, die in der Hoffnung auf Arbeit und Einkommen ihre ländlichen Herkunftsgebiete in Richtung Großstadt verlassen, weil vor Ort keine Industrieunternehmen entstehen, in denen sie arbeiten könnten.

Resümierend lässt sich daher festhalten, dass manche der seit Jahren angeführten Bedingungen und vermeintlichen Ursachen zwar wichtige und zum Teil unabdingbare Voraussetzungen für eine erfolgreiche Industrialisierung darstellten, jedoch weder für

25 Zum relativ geringen anfänglichen Kapitalbedarf vgl. Evans (1996), 110.

26 Vgl. etwa Wallerstein (1989), 6. 
sich allein noch in Kombination miteinander ausreichten, um eine solche auszulösen. Damit sie ihre Wirkung entfalten konnten, bedurften sie - wie hier zum ersten Mal im globalen Vergleich zu zeigen sein wird - eines entsprechend großen Marktes, der die industriell hergestellten Massenprodukte nachfragte und erst auf diese Weise ihre Produktion profitabel werden ließ. Wenn in der einschlägigen Fachliteratur auf die Bedeutung des Marktes hingewiesen wurde, geschah es entweder mit dem Verweis auf die durch koloniale Eroberung entstandenen, außereuropäischen Märkte oder in Bezug auf die seit dem 18. Jahrhundert rascher wachsende, europäische Bevölkerung. Dass erstere für die Abnahme der in Europa in großen Mengen hergestellten Industriewaren nicht aufnahmefähig genug waren, wurde weiter oben gezeigt. Letztere hingegen konnte ihre potentielle Wirkung auf die Errichtung von Industrieunternehmen so lange nicht entwickeln, so lange sich die Bevölkerungszunahme auf Gebiete ohne große Ballungszentren verteilte. Zu hoch waren in diesem Fall die sich aus der Entfernung zwischen Produktionsstätte und Abnehmer ergebenden Kosten, um einen profitablen Absatz zu ermöglichen. Erst die Konzentration zahlreicher potentieller Abnehmer auf ein relativ eng begrenztes Gebiet, wie sie seit dem 18./19. Jahrhundert zunächst in den Großstädten Europas und Nordamerikas, später auch in anderen Teilen der Erde stattfand, schuf den Massenmarkt, der für eine profitable Massenproduktion nicht nur notwendig war, sondern sie auch anzuregen vermochte. Es wird Aufgabe der folgenden, nach Kontinenten und deren Teilen gegliederten Ausführungen sein, diese neue Theorie von der zentralen und ursächlichen Bedeutung der Großstädte für eine erfolgreiche Industrialisierung empirisch zu belegen. ${ }^{27}$

27 Damit soll auch die Lücke gefüllt werden, auf die Jürgen Osterhammel in Osterhammel (2010), 913 hinweist, wenn er meint, dass ,in den letzten drei Jahrzehnten den älteren oder 'klassischen' Konzepten von Industrialisierung wenig grundsätzlich Neues hinzugefügt worden ist." 



\section{Europa}

\section{Urbanisierung in der Antike}

Auch nur annähernd verantwortungsvolle Schätzungen zur Gesamtbevölkerung Europas und seiner Teilgebiete sind für die vorchristlichen Jahrhunderte kaum möglich. ${ }^{28}$ Dennoch sind sie immer wieder versucht worden, in jüngerer Zeit unter anderem vom britischen Wirtschaftshistoriker Angus Maddison. ${ }^{29}$ Für die Zeit um Christi Geburt schätzt er die Bevölkerung Europas ohne das Gebiet der ehemaligen Sowjetunion auf knapp 30 Millionen Menschen. Dies hätte einem Siebzehntel des heutigen Standes entsprochen. Der Großteil der europäischen Bevölkerung, nämlich rund zwei Drittel, hätte nach Maddison in den heutigen Ländern Italien, Spanien, Frankreich und Deutschland gelebt. Wenn auch die absoluten Zahlen als fragwürdig gelten müssen, scheint die höhere Bevölkerungsdichte im Westen und Süden Europas unbestritten zu sein. Sie spiegelt sich auch in der größeren Städtedichte in diesem Teil Europas wider.

Hier war die Bevölkerung offenbar dicht genug, um speziell im Mittelmeerraum bereits im ersten Jahrtausend vor Christus stadtähnliche Siedlungen entstehen zu lassen. Am besten dokumentiert sind sie im alten Griechenland sowie in der Folge im Römischen Reich, wo sich Städte speziell im heutigen Italien, auf der Iberischen Halbinsel und in Westeuropa bis hin zu den Britischen Inseln entwickelten. Tendenziell weniger Städte entstanden in der Antike außerhalb des Römischen Reiches im Osten und Norden Europas. Eine weiterführende wirtschaftliche Entwicklung in Richtung Industrialisierung wäre daher - wenn überhaupt - im westlichen und südlichen, weniger bis gar nicht hingegen im noch fast ausschließlich agrarischen bis voragrarischen, restlichen Europa zu erwarten gewesen.

Und tatsächlich waren fast alle Voraussetzungen einer Industrialisierung bereits in der römisch-griechischen Antike gegeben. ${ }^{30}$ Wie in späteren Jahrhunderten lebten bereits in den antiken Städten Handwerker und Kaufleute. Sie verfügten über technisches Wissen und unternehmerische Investitionsbereitschaft, wie sie sich beispielhaft im Bereich des hoch entwickelten Bauwesens oder des weit gespannten Fernhandels widerspiegeln. Ver-

28 Houtte (1980), 14-16.

29 Maddison (Population).

30 Vgl. Mathis (2011), 100-108. 
wertbare Rohstoffe etwa im Textil- oder im Metallbereich waren ebenso vorhanden wie investitionsfähiges Kapital. Auch an Arbeit suchenden Menschen und einem effizienten Verkehrsnetz zu Wasser und zu Land bestand kein Mangel. Ebenso war die Versorgung der städtischen Bevölkerung mit Nahrungsmitteln - sei es aus der lokalen Landwirtschaft, sei es mittels Importen von außen - weitgehend gesichert und hätte wohl ohne große Probleme auf zusätzliche nicht-landwirtschaftliche Bevölkerungsgruppen ausgeweitet werden können.

Was zur Entstehung einer industriellen Massenproduktion jedoch fehlte, war die Aufnahmebereitschaft und die Nachfrage großer städtischer Massenmärkte. Erst sie hätten risikoreiche und relativ kostspielige Industrieinvestitionen anregen können sowie derartige Investitionen lohnend und profitabel erscheinen lassen. Für eine solche Massennachfrage reichten jedoch die Einwohnerzahlen der antiken Städte nicht aus. Die weit überwiegende Zahl der römischen Städte zählten - und auch dies nur gemeinsam mit umliegenden Landgemeinden - zwischen 2.000 und 10.000, der eigentliche Kern daher deutlich weniger Einwohner. ${ }^{31}$ Nur wenige Siedlungen wie vielleicht die Vorläufer der heutigen Städte Mailand, Aquileia, Padua, Lyon, Trier oder Cádiz konnten als größere Städte mit wohl über 50.000 Einwohnern bezeichnet werden. ${ }^{32}$ Mehr als 100.000 Menschen lebten im europäischen Teil des Römischen Reiches nur in Rom, dessen Einwohnerzahl auf 250.000 bis weit über eine Million geschätzt wurde, sowie nach seiner Erhebung zur neuen Hauptstadt wohl auch in Konstantinopel, für das im 6. Jahrhundert zwischen 300.000 und einer Million Einwohner angenommen werden. Angesichts der Tatsache, dass die Flächen Roms im 3. Jahrhundert mit 13 bis $14 \mathrm{~km}^{2}$ sowie Konstantinopels mit kaum mehr als $10 \mathrm{~km}^{2}$ um einiges kleiner waren als das bebaute Stadtgebiet einer Stadt wie etwa des heutigen Innsbruck, scheinen die niedrigeren Schätzungen allerdings realistischer. ${ }^{33}$

Der für eine erfolgreiche und breite Industrialisierung notwendige Massenmarkt fehlte daher im antiken Europa in zweifacher Hinsicht: erstens waren die dafür in Frage kommenden Städte Rom und Konstantinopel trotz ihrer Größe im Vergleich zu den europäischen oder US-amerikanischen Großstädten des 19. Jahrhunderts nicht groß genug und zweitens lagen sie zu weit auseinander, um eine sich lohnende Massenproduktion anzuregen. ${ }^{34}$

31 Vittinghoff (1990), 197.

32 Vittinghoff (1990), 198.

33 Kolb (1984), 191 und Kolb (2006), 93.

34 Mathis (2011), 111. 


\section{Urbanisierung im Mittelalter und in der frühen Neuzeit}

An der für eine Industrialisierung zu geringen Größe und Zahl von Großstädten sollte sich auch nach dem Ende des weströmischen Reiches um 476 n. Chr. nichts ändern. Im Gegenteil, die vermehrten kriegerischen Auseinandersetzungen im Zuge der schon zuvor begonnenen und in den folgenden Jahrzehnten anhaltenden Völkerwanderung sowie die speziell im 6. und 7. Jahrhundert gehäuft auftretenden Seuchenzüge führten statt zu einem weiteren Wachstum zu einem Rückgang der europäischen Bevölkerung. ${ }^{35}$ Er hatte - nicht zuletzt dank zahlreicher Plünderungen - auch einen Rückgang der Städte, ihrer Einwohnerzahlen und des städtischen Lebens ganz allgemein zur Folge. Man spricht in diesem Zusammenhang von einer Reagrarisierung von Wirtschaft und Gesellschaft. Auch wenn sie im Mittelmeerraum als dem Zentrum des ehemaligen Römischen Reiches schwächer ausfiel als in den davon weiter entfernten Regionen, ging auch hier der Grad der Urbanisierung hinter das zuvor erreichte Niveau zurück. Rom büßte viel von seiner einstigen Größe ein und zählte nur noch wenige zehntausend Einwohner, was bei Konstantinopel als Hauptstadt des Byzantinischen Reiches wohl erst gegen Ende des Mittelalters der Fall war. ${ }^{36}$

Allerdings dürfte sich der Trend spätestens im 8./9. Jahrhundert umgedreht haben. Die Bevölkerung Europas nahm in all seinen Großregionen wieder zu, ohne jedoch vorerst, d.h. bis zur Jahrtausendwende, den Stand um Christi Geburt wesentlich zu übertreffen. ${ }^{37}$ Das Wachstum setzte sich im neuen Jahrtausend fort, bevor es um 1347/50 zu einem neuerlichen, drastischen Einbruch kam. Damals soll die europäische Bevölkerung infolge einer verheerenden Beulenpest, die zuvor lange Zeit nur sporadisch aufgetreten war, um bis zu einem Drittel geschrumpft sein.

Zuvor jedoch war das Bevölkerungswachstum mit der Kultivierung zusätzlichen Bodens auf der einen und einem Wiederaufblühen vieler alter und der Entstehung zahlreicher neuer Städte einhergegangen. ${ }^{38}$ Zunehmende Bevölkerungsdichte und die Herausbildung alter und neuer, geistlicher wie weltlicher Eliten führten zu einer verstärkten Handels- und Verwaltungstätigkeit. Sie ließen kleinere und größere, durch Zuzug wach-

35 Vgl. Houtte (1980), 16 und 119 f; Cameron/Neal (2003), 59.

36 Bairoch/Batou/Chèvre (1988), 47. Zu den teils umstrittenen Einwohnerzahlen von Konstantinopel vgl. Wikipedia (Konstantinopel).

37 Maddison (Population).

38 Vgl. Houtte (1980), 121-124. 
sende Handels- und Verwaltungszentren entstehen. Allerdings erreichten sie vorerst wie in der Antike und im Vergleich zu heute nur relativ bescheidene Einwohnerzahlen. Sogar die größten unter ihnen dürften ungeachtet der zum Teil höheren, aber wenig realistischen Schätzungen maximal 100.000 Menschen gezählt haben. Nach den von Paul Bairoch, Jean Batou und Pierre Chèvre erstellten Listen gab es um 1300 in Europa 11 Städte mit mehr als 50.000 Einwohnern. ${ }^{39}$ Nur zwei davon, Paris und Köln, lagen nördlich der Alpen, die anderen, nämlich Mailand, Genua, Venedig, Florenz, Neapel und Palermo, in Italien sowie Córdoba, Granada und Sevilla in Spanien. Letztere profitierten unter anderem von der mehrhundertjährigen Einbeziehung in den islamischen Machtbereich mit seiner urbanen Tradition. Deutlich größer war naturgemäß die Zahl der Städte, in denen damals zwischen 20.000 und 50.000 Einwohner lebten (vgl. Tabelle 1).

Karte 1: Städte mit über 20.000 Einwohnern in Europa um 1300

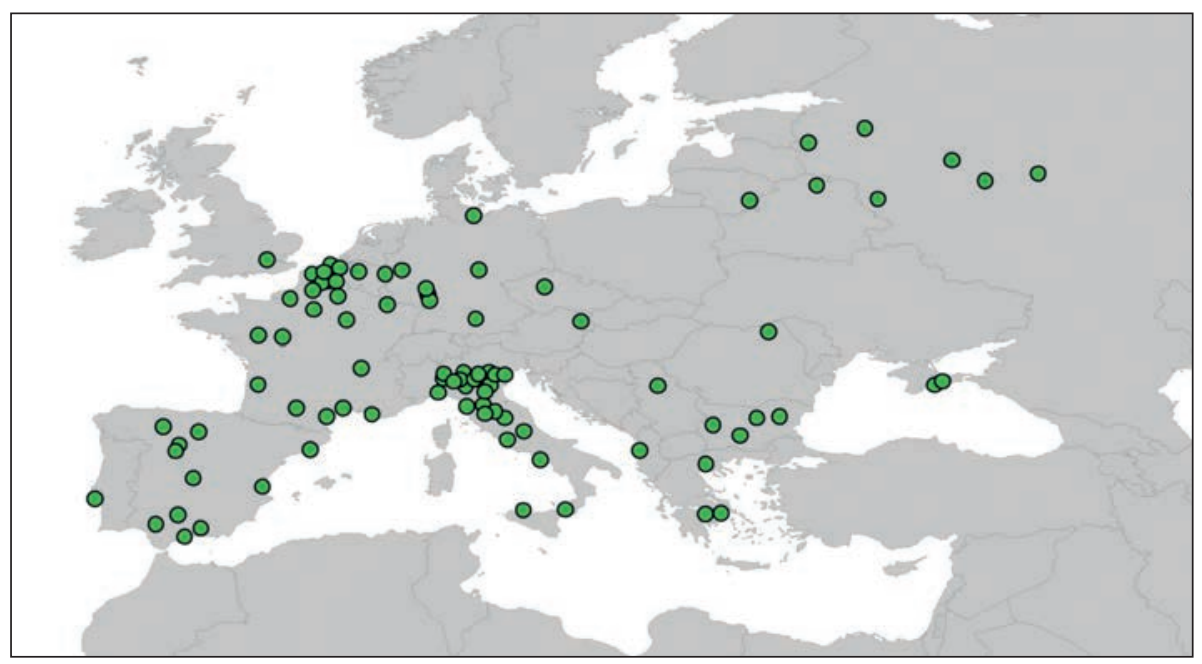

Tirol Atlas - Bearbeitung Klaus Förster nach Tabelle 1. Kartenhintergrund: World Borders Dataset - http://thematicmapping.org/downloads/world_borders.php

Auch wenn die Einwohnerzahlen mancher Städte eher auf Schätzungen als auf Berechnungen beruhen und daher vielleicht zu hoch ausgefallen sind, lässt sich, was die

39 Bairoch/Batou/Chèvre (1988). 
geographische Verteilung der insgesamt 92 Städte betrifft, eine klare Tendenz erkennen (vgl. Karte 1). Fast die Hälfte entfiel auf nur zwei relativ kleine Regionen nördlich und südlich der Alpen. Die eine umfasste in etwa das nordwesteuropäische Gebiet zwischen London, Paris, Speyer und Köln, die andere die oberitalienische Städtelandschaft zwischen Genua, Mailand, Venedig und Rom. In jeder der beiden Regionen fanden sich um 1300 etwa gleich viele Städte mit mehr als 20.000 Einwohnern wie im viel größeren Ost- und Südeuropa ohne Spanien und jeweils fast doppelt so viele wie auf der ebenfalls größeren, iberischen Halbinsel.

Der Schwerpunkt der Urbanisierung hatte sich somit zwar nicht ganz, aber doch tendenziell vom Mittelmeerraum in Richtung Mittel- und nördliches Westeuropa verlagert. Wenn daher Urbanisierung eine wichtige Voraussetzung für die spätere Industrialisierung darstellte, war diese in Oberitalien und Nordwesteuropa eher gegeben als in den anderen Teilen des Kontinents. Dort verteilten sich die Städte auf eine viel größere Fläche, was einen deutlich niedrigeren Urbanisierungsgrad zur Folge hatte. Allerdings waren die Städte auch in den beiden wirtschaftlichen Fortschrittsregionen Europas noch zu klein, um eine andere als die herkömmliche, handwerkliche Produktionsweise nahe zu legen. Sie reichte nicht nur zur Deckung des lokalen Bedarfes der Städte und ihres Umlandes, sondern auch zur Herstellung etwaiger Exportprodukte, wie sie sich bereits damals in nicht wenigen Städten etablierte.

Der handwerkliche, vorindustrielle Charakter der gewerblichen Produktion blieb vorerst auch in den folgenden vier bis fünf Jahrhunderten erhalten. Nach dem drastischen Bevölkerungsrückgang um die Mitte des 14. Jahrhunderts begann die europäische Bevölkerung abermals zu wachsen und erreichte nach den Schätzungen nicht nur von Maddison um 1500 mit rund 80 Millionen Menschen einen Stand, der geringfügig über dem Niveau vor der großen Pest lag. ${ }^{40}$ Auch in der Folge wuchs die Bevölkerung nur relativ langsam und hielt um 1750, am Vorabend der Industriellen Revolution, bei 120 bis 140 Millionen. Parallel dazu nahm infolge steigender Bevölkerungsdichte auch der Grad der Urbanisierung zu. Statt der 92 Städte von 1300 weisen Bairoch/Batou/Chèvre für 1750 nunmehr 154 Städte mit mehr als 20.000 Einwohnern aus, von denen einige besonders rasch wuchsen (vgl. Tabelle 2). ${ }^{41}$ Dazu zählten die insgesamt 15 Haupt- und bedeutenderen Handelsstädte, die in diesem Zeitraum die Grenze von 100.000 Einwohnern überschritten.

40 Maddison (Population); Mathieu (2011), 87.

41 Bairoch/Batou/Chèvre (1988). 
Neben London und Paris, in denen jeweils bereits mehr als eine halbe Million Menschen lebten, waren dies in der Reihenfolge ihrer Größe Neapel, Amsterdam, Lissabon, Wien, Madrid, Rom, Venedig, Moskau, Dublin, Mailand, Palermo, Lyon und Berlin.

Karte 2: Städte mit über 20.000 Einwohnern in Europa um 1750

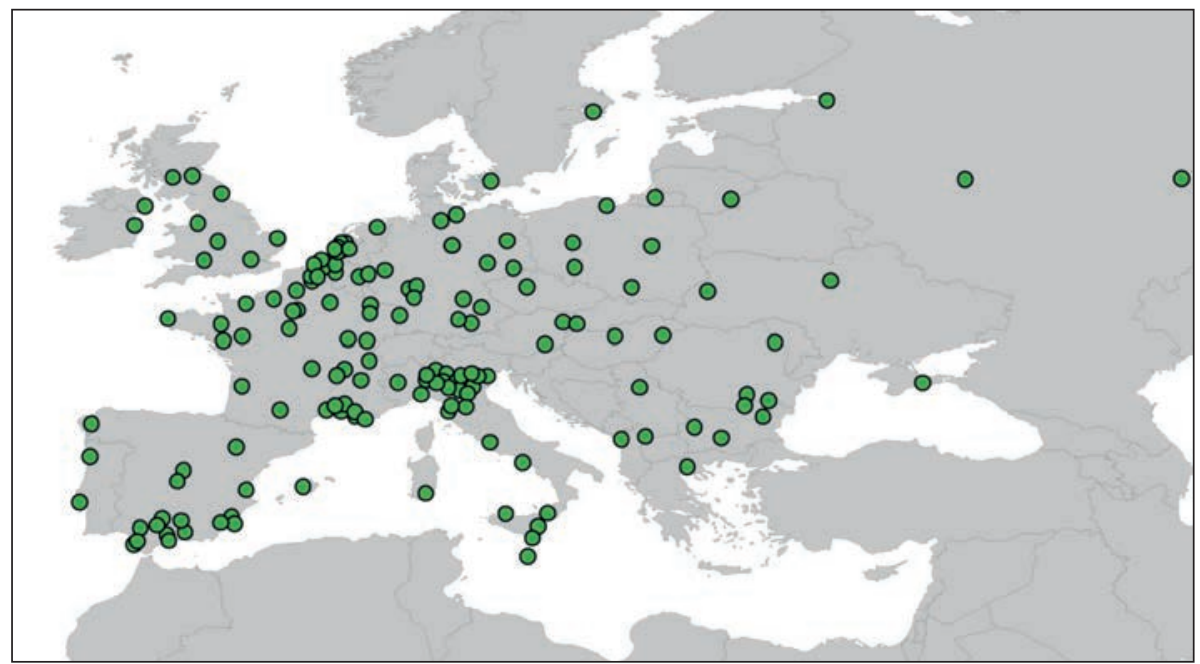

Tirol Atlas - Bearbeitung Klaus Förster nach Tabelle 2. Kartenhintergrund: World Borders Dataset http://thematicmapping.org/downloads/world_borders.php

Wie bereits um 1300 zeichneten sich einige europäische Regionen durch eine überdurchschnittlich hohe Städtedichte aus (vgl. Karte 2). Die zuvor noch relativ kleinen Städtelandschaften Oberitalien und Nordwesteuropa hatten sich nicht nur weiter verdichtet, sondern um nahe gelegene Nachbarregionen in Frankreich, Belgien, den Niederlanden und Deutschland erweitert. Auf diese Weise war ein breites, aus gesamteuropäischer Perspektive jedoch noch immer relativ schmales Band mit einer größeren Städtedichte entstanden, das von den Niederlanden bis nach Oberitalien reichte. Mit zunehmender Entfernung von diesem Band nahm die Städtedichte tendenziell ab, wenn auch nicht in jede Richtung im selben Ausmaß.42

42 Vgl. auch Karte in Bairoch/Batou/Chèvre (1988), 239. 
Urbanisierung und Industrialisierung im späten 18. und langen 19. Jahrhundert

Allerdings reichten das dichtere Städtenetz und die vereinzelten Großstädte noch immer nicht aus, um einen für eine maschinelle Massenproduktion notwendigen oder zumindest förderlichen Massenmarkt zu bilden. Dafür bedurfte es der massiven Veränderungen der kommenden Jahrzehnte. In nur 100 Jahren zwischen 1750 und 1850 sollte sich die Zahl der Städte mit mehr als 20.000 Einwohnern, die in den viereinhalb Jahrhunderten zuvor nur um rund 70 Prozent zugenommen hatte, auf insgesamt 417, ohne Großbritannien auf 333 mehr als verdoppeln. ${ }^{43}$ Ursache der verstärkten Urbanisierung war eine beschleunigte Bevölkerungszunahme. Dank sinkender Sterberaten kam es im selben Zeitraum zu einer Verdoppelung der europäischen Bevölkerung auf knapp 270 Millionen Menschen. ${ }^{44}$

Großbritannien, wo sich die Städte dieser Größenordnung sogar mehr als verzehnfachten, ist insofern gesondert zu betrachten, als die weit überdurchschnittliche Zunahme nicht mehr nur als Voraussetzung, sondern bereits auch als Folge der hier ab den 1770er Jahren - und damit früher als auf dem europäischen Festland - einsetzenden Industrialisierung anzusehen ist. Allerdings hatte sich die Zahl der britischen Städte mit über 20.000 Einwohnern auch schon zuvor zwischen 1750 und 1800 von 8 auf 23 verdreifacht. ${ }^{45}$

Entscheidender als die rasche Zunahme der mittelgroßen und größeren Städte dürfte jedoch das besonders starke Wachstum allein der britischen Hauptstadt gewesen sein. London, das um 1600 noch deutlich hinter Paris zurück gelegen war, überholte bis 1700 mit 575.000 Einwohnern die französische Metropole als größte Stadt Europas. 100 Jahre später war Londons Bevölkerung auf rund eine Million Einwohner angewachsen, während Paris nach wie vor bei etwa 550.000 Einwohnern hielt. ${ }^{46}$ Auch keine andere der europäischen Großstädte kam um diese Zeit an London heran, sie blieben auch deutlich hinter Paris zurück. Es spricht daher vieles dafür, dass es vor allem die Größe Londons war, die in England früher als im restlichen Europa die für eine Industrialisierung kritische bzw. notwendige Massennachfrage entstehen ließ. Zwischen 1772 und 1815 sollte

43 Bairoch/Batou/Chèvre (1988).

44 Fischer (1985), 12.

45 Bairoch/Batou/Chèvre (1988).

46 Bairoch/Batou/Chèvre (1988). 
sich die Zahl der Warenhäuser als Spiegelbild eines rasch wachsenden Marktes von 120 auf 729 versechsfachen. ${ }^{47}$

London im 19. Jahrhundert

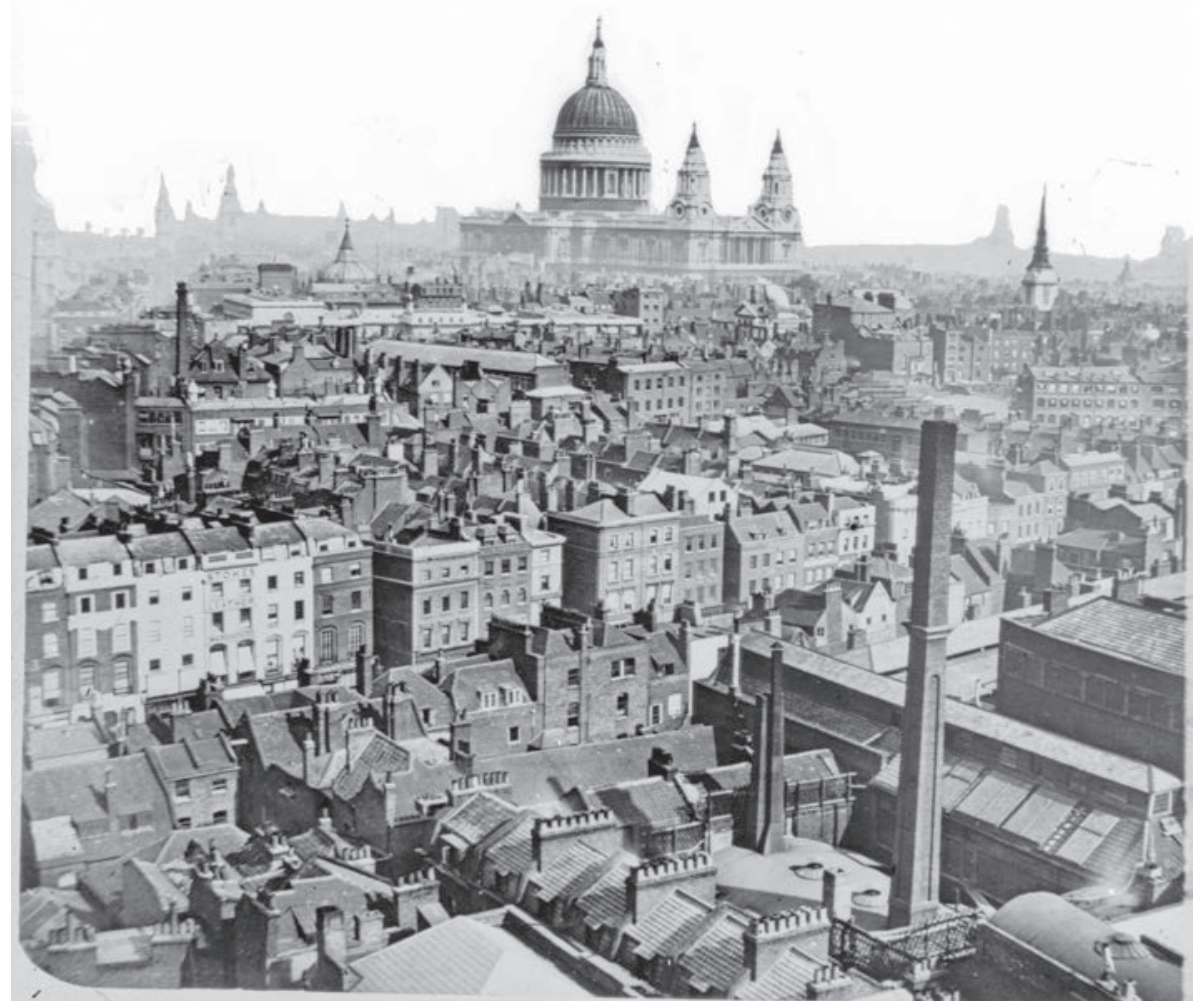

http://commons.wikimedia.org/wiki/London\#/media/File:On_the_rooftops_of_London.jpg

Da die Industrialisierung in Großbritannien - wie später auch in vielen anderen Ländern - mit der Mechanisierung der Baumwollwarenproduktion begann, eignet sich die relativ gut dokumentierte Verarbeitung von Rohbaumwolle als aussagekräftiger Indikator für deren

47 Vgl. Mathis (2006), $227 \mathrm{f}$ und Chapman (1990), $31 \mathrm{f..}$ 
Entwicklung. Zwischen der Mitte des 18. Jahrhunderts, als die Baumwolle noch mit handwerklichen Methoden verarbeitet wurde, und dem Ende des Jahrhunderts, als bereits die neuen, mechanischen Spinnmaschinen zum Einsatz kamen, stieg die Verarbeitung von Rohbaumwolle im Vereinigten Königreich um mehr als das Zehnfache. ${ }^{48}$ Dementsprechend stark nahm die mit den neuen Spinn- und schon bald auch Webmaschinen erzielte Produktion von Baumwollwaren zu, nämlich zwischen 1770 und 1815 auf mehr als das Zwanzigfache. ${ }^{49}$ Im ersten Jahrzehnt des 19. Jahrhunderts wurde im Vereinigten Königreich rund vier Mal so viel Rohbaumwolle verarbeitet wie in dem mehr als doppelt so bevölkerungsreichen Frankreich und zu Beginn der 30er Jahre fast $30 \mathrm{Mal}$ so viel wie in den ebenfalls bevölkerungsreicheren Ländern des späteren Deutschen Reiches. ${ }^{50}$

Schon bald wurden auch andere Branchen von der Industrialisierung erfasst. Dank der neuen Antriebsmittel der Dampfmaschine und den seit den 20er und 30er Jahren in Betrieb genommenen Eisenbahnen entwickelten sich insbesondere eine Maschinensowie die ihr zugrunde liegende Eisen- und Stablindustrie. 1840 entfiel rund die Hälfte des gesamteuropäischen Eisenbahnnetzes allein auf Großbritannien und Irland. ${ }^{51}$ Die Roheisenproduktion erhöhte sich im Vereinigten Königreich zwischen den 80er Jahren des 18. und dem ersten Jahrzehnt des 19. Jahrhunderts in nur 30 Jahren auf mehr als das Dreifache. ${ }^{52}$ Zuvor war sie noch hinter der französischen Produktion zurück gelegen. In den 20er Jahren des 19. Jahrhunderts erreichte sie einen Stand, der inzwischen drei Mal so hoch war wie der französische und etwa sieben Mal so hoch wie der deutsche. ${ }^{53}$

Eisen- und Stahlindustrie, Maschinenbau und Eisenbahnbau hatten auch eine dramatische Steigerung der Steinkoblenförderung zur Folge. Dank dem zunehmenden Einsatz von Dampfmaschinen trat die Steinkohle sowohl in der industriellen Produktion als auch im Transportwesen immer mehr an die Stelle früherer Energieträger wie Holzkohle, Wasserkraft und tierische Energie. Im Bereich der Steinkohlenförderung war der Vorsprung des Vereinigten Königreiches noch dramatischer als beim Roheisen. Um 1815 übertraf die Produktion mineralischer Kohle die französische um nicht weniger als etwa das 18-fache und die deutsche Förderung um das gut 13 -fache. ${ }^{54}$

48 Mitchell (1977), 509.

49 Rule (1992), 35.

50 Mitchell (1977), 489 und 509. Zur Bevölkerung der einzelnen Ländern vgl. Tabelle 3.

51 Bei Fischer (1985), 157 mit 1.348 km weniger, bei Mitchell (1977), 514 mit $2.411 \mathrm{~km}$ mehr als die Hälfte.

52 Mitchell (1977), 504.

53 Mitchell (1977), 504.

54 Mitchell (1977), 503. 
Wie sehr die mit diesen wenigen Beispielen angedeutete, rasche Industrialisierung die Wirtschaftsstruktur Großbritanniens veränderte, geht auch daraus hervor, dass zunächst relativ, dann aber auch absolut immer weniger Menschen in der Land- und Forstwirtschaft arbeiteten. Um die Mitte des 19. Jahrhunderts waren es nur noch knapp 25 Prozent aller Beschäftigten. ${ }^{55}$ Dagegen war die Hälfte aller Erwerbstätigen damals bereits im sekundären Sektor der gewerblichen Produktion einschließlich der Industrie beschäftigt. In allen anderen, größeren wie kleineren europäischen Ländern war der Anteil der Landwirtschaft noch deutlich höher. Er lag in den übrigen west- und mitteleuropäischen Ländern bei etwa 50 Prozent, im restlichen Europa dagegen noch bei über 60 und teilweise über 70 Prozent. ${ }^{56}$

Es braucht daher nicht zu überraschen, dass die gesamtwirtschaftliche Pro-Kopf-Leistung zwischen 1700 und 1820 in keiner anderen Volkswirtschaft so rasch wuchs wie im Vereinigten Königreich. Einer von Maddison geschätzten Zunahme um etwa 36 Prozent standen Zuwächse von 25 Prozent und weniger in Frankreich, Deutschland und anderen Ländern gegenüber - ein Unterschied, der nur deshalb nicht spektakulärer ausfiel, weil der Zeitraum mehrere vorindustrielle Jahrzehnte mit vergleichsweise langsamerem Wachstum umfasst. ${ }^{57}$

Was das Wachstum der als Massenmärkte in Frage kommenden Großstädte auf dem europäischen Festland betrifft, kamen sie auch im 19. Jahrhundert nicht annähernd an London heran. Paris als zweitgrößte Stadt Europas war durchwegs nicht einmal halb so groß wie die weiter wachsende britische Metropole. Dennoch wuchsen auch sie deutlich rascher als zuvor. Um 1800 gab es auf dem Festland erst 18 Städte, die mehr als 100.000 Einwohner zählten, 1850 waren es bereits 32 (vgl. Tabelle 4). Die Zahl der in diesen Großstädten lebenden Menschen stieg von 3,6 auf 7,3 Millionen, davon über eine Million allein in Paris, während die übrigen - ausgenommen Sankt Petersburg - um 1850 durchwegs weniger als eine halbe Million Einwohner zählten. ${ }^{58}$

55 Fischer (1985), 126.

56 Fischer (1985), 126; Kahan (1985), 520; Berend/Ránki (1985), 615;.Delivanis/Sundhausen (1985), 655; Bernecker/ Segura (1985), 670; Serrao/Thomas (1985), 694.

57 Eigene Berechnungen nach Maddison (Per Capita GDP).

58 Bairoch/Batou/Chèvre (1988). 
Karte 3: Großstädte mit über 100.000 Einwohnern in Europa um 1850

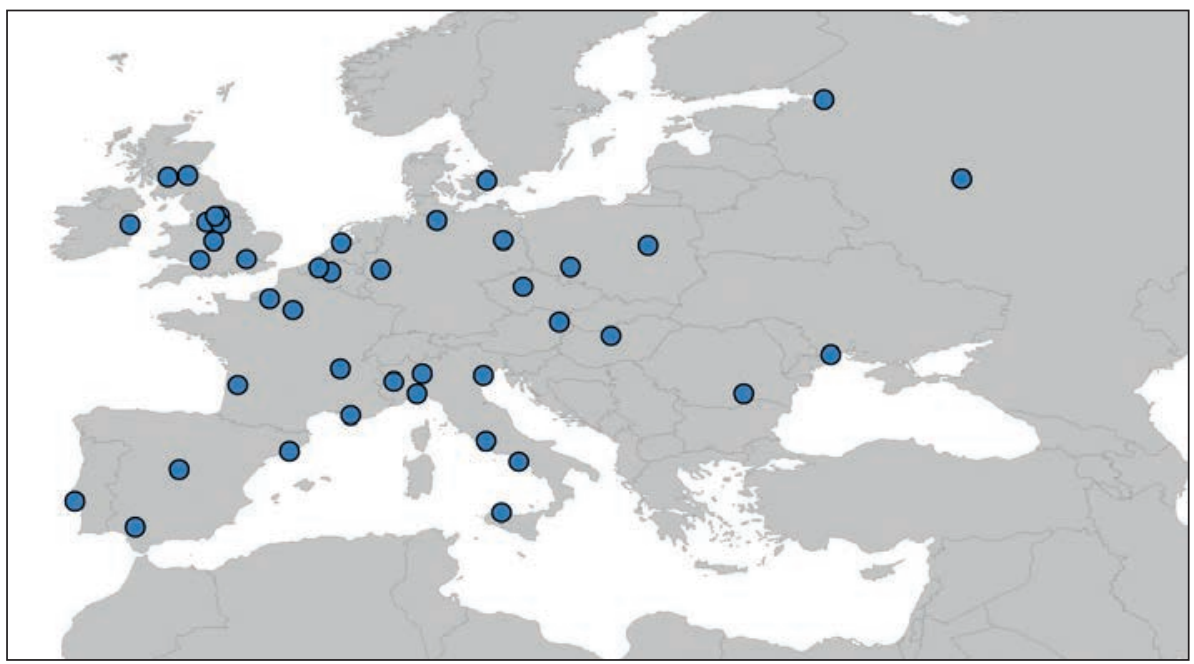

Tirol Atlas - Bearbeitung Klaus Förster nach Tabelle 4. Kartenhintergrund: World Borders Dataset http://thematicmapping.org/downloads/world_borders.php

Sie konzentrierten sich auf ein Gebiet, das das festländische West- und Mitteleuropa umfasste und in groben Zügen von Kopenhagen im Norden über Amsterdam und Rouen im Westen nach Marseille und Genua im Süden sowie über Venedig nach Budapest und Breslau im Osten reichte (vgl. Karte 3). In diesem Gebiet lag zur Mitte des 19. Jahrhunderts der Großteil aller Großstädte mit über 100.000 Einwohnern, während sich die übrigen auf das flächenmäßig viel größere Nord-, Ost- und Südeuropa verteilten.

Eine potentielle Massennachfrage nach in großer Zahl produzierten Industriegütern war daher in West- und Mitteleuropa eher zu erwarten als im übrigen Europa. Und da die Verteilung der mittelgroßen Städte zwischen 20.000 und 100.000 Einwohnern eine ähnliche Konzentration auf diesen Teil Europas auswies, war auch das tendenziell in den Städten ganz allgemein konzentrierte Angebot potentieller Unternehmer und fachkundiger Arbeitskräfte hier eher vorhanden als anderswo. Zwar profitierten auch in West- und Mitteleuropa nicht alle Regionen im selben Ausmaß und zur selben Zeit vom höheren Urbanisierungsgrad, doch waren tendenziell mehr Regionen positiv davon betroffen als in Nord-, Ost- und Südeuropa. Hier blieben die Anfänge einer Industrialisierung auf relativ wenige Regionen im Umfeld der weiter auseinander liegenden Großstädte be- 
schränkt. Je nachdem, ob mehr oder weniger, kleinere oder größere Regionen in den Prozess der Industrialisierung mit einbezogen wurden, fielen auch die gesamtstaatlichen Produktionswerte in den einzelnen Ländern unterschiedlich aus.

Wie zuvor in Großbritannien setzte nun auch auf dem Festland in verschiedenen Regionen eine Mechanisierung der gewerblichen Produktion ein. Und wie in Großbritannien regte die Massennachfrage der Großstädte nicht nur in ihnen selbst und ihrer unmittelbaren Umgebung die Gründung industrieller Unternehmen an. Auch in den umliegenden Regionen der Großstädte entstanden zahlreiche weitere Fabriken, wobei sie für potentielle Unternehmer auf mindestens zweifache Weise günstige Voraussetzungen bieten konnten: zum einen dank der in ihnen vorhandenen Rohstoffe, zum anderen dank ihres Angebotes an gelernten wie ungelernten Arbeitskräften. Facharbeiter fanden sich in den zahlreichen kleineren und mittelgroßen Städten, ungelernte Arbeiter vor allem in Regionen relativer Übervölkerung, wo unterbeschäftigte und Arbeit suchende Menschen ein billiges Arbeitskräftepotential darstellten. Allerdings durften auch in diesen Fällen die großen Städte als Abnehmer der von ihnen erzeugten Halb- und Fertigwaren nicht allzu weit entfernt sein, damit sich entsprechende Investitionen für potentielle Unternehmer lohnten.

Wie in England lässt sich auch auf dem Festland die beginnende Industrialisierung besonders gut an der Entwicklung der Textilindustrie sowie des Bergbaus und der Eisen- und Stahlindustrie ablesen. Die jährliche Verarbeitung von Robbaumwolle stieg dank der zunehmenden Verwendung mechanisch betriebener Spinnmaschinen zwischen dem Beginn und der Mitte des 19. Jahrhunderts in Frankreich von nur 8.000 auf 65.000 t, in Deutschland von knapp $4.000 \mathrm{t}$ in den frühen 30er Jahren auf über $21.000 \mathrm{t}$ um 1850 sowie in der Habsburgermonarchie in etwa demselben Zeitraum von weniger als $7.000 \mathrm{t}$ auf über 26.000 t. ${ }^{59}$ Aber auch in dem außerhalb der Kernzone gelegenen Russland setzte dank der Nachfrage seiner beiden Großstädte Moskau und Sankt Petersburg ein Industrialisierungsprozess ein, der sich in einem Anstieg der jährlichen Verarbeitung von Rohbaumwolle von weniger als $1.000 \mathrm{t}$ zu Beginn auf über $21.000 \mathrm{t}$ um die Mitte des Jahrhunderts widerspiegelte. ${ }^{60}$ Wie sehr es sich in diesen und anderen Ländern aber erst um die Anfänge einer Industrialisierung handelte, wird daraus ersichtlich, dass im Vereinigten Königreich ähnliche Werte bereits um die Jahrhundertwende erreicht worden wa-

59 Mitchell (1977), 509.

60 Mitchell (1977), 509. 
ren und sich die Verarbeitung von Rohbaumwolle bis zur Jahrhundertmitte noch einmal

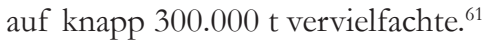

Ähnliches gilt für die Förderung von Stein- und Braunkoble, die um 1800 außer in Großbritannien in allen Ländern noch unter bzw. bei kaum mehr als einer Million Tonnen lag. Zwar stieg sie bis zur Mitte des 19. Jahrhunderts in Deutschland auf 9,2 Millionen, in Frankreich auf 5,3 und in Belgien auf 6,8 Millionen an, blieb damit aber weit hinter der britischen Kohleförderung von über 50 Millionen Tonnen zurück. ${ }^{62}$ Kaum anders verhielt es sich mit der Roheisenproduktion, die auf dem Festland nach der Jahrhundertwende ebenfalls stark zulegte, mit fast durchwegs weniger als einer halben Million Tonnen jedoch bis 1850 nicht annähernd an die 2,7 Millionen des Vereinigten Königreiches herankam. ${ }^{63}$ Und schließlich war auch der Eisenbabnbau, der sowohl eine Begleiterscheinung als auch einen zusätzlichen Motor der Industrialisierung darstellte und seit den 30er Jahren auch auf dem Festland in Angriff genommen wurde, noch lange nicht so weit gediehen wie in Großbritannien. Mit rund $10.000 \mathrm{~km}$ vereinigten die britischen Inseln noch immer fast die Hälfte des europäischen Eisenbahnnetzes auf sich, gefolgt von Deutschland mit etwa 6.000, Frankreich mit circa 3.000 und Österreich-Ungarn mit rund 1.600 Kilometern. $^{64}$

Schon damals war die Eisenbahn auch Spiegelbild von mehr oder weniger Industrialisierung und Urbanisierung. Um 1860, als fast alle Länder mit dem Eisenbahnbau begonnen hatten, lagen die Länder mit der höchsten Eisenbahndichte pro Einwohner, nämlich Großbritannien, Deutschland, Belgien, Frankreich und die Schweiz, durchwegs im urbanisierten West- und Mitteleuropa (vgl. Grafik 1).

Die unterschiedliche Entwicklung zwischen West- und Mitteleuropa auf der einen und dem restlichen Europa auf der anderen Seite setzte sich auch in der zweiten Hälfte des 19. Jahrhunderts und vorerst bis zum Vorabend des Ersten Weltkrieges fort. Überall jedoch sollte sich nunmehr die Beziehung zwischen Urbanisierung und Industrialisierung ändern. Während zuvor ein höherer Grad an Urbanisierung und insbesondere die Entstehung von Großstädten in verschiedenen Regionen einen Industrialisierungsprozess auslöste, förderte nun umgekehrt die Industrialisierung ihrerseits die weitere Urbanisierung. Die zwar nicht nur, aber vorwiegend in den Städten entstehenden Fabriken boten einen

61 Mitchell (1977), 509.

62 Mitchell (1977), 503.

63 Mitchell (1977), 504.

64 Mitchell (1977), 514. 
Grafik 1: Eisenbahnen in Europa um 1860

(Kilometer pro 1 Million Einwohner)

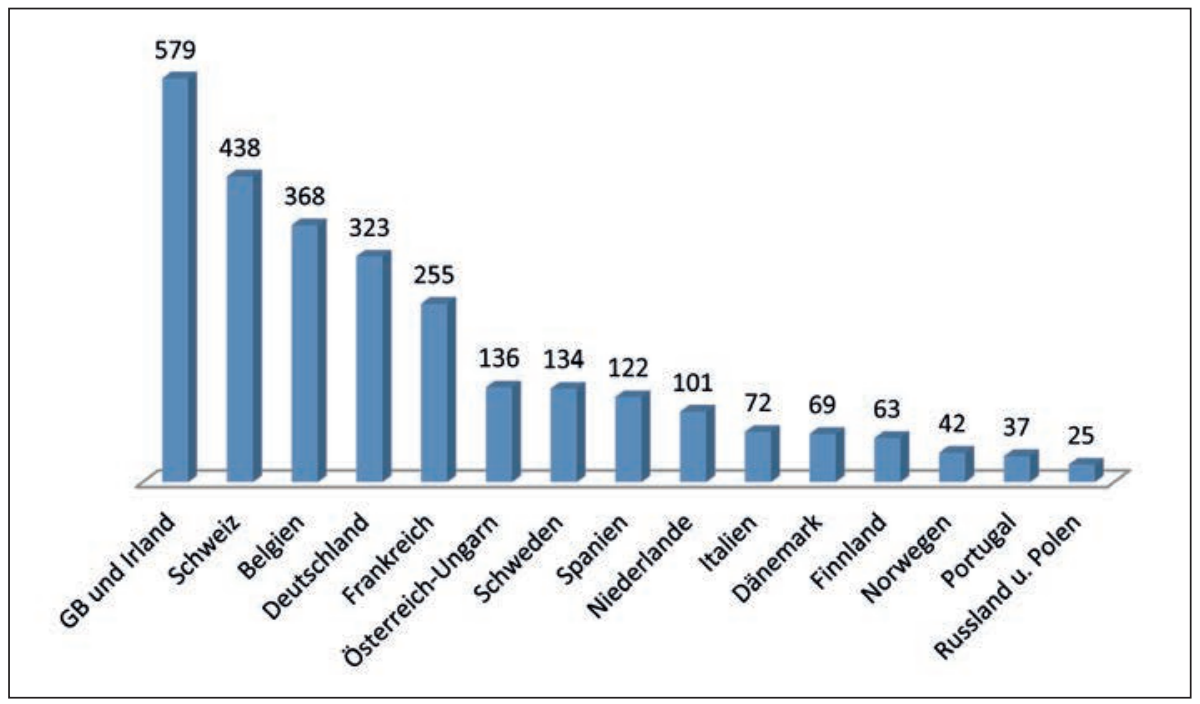

Eigene Berechnungen nach Fischer (1985), 14 und 157.

zusätzlichen Anreiz für die Abwanderung vom Land. Die Pull-Faktoren einer zwar lange Zeit nur schlecht entlohnten, tatsächlichen oder zumindest erhofften Erwerbsarbeit in den Städten hatten gemeinsam mit den Push-Faktoren einer rasch wachsenden Bevölkerung eine verstärkte Landflucht zur Folge. In den nur 60 Jahren zwischen 1850 und 1910 stieg die Bevölkerung in Europa um nicht weniger als zwei Drittel auf rund 450 Millionen Menschen an. ${ }^{65}$ Noch rascher wuchsen dank der genannten Push- und Pull-Faktoren die Städte, was die Massennachfrage nach gewerblich-industriellen Gütern weiter erhöhte. Urbanisierung, Massennachfrage und Industrialisierung stimulierten sich nicht mehr nur in eine Richtung, sondern gegenseitig - ein Prozess, der beim Frühstarter Großbritannien schon in der ersten, auf dem Festland dagegen erst in der zweiten Hälfte des 19. Jahrhunderts zu beobachten war.

65 Fischer (1985), 12. 
Berlin, Unter den Linden, um 1900

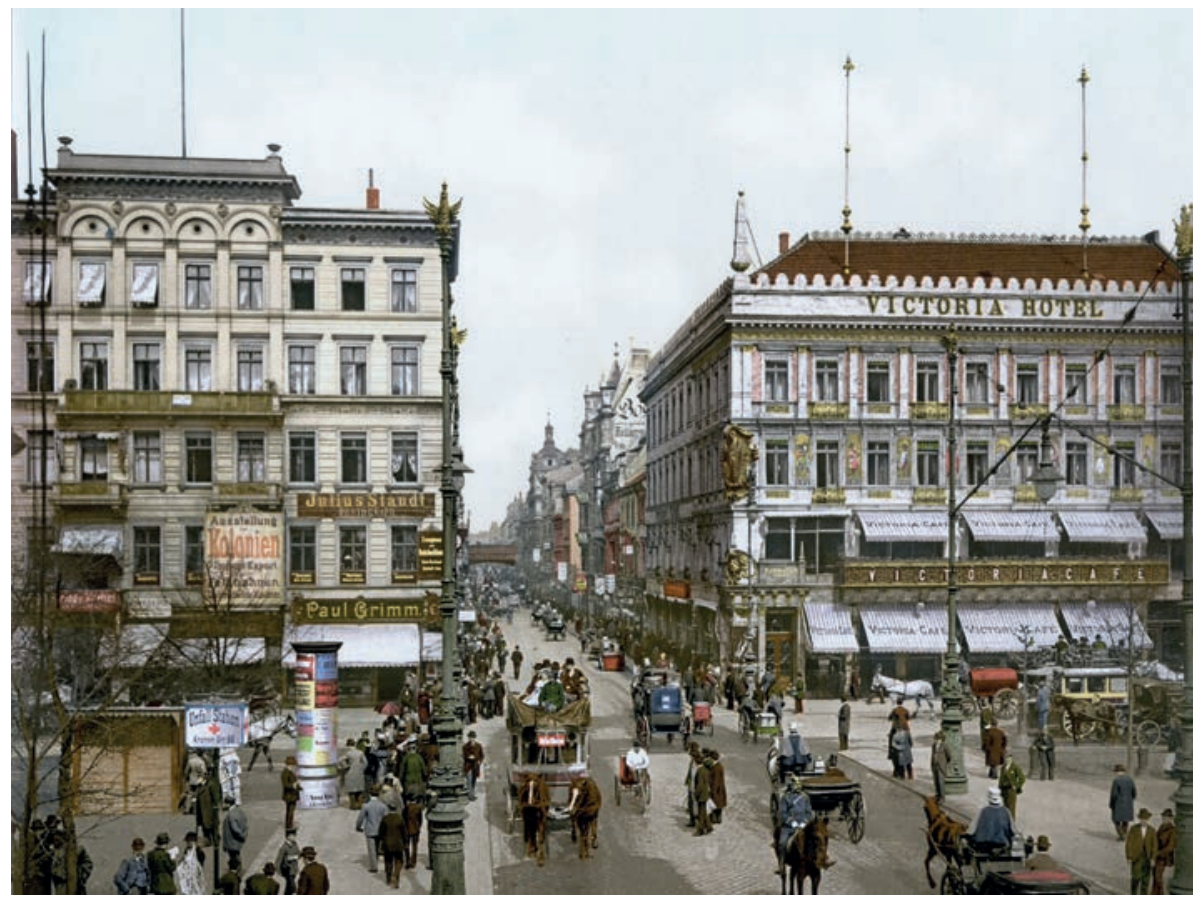

http://de.wikipedia.org/wiki/Berlin\#/media/File:Berlin_Unter_den_Linden_Victoria_Hotel_um_1900.jpg

Neben einer weiteren Zunahme der Großstädte mit über 100.000 Einwohnern überschritten bis zum Ende des Jahrhunderts neben London mit inzwischen fast sieben und Paris mit über drei Millionen Einwohnern nunmehr auch Berlin, Wien, Sankt Petersburg und Moskau die Grenze zur Millionenstadt. ${ }^{66}$ Wie zuvor in England gab es inzwischen auch auf dem Festland eine Reihe von Großstädten, die erst infolge der Industrialisierung stark wuchsen wie zum Beispiel Dortmund, Duisburg, Düsseldorf oder Essen im deutschen Ruhrgebiet, die von der rasch wachsenden Nachfrage nach der dort abgebauten Kohle und von der im Anschluss entstehenden Eisen- und Stahlindustrie profitierten. Alle europäischen Großstädte zusammen zählten am Vorabend des Ersten Weltkrieges über

66 Mitchell (1977), 490. In der Agglomeration zählten um die Jahrhundertwende nach Bairoch/Batou/Chèvre (1988), 283 auch Birmingham, Manchester und Glasgow mehr als 1 Million Einwohner. 
45 Millionen oder fast vier Mal so viele Einwohner wie noch 1850. Damit hatte die Zahl der in Großstädten lebenden Menschen im selben Zeitraum mehr als vier Mal so stark zugenommen wie die Gesamtbevölkerung. ${ }^{67}$ Eine derart starke Zunahme potentieller Nachfrager - von den Bewohnern mittlerer und kleinerer Städte ganz abgesehen musste zwangsläufig zu einer weiteren Industrialisierung führen.

Sie fand - nach den bisherigen Ausführungen keineswegs überraschend - insbesondere in West-und Mitteleuropa statt, wo sich auch zu Beginn des 20. Jahrhunderts rund zwei Drittel aller europäischen Großstädte mit über 100.000 Einwohnern befanden. ${ }^{68}$ Hier kam es daher eher zu einer Beschleunigung und Verbreiterung des Industrialisierungsprozesses als in anderen Teilen Europas, wo er im Wesentlichen auf die vereinzelten Großstädte und ihre unmittelbare Umgebung beschränkt blieb. Beispiele für das eine wären etwa England in der ersten oder Oberitalien in der zweiten Hälfte des 19. Jahrhunderts, Beispiele für das andere dagegen Russland oder das südliche Italien. Während sich zwischen London und Manchester und später zwischen Mailand, Genua und Turin eine dichte Städte- und Industrielandschaft entwickelte, herrschte zwischen Moskau und Sankt Petersburg ebenso wie außerhalb der süditalienischen Metropolen Neapel und Palermo noch lange Zeit eine agrarisch geprägte Wirtschaft vor. ${ }^{69}$

Die regional unterschiedliche Verdichtung und Verbreitung von Urbanisierung und Industrialisierung schlugen sich in den Produktionszahlen der betroffenen Länder nieder. Noch immer war die industrielle Entwicklung in hohem Maße von der Expansion der Baumwollwarenindustrie bestimmt. Sie lässt sich statistisch am besten über die Verarbeitung von Rohbaumwolle erfassen, die auch in der zweiten Hälfte des 19. Jahrhunderts weiter zunahm, wenn auch nicht überall im selben Tempo.

Grafik 2 lässt deutlich erkennen, dass die Baumwollindustrie in den west- und mitteleuropäischen Ländern die größten Fortschritte erzielte. Das Bild fällt noch stärker zugunsten West- und Mitteleuropas aus, wenn man berücksichtigt, dass in Italien über 90 Prozent der Baumwollspindeln allein in Piemont, Ligurien und der Lombardei installiert waren, in Spanien die allermeisten Baumwollwaren in Katalonien hergestellt wurden und sich in Österreich-Ungarn die Baumwollspinnerei auf die westliche Hälfte der Habsburgermonarchie, insbesondere die Sudentenländer, den Wiener Raum und Vorarlberg konzentrierte. ${ }^{70}$

67 Eigene Berechnungen nach Fischer (1985), 12, Mitchell (1980), 425 f. und Bairoch/Batou/Chèvre (1988), 283.

68 Mitchell (1980), 425 f. und Bairoch/Batou/Chèvre (1988), 283.

69 Vgl. Mathis (2006), 229 und Mathis (2007).

70 Mathis (2007), 338; Nadal (1977), 395; Matis/Bachinger (1973), 203. 
In diesen nahe der west- und mitteleuropäischen Kernzone gelegenen Regionen waren die Pro-Kopf-Werte daher höher als in den davon weiter entfernten Teilen dieser Länder.

Grafik 2: Verarbeitung von Rohbaumwolle in Europa 1909/13

(Kilogramm pro Einwohner, Jahresdurchschnitte)

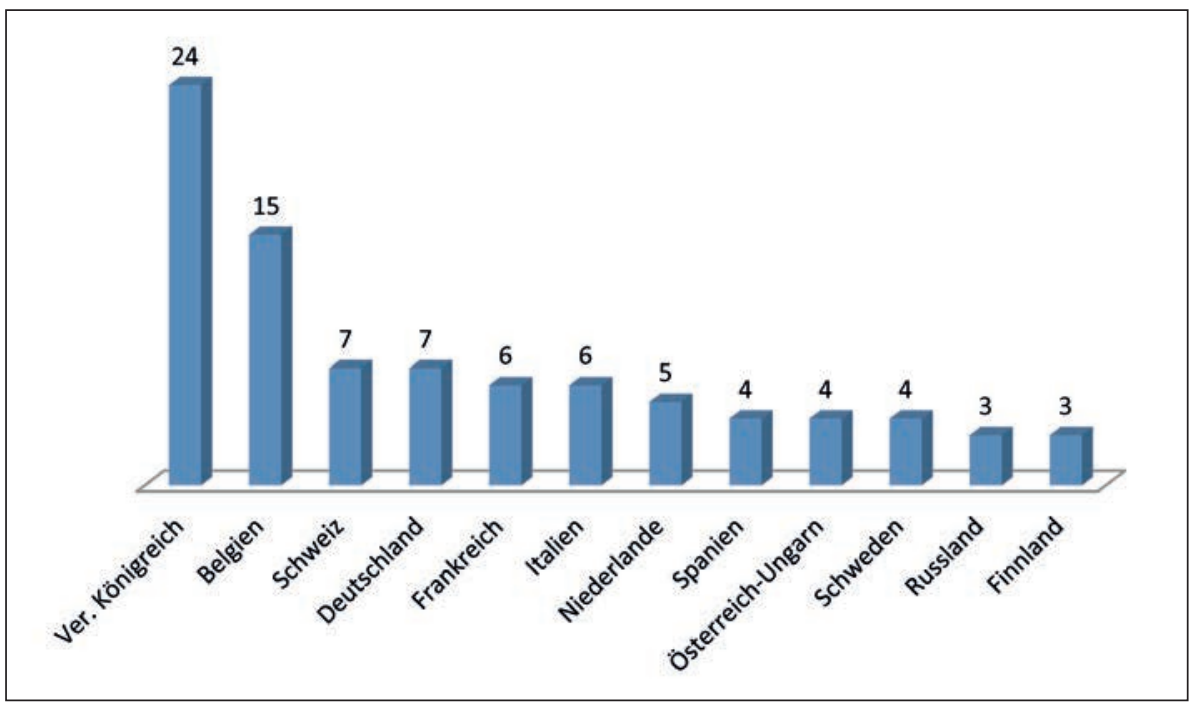

Eigene Berechnungen nach Fischer (1985), 14 und 151.

Auch die zweite Phase der Industrialisierung, die Modernisierung der Eisen- und Stablindustrie samt nachgelagerten Branchen zeigt ein ähnliches Bild (vgl. Grafik 3). Obwohl die Roheisenerzeugung bis zu einem gewissen Grad von der Existenz von Eisenerzvorkommen abhängt, zeigt die geringe Pro-Kopf-Produktion in Russland und Österreich-Ungarn, die beide über große Eisenerzvorkommen verfügten, dass für die Entstehung einer umfangreichen Eisen- und Stahlindustrie weniger das Angebot an Eisenerz als vielmehr die Nachfrage nach Eisen und Stahl entscheidend war. Sie wuchs parallel zu dem im Zuge der Industrialisierung zunehmenden Einsatz von Maschinen und dem Ausbau des Eisenbahnwesens und entwickelte sich daher in West- und Mitteleuropa stärker als in anderen Teilen Europas. 
Grafik 3: Produktion von Roheisen in Europa 1910/13

(Kilogramm pro Einwohner, Jahresdurchschnitte)

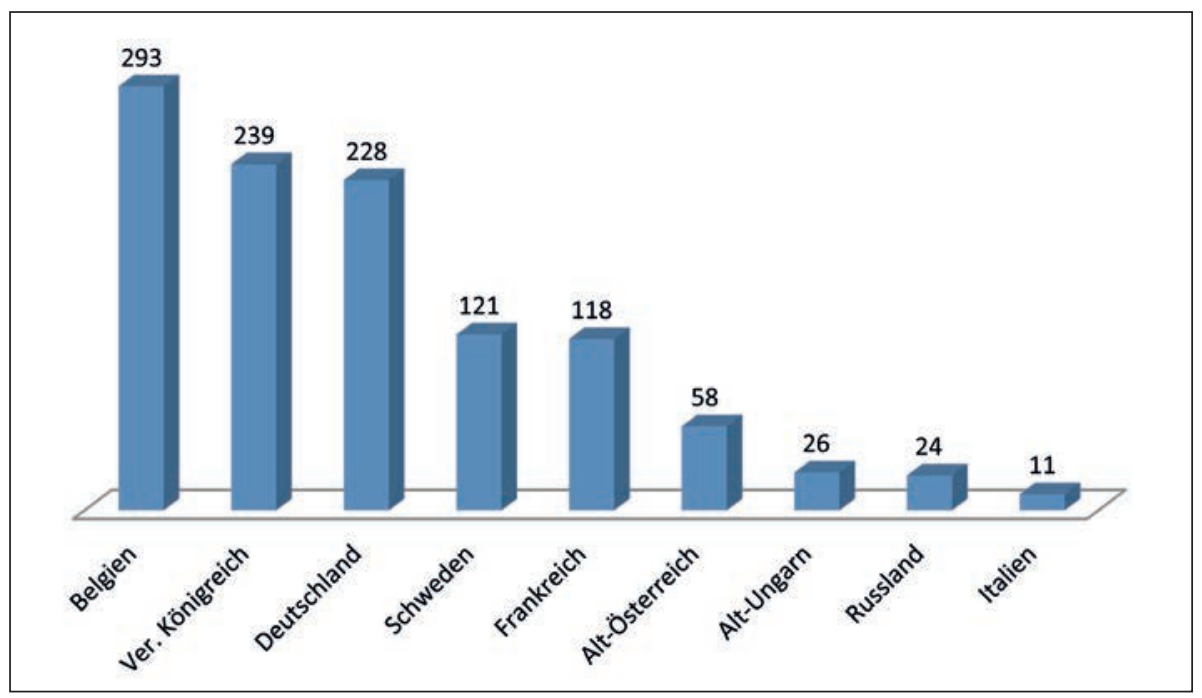

Eigene Berechnungen nach Mitchell (1977), 489 und 505.

Der Umfang des Eisenbahnnetzes korrelierte zwar nicht nur, aber in hohem Maße mit dem Bedarf an effizienteren Verkehrsmitteln, der seinerseits vom Handelsvolumen abhing. Das Handelsvolumen wiederum wuchs sowohl mit dem Grad der Arbeitsteilung und damit dem Urbanisierungsgrad als auch mit der für den Markt bestimmten Produktion und somit vor allem mit dem Industrialisierungsgrad eines Landes oder einer Region. So war in den Ländern, die am Vorabend des Ersten Weltkrieges eine Roheisenproduktion von über $100 \mathrm{~kg}$ pro Einwohner aufwiesen und mit Ausnahme Schwedens durchwegs in West- und Mitteleuropa lagen, bis 1913 auch rund die Hälfte aller in Europa errichteten Eisenbahnen gebaut worden, obwohl sie nur etwa ein Fünftel der Fläche und nur ein gutes Drittel der Bevölkerung Europas auf sich vereinigten. ${ }^{71}$

Dieselben kontinentaleuropäischen Länder einschließlich der erzarmen Schweiz kamen auch mit ihrer gesamten industriellen Pro-Kopf-Produktion bis 1913 am Nächsten an das Vereinigte Königreich heran. Sie lag in Belgien, Deutschland, der Schweiz, Schweden und

71 Fischer (1985), 14 und 157. 
Frankreich zwischen 76 und 51 Prozent des britischen Wertes, in allen anderen Ländern hingegen lediglich zwischen 9 und 29 Prozent. ${ }^{72}$ Und da der Grad der Industrialisierung dank der durch sie erzielten Produktivitätssteigerung in hohem Maße auch für das ProKopf-Einkommen eines Landes insgesamt verantwortlich zeichnete, braucht es nicht zu überraschen, wenn am Vorabend des Ersten Weltkriegs die reichsten Länder - nämlich das Vereinigte Königreich, die Schweiz, Belgien und die stärker vom Außenhandel profitierenden Niederlande sowie Dänemark, Frankreich, Deutschland und das heutige Österreich - durchwegs in West- und Mitteleuropa lagen. Etwas geringer fiel das Bruttoinlandsprodukt pro Einwohner in Norwegen, Schweden und Italien, deutlich niedriger dagegen in den restlichen, vor allem ost- und südeuropäischen Ländern aus. ${ }^{73}$

\section{Industrialisierung im 20. Jahrhundert}

Der im späten 18. und vor allem im 19. Jahrhundert unterschiedlich schnelle und unterschiedlich breite Industrialisierungsprozess, der sich letztlich aus einem ebenfalls unterschiedlichen Urbanisierungsprozess erklären lässt, hatte die schon zuvor vorhandenen Unterschiede zwischen West- und Mitteleuropa auf der einen und dem restlichen Europa auf der anderen Seite deutlich verschärft. Daran sollte sich im 20. Jahrhundert - mit Ausnahme der Sowjetunion und Skandinaviens - vorerst nichts Wesentliches ändern. Im Gegenteil, die Schere ging bis zur Jahrhundertmitte sogar noch weiter auseinander. ${ }^{74}$

Zunächst einmal schritt die Urbanisierung dank anhaltender Landflucht und trotz abgeschwächtem Bevölkerungswachstum fort. ${ }^{75}$ Die Zahl der europäischen Millionenstädte erhöhte sich zwischen 1910 und 1950 von sieben auf 17, die Zahl der in ihnen lebenden Menschen verdoppelte sich von knapp 19 auf über 40 Millionen. ${ }^{76}$ Allein zehn von ihnen lagen im weiteren West- und Mitteleuropa zwischen Glasgow, Mailand, Budapest und Kopenhagen, die restlichen sieben verteilten sich auf das viel größere Ost- und Südeuropa zwischen Leningrad, Moskau, Athen und Madrid (vgl. Karte 4).

Aber auch der breitere Urbanisierungsgrad, der sich am Bevölkerungsanteil der Menschen messen lässt, die in Städten mit über 20.000 Einwohnern lebten, war in den west-

\footnotetext{
72 Fischer (1985), 149.

73 Maddison (Per Capita GDP).

74 Vgl. Maddison (Per Capita GDP).

75 Die europäische Bevölkerung, die sich im 19. Jahrhundert mehr als verdoppelt hatte, stieg im 20. Jahrhundert um nur noch knapp 80 Prozent auf 728 Millionen an. Mathieu (2011), 87.

76 Eigene Berechnungen nach Mitchell (1980), 425 f.
} 
und mitteleuropäischen Ländern fast durchwegs höher als im restlichen Europa. ${ }^{77}$

Wie schon zuvor war daher in West- und Mitteleuropa eine stärkere Nachfrage nach in Massenproduktion hergestellten Industriegütern vorhanden. Dazu kam, dass mit zunehmender Verbilligung der Transportkosten speziell durch die Eisenbahn auch weiter entfernte Märkte leichter von bereits etablierten Industriefirmen bzw. Industrieregionen beliefert werden konnten, wodurch der Einstieg neuer Anbieter erschwert wurde. Auf diese Weise wirkte sich der zeitliche Vorsprung der Unternehmen in West- und Mitteleuropa auf die weitere Industrialisierung dieses Gebietes positiv verstärkend, der Rückstand in Ost- und Südeuropa hingegen negativ, d. h. entwicklungshemmend aus.

Karte 4: Millionenstädte in Europa um 1950

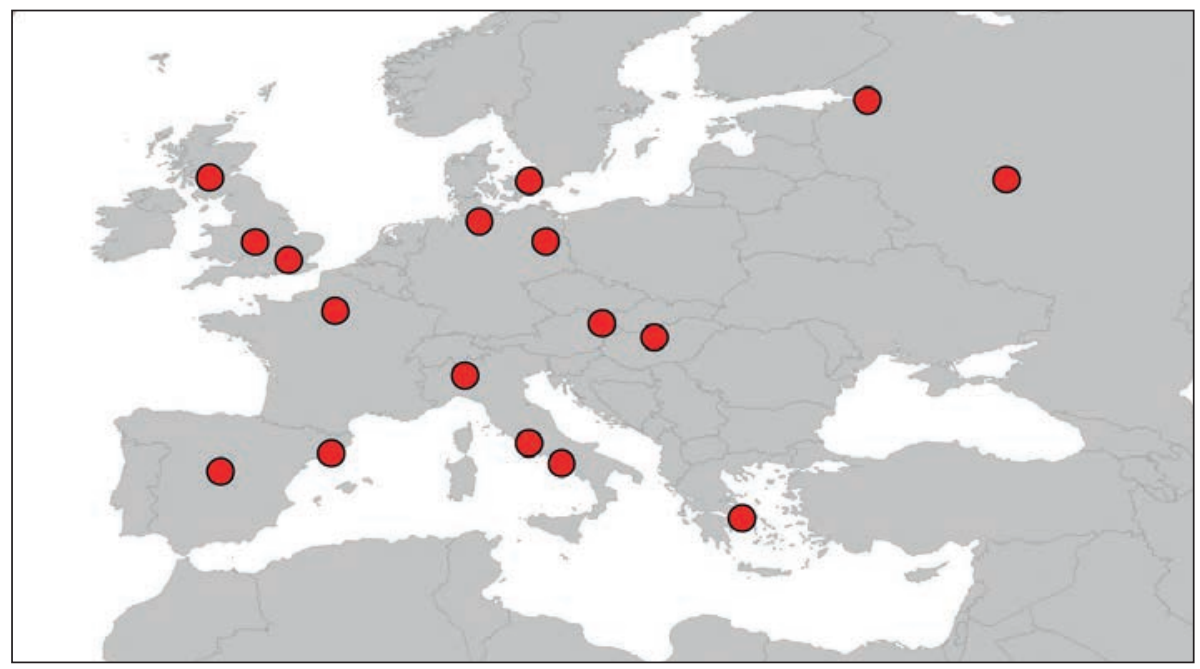

Tirol Atlas - Bearbeitung Klaus Förster nach Tabelle 5. Kartenhintergrund: World Borders Dataset http://thematicmapping.org/downloads/world_borders.php

Anders verhielt es sich diesbezüglich in der Sonjetunion. Nach der bolschewistischen Revolution und der Einführung einer staatlichen Planwirtschaft wurde die weitere Industrialisierung nicht nur dem Einfluss der Marktkräfte entzogen, sondern konnte sich infolge einer weitgehenden Entkoppelung aus der internationalen Wirtschaft auch relativ

77 Fischer (1987), 54. 
unbehelligt von ausländischer Konkurrenz entfalten. Folgt man den Berechnungen von Paul Bairoch und Angus Maddison, nahmen der Industrialisierungsgrad und damit die durchschnittlichen Einkommen pro Einwohner in keinem anderen Land Ost- und Südeuropas bis zur Mitte des Jahrhunderts derart stark zu wie in der Sowjetunion, wo sich die Produktion von Industrie und verarbeitendem Gewerbe zwischen 1913 und dem Vorabend des Zweiten Weltkrieges mehr als verachtfachte. ${ }^{78}$ Noch 1928 machte die industrielle Pro-Kopf-Produktion kaum mehr als ein Sechstel des Wertes im Vereinigten Königreich aus, bis 1953 stieg sie auf über ein Drittel an. Damit lag die Sowjetunion zwar hinter den nach Mitteleuropa hinein reichenden Ländern Ungarn und der Tschechoslowakei, aber vor Polen, Rumänien, Bulgarien und Jugoslawien sowie auch vor Italien, Griechenland, Spanien und Portugal. ${ }^{79}$ Die stärkere Industrialisierung wirkte sich naturgemäß auf das durchschnittliche Pro-Kopf-Einkommen der mehrheitlich in Europa lebenden, sowjetischen Bevölkerung aus. Während das Bruttoinlandsprodukt pro Einwohner im übrigen Osteuropa zwischen 1913 und 1950 lediglich um ein Viertel anstieg, wuchs es in der Sowjetunion auf fast das Doppelte und damit auch deutlich stärker als in den südeuropäischen Ländern. ${ }^{80}$

Dank einer beispiellosen Steigerung sowohl der Stablerzengung als auch der Baumwollverarbeitung kam die Sowjetunion bis zum Beginn der 50er Jahre pro Einwohner deutlich näher an die britischen, deutschen und französischen Werte heran und rangierte bei der Baumwollverarbeitung hinter Belgien, Großbritannien und der Schweiz sogar an vierter Stelle der europäischen Länder. ${ }^{81}$ Ähnlich spektakulär fiel die Entwicklung des modernen Energieträgers Elektrizität aus, mit dem Ergebnis, dass die Pro-Kopf-Produktion elektrischer Energie in den 50er Jahren um ein Vielfaches über der Produktion der 20er Jahre und damit deutlich über den Werten der restlichen Länder Ost- und Südeuropas lag. Allerdings reichte die Steigerung nicht aus, um die Werte der meisten west- und mitteleuropäischen Länder zu erreichen. ${ }^{82}$

In diesen wiederum setzte sich die erfolgreiche Industrialisierung des 19. Jahrhunderts trotz der beiden Weltkriege und der Weltwirtschaftskrise im Großen und Ganzen auch im 20. Jahrhundert fort. Allerdings wirkten sich speziell die kriegsbedingten Einbrü-

78 Bairoch (1982), 302 und 331; Maddison (Per Capita GDP); Lal (1988), 201.

79 Fischer (1987), 137, nach Bairoch (1982), 302 und 331.

80 Maddison (Per Capita GDP).

81 Eigene Berechnungen nach Mitchell (1980), 424, 461 und 463.

82 Eigene Berechnungen nach Fischer (1987), 12 f. und 120. 
che nicht in allen Volkswirtschaften West- und Mitteleuropas gleichermaßen aus. Ländern wie Deutschland und Österreich, deren wirtschaftliche Pro-Kopf-Leistung 1950 kaum höher war als 1913, standen Länder wie die Schweiz oder auch die skandinavischen Länder Schweden, Norwegen, Dänemark und Finnland gegenüber, die in derselben Zeit einen Wachstumsschub auf mehr als das Doppelte der Vorkriegsleistung erlebten. Zwischen diesen beiden Extremen bewegten sich Frankreich, Belgien, die Niederlande, Italien und das Vereinigte Königreich, deren Bruttoinlandsprodukt pro Einwohner um 30 bis 50 Prozent zulegten. ${ }^{83}$

Offenbar gelang es den skandinavischen Ländern - und zwar bereits seit dem 19. Jahrhundert - besser als den süd- und osteuropäischen Ländern, von der zunehmenden Nachfrage der europäischen Kernregionen zu profitieren. Bereits 1913 war der Anteil Schwedens, Norwegens und Dänemarks an den Exporten der europäischen Länder im Verhältnis zu ihrer Bevölkerungsgröße vier bis sechs Mal so hoch wie in Spanien und sechs bis $20 \mathrm{Mal}$ so hoch wie in Rumänien, Bulgarien, Portugal und Griechenland. ${ }^{84}$ Bis zum Vorabend des Zweiten Weltkrieges sollte sich der Abstand weiter vergrößern, und sogar die neu geschaffene Tschechoslowakei und Ungarn lagen trotz ihrer Nähe zu Mitteleuropa diesbezüglich hinter den skandinavischen Ländern zurück. Exporte ergänzten nicht nur unmittelbar den auch in diesen Ländern im Vordergrund stehenden Binnenmarkt, sondern erhöhten auch die Erlöse und damit die Kaufkraft der exportierenden Firmen und ihrer Mitarbeiter, wodurch die inländische Nachfrage zusätzlich erweitert wurde. Binnenmarkt und zusätzliche Kaufkraft durch die Exporte dürften daher in den skandinavischen Ländern - wie schon zuvor in den größenmäßig vergleichbaren Benelux-Ländern und der Schweiz - zu einer erfolgreichen Industrialisierung beigetragen haben. 1953 lag Schweden mit seiner industriellen Pro-Kopf-Produktion hinter dem nach wie vor mit großem Abstand führenden Vereinigten Königreich und nur knapp hinter der Schweiz an dritter, Dänemark noch vor der Bundesrepublik Deutschland an vierter und Norwegen vor Belgien an sechster Stelle der europäischen Industrieländer. ${ }^{85}$

In Ost- und Südeuropa dagegen fielen die Anfänge einer Industrialisierung bis zur Mitte des 20. Jahrhunderts wesentlich bescheidener aus. Noch am Vorabend des Zweiten Weltkrieges machte die industrielle Pro-Kopf-Produktion in den Ländern Ost- und Südeuropas weniger als 15 Prozent der britischen Produktion aus. Lediglich in Ungarn und der Sowjet-

83 Maddison (Per Capita GDP)

84 Eigene Berechnungen nach Fischer (1987), 12 f. und 157.

85 Fischer (1987), 138. 
union lag sie leicht, in der Tschechoslowakei deutlich über diesen ausgesprochen niedrigen Werten. ${ }^{86}$ Erst danach gelang es, den Abstand erheblich zu verringern, in Osteuropa nicht zuletzt dank einer forcierten Industrialisierungspolitik im Rahmen zentraler staatlicher Planung. 1973 bewegte sich die industrielle Pro-Kopf-Produktion der süd- und osteuropäischen Länder zwischen knapp 30 und 50 Prozent des inzwischen mehr als doppelt so hohen, britischen Niveaus, in der Sowjetunion sogar bei 65 Prozent. ${ }^{87}$ Die ostmitteleuropäischen Länder Ungarn, die Tschechoslowakei und die DDR erreichten inzwischen bereits west- und mitteleuropäische Werte. Parallel dazu nahm auch der Urbanisierungsgrad deutlich rascher zu als zuvor, wobei sich beide, Industrialisierung und Urbanisierung, nunmehr auch in diesen Teilen Europas gegenseitig beeinflussten. 1980 zählten 35 europäische Städte - zum Teil einschließlich ihres unmittelbaren Umlandes - über eine Million Einwohner, ein gutes Drittel davon in den Planwirtschaften des östlichen Europa. ${ }^{88}$

Der Aufholprozess Ost- und Südeuropas wirkte sich naturgemäß auf die gesamte durchschnittliche Wertschöpfung der entsprechenden Länder aus. Lag das Bruttoinlandsprodukt pro Einwohner noch 1950 auf dem Niveau, das West-, Mittel- und Nordeuropa im Schnitt bereits 1870 erreicht hatte, dauerte es nunmehr nur etwa 20 Jahre, um es auf den Wert - und zum Teil darüber hinaus - anzuheben, den das entwickeltere Europa 1950 erzielte. ${ }^{89}$ Der raschere und breitere Industrialisierungsprozess ließ somit auch die Länder Ost- und Südeuropas zu Industrieländern werden, deren reale Wertschöpfung pro Einwohner die noch vorindustriellen Werte des frühen 19. Jahrhunderts um mehr als das Siebenfache übertrafen. ${ }^{90}$ Allerdings gelang es weder jetzt noch später, zu den nach dem Krieg ebenfalls rasch wachsenden west-, mittel- und nordeuropäischen Ländern aufzuschließen.

Der nach wie vor bestehende Rückstand kommt unter anderem in der unterschiedlichen Entwicklung älterer und jüngerer Industriezweige zum Ausdruck. Als Beispiele für ältere Branchen können die bereits mehrfach angesprochene Verarbeitung von Rohbaumwolle oder die Rohstahlerzeugung, für jüngere Branchen dagegen die Herstellung langlebiger Elektrogeräte sowie von Automobilen herangezogen werden.

Während die traditionelle Baumwollindustrie, gemessen an der Pro-Kopf-Verarbeitung an Rohbaumwolle, im Mutterland der Industrialisierung sowie in Belgien ihren Höhe-

86 Fischer (1987), 137.

87 Fischer (1987), 137.

88 Fischer (1987), 52 und Liste der Städte (einzelne Länder).

89 Maddison (Per Capita GDP).

90 Maddison (Per Capita GDP). 
punkt bereits in den 30er Jahren und in den meisten übrigen Ländern West-, Mittel- und Nordeuropas bald nach dem Zweiten Weltkrieg erreicht hatte und anschließend zusehends durch andere, meist höherwertige Konsumgüter ersetzt wurde, stieg sie in Ostund Südeuropa fast durchwegs bis in die 70er und 80er Jahre weiter an (vgl. Grafik 4). Dennoch lag das nunmehr erzielte, durchschnittliche Produktionsniveau der einzelnen Großregionen mit Ausnahme der Sowjetunion und Südeuropas noch immer unter dem zuvor erreichten Höchststand der west- und mitteleuropäischen Länder, wobei in der Grafik 4 und in den folgenden Vergleichen neben der DDR auch Italien und die Tschechoslowakei wegen ihrer stärker industrialisierten westlichen und nördlichen Landesteile zu Mitteleuropa gezählt wurden.

Grafik 4: Verarbeitung von Rohbaumwolle in Europa 1930-1983

(Kilogramm pro Einwohner, Jahresdurchschnitte)

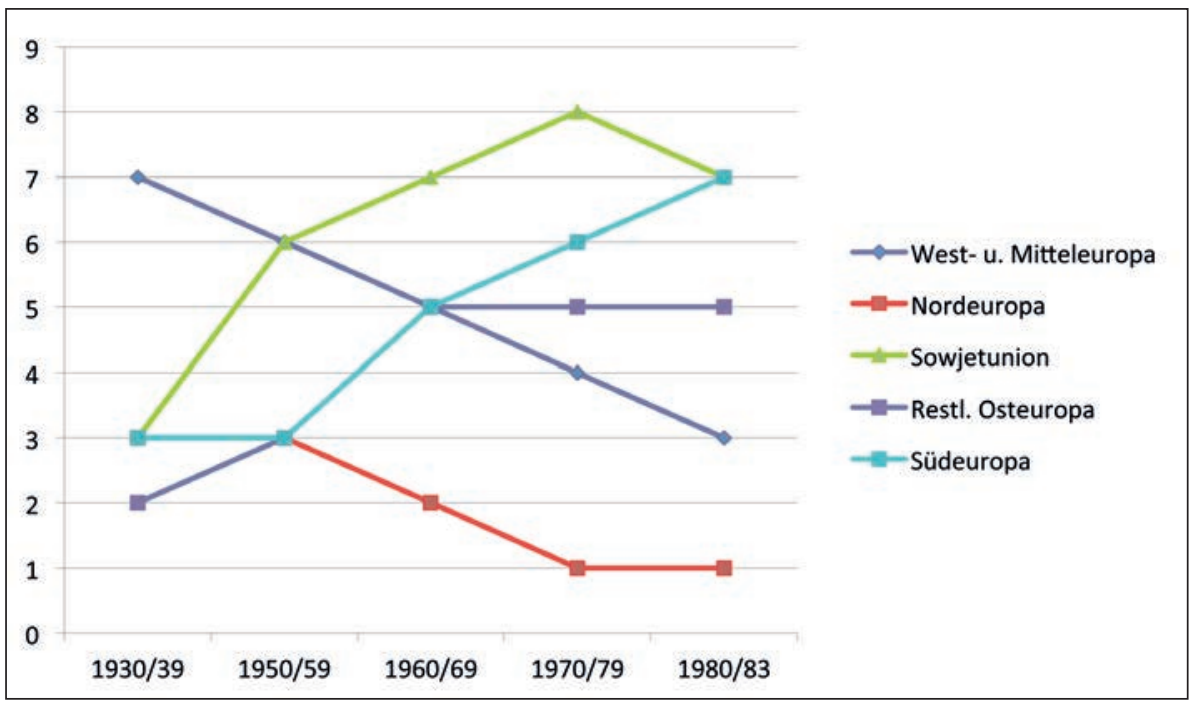

West- und Mitteleuropa: Belgien, Deutschland, Frankreich, Irland, Italien, Luxemburg, Niederlande, Österreich, Schweiz, Tschechoslowakei, Vereinigtes Königreich.

Nordeuropa: Dänemark, Norwegen, Finnland, Schweden.

Restliches Osteuropa: Polen, Ungarn, Jugoslawien, Rumänien, Bulgarien.

Südeuropa: Griechenland, Portugal, Spanien.

Eigene Berechnungen nach Fischer (1987), 12 f. und 135. 
Einen sehr viel stärkeren Wachstumsschub erlebte die Rohstableræeugung. Zum einen war der weitere Industrialisierungsprozess im 20. Jahrhundert von einer zunehmenden Bedeutung der Investitions- oder Kapitalgüterindustrie gekennzeichnet, da im Zuge fortschreitender Mechanisierung und Automatisierung immer mehr Maschinen an die Stelle menschlicher Arbeitskraft traten. Zum anderen setzte die zentrale staatliche Planung zunächst in der Sowjetunion und nach dem Zweiten Weltkrieg auch in den anderen osteuropäischen Ländern auf einen forcierten Ausbau der Grundstoffindustrie. Damit sollte in der Zeit des Kalten Krieges eine vom Westen möglichst unabhängige Basis sowohl für die nachgelagerten Konsumgüterindustrien als auch für die Rüstungsindustrie gelegt werden. Im Unterschied zur Baumwollverarbeitung, die in West- und Mitteleuropa seit den 20er Jahren stagnierte bzw. zurückging und sich im restlichen Europa bis in die 80er Jahre lediglich etwa verdreifachte, legte die Stahlproduktion hier wie dort gewaltig zu (vgl. Grafik 5).

Grafik 5: Produktion von Rohstahl in Europa 1920-1998

(Kilogramm pro Einwohner, Jahresdurchschnitte)

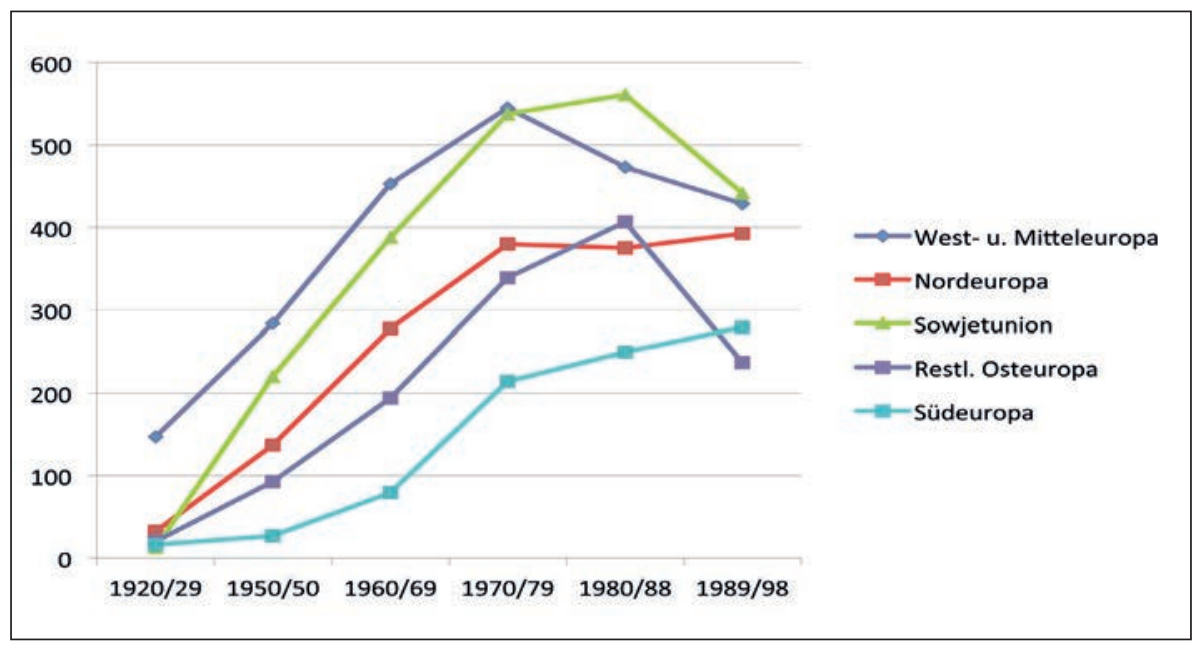

Regionen wie in Grafik 4. Vgl. Tabelle 6.

In West- und Mitteleuropa sollte sich die an sich schon umfangreiche Herstellung von Rohstahl zwischen den 20er und 50er Jahren sowie noch einmal bis in die 70er Jahre 
pro Kopf jeweils verdoppeln. Noch stärker fiel der Zuwachs in den anfänglich weniger industrialisierten Regionen aus, deren Pro-Kopf-Produktion in den 20er Jahren erst einen kleinen Bruchteil des west- und mitteleuropäischen Wertes ausmachte. Gut 50 Jahre später erreichte und übertraf die Sowjetunion das Niveau von West- und Mitteleuropa, das restliche Osteuropa jenes des ebenfalls stark wachsenden Skandinavien. Lediglich die drei südeuropäischen Länder blieben trotz relativ stärkstem Nachkriegswachstum hinter dem übrigen Europa zurück. Damit war in den 80er Jahren fast überall in Europa der Höhepunkt der Rohstahlproduktion erreicht, da und dort ging sie - wie zuvor die Herstellung von Baumwollwaren - sogar zurück. Besonders drastisch fiel der Rückgang in Osteuropa aus, was zweifellos dem Ende der zentralen Planwirtschaften und den damit verbundenen Umstellungen auf die Marktwirtschaft geschuldet war. Nur in wenigen Ländern wuchs die Stahlproduktion auch im neuen Jahrhundert weiter an, unter den größeren Produzenten insbesondere in den Niederlanden, Österreich, Spanien, Finnland, Weißrussland und der Russischen Föderation. ${ }^{91}$

Während Ost- und Südeuropa bei den für die frühe Industrialisierung typischen Produkten zumindest teilweise aufholte, hinkte es bei den jüngeren Konsumgütern wie etwa langlebigen Elektrogeräten oder Automobilen deutlich hinterher. Obwohl sich die Elektroindustrie in den einzelnen Ländern in zum Teil sehr unterschiedlichem Ausmaß entwickelte, produzierte Ost- und Südeuropa als Ganzes trotz zum Teil hoher Wachstumsraten deutlich weniger Fernsehapparate, Kühlschränke und Waschmaschinen; in den 70er und frühen 80er Jahren waren es pro Einwohner nur etwas mehr als halb so viele wie in Westund Mitteleuropa. ${ }^{92}$

Einen noch besseren Indikator für eine fortgeschrittene Industrialisierung stellt die Produktion von Automobilen dar. Allerdings trifft dies vor allem auf die größeren Länder zu, da sich eine eigene Automobilproduktion wegen des beschränkten Binnenmarktes in kleineren Ländern in der Regel weniger gut behaupten konnte (vgl. Grafik 6).

In den 50er Jahren produzierten die Bundesrepublik Deutschland, Frankreich und Großbritannien pro Einwohner mit Abstand am meisten Autos. Obwohl in der Folge andere Länder etwas aufholten, lagen die Bundesrepublik und Frankreich auch in den 80er und 90er Jahren sowie zu Beginn des neuen Jahrhunderts zum Teil mit großem Abstand an der Spitze der Auto produzierenden Länder. Lediglich Schweden und später

91 Stahl (Tabellen und Grafiken).

92 Eigene Berechnungen nach Fischer (1987), $130 \mathrm{f}$. 
auch Spanien zogen stärker nach, während die osteuropäischen Länder einschließlich der Sowjetunion in ihrer Automobilproduktion trotz relativ starker Zuwächse weit hinter West- und Mitteleuropa zurückblieben und erst in jüngerer Zeit infolge von Standortverlagerungen wie etwa in die relativ kleine Slowakei stärker zulegten.

Grafik 6: Produktion von Automobilen (PKW und Lastkraftwagen) in Europa 1950-2009 (Jahresdurchschnitte pro 1.000 Einwohner)

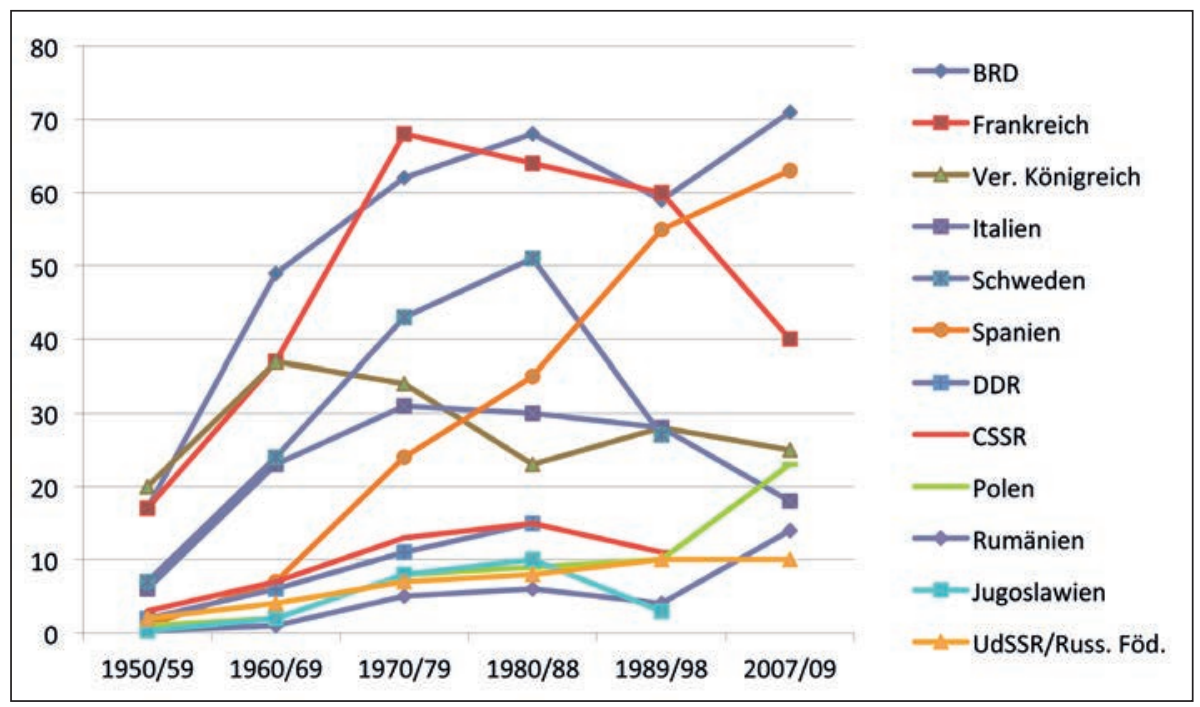

Vgl. Tabelle 7.

Neben der Automobilproduktion ist auch die Ausstattung eines Landes mit importierten wie selbst hergestellten Personenkraftwagen, die so genannte PKW-Dichte, mit dem Industrialisierungsgrad und den Pro-Kopf-Einkommen ganz allgemein verbunden. Neben nur schwer erschwinglichen Luxusgütern wie Schiffsjachten oder Privatflugzeugen stellt das Auto das kostspieligste der für die Allgemeinheit zugänglichen, industriellen Konsumgüter dar und bietet sich daher in hervorragender Weise als Wohlstandsindikator an (vgl. Grafik 7).

1949, nur wenige Jahre nach Kriegsende, entfielen im Vereinigten Königreich und in Frankreich 42 bzw. 37 PKW auf 1.000 Einwohner, gefolgt von Schweden, der Schweiz, Belgien, Dänemark und Irland, wo es 26 bis 28 PKW waren (vgl. Tabelle 10). Die Ver- 
teilung entsprach also durchaus dem Verlauf der Industrialisierung in West- und Mitteleuropa, mit Ausnahme der kriegsbedingten Unterbrechung in Deutschland und Österreich, wo damals erst sechs bis sieben PKW pro 1.000 Einwohner gezählt wurden. Fast durchwegs noch geringer war die PKW-Dichte in den ost- und südeuropäischen Ländern. In der Folge stieg die PKW-Dichte überall rasant an und hielt etwa 1988 in Italien, Deutschland, der Schweiz und in Schweden bei über 400 und im restlichen West-, Mittel- und Nordeuropa außer in Irland bei über 300 PKW pro 1.000 Einwohner. Weit weniger waren es nach wie vor in den süd- und osteuropäischen Ländern, am wenigsten in der Sowjetunion, wo nicht zuletzt infolge einer die Konsumgüter vernachlässigenden Planung weniger als 100 PKW auf 1.000 Einwohner entfielen. Im Zuge der fortgesetzten Industrialisierung vermochten dann speziell die südeuropäischen Länder zu West- und Mitteleuropa aufzuschließen, während die osteuropäischen Länder einschließlich der ehemaligen Sowjetunion mit wenigen Ausnahmen noch zu Beginn des neuen Jahrhunderts deutlich hinter dem restlichen Europa zurücklagen (vgl. Tabelle 10).

Grafik 7: PKW pro 1.000 Einwohner in Europa 1949-2006

(größere Länder)

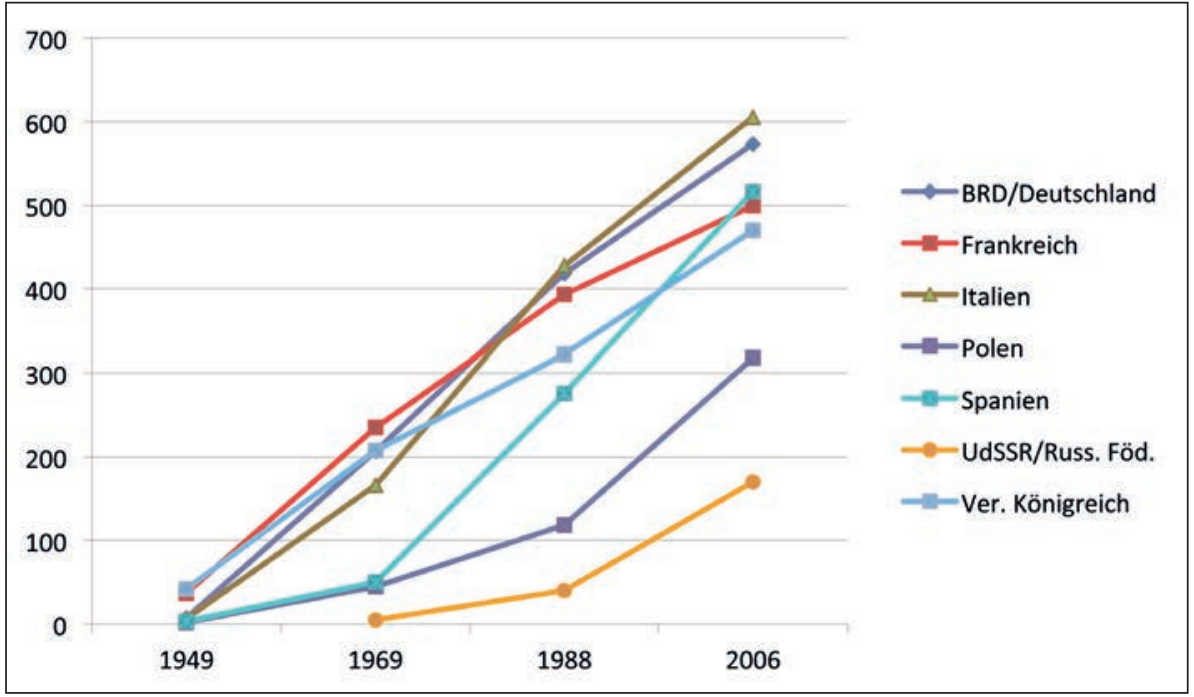

Vgl. Tabelle 10, auch für die kleineren Länder. 
Das Wohlstandgefälle zwischen West-, Mittel- und Nordeuropa auf der einen und vor allem Osteuropa auf der anderen Seite spiegelt sich neben der PKW-Dichte auch in der ihr zugrunde liegenden, realen Wertschöpfung pro Einwohner wider. ${ }^{93}$ Dabei schnitten die südeuropäischen Länder Griechenland, Portugal und vor allem Spanien klar besser ab als Osteuropa, indem sie bis 2008 das west-, mittel- und nordeuropäische Wohlstandsniveau von 1990 erreichten und zum Teil übertrafen. Ganz anders verlief dagegen die Entwicklung in den ehemaligen Planwirtschaften des Ostens, wo sich das Wirtschaftswachstum bereits in den letzten Jahren der Planwirtschaft verlangsamte und durch die Umstellung auf die Marktwirtschaft zu Beginn der 90er Jahre vorübergehend sogar unterbrochen wurde. Obwohl noch vor der Jahrtausendwende ein neuerliches Wachstum einsetzte, bewegte sich das Bruttoinlandsprodukt pro Einwohner - mit wenigen Ausnahmen wie Slowenien oder Estland und mit großen regionalen Unterschieden - 2008 erst auf dem Stand, den die west-, mittel- und nordeuropäischen Länder bereits in den 60er und 70er Jahren des 20. Jahrhunderts erzielt hatten.

Die Unterschiede zwischen den industriellen Frühstartern und den übrigen Ländern Europas werden schließlich auch aus der unterschiedlichen Ausstattung mit Computern ersichtlich, die als aussagekräftiger Indikator speziell der jüngeren wirtschaftlichen Entwicklung angesehen werden kann. 1995 besaß im westlichen Europa im Durchschnitt jeder Vierte und in den Mittelmeerländern immerhin jeder Zehnte einen Computer, während in der Tschechischen Republik, Ungarn, der Russischen Föderation und Rumänien jeweils nur 53, 39, 18 und 5 Computer auf 1.000 Einwohner entfielen. ${ }^{94}$ In den folgenden Jahren fand teilweise ein Aufholprozess statt, doch war der Abstand im ersten Jahrzehnt des neuen Jahrhunderts noch immer erheblich und größer als bei der PKW-Dichte (vgl. Grafik 8 und Tabelle 8).

Zwar gab es neben den Spitzenreitern Schweiz, Luxemburg und Schweden mit über 700 Computern pro 1.000 Einwohner eine mittlere Gruppe mit 300 bis über 600 Computern, in der sich neben den anderen west-, mittel- und nordeuropäischen Ländern auch einige wenige aus Ost- und Südeuropa befanden. In den meisten von ihnen verfügten jedoch nur ein Fünftel und weniger der Bevölkerung über einen Computer, in den südlichen Teilen des ehemaligen Jugoslawien sowie in Albanien, Moldawien und der Ukraine sogar weniger als ein Zehntel.

93 Maddison (Per Capita GDP).

94 Berend (2006), 210. 


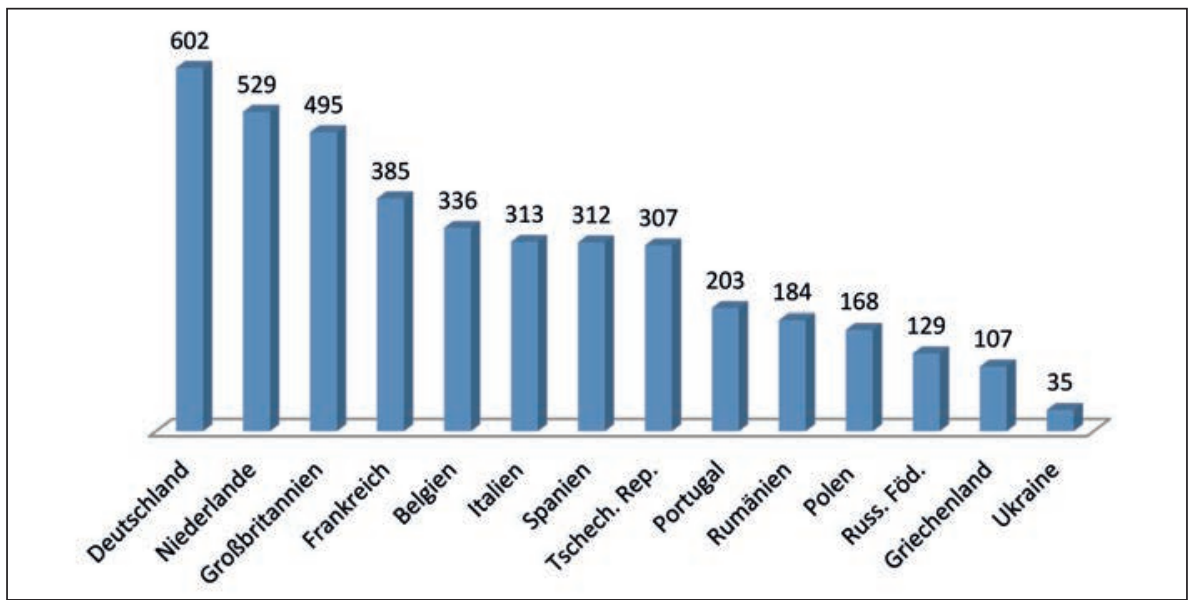

Welt in Zahlen (Computer). Für die kleineren Länder vgl. Tabelle 8.

AllerdingsbestandeninnerhalbdereinzelnenLänderzumTeilerhebliche regionale Unterschiede. Sie werden seit kurzem in der Europäischen Union eigens erfasst und unterstreichen abermals das nach wie vor bestehende Entwicklungs- und Einkommensgefälle innerhalb Europas. ${ }^{95} 2010$ lagen von den insgesamt 267 Regionen, deren Bruttowertschöpfung pro Einwohner unter Berücksichtigung des nationalen Preisniveaus miteinander verglichen wurde, 41 Regionen um 25 oder mehr Prozent über und 68 Regionen um 25 oder mehr Prozent unter dem Durchschnitt aller EU-Regionen. Erstere, also die reicheren Regionen, fanden sich einschließlich der norditalienischen Lombardei, des Aostatales und der Provinz Bozen, der zwei nordspanischen Regionen Navarra und Baskenland sowie der drei Hauptstadtregionen Prag, Pressburg und Madrid ausschließlich in West-, Mittel- und Nordeuropa. Dagegen befanden sich die ärmeren Regionen mit Ausnahme Cornwalls und des westlichen Wales zur Gänze in Ost- und Südeuropa einschließlich der fünf süditalienischen Regionen Kampanien, Apulien, Kalabrien, Sizilien und der Basilikata. ${ }^{96}$

95 BIP pro Kopf 2010.

96 In Polen, Ungarn, Bulgarien, Rumänien, Slowenien, der Slowakei und der Tschechischen Republik fielen außer der jeweiligen Hauptstadtregion sämtliche Regionen in die Gruppe der am wenigsten entwickelten Regionen. In Grie- 


\section{Von der Industrie- zur urbanen Dienstleistungsgesellschaft}

Wenn jedoch zur selben Zeit trotz seiner relativ großen Zahl ärmerer Regionen in keinem der größeren Länder so viele PKW pro Einwohner registriert waren wie in Italien ${ }^{97}$ deutet dies daraufhin, dass sich fortgesetzte wirtschaftliche Entwicklung nicht mehr wie früher allein oder vorrangig in der Ausstattung mit materiellen Gütern wie etwa Autos niederschlug. Ab einem gewissen Zeitpunkt - in den zuerst industrialisierten Ländern West-, Mittel- und Nordeuropas seit den 60er und 70er Jahren des 20. Jahrhunderts - wurden die steigenden Einkommen zumindest relativ immer weniger für zusätzliche Konsumgüter ausgegeben. Dank einer partiellen Bedarfssättigung wuchs die Nachfrage nach Konsumgütern langsamer als zuvor. Gleichzeitig nahm die Arbeitsproduktivität infolge zunehmender Automatisierung und sonstiger technischer Verbesserungen sowohl in quantitativer als auch in qualitativer Hinsicht weiter zu. Dies hatte zur Folge, dass einerseits zur Deckung der langsamer wachsenden Nachfrage nach Industriegütern immer weniger Menschen benötigt wurden und andererseits die in der Industrie erzielten Einkommen weiter anstiegen. Für viele - wenn auch nicht für alle - der in der Industrie frei gesetzten Arbeitskräfte fanden sich neue Arbeitsplätze im Bereich der Dienstleistungen, die dank steigender Einkommen und steuerlicher Abgaben sowohl von privaten Konsumenten als auch von der öffentlichen Hand in zunehmend stärkerem Maße nachgefragt wurden. ${ }^{98}$ Diese Entwicklung spiegelt sich am besten in der Verteilung der Erwerbstätigen auf die drei Hauptsektoren einer Volkswirtschaft wider.

Im Zuge der Industrialisierung ging zunächst der Anteil der in der Landwirtschaft oder im primären Sektor Erwerbstätigen kontinuierlich zurück. Zum einen waren dank der auch in der Landwirtschaft steigenden Produktivität immer weniger Menschen notwendig, um den Bedarf an Nahrungsmitteln zu decken. Zum anderen war die Nachfrage nach Industriegütern lange Zeit derart groß, dass trotz arbeitssparender Mechanisierung und Automatisierung immer mehr der in der Landwirtschaft frei gesetzten Menschen im sekundären, industriell-gewerblichen Sektor Beschäftigung fanden. Erst als sich die

chenland waren es sieben von zwölf und in Portugal drei von sieben, in Spanien hingegen mit der Extremadura nur eine Region. Auch die jeweils als eine Region erfassten baltischen Staaten Estland, Lettland und Litauen erreichten deutlich weniger als 75 Prozent der durchschnittlichen Pro-Kopf-Produktion der EU. BIP pro Kopf 2010.

97 Vgl. Tabelle 10.

98 Zum massiven, sowohl absoluten als auch relativen Anstieg der öffentlichen Ausgaben vgl. Berend (2006), Table 5.1 
Nachfrage nach Industriewaren abschwächte und ein ständig größerer Anteil der wachsenden Einkommen in den Kauf von Dienstleistungen floss, begann auch der Anteil der im sekundären Sektor Beschäftigten zugunsten des tertiären, des Dienstleistungssektors, zu sinken. Naturgemäß war dies in Ländern, in denen die Industrialisierung früher eingesetzt hatte, tendenziell früher der Fall als in anderen. Außerdem kamen die Erwerbsmöglichkeiten, die sich dank steigender Nachfrage nach Dienstleistungen im tertiären Sektor boten, wie schon zuvor auch den aus der Landwirtschaft abwandernden Erwerbstätigen zugute, was zu einem weiteren Rückgang der im primären Sektor arbeitenden Menschen führte. Er sank fast überall in Europa auf zuletzt weniger als 10 Prozent. Lediglich in Rumänien, Mazedonien, Kroatien, Griechenland und Polen arbeiteten im Jahre 2013 noch mehr als 10 Prozent aller Erwerbstätigen in der Landwirtschaft. ${ }^{99}$

Das Maximum der Beschäftigung im sekundären Sektor, das außer vom Industrialisierungsprozess selbst von den sich bietenden Möglichkeiten anderer wirtschaftlicher Tätigkeiten abhing, lag in der Regel zwischen 40 und 50 Prozent aller Erwerbstätigen, von denen die meisten in der Industrie und im verarbeitendem Gewerbe arbeiteten. Es wurde in den meisten Ländern West-, Mittel- und Nordeuropas in den 60er Jahren, im Osten und Süden dagegen erst in den 70er und 80er Jahren erreicht. ${ }^{100}$ Obwohl von einer Sättigung des Bedarfs an Industriegütern speziell in den weniger entwickelten Ländern noch lange nicht gesprochen werden kann, ist dank wachsender Produktivität und dank zunehmender Handelsverflechtungen über die Länder hinweg der Anteil des sekundären Sektors an den Erwerbstätigen danach fast überall wieder gefallen. Er pendelt mittlerweile zwischen knapp 20 und 30 Prozent, lediglich in manchen Ländern Osteuropas lag er um 2011 noch leicht darüber. ${ }^{101}$

Überall jedoch arbeiteten zuletzt nicht nur relativ, sondern auch absolut weniger Menschen im industriell-gewerblichen Sektor als in früheren Jahren, ${ }^{102}$ so dass der Industrialisierungsprozess, zumindest gemessen an der Zahl der Erwerbstätigen, überall in Europa als abgeschlossen betrachtet werden kann. Er hatte spätestens nach dem Zweiten Weltkrieg fast ganz Europa erfasst und zu einem Lebensstandard geführt, der - wenn auch nicht überall im selben Ausmaß - um ein Vielfaches über dem Niveau vorindustrieller

99 Beschäftigungsstruktur 2013.

100 Eigene Berechnungen nach Fischer (1987), 93, Mitchell (1980), 434-439, Mitchell (1992), 141-156 und Mitchell (2003), 145-162.

101 Statistisches Jahrbuch (2013), 576.

102 Mitchell (2003), 145-162. 
Jahrhunderte lag. ${ }^{103}$ Allerdings profitierten, wie an mehreren Parametern gezeigt werden konnte, bei weitem nicht alle Menschen in Europa im selben Ausmaß vom wachsenden Wohlstand. Neben der überall bestehenden Ungleichheit innerhalb der einzelnen Länder gab es auch zwischen den Staaten zum Teil erhebliche Unterschiede. 2008 lagen die Wertschöpfung pro Einwohner und damit die durchschnittlichen Einkommen in einzelnen Fällen wie Rumänien, Serbien, Albanien und Mazedonien oder in Moldawien und der Ukraine als europäischen Nachfolgestaaten der ehemaligen Sowjetunion bei lediglich einem Fünftel bis einem Viertel und in den übrigen Ländern Osteuropas - von wenigen Ausnahmen abgesehen - bei maximal der Hälfte der für die west-, mittel- und nordeuropäischen Länder errechneten Werte. ${ }^{104}$

Beides, Industrialisierung und höherer Lebensstandard, gingen mit einer beschleunigten Urbanisierung einher, die sowohl Ursache als auch Folge wirtschaftlicher Entwicklung war. ${ }^{105}$ Um 2010 lebten in Europa einschließlich der Russischen Föderation gut 40 Prozent aller Menschen in Großstädten mit über 100.000 Einwohnern. ${ }^{106}$ Zwar bestanden im an ihnen gemessenen Urbanisierungsgrad der einzelnen Länder zum Teil noch immer erhebliche Unterschiede, ${ }^{107}$ doch hatten sich die europäischen Großregionen bereits sehr einander angeglichen. Das nach wie vor bestehende Wohlstandsgefälle innerhalb Europas lässt sich daher - anders als der unterschiedlich frühe Beginn der Industrialisierung - nur mehr schwerlich mit dem Anteil von Großstädten erklären. Die aus der Urbanisierung resultierende, wachsende Nachfrage nach Industriegütern hatte zuletzt offenbar keine zusätzliche Industriebeschäftigung mehr zur Folge. Im Gegenteil, dank weiterhin steigender Produktivität ging die Zahl der in der Industrie beschäftigten Menschen - wie bereits erwähnt - trotz wachsender Nachfrage zunächst relativ und schließlich auch absolut zurück.

Allerdings vermochten die Industrieunternehmen im Zuge des anhaltenden Wettbewerbes nicht überall im selben Ausmaß ihre Produktivität zu steigern. In den bereits früh industrialisierten und einigen benachbarten Regionen waren sie diesbezüglich erfolgreicher als in den anderen Regionen, die in ihrer Produktivität trotz nachholender Industrialisierung hinter ihnen zurückblieben. Versucht man, aus der nicht-landwirtschaftlichen Sachgüterproduktion des Jahres 2006 und der Zahl der Erwerbstätigen die durchschnitt-

103 Maddison (Per Capita GDP).

104 Maddison (Per Capita GDP).

105 Vgl. Fischer (1987), 54

106 Eigene Berechnungen nach Liste der Städte (Länder Europas).

107 Zwischen weniger als 20 Prozent in Belgien, Portugal und der Slowakei auf der einen und dem Vereinigten Königreich, Spanien und der Ukraine mit über 50 Prozent auf der anderen Seite. 
liche Pro-Kopf-Produktion der im sekundären Sektor Beschäftigten zu errechnen, lassen sich die europäischen Länder in vier Gruppen mit unterschiedlich hoher ,industrieller“ Produktivität einteilen. ${ }^{108}$ Am produktivsten waren neben dem Sonderfall Norwegen, das dank seiner Öl- und Gasproduktion mit 235.000 Dollar die Liste mit großem Abstand anführte, auch die drei anderen skandinavischen Länder mit einer industriellen Wertschöpfung von circa 100.000 bis 120.000 Dollar pro Beschäftigtem. Es folgten mit etwa 80.000 bis 100.000 Dollar die west- und mitteleuropäischen Länder, zu denen diesbezüglich inzwischen auch Spanien und Italien aufgeschlossen hatten, nicht jedoch Portugal oder die Tschechische Republik, die wie andere osteuropäische Länder einschließlich der baltischen Staaten auf eine durchschnittliche industrielle Wertschöpfung von lediglich etwa 20.000 bis 40.000 Dollar pro Beschäftigtem kamen. Lediglich Slowenien und Griechenland schnitten mit knapp 50.000 bzw. über 60.000 Dollar deutlich besser ab, wogegen die Slowakei, vor allem aber Bulgarien, Rumänien, Mazedonien und Albanien sowie Russland, Weißrussland, die Ukraine und Moldawien als Nachfolgestaaten der ehemaligen Sowjetunion mit 10.000 Dollar und weniger weit zurücklagen.

Aufgrund der längeren Tradition und des angesammelten industriellen Wissens gelang es den Frühstartern in West-, Mittel- und Nordeuropa, ihr Know-how und damit ihre Produktivität in einer Weise weiter zu entwickeln und zu steigern, dass sie - nicht zuletzt mit neuen Produkten - ihre Position als ständig produktivere Industrieregionen behaupteten. Die anderen holten deren Entwicklung zwar zum Teil nach, schlossen jedoch nur in Ausnahmefällen zu ihnen auf. Höhere Produktivität führte zu höheren Einkommen, die unter anderem für höherwertige Dienstleistungen ausgegeben werden konnten. Auf diese Weise blieb die Produktivitätssteigerung nicht auf die industriell-gewerbliche Produktion beschränkt, sondern griff auf den nunmehr größten, tertiären Wirtschaftssektor über. Trotz dem relativ sinkenden Anteil der Industrie an der gesamten Wertschöpfung eines Landes profitierte die gesamte Volkswirtschaft von den in der Industrie erzielten Produktivitätssteigerungen. Die höhere Produktivität in Industrie und verarbeitendem Gewerbe hatte sowohl direkt als auch indirekt über die Dienstleistungen eine höhere gesamtwirtschaftliche Wertschöpfung zur Folge, die daher in den produktiveren Ländern stärker ausfiel und zu höheren Einkommen führte als in den anderen.

Resümierend kann daher festgehalten werden, dass es den Volkswirtschaften in Ost-

108 Annäherungswerte aus eigenen Berechnungen nach Welt in Zahlen (Industrieproduktion), Beschäftigungsstruktur 2013, WKO Länderprofile und Maddison (Population). 
und Südeuropa nach dem Zweiten Weltkrieg zwar gelang, den Industrialisierungsprozess nachzuholen, den West- und Mitteleuropa sowie etwas zeitversetzt auch Nordeuropa einige Jahrzehnte zuvor begonnen hatten. Auf diese Weise war es möglich, auch in diesen Teilen Europas die Mehrheit der Bevölkerung aus der vorindustriellen Armut herauszuführen. Allerdings mussten sich die Länder Ost- und Südeuropas zumindest bislang damit begnügen, das Wohlstandsniveau des weiter entwickelten West-, Mittel- und Nordeuropa jeweils mit einer gewissen Verspätung zu erreichen, obwohl es einzelnen Regionen, die tendenziell innerhalb oder in der Nähe der industriellen Kernzonen lagen, auch schon früher gelang, zu den traditionellen Industriegebieten aufzuschließen. 



\section{Amerika}

Ähnlich wie Europa waren die beiden amerikanischen Halbkontinente über Jahrtausende nur sehr dünn besiedelt. Wie anderswo in der Welt lebten die Menschen lange Zeit als Jäger und Sammler und gingen erst mit zunehmender Bevölkerungsverdichtung vereinzelt zu einer sesshaften Lebensweise mit Ackerbau und Viehhaltung über. ${ }^{109}$ Da und dort - speziell im Gebiet des heutigen Peru, Mexiko und südlich davon - entstanden in den Jahrhunderten vor und nach Christi Geburt bereits städtische Siedlungen. Sie waren verbunden mit der Entstehung der frühen Hochkulturen der Inkas, der Azteken und der Maya, die in mancher Hinsicht an die frühen Hochkulturen im alten Orient erinnern. Hier wie dort erweiterten die Städte die agrarische Produktion um handwerkliche und händlerische Tätigkeiten, waren jedoch zu klein und zu isoliert, um einen Massenmarkt für Industriewaren entstehen zu lassen.

Daran sollte sich bis zur Entdeckung der beiden Amerikas durch europäische Seefahrer und Eroberer um 1500 nichts Wesentliches ändern. Auch wenn genauere Bevölkerungszablen oder auch nur grobe Schätzungen noch schwerer zu erstellen sind als für das antike Europa - Maddison nimmt für Nord- und Südamerika jeweils rund zehn Millionen an, bei Mathieu finden sich zusammen 42 Millionen $-{ }^{110}$ ist jedenfalls davon auszugehen, dass der allergrößte Teil Amerikas nur von relativ wenigen Jägern und Sammlern bewohnt wurde. Aber auch in den wirtschaftlich weiter entwickelten, räumlich beschränkten Gebieten der frühen Hochkulturen war aufgrund der geringen Bevölkerungsdichte eine Industrialisierung ebenso wenig zu erwarten wie im antiken Mittelmeerraum oder im mittelalterlichen Europa.

Dazu kam, dass die ohnehin schon geringe Bevölkerungsdichte durch die militärischen Auseinandersetzungen mit den europäischen Eroberern und noch mehr durch die von ihnen eingeschleppten Krankheiten, gegen die die Einheimischen nicht immun waren, weiter reduziert wurde. Langfristig konnte sich die einheimische Bevölkerung im Süden trotz absolut größeren Verlusten besser behaupten als im Norden, wo sie in den späteren

109 Salisbury (1996), 1-10.

110 Maddison (Population); Mathieu (2011), 87. Insgesamt 50 bis 60 Millionen laut Newson (2006), 143. Bis zu 18 Millionen allein für Nordamerika nördlich des Rio Grande nach Couturier (1994), 5. Insgesamt schwanken die Schätzungen laut Newson (2006), 144 zwischen 8 Millionen und 90 bis 112 Millionen. 
USA und Kanada bis 1865 auf nur noch 350.000 Menschen zurückging. ${ }^{111}$ Dennoch wurde insgesamt - vor allem infolge wachsender Zuwanderung aus Europa und der Verschleppung von Sklaven aus Afrika - die Bevölkerungszahl von 1500 außer in Mexiko und Peru während des 18. Jahrhunderts wieder erreicht. ${ }^{112}$

In der weiteren Entwicklung gingen die beiden Halbkontinente getrennte Wege. Während sich die Bevölkerung in Südamerika einschließlich Mexikos - heute inzwischen als Lateinamerika bezeichnet - zwischen 1700 und 1820 von etwa zehn bis zwölf Millionen auf über 20 Millionen nicht einmal verdoppelte, stieg sie auf dem Gebiet der späteren USA und Kanadas im selben Zeitraum von rund zwei Millionen auf mehr als das Fünffache, nämlich auf circa 11 Millionen an. ${ }^{113}$ Das unterschiedliche Tempo der Bevölkerungszunahme, das vor allem auf die weit größere Zahl europäischer Einwanderer im Norden zurückzuführen war, setzte sich auch im 19. Jahrhundert fort. Bis 1913 sollte sich die Einwohnerzahl der USA und Kanadas auf über 100 Millionen fast verzehnfachen, ${ }^{114}$ während sie sich im flächenmäßig größeren Lateinamerika auf lediglich gut 80 Millionen vervierfachte. ${ }^{115}$ Wenn daher eine zunehmende Bevölkerungsdichte Urbanisierung und die Entstehung eines Massenmarktes anregen konnte, war dies im Norden tendenziell eher zu erwarten als im Süden.

Außerdem konzentrierte sich die rasch wachsende Bevölkerung im Norden auf ein relativ kleines Gebiet, wodurch Bevölkerungsdichte und Urbanisierung zusätzlich gefördert wurden. Wohl aufgrund der kürzeren Entfernungen und der somit niedrigeren Transportkosten gingen die meisten europäischen Auswanderer im Nordosten, also vor allem in den Häfen von Montreal, Boston, New York, Philadelphia und Baltimore an Land. Trotz des anfangs für viele gemeinsamen Zieles, im neuen Land eine Existenz als unabhängige Bauern aufzubauen, drangen nicht alle weiter ins Landesinnere vor. Viele zogen es vor, in den Häfen zu bleiben und die sich in ihnen bietende Chance auf Arbeit und Einkommen zu nutzen. Aber auch die anderen ließen sich zumindest anfangs eher in Küstennähe als weiter im Landesinneren nieder. Gegen Ende des 18. Jahrhunderts lebte fast die gesamte Bevölkerung der USA in den Bundesstaaten, die an den Atlantik grenzten, in Kanada war es kaum anders. ${ }^{116}$

\footnotetext{
111 Salisbury (1996), 11.

112 Maddison (Population).

113 Maddison (Population) und Mathieu (2011), 87.

114 Laut Maddison (Population) 97,6 Millionen in den USA und 7,85 Millionen in Kanada.

115 Laut Maddison (Population) 80,8 Millionen.

116 Haines (2000), 189 und Cardin/Couture (1997), 41.
} 


\section{USA}

Dank fortgesetztem Zustrom von außen und einem relativ hohen, natürlichen Bevölkerungswachstum der neuen Siedler erreichte die Bevölkerungsdichte an der Ostküste ein Ausmaß, das auch abseits der Hafenstädte aus anfänglichen Dörfern kleinere und größere Städte entstehen ließ. Sie wurden ihrerseits zu Anziehungspunkten weiterer Zuwanderung. Obwohl in der Folge eine verstärkte Wanderung nach Westen einsetzte, vereinigten die an der Ostküste liegenden Staaten der USA um 1830 fast drei Viertel der Gesamtbevölkerung und rund 90 Prozent der vorerst noch langsam wachsenden, städtischen Bevölkerung auf sich. ${ }^{117}$

In den folgenden Jahrzehnten nahm die Bevölkerungsdichte insbesondere im erweiterten Nordosten der USA zu, während der Süden relativ zurückblieb. Während sich um 1790 die US-amerikanische Bevölkerung zu jeweils rund der Hälfte auf den Nordosten und den Süden verteilt hatte, entfielen 100 Jahre später fast zwei Drittel auf die nordöstlichen Bundesstaaten des Mittleren Westens und des „alten“ Nordostens zwischen North Dakota, Kansas, New Jersey und Maine, weniger als ein Drittel hingegen auf den ,alten“ und den „,neuen“ Süden zwischen den Bundesstaaten Delaware, Florida und Texas. ${ }^{118}$ Die unterschiedliche Bevölkerungsdichte hatte auch einen unterschiedlichen Urbanisierungsgrad der beiden Großregionen zur Folge. Er lag im äußersten Nordosten, also in den Neuenglandstaaten und den mittleren Atlantikstaaten New York, Pennsylvania und New Jersey, bei rund 60 sowie im Mittleren Westen mit einem deutlichen Ost-West-Gefälle bei 33 Prozent, während er in den östlichen wie westlichen Südstaaten weniger als 20 Prozent ausmachte. ${ }^{119}$

Der höhere Verstädterungsgrad hatte trotz lange Zeit vorherrschender Subsistenzwirtschaft relativ früh eine stärkere Marktintegration der nordöstlichen Bevölkerung zur Folge. Im Süden hingegen verteilten sich die überdurchschnittlich hohen Erlöse aus der exportorientierten Plantagenwirtschaft auf relativ wenige Großgrundbesitzer, während die von ihnen ausgebeuteten Sklaven und die auf Selbstversorgung ausgerichteten Bauern über keine bis nur wenig Geldeinkommen verfügten. Infolgedessen lagen etwa um 1840, noch vor dem Beginn einer breiten Industrialisierung, die durchschnittlichen

117 Haines (2000), 189.

118 Haines (2000), 189 und Heim (2000), 94.

119 Eigene Berechnungen nach Haines (2000), 189. 
Pro-Kopf-Einkommen im Süden um ein Viertel unter dem nationalen Durchschnitt, in Neuengland und den mittleren Atlantikstaaten dagegen um ein Drittel darüber. ${ }^{120}$

Die stärkere Urbanisierung des Nordostens bot auch günstigere Voraussetzungen für eine Industrialisierung. Ausgelöst wurde sie wie in West- und Mitteleuropa vor allem durch die Entstehung von Großstädten. 1850 zählte man in den USA sechs und 1900 bereits 34 Großstädte mit mehr als 100.000 Einwohnern. ${ }^{121}$

New York City, Mulberry Street, um 1900

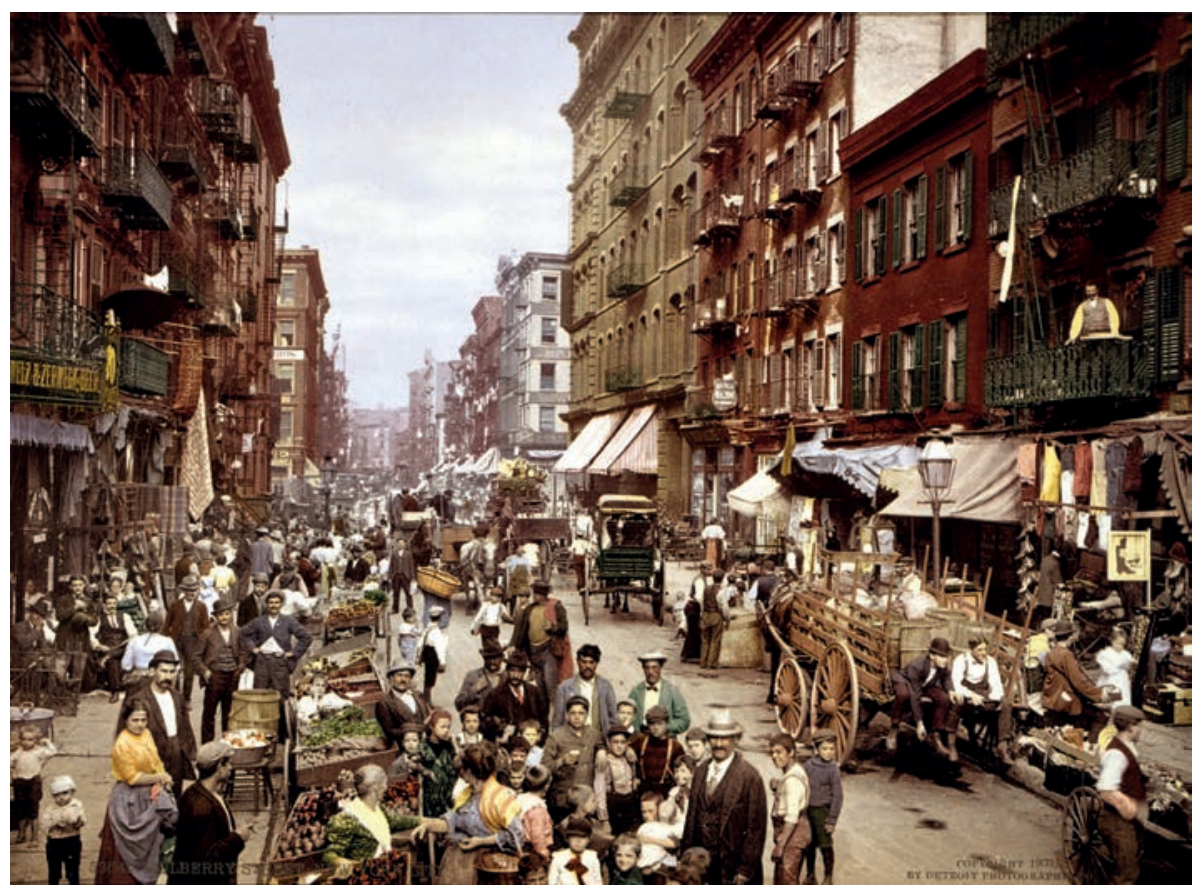

http://en.wikipedia.org/wiki/File:Mulberry_Street_NYC_c1900_LOC_3g04637u_edit.jpg

New York City, Chicago und Philadelphia hatten bis zur Jahrhundertwende die Millionengrenze überschritten, gefolgt von St. Louis, Boston, Baltimore und Pittsburgh

120 Gallman (2000), 53 .

121 Mitchell (1998), 46-53. 
mit jeweils etwa einer halben Million Einwohner. ${ }^{122}$ Sie alle lagen wie die meisten sonstigen Großstädte innerhalb eines relativ kleinen Gebietes zwischen Boston, Chicago, St. Louis und Washington, D.C. (vgl. Karte 5). ${ }^{123}$

Karte 5: Großstädte mit über 100.000 Einwohnern in den USA und Kanada um 1900

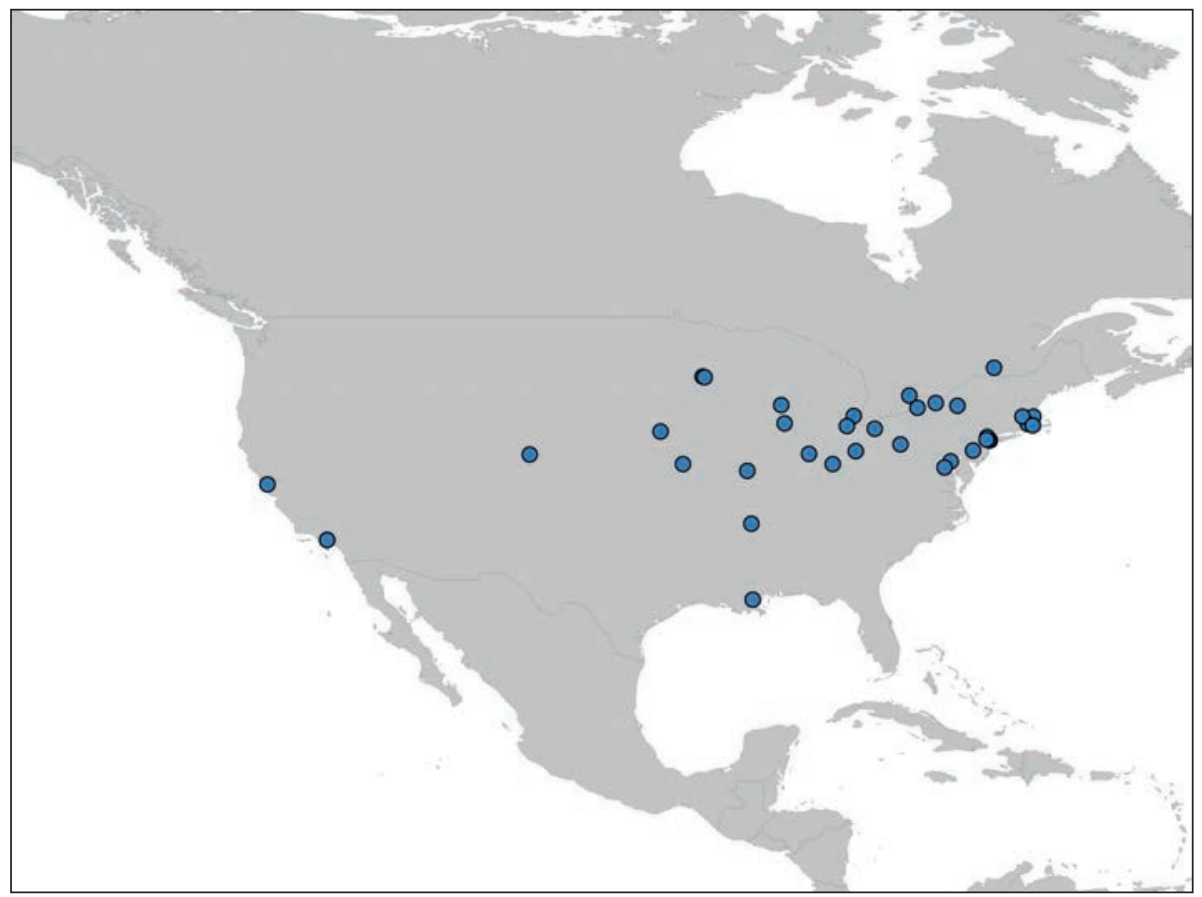

Tirol Atlas - Bearbeitung Klaus Förster nach Tabelle 9.

Kartenhintergrund: World Borders Dataset - http://thematicmapping.org/downloads/world_borders.php

Im städtereichen Nordosten des Landes setzte auch der Prozess der Industrialisierung früher und in breiterem Ausmaß ein als im Süden. Er begann wie in Europa im frühen 19. Jahrhundert mit der maschinellen Fabrikproduktion von Baumwollwaren. Obwohl

122 Mitchell (1998), 46-53.

123 Von den 16 Großstädten mit mehr als einer Viertelmillion Einwohnern befand sich neben Baltimore und Washington, die unmittelbar an den Nordosten grenzten, nur eine, nämlich die günstig gelegene Hafenstadt New Orleans, in den Südstaaten. 
die Rohbaumwolle im Süden angebaut wurde und sich ebenfalls im Süden wohlhabende, kapitalkräftige Plantagenbesitzer befanden, die zu potentiellen Industrieunternehmern hätten werden können, entstanden die ersten Baumwollspinnereien in Neuengland. Hier gab es die rasch wachsenden und Gewinne versprechenden Märkte, die Investitionen in die industrielle Baumwollverarbeitung lohnend erscheinen ließen. Von Neuengland setzte sich die Industrialisierung in die mittleren Atlantikstaaten sowie in der Folge in die bevölkerungsreichen Staaten Ohio, Michigan, Indiana, Illinois und Wisconsin im östlichen Mittleren Westen fort. Neben der Baumwollindustrie wurden schon bald auch andere Industriezweige in die maschinelle Massenproduktion miteinbezogen. ${ }^{124}$

Auf den Süden entfiel hingegen nur ein kleiner Teil der US-amerikanischen Industrieproduktion, und zwar vor dem Bürgerkrieg der frühen 60er Jahre ebenso wie danach. Noch 1909 stammten etwa drei Viertel der in der Industrie geschaffenen Werte aus Neuengland und den oben genannten Staaten des weiteren Nordostens, obwohl sie weniger als die Hälfte der Bevölkerung stellten. ${ }^{125}$ Gleichzeitig ging der relative Anteil der in der Landwirtschaft beschäftigten Menschen in Neuengland und den mittleren Atlantikstaaten auf 12 bis 13 Prozent zurück, während er im Süden noch immer bei rund 60 Prozent lag. ${ }^{126}$ Die durchschnittlichen Pro-Kopf-Einkommen klafften weiter auseinander als zuvor und waren um die Jahrhundertwende im äußersten Nordosten fast drei Mal und im Mittleren Westen doppelt so hoch wie im Süden. ${ }^{127}$

Wie sehr der Nordosten zum wirtschaftlichen Zentrum der USA geworden war, spiegelt auch das den zunehmenden Handel tragende Transportwesen wider. Der Erie-Kanal zwischen Albany und Buffalo, der die Ostküste mit den Großen Seen verband, verzeichnete zwischen den frühen 40er Jahren und 1880 einen Anstieg des Gütervolumens auf fast das Sechsfache und vereinigte knapp die Hälfte aller auf den US-amerikanischen Kanälen verschifften Güter auf sich. ${ }^{128}$ Kaum anders verhielt es sich mit der Eisenbahn, die schon bald die Kanal- und Flussschifffahrt als wichtigstes Transportmittel ablöste. Als in den 1840er Jahren der Bau von Eisenbahnen in größerem Ausmaß begann, entfielen 60 Prozent aller Bahnlinien auf Neuengland und New York, von wo sie sich bald auf andere Staaten des Nordostens ausdehnten. ${ }^{129}$ Um die Mitte des Jahrhunderts zählten

124 Engerman/Sokoloff (2000), 373 f. und 383.

125 Heim (2000), 117.

126 Margo (2000), 213.

127 Gallmann (2000), 53.

128 Fishlow (2000), 562.

129 Fishlow (2000), 584. 
New York, Pennsylvania, Ohio, Illinois und Indiana zu den führenden Bundesstaaten im Eisenbahnbau, ${ }^{130}$ und auch danach wurden im Nordosten und Mittleren Westen zwei bis drei Mal so viele Eisenbahnstrecken gebaut wie im „alten“ Süden. ${ }^{131}$ Es war daher vor allem den Bundesstaaten im Nordosten der USA zu verdanken, wenn das Land am Vorabend des Ersten Weltkrieges mit $4.200 \mathrm{~km}$ pro einer Million Einwohner von einem weit dichteren Eisenbahnnetz überzogen war als jedes der europäischen Länder einschließlich Großbritanniens. ${ }^{132}$ Und sie waren auch hauptverantwortlich für die stark steigende, wirtschaftliche Pro-Kopf-Leistung und das hohe Pro-Kopf-Einkommen der USA. Das Bruttoinlandsprodukt pro Einwohner übertraf den Wert von 1820 inzwischen um mehr als das Vierfache und war seit 1905 höher als in jedem Land Europas, woran sich bis heute nichts ändern sollte. ${ }^{133}$

Was sich im 20. Jahrbundert jedoch änderte, war der Abstand zwischen den höher und den weniger entwickelten Regionen innerhalb der USA. Zunächst einmal nahm die Gesamtbevölkerung der USA weiter zu, und zwar deutlich schneller als in Europa. Dank fortgesetzter Zuwanderung, nun in verstärktem Maß auch aus anderen Teilen der Welt, und dank deutlich geringerer Verluste in den beiden Weltkriegen wuchs sie zwischen 1913 und 2003 von knapp 100 auf fast 300 Millionen Menschen an. ${ }^{134}$ Der Schwerpunkt der Zunahme verschob sich vom Nordosten in den ,alten“ Süden und insbesondere in den fernen Westen, der seit der Errichtung der transkontinentalen Eisenbahnlinien in der zweiten Hälfte des 19. Jahrhunderts einen enormen Zuzug verzeichnete (vgl. Tabelle 11). Während sich die Bevölkerung im Nordosten und Mittleren Westen zwischen 1900 und 1990 mehr als verdoppelte, stieg sie im Süden auf das Dreieinhalbfache und an der Westküste sogar auf das Fünfzehnfache an.

Parallel dazu nahm auch die Verstädterung im Süden und Westen nunmehr stärker zu als in den nordöstlichen Bundesstaaten, nämlich von 18 auf 69 Prozent im Süden sowie von 45 auf 89 Prozent an der bereits früh urbanisierten Westküste, womit die beiden Großregionen nahe an den Nordosten und Mittleren Westen herankamen und sie zum Teil übertrafen (vgl. Grafik 9 und Tabelle 11).

130 Niemi (1997), 74.

131 Fishlow (2000), 584.

132 Eigene Berechnungen nach Maddison (Population), Mitchell (1977), 514 und Cameron/Neal (2003), 201.

133 Maddison (Per Capita GDP).

134 Maddison (Population). 
Grafik 9: Städtische Bevölkerung in den USA 1900-1990

(Prozent der Bevölkerung)

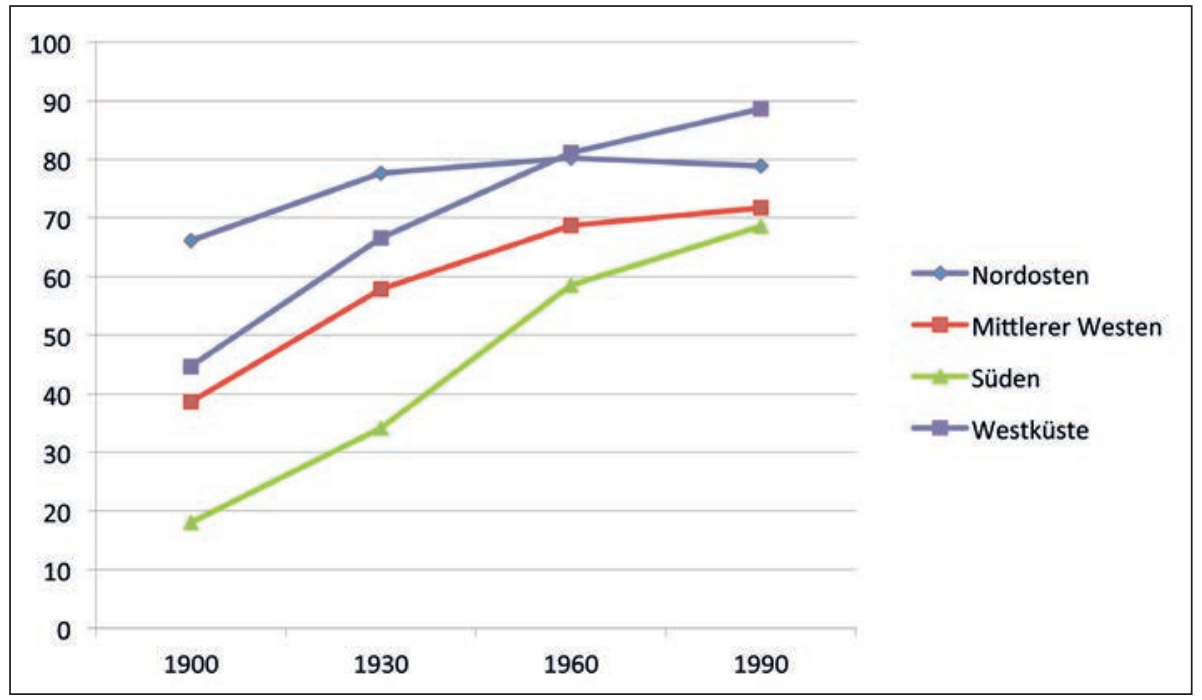

Vgl. Tabelle 11.

Neben der Urbanisierung im Allgemeinen wuchs auch die Zahl der Großstädte, von denen nunmehr auch im Süden und Westen ähnliche Industrialisierungsimpulse ausgingen wie zuvor im Norden und Osten des Landes. 1950 lagen zwar noch immer fast sämtliche der inzwischen 14 Millionenstädte im Gebiet des Nordostens und des Mittleren Westens, doch hatten inzwischen auch Baltimore, Washington, Los Angeles und San Francisco die Millionengrenze überschritten (vgl. Karte 6).

Unter den ebenfalls 14 Großstädten mit über einer halben Million Einwohner befanden sich bereits fünf im Süden und vier im Westen der USA (vgl. Tabelle 12). Parallel zur Urbanisierung nahm auch der Anteil des Südens und Westens an der industriellen Wertschöpfung und an den Industriebeschäftigten zu, wobei sich insbesondere in Kalifornien ähnliche Strukturen entwickelten wie im Osten des Landes. ${ }^{135}$

135 Heim (2000), $116 \mathrm{f}$. 
Karte 6: Millionenstädte in den USA und Kanada um 1950

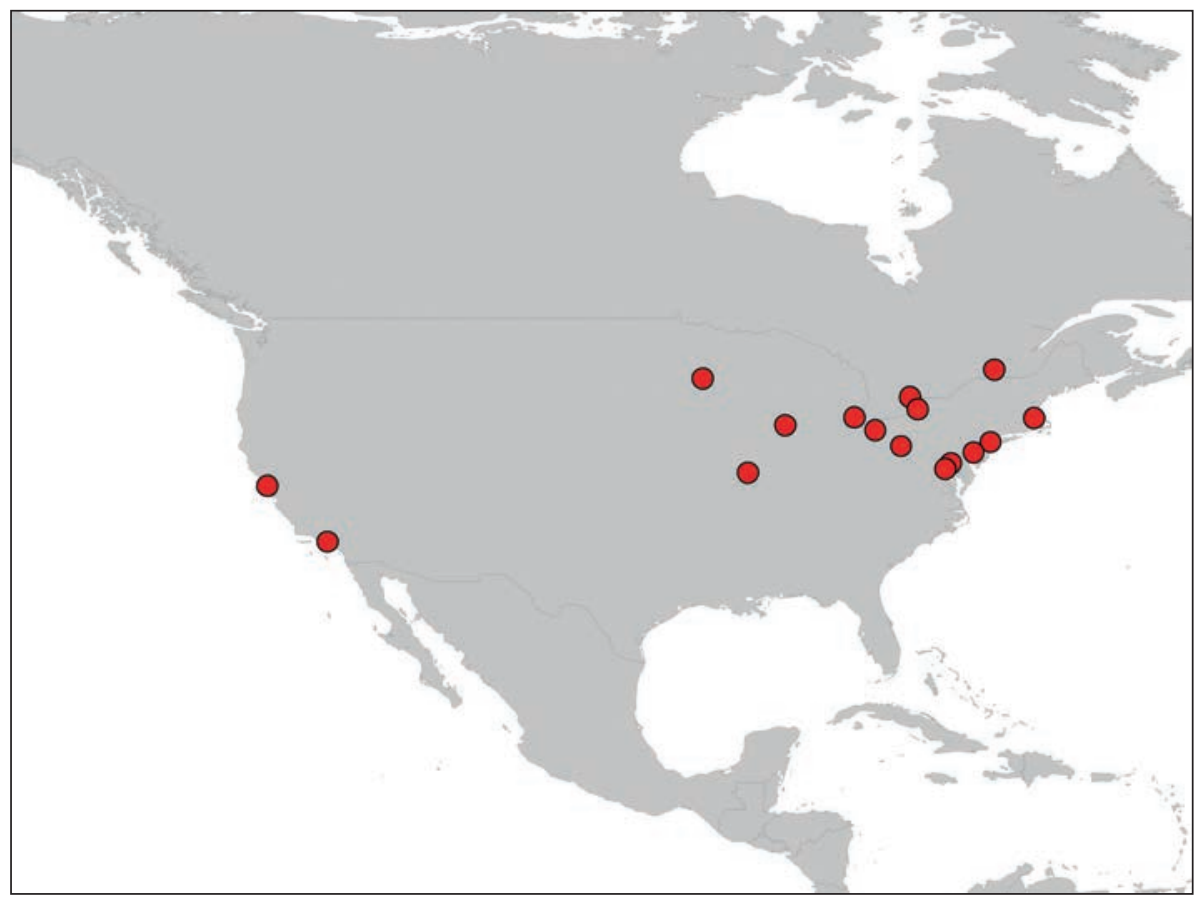

Tirol Atlas - Bearbeitung Klaus Förster nach Tabelle 12.

Kartenhintergrund: World Borders Dataset - http://thematicmapping.org/downloads/world_borders.php

Der Anteil von Industrie und verarbeitendem Gewerbe an der Gesamtbeschäftigung erreichte zwar nicht mehr die Spitzenwerte des Nordostens, kam aber mit 23 Prozent an der Westküste und 24 Prozent im Südosten deutlich näher an sie heran als zuvor (vgl. Grafik 10). Danach ging der relative Anteil der Industriebeschäftigten dank zunehmender Automatisierung und wegen des wie in Europa auch in den USA stattfindenden Überganges in eine Dienstleistungsgesellschaft in sämtlichen Großregionen der USA zugunsten des Dienstleistungssektors zurück.

Der Süden und der Westen schlossen aber auch in ihrer Produktivität zu den industriellen Frühstartern auf und vermochten auf diese Weise, ihre Pro-Kopf-Einkommen zusätzlich zu erhöhen. Gemessen an der Wertschöpfung pro Industriebeschäftigtem konnte der Süden den zu Beginn des Jahrhunderts gegebenen Rückstand zunächst zwar nur 
langsam verringern, nach dem Zweiten Weltkrieg indessen fast zur Gänze beseitigen. ${ }^{136}$ Für die früher und stärker urbanisierte Westküste lassen sich bereits seit Beginn des Jahrhunderts leicht höhere Werte als für den Nordosten berechnen. Der Nachholprozess des Südens und des Westens fand auch in den durchschnittlichen Pro-Kopf-Einkommen der einzelnen Großregionen seinen Niederschlag. Waren sie um 1900 in Neuengland und den mittleren Atlantikstaaten fast dreimal so hoch wie im Südosten der USA, lagen sie 1970 und 1990 lediglich ein Drittel darüber. ${ }^{137}$ Infolge einer inzwischen fast alle Regionen erfassenden Industrialisierung präsentierten sich die USA daher zuletzt als eine regional fast ähnlich ausgeglichene und hoch entwickelte Dienstleistungsgesellschaft wie West-, Mittel- und Nordeuropa auf der anderen Seite des Atlantiks. ${ }^{138}$

Grafik 10: Erwerbstätige in Industrie und verarbeitendem Gewerbe in den USA 1900-1990

(Prozent aller Erwerbstätigen)

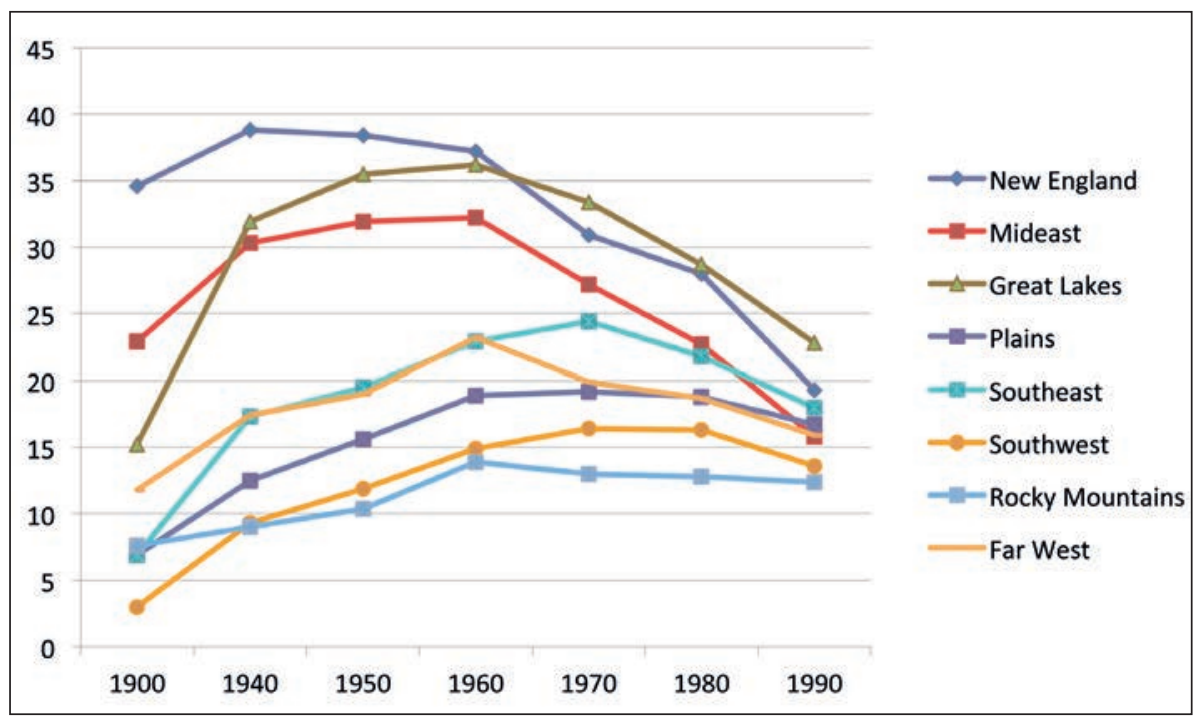

Vgl. Tabelle 13.

136 Eigene Berechnungen nach Heim (2000), 101 und $117 \mathrm{f}$.

137 Heim (2000), 102.

138 Vgl. Maddison (Per Capita GDP) für die etwas geringeren Unterschiede zwischen den Ländern West-, Mittel- und Nordeuropas. 


\section{Kanada}

Eine ähnliche Entwicklung wie in den USA lässt sich in Kanada beobachten, mit dem fast einzigen Unterschied, dass es hier - geographisch bedingt - keinen ,,nachhinkenden“ Süden gab. Auch in Kanada begann die neuzeitliche Besiedlung durch europäische Einwanderer im Osten und griff später auf den Westen über, wenn auch etwas später und in kleinerem Maßstab als in den USA. Noch zu Beginn des 19. Jahrhunderts lebten in den britischen Kolonien des späteren Kanada weniger als 400.000 Menschen, 50 Jahre später waren es 2,4 Millionen, ${ }^{139}$ darunter nur noch einige tausend als Nachfahren der ursprünglichen autochthonen Bevölkerung. ${ }^{140}$ Die Besiedlung konzentrierte sich anfangs auf einen relativ schmalen Streifen an beiden Seiten des Sankt-Lorenz-Stromes, der als zentrales Einfallstor für die Zuwanderung diente. ${ }^{141}$ Deutlich weniger Menschen ließen sich in den bereits zuvor erschlossenen, maritimen Provinzen Neuschottland, Neubraunschweig und auf der PrinzEdward-Insel im äußersten Osten nieder. Als größere städtische Siedlungen entstanden zunächst Québec und weiter stromaufwärts Montreal.

Montreal um 1889

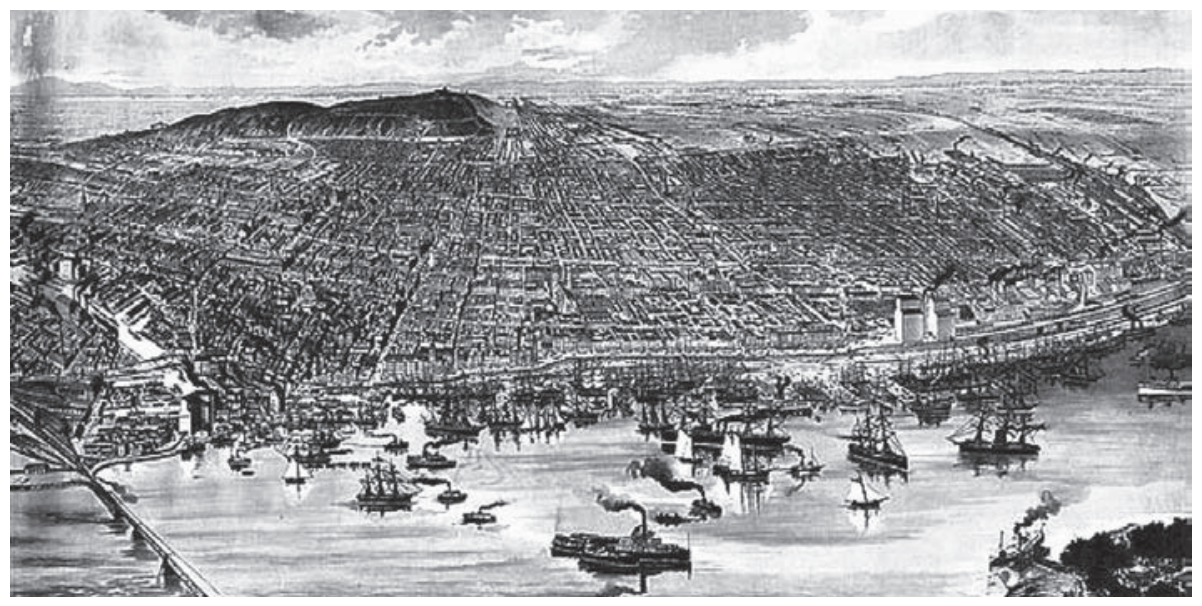

http://de.wikipedia.org/wiki/Wirtschaftsgeschichte_Kanadas

139 Köllman (1965), 44 und Couturier (1994), 114.

140 Couturier (1996), 1 und 5.

141 McInnis/Horn (1982), 303. 
Vor allem Montreal, das 1801 erst etwa 22.000 Einwohner zählte, entwickelte sich in der Folge zum kommerziellen Zentrum der Region. ${ }^{142}$

Die weitere Besiedlung verlief in südwestlicher Richtung in die zunächst ebenfalls relativ schmalen Gebiete nördlich des Ontario- und des Eriesees. ${ }^{143}$ Auch hier wuchs vor allem eine Siedlung, nämlich Toronto, zu einem regionalen Handels- und Verwaltungszentrum heran. Noch 1812 mit weniger als 1.000, zählte Toronto 1880 rund 96.000 Einwohner, während in Montreal inzwischen 155.000 Menschen lebten. ${ }^{144}$ Dies war zwar noch relativ wenig, reichte aber aus, um zunächst in Montreal samt Umgebung und später auch in Toronto erste Fabriken entstehen zu lassen.

Wie in Europa und den USA folgten auf die anfängliche Textilindustrie schon bald auch andere Branchen, darunter insbesondere die Herstellung landwirtschaftlicher Geräte und Maschinen. ${ }^{145}$ Während die Textilindustrie durch die Nachfrage der wachsenden Städte angeregt wurde, deckte letztere den Bedarf der zahlreichen Bauern, die außer für sich selbst ebenfalls für die Städte und den Export produzierten. Nach der Gründung der ersten Baumwollfabrik im östlich von Montreal gelegenen Sherbrooke (1844) gab es 1881 fast 2.000 und zehn Jahre später bei einer Gesamtbevölkerung von inzwischen 4,8 Millionen Menschen rund 4.000 Baumwollspinnereien. ${ }^{146}$

Obwohl Montreal seine Bedeutung als größte Stadt des Landes beibehielt, verschob sich der Schwerpunkt der Entwicklung schon bald zu den großen Seen in der Provinz Ontario, wo 1851 bereits mehr Menschen lebten als in der Provinz Québec. ${ }^{147}$ Auch die Urbanisierung schritt in Ontario rascher voran. Die Zahl der Städte mit über 2.500 Einwohnern stieg zwischen 1851 und 1871 auf über 31, in Québec dagegen nur auf acht an. ${ }^{148}$ Etwa gleich schnell wuchsen die beiden Großstädte Montreal und Toronto. Beide zählten um die Jahrhundertwende über 200.000 Einwohner. ${ }^{149}$

Die rasch fortschreitende Urbanisierung ging mit einer ebenso raschen Industrialisierung einher. 1912 waren mit über 800.000 rund sieben Mal so viele Baumwollspindeln in

142 McInnis/Horn (1982), 205.

143 McInnis/Horn (1982), 303.

144 Köllmann (1965), 124 und McInnis/Horn (1982), 205.

145 McInnis (2000), 86.

146 Couturier (1996), 89.

147 McInnis/Horn (1982), 301. 50 Jahre später wohnten rund 40 Prozent der kanadischen Bevölkerung in Ontario und gut 30 Prozent in Quebec. Köllmann (1965), 122.

148 McInnis (2000), 89.

149 Köllman (1965), 124 und Mitchell (1998), 51 und 53. 
Verwendung wie 30 Jahre zuvor. ${ }^{150}$ In Toronto stieg die Zahl der Industrieunternehmen zwischen 1871 und 1891 von 561 auf über 2.000, die Zahl der in ihnen Beschäftigten von 9.400 auf fast 25.000 und die jährliche Produktion von knapp 14 auf 42,5 Millionen Dollar an. ${ }^{151}$ Neben Montreal und Toronto, die mehr als die Hälfte der Industrieproduktion auf sich vereinigten, kam es auch in vielen anderen Städten in mehreren Branchen zur Gründung von Industriebetrieben. ${ }^{152}$ Die Zahl der Industriebeschäftigten wuchs im selben Zeitraum mehr als doppelt so schnell wie die Bevölkerung, nämlich um fast 80 Prozent, ihre Produktion um 138 Prozent. ${ }^{153}$ Parallel zur Industrialisierung erfolgte wie in Europa und den USA seit etwa 1850 ein rascher Ausbau des Eisenbahnwesens: 1865 umfasste das kanadische Eisenbahnnetz 3.600 km, 20 Jahre später bereits $16.500 \mathrm{~km} .{ }^{154}$ Ausgelöst und vorangetrieben durch die vor allem großstädtische Nachfrage im Osten machte die Industrialisierung derart starke Fortschritte, dass die Industrieproduktion pro Einwohner gegen Ende des Jahrhunderts höher war als in Deutschland oder Frankreich und lediglich hinter Großbritannien, Belgien und den USA zurück blieb. ${ }^{155}$

In der Folge setzten sich parallel zu einer rasch wachsenden Gesamtbevölkerung beides, Urbanisierung und Industrialisierung, weiter fort. Montreal und Toronto überschritten bis 1920 die halbe Million, vier weitere Städte mit über 100.000 Einwohnern die Grenze zur Großstadt. ${ }^{156}$ Insgesamt lebten damals mehr als die Hälfte der kanadischen Bevölkerung von mittlerweile über 7 Millionen Menschen in Städten. ${ }^{157}$ In der Industrie stieg der Bruttoproduktionswert innerhalb von 25 Jahren nominell auf fast das Vierfache an. ${ }^{158}$ Typisch für eine fortgeschrittene, breite Industrialisierung erlebte nunmehr neben der traditionellen Textilproduktion auch die Eisen- und Stahlindustrie einschließlich der Metallverarbeitung ein besonders starkes Wachstum. ${ }^{159}$ Im internationalen Vergleich rangierte Kanada am Vorabend des Ersten Weltkrieges, gemessen am Bruttoinlandsprodukt pro Einwohner, hinter den USA, Australien, Neuseeland und Großbritannien an fünfter Stelle. ${ }^{160}$

150 Kerr (1990), Plate 7.

151 Couturier (1994), 213 und Couturier (1996), 89.

$152 \operatorname{Kerr}(1990)$, Plate 1.

153 Couturier (1996), 89 und McInnis/Horn (1982), 405.

154 Couturier (1996), 85 und McInnis (2000), 83.

155 McInnis (2000), 58.

156 Köllmann (1965), 268.

157 Canada Year Book (1997), 31

158 McInnis/Horn (1982), 437.

159 Couturier (1994), 240.

160 Maddison (Per Capita GDP). 
Innerhalb des Landes hatte sich eine Art Arbeitsteilung ergeben. Auf der einen Seite standen die sich vor allem in ihren südlichen Teilen industrialisierenden und mit Abstand bevölkerungsreichsten Provinzen Ontario und Québec, auf der anderen die weiter westlich gelegenen Provinzen, in denen vor allem mineralische Rohstoffe und Produkte der Land- und Forstwirtschaft gefördert bzw. hergestellt wurden. Beides ging vor allem in den Export und steigerte auf diese Weise die Kaufkraft der Bevölkerung im Westen. 1929 lagen die mittleren Pro-Kopf-Einkommen in Manitoba, Saskatchewan, Alberta und Britisch-Kolumbien über oder nur knapp unter dem nationalen Durchschnitt. Dennoch ging von ihnen aufgrund der geringeren Bevölkerung - im riesigen Gebiet der westlichen Provinzen lebten lange Zeit nicht einmal ein Zehntel und 1931 noch immer weniger als ein Drittel der kanadischen Bevölkerung ${ }^{161}$ - nur eine zusätzliche Nachfrage nach Industriewaren aus. Die Hauptnachfrage erwuchs aus der städtischen Bevölkerung der östlichen Provinzen, wo allein in Montreal und Toronto um die Jahrhundertwende auf kleinem Raum fast gleich viele und 30 Jahre später knapp halb so viele Menschen lebten wie in dem weit größeren Gebiet der westlichen Provinzen zusammen. ${ }^{162}$ Nicht weniger als 80 Prozent aller Industriebeschäftigten arbeiteten zu Beginn des 20. Jahrhunderts in Ontario und Québec. ${ }^{163}$

Erst in den folgenden Jahrzehnten griff die Industrialisierung in stärkerem Maße auch auf den Westen über, wohin sich nach der Eröffnung der ersten transkontinentalen Eisenbahn im Jahre 1886 der Schwerpunkt der weiteren Bevölkerungszunahme verlagert hatte. ${ }^{164}$ Schon bald begann auch in den westlichen Provinzen die städtische Bevölkerung rascher zu wachsen als die ländliche, insbesondere in Vancouver, dem zentralen Umschlagplatz an der Westküste. ${ }^{165} 1961$ produzierten neben Québec und Ontario auch Britisch-Kolumbien und Manitoba mehr Industriewaren als andere Güter. ${ }^{166} 20$ Jahre später wurden in Kanada insgesamt acht Mal so viele Industriewaren wie landwirtschaftliche Produkte erzeugt. ${ }^{167}$ Im Unterschied zu Ontario und Québec, wo inzwischen neben Montreal und Toronto auch in deren Umgebung eine Reihe weiterer Industriestädte wie

161 Köllmann (1965), 122 und 265.

1620,5 und 0,6 bzw. 1,45 und 3 Millionen. Köllmann (1965), 122, 124, 265 und 268.

$163 \operatorname{Kerr}(1990)$, Plate 13.

164 McInnis (2000), 97 und Kerr (1990), 31. 1891 wohnten erst 7 Prozent der kanadischen Bevölkerung westlich von Ontario, 1911 waren es schon 24 und 1961 rund 26 Prozent der mittlerweile 18,2 Millionen Einwohner. Couturier (1994), 271, Kerr (1990), Plate 4 und Köllmann (1965), 122 und 265.

165 Köllmann (1965), 124 und 268; Couturier (1994), 241; Kerr (1990), Plate 4.

$166 \operatorname{Kerr}(1990)$, Plate 3.

167 Green (2000), 237. 
Hamilton, Kitchener, Windsor, London oder Oshawa entstanden waren, konzentrierte sich die Industrie im Westen in stärkerem Maße auf einige wenige Großstädte, die relativ weit auseinander lagen. ${ }^{168}$ Knapp die Hälfte der dortigen Industriebeschäftigten arbeiteten 1957 in Vancouver und Winnipeg, ein weiteres Siebtel in Edmonton und Calgary. ${ }^{169}$ Allerdings lebten anders als in Ost- und Südeuropa oder - wie zu zeigen sein wird - in vielen anderen Teilen der Welt außerhalb der Großstädte nur relativ wenige Menschen. Die von und in den Großstädten angeregte, Arbeit und Einkommen schaffende Industrialisierung reichte daher aus, die Entstehung eines größeren Entwicklungsgefälles zwischen Ost und West zu verhindern. Im Gegenteil, Ende der 70er Jahre lagen die durchschnittlichen Pro-Kopf-Einkommen in Britisch-Kolumbien und Alberta sogar leicht über dem Wert von Ontario und knapp 18 Prozent über den mittleren Einkommen in Québec, Saskatchewan und Manitoba. Deutlich niedriger fielen sie in den weniger industrialisierten, atlantischen Provinzen aus. ${ }^{170}$

Insgesamt blieben die westlichen Provinzen dank der geringeren Bevölkerung sowohl in der Zahl der Industriebeschäftigten als auch in der Industrieproduktion des Landes hinter den alten Industriezentren zurück. Obwohl ein Großteil der Rohstoffe im Westen gewonnen wurde, konzentrierten sich die Betriebe der verarbeitenden Industrie auf die Ballungs- und Nachfragezentren im Osten des Landes. Mitte der 90er Jahre kamen Ontario und Québec mit etwa 60 Prozent der Gesamtbevölkerung noch immer für mehr als drei Viertel der Industrieproduktion auf und stellten auch drei Viertel aller Industriebeschäftigten. ${ }^{171}$ Weitere 10 Prozent arbeiteten in Britisch-Kolumbien und noch einmal so viele in Alberta, Saskatchewan und Manitoba zusammen. Wenn daher Kanada bis zuletzt zu den höchst entwickelten Industrieländern der Welt zählte und 2008 gemessen am Bruttoinlandsprodukt pro Einwohner hinter den USA, Norwegen und Irland etwa gleichauf mit Australien an vierter Stelle rangierte, ${ }^{172}$ war dies in noch stärkerem Maße als in den USA vor allem den beiden bevölkerungsreichen und hoch entwickelten Provinzen im Osten des Landes zu verdanken.

Wie andere Industrieländer hatte inzwischen auch Kanada den Übergang von einer Industrie- zu einer urbanisierten Dienstleistungsgesellschaft vollzogen. Im Jahre 2011, als die

$168 \operatorname{Kerr}(1990)$, Plate 51.

$169 \operatorname{Kerr}(1990)$, Plate 51.

170 McInnis/Horn (1982), 682.

171 Errechnet aus Canada Year Book (1997), 210 und 366 f.

172 Maddison (Per Capita GDP). 
Gesamtbevölkerung auf 33,5 Millionen angestiegen war, zählten Toronto und Montreal - ohne Metropolregionen - über 5 bzw. 3,4 Millionen, Vancouver über 2 Millionen sowie Calgary und Edmonton jeweils rund eine Million Einwohner. ${ }^{173}$ Sie waren damit deutlich schneller gewachsen als die Gesamtbevölkerung der Provinzen, in denen sie lagen. Fast die Hälfte der kanadischen Bevölkerung lebte zuletzt in den sechs Metropolregionen mit jeweils über einer Million Einwohner. ${ }^{174}$ Drei Viertel aller Erwerbstätigen arbeiteten mittlerweile im Dienstleistungssektor, mit nur geringfügigen Unterschieden zwischen Ost und West. ${ }^{175}$ Die durchschnittliche Pro-Kopf-Leistung der einzelnen Provinzen bewegte sich 1995 - durchaus vergleichbar mit den USA - zwischen 31.000 kanadischen Dollar in Alberta auf der einen und knapp 24.000 Dollar in Québec und Saskatchewan auf der anderen Seite, worin sich eine relativ ausgewogene Wirtschaftsstruktur widerspiegelt. ${ }^{176}$ Lediglich die atlantischen Provinzen im äußersten Osten, die zusammen nur 8 Prozent der Bevölkerung stellten, hinkten mit durchschnittlich 20.000 Dollar in ihrer wirtschaftlichen Entwicklung etwas hinterher. Misst man den wirtschaftlichen Wohlstand an der Ausstattung des Landes mit PKW, lagen der Westen und der äußerste Osten mit 712 und 628 Autos pro 1.000 Einwohnern über, der Zentralraum Ontario und Québec mit 545 Autos unter dem nationalen Wert von 601 PKW. ${ }^{177}$ Auch daraus wird ersichtlich, wie sehr sich in Kanada die einzelnen Landesteile auf einem hohen Niveau angeglichen hatten.

\section{Lateinamerika}

Wenn die jüngere Entwicklung der kanadischen Wirtschaft vieles mit jener im Nordosten und im Westen der USA gemeinsam hatte, ähnelte die Entwicklung in Lateinamerika als Ganzem in vielerlei Hinsicht dem Süden der USA. Beide blieben lange Zeit relativ dünn besiedelt, die Städte wuchsen bis ins 20. Jahrhundert langsamer und lagen weiter auseinander als im Nordosten der USA und im Osten Kanadas. Aufgrund der geringen Städtedichte herrschte am Land Subsistenzwirtschaft vor, die Überschussproduktion für städtische Märkte hielt sich in Grenzen. Wie im Süden der USA war die Kaufkraft der ländlichen Bevölkerung überaus bescheiden, da sie sich neben zahlreichen Kleinbauern

173 Wikipedia (Kanada).

174 Neben den genannten Millionenstädten die Metropolregion Ottawa-Gatineau. Liste der Städte (Kanada).

175 Canada Year Book (1997), 210.

176 Eigene Berechnungen nach Canada Year Book (1997), 77 und 282.

177 Eigene Berechnungen nach Canada Year Book (1997), 77 und 401. 
zu einem Großteil aus Sklaven zusammensetzte, die aus Afrika verschleppt worden waren. Die Gewinne der relativ wenigen, exportorientierten Großgrundbesitzer - sie ließen vor allem landwirtschaftliche Produkte wie Zucker, Kaffee, Tabak und Kakao anbauen - verblieben zum größten Teil in der Landwirtschaft oder wurden für den Import gewerblicher Produkte aus Europa und später auch aus den USA verwendet. Für mehr als nur punktuelle Industrieinvestitionen fehlten die Anreize einer genügend großen Zahl und Dichte großstädtischer Märkte.

Lange Zeit hatten sich die beiden Halbkontinente Amerikas in dieser Hinsicht kaum voneinander unterschieden. Beide waren um 1800 mit geschätzten 5 Millionen Einwohnern nördlich und knapp 20 Millionen südlich des Rio Grande überaus dünn besiedelt. ${ }^{178}$ Städtische Siedlungen waren nach der Zerstörung der alten Hochkulturen erst in Ansätzen neu entstanden. In den folgenden Jahrzehnten jedoch erlebte der Norden dank stärkerer Zuwanderung aus Europa eine viel raschere Bevölkerungszunahme als der Süden. Um 1900 lebten in den USA und Kanada über 80 Millionen, in Lateinamerika hingegen erst 65 Millionen Menschen (vgl. Tabelle 14). ${ }^{179}$ Außerdem konzentrierte sich die Besiedlung - und darin liegt der entscheidende Unterschied - im Norden auf eine weit kleinere Fläche als im Süden. Anders als der Nordosten der USA und der Osten Kanadas gab es im Süden keine Region, die sich so sehr zum Zentrum der Einwanderung entwickelte. Stattdessen verteilten sich die Zuwanderer auf mehrere Gebiete zwischen dem Rio Grande und der Südspitze des Kontinents, so dass nirgendwo eine ähnlich hohe Dichte zustande kam wie zwischen Montreal, Chicago, St. Louis und Washington.

Die dünnere Besiedlung erschwerte zunächst die Entwicklung größserer Städte, die auch in Lateinamerika als Zentren des Außenhandels sowie als Hauptstädte der neuen Länder entstanden. Obwohl sie speziell in der zweiten Hälfte des 19. Jahrhunderts ein rasches Wachstum erlebten, blieben sie vorerst sowohl an Zahl als auch an Größe deutlich hinter den Großstädten des Nordens zurück (vgl. Tabelle 9 und Tabelle 15). Während es im Nordosten und Mittleren Westen der USA um 1900 bereits 27 Großstädte mit mehr als 100.000 Einwohnern gab, waren es in dem viel größeren Gebiet zwischen Mexico City und Buenos Aires lediglich 13 (vgl. Karte 5 und Karte 7). Sie lagen nicht nur wesentlich weiter auseinander, sondern vereinigten zusammen nur knapp 6 Prozent der gesamten, lateinamerikanischen Bevölkerung auf sich - im Nordosten und Mittleren Westen der

178 Mathieu (2011), 87.

179 Maddison (Population). 
USA waren es über 25 Prozent. ${ }^{180}$ Außerdem waren sie bis zum Beginn des Eisenbahnbaus in der zweiten Hälfte des 19. Jahrhunderts nur unzureichend bis gar nicht miteinander verbunden.

Angesichts der relativ geringen Urbanisierung und der damit verbundenen, nur schwachen Marktintegration des größten Teils der Bevölkerung entwickelten sich auch moderne Industrien nur sehr langsam und vereinzelt. Der niedrige Urbanisierungsgrad beschränkte die Zahl kaufkräftiger Konsumenten, deren Nachfrage nach gewerblichen Gütern außer mit Importen aus Europa und den USA vom ländlichen und städtischen Handwerk ausreichend gedeckt werden konnte. ${ }^{181}$ Zwar hatte sich auch in Lateinamerika seit dem 18. Jahrhundert neben der traditionellen Schafwollverarbeitung in den „obrajes de paño" eine handwerkliche und wie in Europa von Großhändlern organisierte Produktion von Baumwollwaren entwickelt. ${ }^{182}$ Die Mechanisierung der Baumwollspinnereien setzte jedoch erst in den 1830er und die der Baumwollweberei erst in den 1890er Jahren ein. Führend war diesbezüglich Mexiko, wo bereits vor 1800 in Puebla eine bedeutende Wollverarbeitung entstanden war und 1843 bereits 59 mechanische Betriebe mit zusammen über 100.000 Spindeln zur Verarbeitung von Baumwolle gezählt wurden. ${ }^{183}$ Um dieselbe Zeit ging auch die erste Baumwollfabrik im brasilianischen Bahia in Betrieb, doch gab es in Brasilien noch zehn Jahre später erst acht Baumwollspinnereien mit zusammen 4.500 Spindeln. Bezeichnenderweise verlagerten sich ihre Standorte in den folgenden Jahrzehnten aus den Baumwollanbaugebieten im Norden zu den rasch wachsenden Nachfragezentren Rio de Janeiro und São Paulo im Süden des Landes. ${ }^{184}$ In den 50er Jahren entstanden auch die ersten Baumwollfabriken in Peru - zu einer Zeit, als in Großbritannien bereits an die 20 Millionen sowie in Deutschland und Frankreich rund viereinhalb bzw. eine Million Spindeln installiert waren. ${ }^{185}$

Der durch den späten Industrialisierungsbeginn bedingte Rückstand blieb auch in der Folge erhalten. Zwar nahm die Zahl der Baumwollspindeln speziell gegen Ende des 19. Jahrhunderts deutlich zu, doch lagen die beiden damals wie heute größten Länder Lateinamerikas, nämlich Mexiko und Brasilien, mit etwa 750.000 und 1,4 Millionen Spindeln um 1914 nicht nur hinter den Ländern West- und Mitteleuropas, sondern auch hinter den

180 Eigene Berechnungen nach Mitchell (1998), 50-57, Maddison (Population) und Heim (2000), 101.

181 Bulmer-Thomas (1994), 130.

182 Dazu und zum folgenden Gómez-Galvarriato (2006), 377-391.

183 Vgl. auch Donghi (1985), $327 \mathrm{f}$.

184 Bulmer-Thomas (1994), 135.

185 Mitchell (1977), 510. 
Karte 7: Großstädte mit über 100.000 Einwohnern in Lateinamerika um 1900

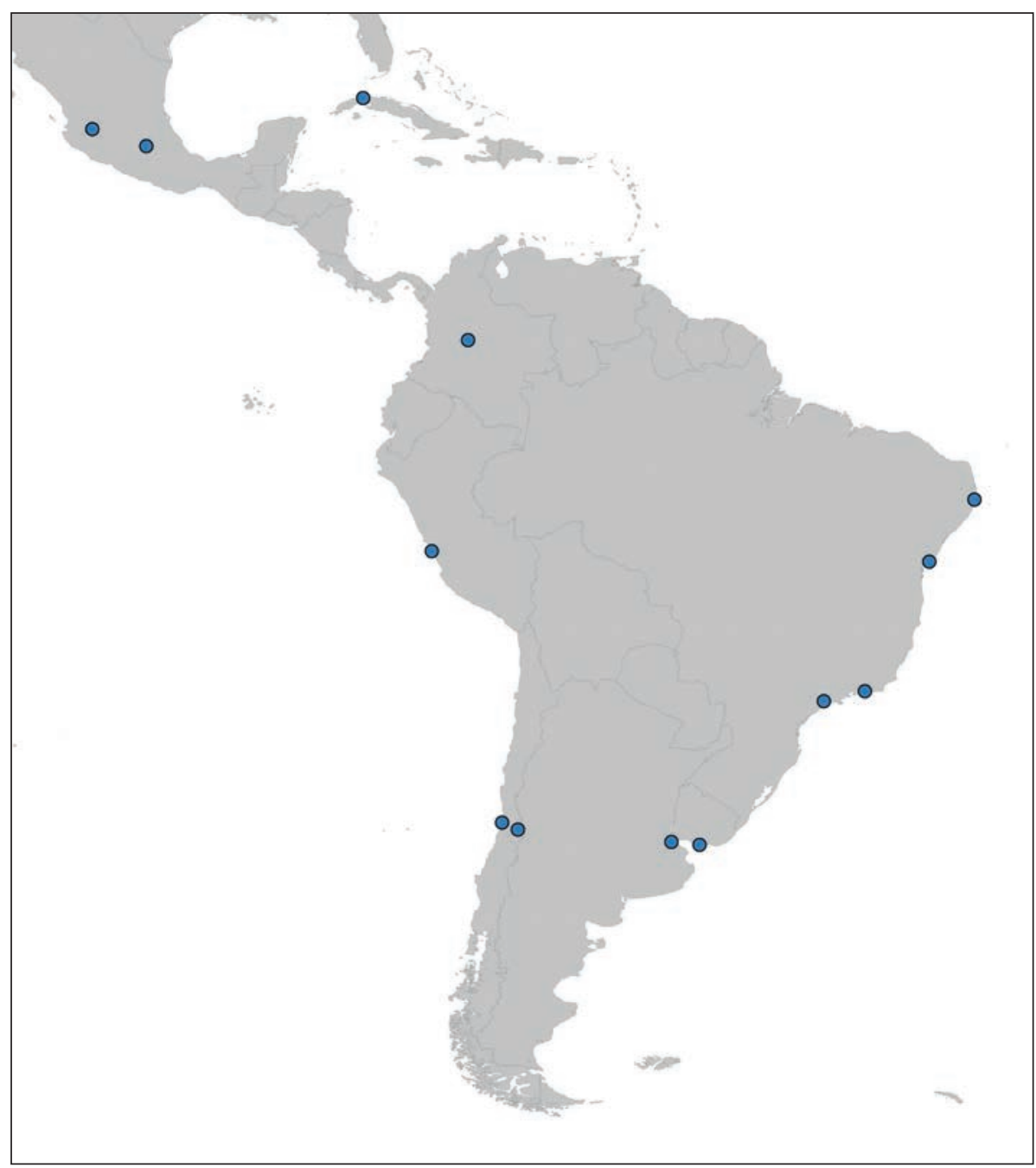

Tirol Atlas - Bearbeitung Klaus Förster nach Tabelle 15.

Kartenhintergrund: World Borders Dataset - http://thematicmapping.org/downloads/world_borders.php 
USA weit zurück. ${ }^{186}$ In Argentinien, wo die frühe Industrialisierung ebenfalls in erster Linie von der Nachfrage nach Konsumgütern ausging, erlebte vor allem die Bekleidungsindustrie einen stärkeren Aufschwung, während die notwendigen Garne zum größten Teil importiert wurden. ${ }^{187}$

Nur sehr schwach entwickelt blieb die Eisen- und Stablindustrie. Lediglich in Mexiko war bis zum Vorabend des Ersten Weltkriegs ein größeres Eisen- und Stahlwerk entstanden, doch machte seine Rohstahlproduktion nur einen Bruchteil etwa der kanadischen Produktion aus. ${ }^{188}$ Dank fehlender Tradition in der Metallverarbeitung wurden die Materialien und Betriebsmittel, die für die Errichtung eines durchaus weit gespannten Eisenbahnnetzes notwendig waren, hauptsächlich aus dem Ausland importiert. Die Eisenbahnen sollten in erster Linie dem Transport der Exportgüter an die Überseehäfen dienen, wurden in der Folge aber auch für den Binnenhandel genutzt. ${ }^{189}$

Dennoch setzte seit dem letzten Viertel des 19. Jahrhunderts trotz der für viele Beobachter im Vordergrund stehenden, raschen Ausweitung des Außenhandels - seit der Jahrhundertwende wurden wie zuvor vor allem Produkte der Landwirtschaft und des Bergbaus exportiert -,${ }^{190}$ in Teilen Lateinamerikas eine stärkere Industrialisierung ein. ${ }^{191}$ In Argentinien wuchs die Produktion im industriell-gewerblichen Sektor zwischen 1875 und 1913 um durchschnittlich 8 Prozent pro Jahr. Am Vorabend des Ersten Weltkrieges wurden rund $18 \mathrm{Mal}$ so viele Industriewaren hergestellt wie 1875. ${ }^{192}$ Zwischen 1895 und 1913 sollte sich sowohl die Zahl der Industriebetriebe als auch die Zahl der in ihnen Beschäftigten mehr als verdoppeln. ${ }^{193}$ In Brasilien lag das entsprechende Wachstum während der beiden ersten Jahrzehnte des 20. Jahrhunderts bei jährlich 6 Prozent. ${ }^{194}$ Auch hier nahmen die Zahl der Industriebetriebe und der darin Beschäftigten rasch zu. ${ }^{195}$ Etwas langsamer vollzog sich die Industrialisierung in Ländern wie Chile und Mexiko, obwohl

186 Mitchell (1998), 376. Während in Mexiko und Brasilien 50 und 60 Spindeln auf 1.000 Einwohner entfielen, waren es in Großbritannien etwa 1.300, in Frankreich und Deutschland 170 bis 180 und in den USA rund 300 Spindeln. Eigene Berechnungen nach Mitchell (1998), 376, Mitchell (1977), 489 und 510 sowie Maddison (Population).

187 Rocchi (2005), $34 \mathrm{f}$.

188 Moreno-Brid/Ros (2009), 51; Bulmer-Thomas (1994), 137 und 319; Haber (2006), 543; Mitchell (1998), 362.

189 Vgl. Haber (2006), 540 f., Clayton/Conniff(1999), 125 f., Summerhill (2006) und Bulmer-Thomas (1994), 107.

$190 \mathrm{Zu}$ den Exporten vgl. u. a. Donghi (1985), 330, Roesler (2009), 69 und 231, Clayton-Conniff, 125, Bulmer-Thomas (1994), 273 und 433, Haber (2006), 540 und Thorp (1998), 53, 114-119, 160, 336 f. und 347.

191 Haber (2006), $537 \mathrm{f}$.

192 Barbero/Rocchi (2003), 267; Rocchi (2005), 17-22; Randall (1977b), 147 f. und 235.

193 Haber (2006), 546.

194 Merrick/Graham (1979), 23; Randall (1977c), 122-125, 135 und 182 f.

195 Zwischen 1889 und 1907 auf das Fünf- bzw. Dreifache. Eine weitere Verdoppelung der Industriebetriebe erfolgte zwischen 1910 und 1915. Randall (1977c), 135 und 183. 
die industriell-gewerbliche Produktion zu Beginn des Jahrhunderts um durchschnittlich etwa 3 bis 4 Prozent pro Jahr zulegte. ${ }^{196}$ All dies hatte zur Folge, dass zu Beginn des Ersten Weltkrieges in Argentinien, Brasilien, Chile, Mexiko und Peru der Bedarf an Konsumgütern bereits zu 50 bis 80 Prozent aus der heimischen Produktion gedeckt wurde. ${ }^{197}$

Die neuen Industrien konzentrierten sich vor allem auf die Großstadtregionen, also auf Buenos Aires, Montevideo, São Paulo, Rio de Janeiro und ihre weitere Umgebung entlang der Atlantikküste, auf die Zentralregion um Mexico City sowie auf Lima und Santiago de Chile am Pazifik. ${ }^{198}$ In Argentinien lebte mehr als die Hälfte der Bevölkerung in der Hauptstadt und den benachbarten Provinzen Buenos Aires und Santa Fe. In ihnen befanden sich vor der Jahrhundertwende rund 70 Prozent der Industriebetriebe des Landes. Um 1914 entfielen nicht weniger als 90 Prozent des in der Industrie investierten Kapitals auf die Region des Mittleren Ostens, in der neben Buenos Aires mit über eineinhalb Millionen Einwohnern auch die drei Großstädte Córdoba, Rosario und La Plata mit zusammen etwa einer halben Million Einwohner lagen. ${ }^{199}$

In Brasilien zog neben Rio de Janeiro vor allem São Paulo einen immer größeren Teil der Industrie auf sich. Dank dem in der Region um São Paulo rasch expandierenden Kaffeeanbau, der zahlreiche Immigranten aus Europa anlockte, vervielfachte sich seine Bevölkerung in nur 20 Jahren von 65.000 Einwohnern um 1890 auf 346.000 im Jahre 1910. ${ }^{200}$ Fünf Jahre später stammten 30 Prozent der brasilianischen Industrieproduktion allein aus São Paulo. ${ }^{201}$ Die übrigen Großstädte Belém, Recife, Salvador und Porto Alegre lagen wesentlich weiter auseinander als in Argentinien. Dementsprechend schwächer waren die Industrialisierungsimpulse, die von ihnen ausgingen. So kam es, dass - anders als im kleineren Argentinien - mit rund 80 Prozent der größere Teil der brasilianischen Bevölkerung, der außerhalb der beiden Bundesstaaten São Paulo und Rio de Janeiro lebte, von der anfänglichen Industrialisierung des Landes nur wenig erfasst wurde. ${ }^{202}$

196 Thorp (1998), 322; Moreno-Brid/Ros (2009), 57; Fischer (2011), 54 f.; Collier/Sater (2004), 159 f.; Randall (1977 a), 136-141 und 188 .

197 Bulmer-Thomas (1994), 145. Vgl. Thorp (1998), 4 und Haber (2006), $544 \mathrm{ff}$.

198 Bulmer-Thomas (1994), 135. Randall (1977d), 136. Zur geringen Industrialisierung außerhalb der großen Städte vgl. Roesler (2009), 111.

199 Mitchell (1998), 56 f.; Randall (1977 b), 235; Rocchi (2005), 26 und 127 f.

200 Mitchell (1998), 55 und 57.

201 Randall (1977c), 183.

202 Mitchell (1998), 39. 
São Paulo, Avenida Paulista, um 1902

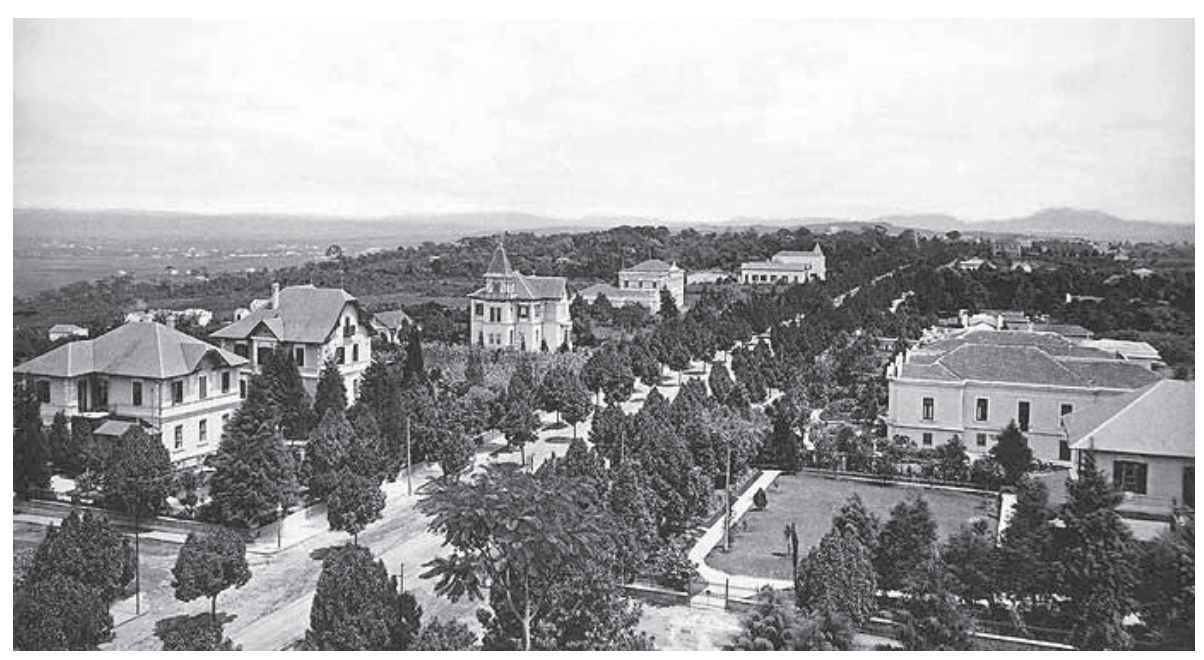

http://de.wikipedia.org/wiki/S\%C3\%A3o_Paulo\#/media/File:Avenida_Paulista_1902.jpg

Ein ähnliches Bild wie Brasilien bot Mexiko, wo eine stärkere Industrialisierung außer in der Hauptstadt und ihrer Umgebung lediglich in Puebla und Monterrey zu beobachten war. ${ }^{203}$ Die Bundesstaaten, in denen sich die drei Industrieregionen befanden, vereinigten jedoch nur gut 20 Prozent der mexikanischen Gesamtbevölkerung auf sich, ${ }^{204}$ so dass auch hier - bezogen auf das ganze Land - eine vorerst nur punktuelle Industrialisierung stattfand.

Die Breitenwirkung der anfänglichen Industrialisierung fiel daher in Lateinamerika relativ bescheiden aus. Die Großstädte, deren wachsende Massennachfrage sie anregte, waren $\mathrm{zu}$ wenige und $\mathrm{zu}$ weit voneinander entfernt, um mehr als nur eine begrenzte Industrialisierung auszulösen. Während es um 1920 in Nordamerika zwischen Montreal, Chicago, St. Louis und Baltimore 12 Großstädte mit über einer halben Million Einwohner gab, zählte man in Südamerika im flächenmäßig etwa gleich großen Gebiet zwischen Rio de Janeiro, Santiago de Chile, Buenos Aires und São Paolo lediglich vier. ${ }^{205}$ In ihnen

203 Bulmer-Thomas (1994), 135.

204 Um 1921. Mitchell (1998), 33.

205 Mitchell (1998), 50-57. 
lebten im einen Fall über 16, im anderen weniger als vier Millionen Menschen. ${ }^{206}$ Obwohl auch in Lateinamerika der ursächliche Zusammenhang zwischen Großstädten und Industrialisierung gegeben war, verhinderten ihre zu geringe Zahl und Dichte lange Zeit eine breitere Industrialisierung. Der relativ kleine Anteil der Großstädte an der Gesamtbevölkerung und die zum Teil großen Distanzen zwischen ihnen ließen nur relativ wenige Menschen an der von ihnen ausgelösten Industrialisierung teilhaben.

Dieser Befund trifft sowohl für Lateinamerika als Ganzes als auch für die meisten seiner Länder im Einzelnen zu. Ausnahmen gab es, wo sich im Rahmen eines Landes die Bevölkerung stärker auf die Großstädte konzentrierte, als es im kontinentalen Durchschnitt der Fall war. So entfielen 1920 in Argentinien und Chile - vergleichbar mit den USA oder Kanada - gut 18 Prozent der Bevölkerung auf Buenos Aires und knapp 14 Prozent auf Santiago de Chile, in Brasilien hingegen nur 6 Prozent auf Rio und São Paulo sowie in Mexiko lediglich 4 Prozent auf Mexico City. ${ }^{207}$ Auf gesamtstaatlicher Ebene schlug daher eine da wie dort stattfindende Industrialisierung unterschiedlich stark zu Buche. Um 1914/1920 lag der Anteil der im industriell-gewerblichen Bereich arbeitenden Menschen an allen Erwerbstätigen in den relativ kleinen Ländern Argentinien und Chile bei knapp 27 bzw. 24 Prozent und damit auf ungefähr demselben Niveau wie in Kanada. Deutlich weniger waren es dagegen mit jeweils rund 10 Prozent in den mit Abstand bevölkerungsreichsten Ländern Brasilien und Mexiko, obwohl in absoluten Zahlen in Brasilien mehr Menschen in Industrie und Gewerbe beschäftigt waren als in Argentinien, und in Mexiko etwa doppelt so viele wie in Chile. ${ }^{208}$ Besonders stark kam das relativ große Gewicht der Hauptstadt auch im kleinen Uruguay zum Tragen, wo in Montevideo etwa 30 Prozent der Gesamtbevölkerung lebten und die Industrieproduktion des Landes pro Einwohner Brasilien um das fast Fünffache und Mexiko um das Dreifache übertraf. ${ }^{209}$

Eine ähnlich ungleiche Breitenwirkung ging im Übrigen auch von der Exportwirtschaft aus. ${ }^{210}$ Das absolute Exportvolumen ergab sich zum einen aus der natürlichen Ausstat-

206 Eigene Berechnungen nach Mitchell (1998), 50-57.

207 Eigene Berechnungen nach Mitchell (1998), 50-57 und Maddison (Population). Zum unterschiedlichen Urbanisierungsgrad, gemessen an der Bevölkerung in Städten mit mehr als 20.000 Einwohnern, vgl. auch Merrick/Graham (1979), 186 und 188.

208 Eigene Berechnungen nach Mitchell (1998), 102-109 und Merrick/Graham (1979), 153, 158 f. und 162. Ein ähnliches Bild ergibt sich aus dem Vergleich der industriell-gewerblichen Produktion, wie sie von Bulmer-Thomas (1994), 192 für 1928 errechnet wurde. Sie war im kleineren Argentinien knapp zwei Mal so umfangreich wie in Brasilien und etwa zweieinhalb Mal so hoch wie in Mexiko; gemessen an der Bevölkerung produzierten Industrie und Gewerbe in Argentinien allerdings fast sechs bzw. vier Mal so viel wie in den beiden anderen Ländern.

209 Eigene Berechnungen nach Mitchell (1998), 308 f. und Maddison (Population).

210 Vgl. Bértola/Ocampo (2012), 86. 
tung mit mineralischen Rohstoffen und landwirtschaftlich nutzbaren Flächen, zum anderen aus der Zahl der Unternehmer und Grundbesitzer, die die Chancen eines aufnahmefähigen, äußeren Marktes nutzten. Die volkswirtschaftliche Bedeutung der Exporte hing dagegen in hohem Maße von der Bevölkerungszahl eines Landes ab. Bei einem absolut ähnlich großen Ausfuhrvolumen schlugen die positiven Effekte der Exporterlöse in einem kleineren Land stärker zu Buche als in einem großen. So exportierte Argentinien um 1912 pro Einwohner mehr als vier Mal so viele Güter wie Brasilien, obwohl sich die Gesamtmengen nicht wesentlich voneinander unterschieden. ${ }^{211}$ Ebenfalls etwa gleich groß war das absolute Exportvolumen in Chile, Kuba und Mexiko, doch wichen die ProKopf-Werte wegen der unterschiedlichen Bevölkerungsgrößen erheblich voneinander ab. Sie waren in Chile mehr als vier Mal und in Kuba etwa sechs Mal so hoch wie in Mexiko. Und obwohl Uruguay nur etwa ein Sechstel des Wertes von Brasilien ausführte, war dies pro Einwohner fast vier Mal so viel. ${ }^{212}$

Die nationalen Wertschöpfungen pro Einwohner waren daher das Resultat einer wachsenden Exportwirtschaft und/oder einer von Großstädten ausgelösten Industrialisierung auf der einen und einer unterschiedlich großen Gesamtbevölkerung auf der anderen Seite. Wo Industrialisierung und/oder eine starke Exportwirtschaft wie in Argentinien, Uruguay, Chile und Kuba mit einer relativ kleinen Bevölkerung einherging, erreichte das Bruttosozialprodukt pro Einwohner Werte, die ähnlich hoch ausfielen wie in manchen west- und mitteleuropäischen Ländern. Wo hingegen Industrialisierung und Exporte mit einer relativ großen Bevölkerung verbunden waren wie in Brasilien oder Mexiko, lagen die entsprechenden Werte auf etwa demselben Niveau wie in den weniger entwickelten Ländern Süd- und Osteuropas. ${ }^{213}$ Auf einem ähnlich niedrigen Niveau blieben sie vorerst auch in den übrigen Ländern Lateinamerikas, in denen dank fehlender Großstädte keine nennenswerte Industrialisierung stattgefunden hatte und auch keine umfangreiche Exportwirtschaft entstanden war. ${ }^{214}$

In den folgenden Jahrzehnten des 20. Jabrhunderts setzte sich die Industrialisierung in den Ländern, wo sie vor der Jahrhundertwende begonnen hatte, fort und griff auf einige andere Länder Lateinamerikas über. Sie war nicht nur mit einer weiteren Bevölkerungszunahme und einem noch schnelleren Wachstum gerade auch der größeren Städte

211 Eigene Berechnungen nach Table 3.5 in Bulmer-Thomas (1994), 69.

212 Eigene Berechnungen nach Table 3.5 in Bulmer-Thomas (1994), 69.

213 Table 13.9 in Escosura (2006), 500.

214 Vgl. Maddison (Per Capita GDP). 
Karte 8: Millionenstädte in Lateinamerika um 1980

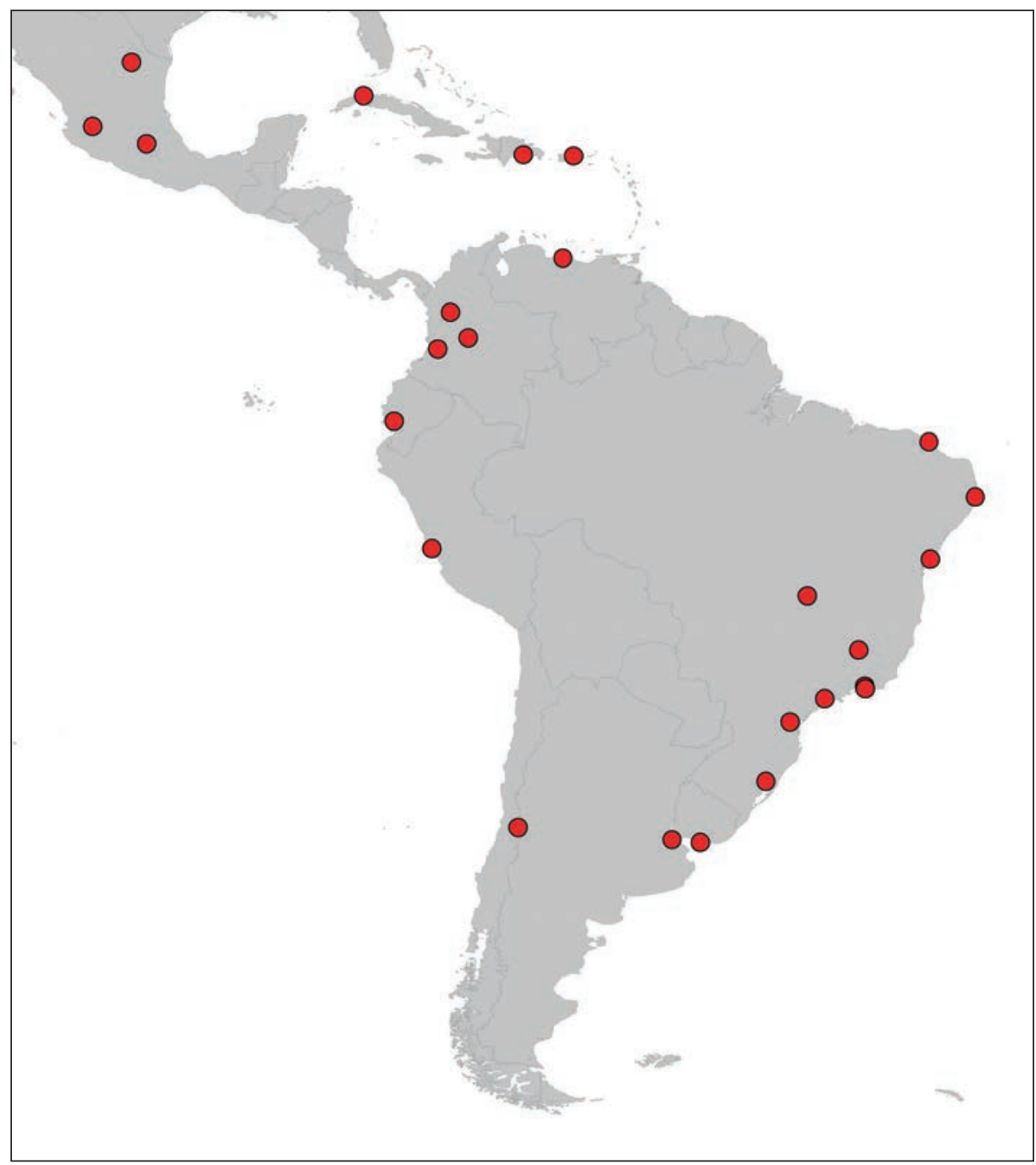

Tirol Atlas - Bearbeitung Klaus Förster nach Tabelle 16.

Kartenhintergrund: World Borders Dataset - http://thematicmapping.org/downloads/world_borders.php 
verbunden, ${ }^{215}$ sondern wurde durch äußere Umstände wie die Weltwirtschaftskrise und den Zweiten Weltkrieg sowie durch eine von den Regierungen betriebene Politik der Importsubstitution zusätzlich unterstützt. ${ }^{216}$

Da sich die Zuwanderung aus Europa abschwächte und in den 50er Jahren praktisch gänzlich zum Erliegen kam, waren es vor allem die sinkenden Sterberaten, die bei nach wie vor hohen Geburtenraten die Bevölkerung insbesondere ab den 50er Jahren geradezu explosionsartig auf zuletzt rund 600 Millionen Menschen ansteigen ließen (vgl. Tabelle 14). ${ }^{217}$ Gleichzeitig veranlassten die Push-Faktoren einer relativen Überbevölkerung am Land, die nicht zuletzt durch die ungleichen Besitzverhältnisse zugunsten des Großgrundbesitzes mit verursacht waren, sowie die Pull-Faktoren nicht-landwirtschaftlicher Arbeit und Einkommen, die man sich von den Großstädten erhoffte, mehr Menschen als je zuvor, vom Land in die Stadt zu ziehen. Die Großstädte wuchsen nicht nur in ihren administrativen Grenzen, sondern vielfach auch darüber hinaus zu metropolitanen Großräumen an. Die Zahl der Millionenstädte vermehrte sich von zwei im Jahre 1920 auf immer noch bescheidene sechs im Jahre 1950, aber bereits 25 im Jahre 1980 (vgl. Karte 8 und Tabelle 16). In ihnen lebten anfangs nur knapp drei Millionen Menschen oder 3 Prozent der lateinamerikanischen Gesamtbevölkerung, 1950 bereits 15 Millionen oder 9 Prozent und 30 Jahre später schon 86 Millionen oder mit 24 Prozent ein Viertel der Gesamtbevölkerung. ${ }^{218}$

Die Landflucht setzte sich auch in den letzten Jahren des 20. und im beginnenden 21. Jahrhundert fort, obwohl sich die Bevölkerungszunahme dank nun auch sinkender Geburtenraten verlangsamte. ${ }^{219}$ Dennoch zählte Lateinamerika zuletzt mehr als sechs Mal so viele Einwohner wie 1920. Die Zahl der Agglomerationen mit mehr als einer Million Einwohnern stieg bis 2010 auf über 50 an. Mit zusammen knapp 200 Millionen Einwohnern lebten in ihnen ein Drittel aller Menschen in Lateinamerika. ${ }^{220}$ Obwohl sich ein Großteil der großstädtischen Bevölkerungen aus vom Land zugewanderten, wenig kaufkräftigen Bewohnern der Elendsviertel zusammensetzte, ${ }^{221}$ stellten die übrigen Be-

\footnotetext{
215 Mitchell (1998), 50-57.

216 Thorp (1998), 161.

217 Nach Maddison (Population) wuchs die Bevölkerung in ganz Lateinamerika zwischen 1920 und 1950 von 90 Millionen um 84 Prozent auf 165,5 Millionen Menschen und in den folgenden 30 Jahren noch einmal um mehr als das Doppelte auf gut 360 Millionen an. Zur Abschwächung der Zuwanderung vgl. Thorp (1998), 22 und BulmerThomas (1994), 308.

218 Eigene Berechnungen nach Tabelle 16 und Maddison (Population).

219 Zwischen 1980 und 2009 um 62 Prozent auf 584 Millionen. Vgl. Tabelle 14 sowie Hofman (2000), 52 und BulmerThomas (1994), 6.

220 Eigene Berechnungen nach Liste der Städte (Länder Lateinamerikas).

221 Vgl. Bulmer-Thomas (1994), 316.
} 
völkerungsschichten einen rasch wachsenden Markt für industriell-gewerbliche Güter alle Art dar.

Buenos Aires, Villa Miseria, um 2006

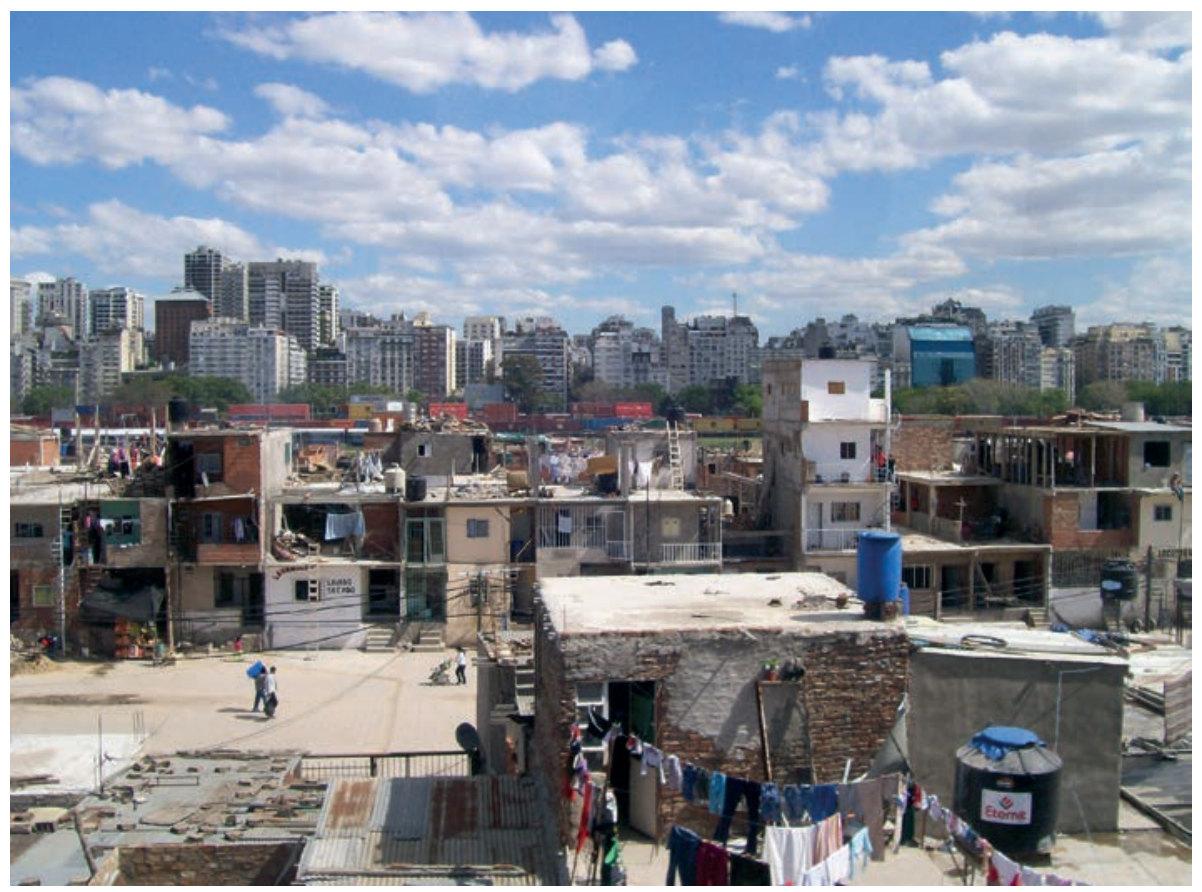

http://commons.wikimedia.org/wiki/File:Villamiseria4.JPG

Neben der fortschreitenden und vor allem im Wachstum der Großstädte zum Ausdruck kommenden Urbanisierung, die als Hauptursache für die weitere bzw. beginnende Industrialisierung anzusehen ist, regten auch äußere Umstände wie die Weltwirtschaftskrise und der Zweite Weltkrieg Investitionen an, die stärker als zuvor auf den heimischen Markt ausgerichtet waren. Sie hatten dank sinkender Nachfrage in den Abnehmerländern einen drastischen Rückgang der traditionellen Exporte aus Lateinamerika zur Folge, was sowohl potentielle Unternehmer als auch die einzelnen Regierungen veranlasste, zur 
Erzielung der erwünschten Erlöse stärker auf die Binnenwirtschaft zu setzen und in die Industrie $\mathrm{zu}$ investieren. 222

Die reduzierten Exportchancen, vor allem aber die Nachfrage der rasch wachsenden Großstädte hatten eine fortgesetzte Industrialisierung zur Folge, die in fast allen Ländern Lateinamerikas - wenn auch in unterschiedlichem Ausmaß und nicht immer zur selben Zeit - zu beobachten war. Sowohl die Zahl der in der Industrie Beschäftigten als auch die industrielle Wertschöpfung nahmen stärker zu als die ohnehin schon rasch wachsende Gesamtbevölkerung und das gesamte Bruttonationalprodukt. ${ }^{223}$ In den größeren Ländern Brasilien, Mexiko, Argentinien, Kolumbien, Venezuela und Chile, die 1980 rund drei Viertel der gesamten Bevölkerung Lateinamerikas auf sich vereinigten, beschäftigte der industriell-gewerbliche, sekundäre Sektor ihrer Volkswirtschaften nunmehr zwischen 26 (Kolumbien) und 36 (Argentinien) Prozent aller Erwerbstätigen. ${ }^{224}$ Um 1955 wurden wertmäßig zum ersten Mal mehr Industriewaren als landwirtschaftliche Produkte hergestellt. ${ }^{225}$ Ein ständig kleinerer Teil der Nachfrage nach Industriewaren wurde durch Importe gedeckt. Wie stark der Zuwachs der Industrieproduktion in den einzelnen Ländern pro Einwohner ausfiel, wird aus Tabelle 17 im Anhang ersichtlich, wobei das letzte der angegebenen Jahre jeweils dem bis 1993 produktionsstärksten Jahr entspricht.

Ähnliche Zuwächse verzeichneten die Produktionswerte einzelner aussagekräftiger Industriegüter, wobei sich der Schwerpunkt der Produktion in der zweiten Jahrhunderthälfte tendenziell und wie anderswo von den Konsumgütern zu den Investitionsgütern verlagerte. Die Verarbeitung von Rohbaumwolle pro Einwohner nahm überall zu, ohne jedoch an die in Europa oder Nordamerika schon früher erzielten Höchstwerte heranzukommen (vgl. Grafik 11, für Europa und Nordamerika Grafik 2, Grafik 4 und Tabelle 18). In Argentinien, wo inzwischen ebenfalls eigene Baumwollspinnereien entstanden waren, ${ }^{226}$ wurde der Höhepunkt der Baumwollwarenproduktion bereits in den 40er Jahren, in Uruguay um 1960, in Brasilien und Kolumbien erst 1992 erreicht.

222 Vgl. Merrick/Graham (1979), 16 f. und Bulmer-Thomas (1994), 9.

223 Bulmer-Thomas (1994), 232.

224 Mitchell (1998), 102-110. Der Anteil der Industrieproduktion an der gesamten Wertschöpfung, der um 1929 auBer in Argentinien durchwegs weniger als 20 Prozent ausgemacht hatte, stieg bis in die 70er Jahre in allen größeren Ländern mit Ausnahme Venezuelas auf über 20 Prozent, in Argentinien und Brasilien sogar auf gut 30 Prozent an. Bértola/Ocampo (2012), 128 f. und 167; Harberger (1988), 167.

225 Bulmer-Thomas (1994), 9.

226 Rocchi (2006), 39. 
Grafik 11: Verarbeitung von Rohbaumwolle in Lateinamerika 1948-1992

(Kilogramm pro Einwohner, Höchstwerte)

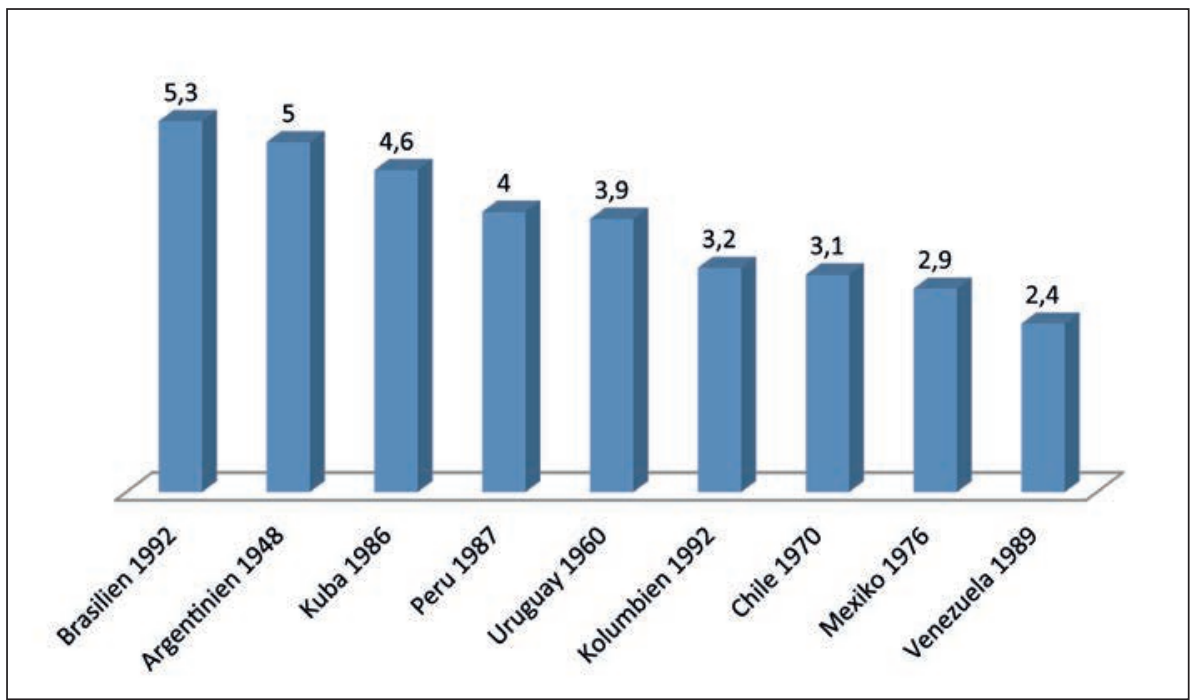

Eigene Berechnungen nach Mitchell (1998), 374 f. und Maddison (Population).

Die eigene Herstellung von Roheisen und Rohstabl, die nunmehr neben Mexiko auch in anderen Ländern Lateinamerikas aufgenommen wurde, legte ebenfalls deutlich zu, mit Spitzenwerten in den 80er und 90er Jahren des 20. Jahrhunderts (vgl. Grafik 12 und Tabelle 18). Allerdings blieben sie in diesem für eine breite Industrialisierung grundlegenden Bereich der industriellen Produktion noch weiter hinter Europa und Nordamerika zurück als bei der Baumwollverarbeitung (vgl. Grafik 3, Tabelle 6 und Tabelle 18). 


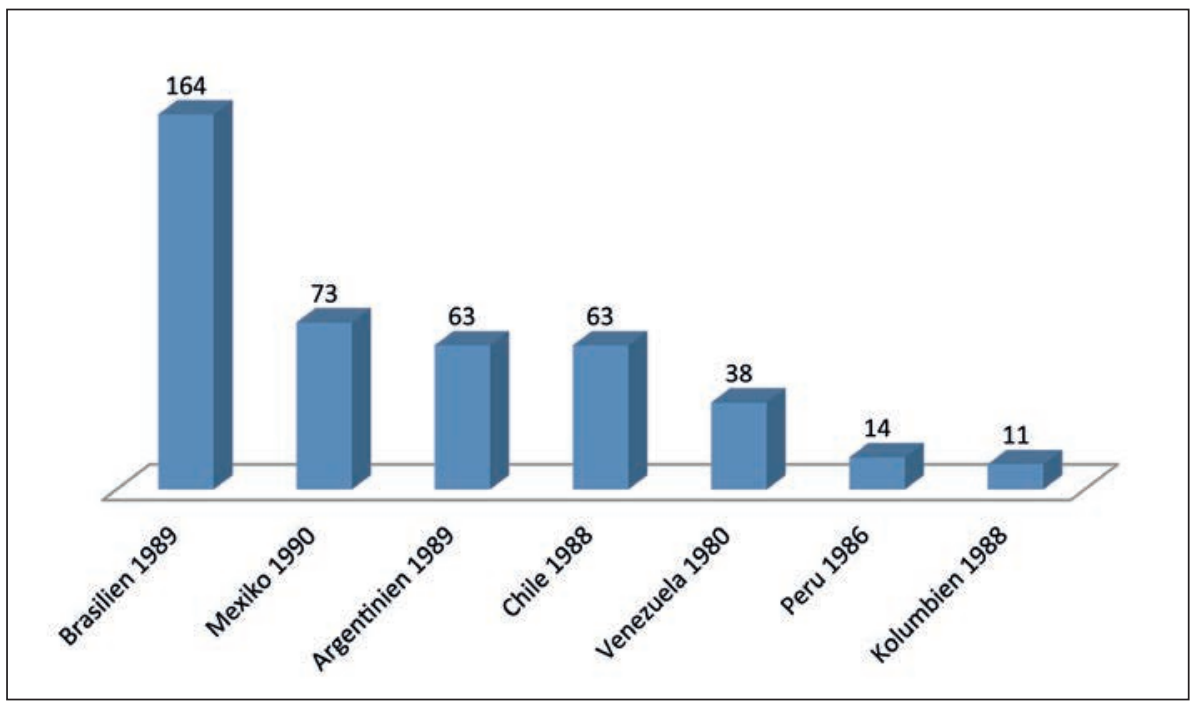

Eigene Berechnungen nach Mitchell (1998), 360 und Maddison (Population).

Ähnliches gilt für die eigene Automobilproduktion, die in Lateinamerika nach dem Zweiten Weltkrieg einsetzte, allerdings pro Einwohner lediglich auf das Niveau der osteuropäischen Länder kam (vgl. Grafik 13, Tabelle 7 und Tabelle 18).

Nach einer Stagnation in den 80er Jahren stieg die industrielle Wertschöpfung weiter an und wuchs in den einzelnen Ländern zwischen 1990 und 2008 um jährlich zwischen zwei und vier Prozent, in Lateinamerika insgesamt um 2,7 Prozent. ${ }^{227}$ Dies entsprach einer Steigerung um fast zwei Drittel, während die Bevölkerung im selben Zeitraum um lediglich ein Drittel zunahm. Allerdings bedurfte die Industrieproduktion dank zunehmender Automatisierung und Kapitalintensität relativ immer weniger Arbeitskräfte, so dass sich der Anteil der Erwerbstätigen in Industrie und verarbeitendem Gewerbe in den meisten Ländern bei weniger als 20 Prozent einpendelte (vgl. Grafik 14 und Tabelle 20). ${ }^{228}$

227 Bértola/Ocampo (2012), 241. Zum Anstieg der Industrieproduktion in Mexiko vgl. Moreno-Brid/Ros (2009), 193.

228 Zum relativen Rückgang der im sekundären Sektor Beschäftigten in Argentinien, Brasilien, Chile, Kolumbien, Mexiko und Venezuela seit etwa 1980 vgl. Hofmann (2000), 57, zur Kapitalintensität der Industrie Skidmore/Smith (2001), 56. 
Grafik 13: Produktion von PKW in Lateinamerika 1976-1993

(Höchstwerte pro 1.000 Einwohner)

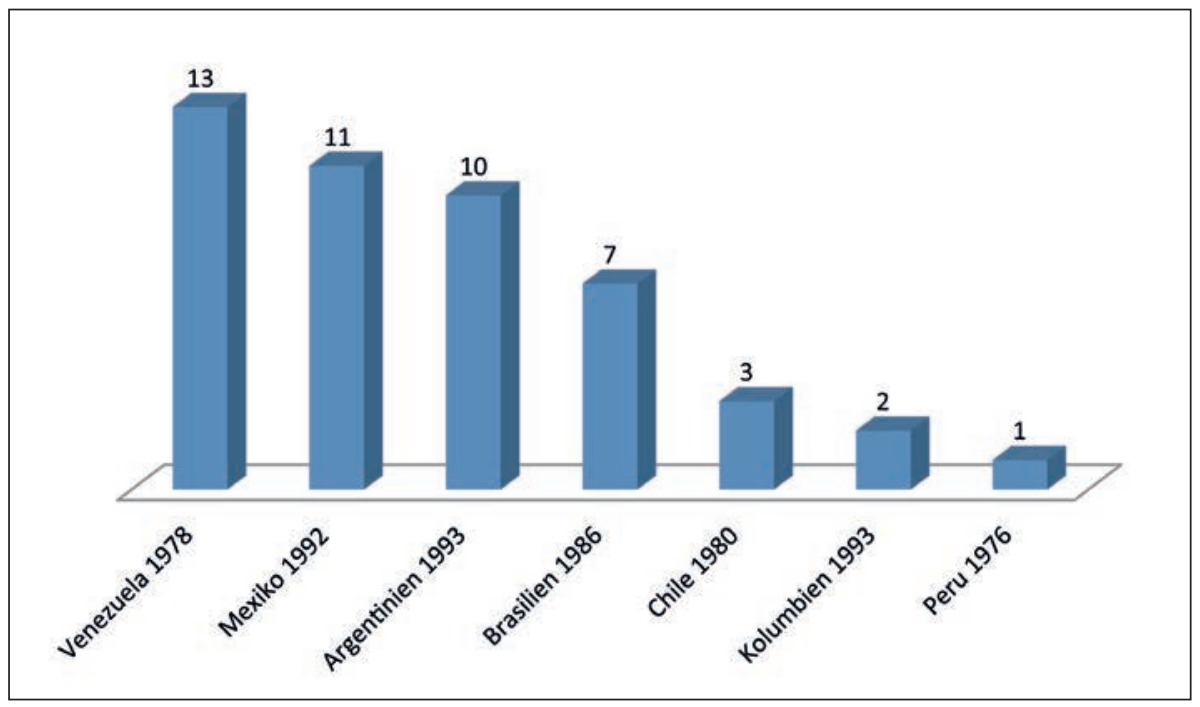

Eigene Berechnungen nach Mitchell (1998), 396 f. und Maddison.

Wie in Ost- und Südeuropa setzte nunmehr auch in Lateinamerika der Wandel zur Dienstleistungsgesellschaft ein, ohne dass ein ähnlich hoher Industrialisierungsgrad wie in West-, Mittel- und Nordeuropa oder den USA und Kanada erreicht worden war. Bereits in den frühen 90er Jahren arbeitete in fast allen Ländern der größte Teil der Erwerbstätigen im Bereich der Dienstleistungen. ${ }^{229}$ Wie in Europa und den beiden nordamerikanischen Industrieländern wurde das Wachstum des Dienstleistungssektors durch die Steigerung der industriellen Produktivität ermöglicht, die von der Krise der 80er Jahre nur kurzfristig unterbrochen wurde. ${ }^{230}$ Die höhere Produktivität erlaubte wachsende Einkommen der in der Industrie tätigen Menschen und ein ebenfalls wachsendes Steueraufkommen. Beides, private Einkommen und Steuern, wurden in zunehmendem Maße für private und öffentliche Dienstleistungen ausgegeben. ${ }^{231}$

229 Skidmore/Smith (2001), 425.

230 Vgl. Moreno-Brid/Ros (2009), 114, Thorp (1998), 328 f. und Ros/Bouillon (2002), 362.

231 Bulmer-Thomas (1994), 317. 


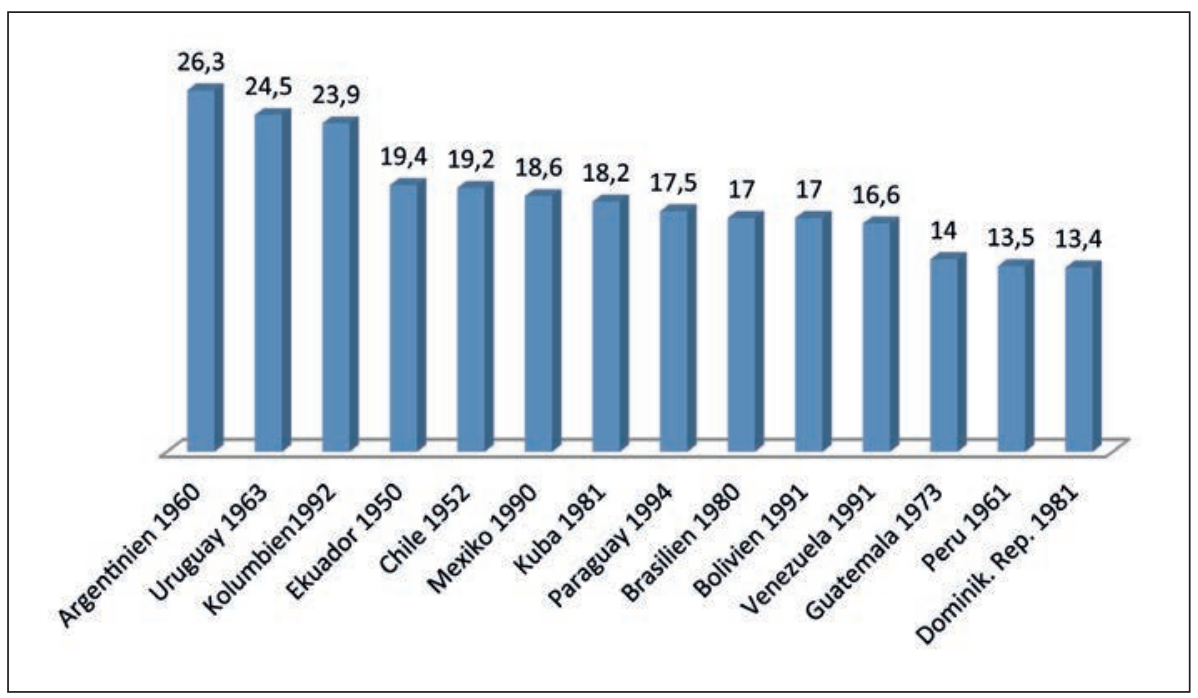

Eigene Berechnungen nach Mitchell (1998), 105-110.

Wenn somit der Industrialisierungsgrad der lateinamerikanischen Länder trotz aller Fortschritte hinter den traditionellen Industrieländern Europas und Nordamerikas zurückblieb und auch zuletzt nicht mehr weiter zunahm, ${ }^{232}$ war dies in erster Linie der vom Anfang an gegebenen, starken Konzentration der Großstädte auf relativ wenige Gebiete geschuldet. Da sich die Industrialisierung vor allem in ihnen und in ihrem Umfeld abspielte, wurde ein großer Teil der außerhalb der metropolitanen Großräume lebenden Menschen davon nur wenig bis gar nicht erfasst. Ende der 1970er Jahre entfielen rund drei Viertel der gesamten Industrieproduktion Lateinamerikas auf nur sechs Bundesstaaten bzw. Provinzen in nur drei Ländern, nämlich auf die Provinzen Buenos Aires und Santa Fe in Argentinien, die Bundesstaaten Rio de Janeiro und São Paulo in Brasilien sowie auf die Bundesstaaten México und Nuevo León mit den Ballungszentren Mexico City und Monterrey in Mexiko. ${ }^{233}$ In ihnen lebten weniger als 20 Prozent der damaligen Gesamtbevölkerung

232 Vgl. die fallenden Anteile des sekundären Sektors an den Erwerbstätigen nach Fischer Weltalmanach (2000) und Fischer Weltalmanach (2011).

233 Thorp (1998), $21 \mathrm{f}$. 
Lateinamerikas. ${ }^{234}$ Auch das restliche Viertel der lateinamerikanischen Industrieproduktion wurde großteils in nur wenigen Regionen, und zwar meist in den Hauptstadtregionen der einzelnen Länder wie Montevideo, Bogotá, Lima oder Santiago de Chile hergestellt. ${ }^{235}$

Wie einseitig und auf nur wenige Gebiete die Industrialisierung auch innerhalb der einzelnen Länder verteilt war, zeigt sich besonders deutlich am Beispiel Brasilien. Im Südosten des Landes mit den Bundesstaaten Rio de Janeiro, São Paulo, Minas Gerais und Espírito Santo lebten 1970 auf einem Zehntel der Landesfläche gut 40 Prozent der Bevölkerung, die mit zwei Dritteln aller Industriebeschäftigten für 80 Prozent der Industrieproduktion aufkamen. ${ }^{236} \mathrm{Ihr}$ relativ hoher Industrialisierungsgrad schlug sich auch in den durchschnittlichen Pro-Kopf-Einkommen nieder, die im Südosten um drei bis vier Mal so hoch waren wie im Norden und Nordosten sowie um die Hälfte höher als im Süden. ${ }^{237}$ Der Anteil der die Industrialisierung begünstigenden Millionenstädte an der Gesamtbevölkerung lag im Südosten mit Rio de Janeiro, São Paulo und Belo Horizonte bei knapp 30 Prozent, im Nordosten mit den damaligen Millionenstädten Recife und Salvador dagegen bei nur etwa 7 Prozent. $^{238}$

Die starke Konzentration nicht nur der anfänglichen, sondern auch der modernen Industrie auf die großen Metropolen deutet darauf hin, dass deren Industrieunternebmen ähnlich wie in Süd- und Osteuropa - dank steigender Produktivität in der Lage waren, den Großteil des auch in den jüngeren Großstädten wachsenden Bedarfes an Industriewaren zu decken. Anders als zu Beginn der Industrialisierung reichte die Nachfrage einer einzelnen Millionenstadt nicht mehr aus, um in ihr und um sie herum eine ähnlich große Industrieregion entstehen zu lassen, wie es bei den früher gewachsenen Großstädten der Fall war. Zum Zeitpunkt, als die neuen Millionenstädte entstanden - vor allem ab den 60er und 70 er Jahren des 20. Jahrhunderts - war die Konkurrenz der traditionellen Industriezentren zu groß, um eine nachholende Industrialisierung ähnlichen Ausmaßes zu erlauben.

Da der Anteil der Industrieregionen nicht nur an der Gesamtbevölkerung Lateinamerikas, sondern auch an der Bevölkerung der einzelnen Länder kleiner war als in West-, Mit-

234 Eigene Berechnung nach Mitchell (1998), 33 und 38 f. sowie Maddison (Population).

235 Vgl. Reichart (1993), 213 f. und 233. Nach Reichart waren zu Beginn der 80er Jahre 53 Prozent der Industriearbeiter in Mexico City beschäftigt, wo 21 Prozent der Bevölkerung lebten. In Argentinien arbeiteten 66 Prozent der Industriebeschäftigten im Industriegebiet von Buenos Aires und Rosario, in Kolumbien konzentrierten sie sich auf das industrielle Städtedreieck Bogotá, Medellín und Cali.

236 Merrick/Graham (1979) 10 und Faria (1989), Table 4.9.

237 Merrick/Graham (1979), 10 und 205.

238 Eigene Berechnung nach Mitchell (1998), 56 und 57 sowie Merrick/Graham (1979), 117. 
tel- und Nordeuropa oder in den USA und Kanada, fiel die durchschnittliche Wertschöpfung pro Einwohner in ihnen entsprechend niedriger aus. Trotz zum Teil erheblicher Unterschiede zwischen den einzelnen Ländern machte das Bruttoinlandsprodukt pro Einwohner in den größeren Ländern Lateinamerikas um die Jahrtausendwende lediglich ein Viertel bis die Hälfte der west- und mitteleuropäischen Werte aus und lag in etwa auf dem Niveau der osteuropäischen Länder. ${ }^{239}$

Wenn daher die Länder Lateinamerikas in ihrer Wertschöpfung pro Einwohner bis zuletzt hinter den älteren Industrieländern zurück blieben, lag dies weniger daran, dass in ihnen keine Industrialisierung stattfand, sondern vielmehr daran, dass in den einzelnen Ländern nur relativ wenige Regionen eine Industrialisierung erfuhren. Sie erlaubte einer Minderheit der Bevölkerung, dass sie sich einen ähnlich hohen Konsum von Industriewaren und Dienstleistungen leisten konnten wie die Menschen in den Industrieländern Europas und Nordamerikas. Im Durchschnitt der Gesamtbevölkerung jedoch bewegte sich das Konsumniveau sowohl quantitativ als auch qualitativ in einem viel bescheideneren Rahmen. Obwohl die Länder Lateinamerikas in der Ausstattung mit langlebigen, sowohl älteren als auch jüngeren Konsumgütern in den letzten Jahrzehnten erheblich aufholten (vgl. Grafik 15 und Grafik 16), blieben sie vom Niveau der frühen Industrieländer in Nordamerika und Europa noch weit entfernt (vgl. Grafik 7, Grafik 8, Grafik 17 und Tabelle 19). ${ }^{240}$

Der nach wie vor gegebene Rückstand erklärt sich allerdings nicht nur aus der regional begrenzten Industrialisierung, sondern auch aus der bis zuletzt niedrigeren, industriellen Produktivität. Wie die regionale Begrenzung trug auch sie dazu bei, dass die Wertschöpfung pro Einwohner und die durchschnittlichen Einkommen deutlich niedriger ausfielen als in den traditionellen Industrieländern. Ein Vergleich der Industrieproduktion pro Einwohner zeigt, dass um 2006 die industrielle Produktivität in West-, Mittel- und Nordeuropa ebenso wie in Kanada und den USA trotz nationaler Unterschiede die entsprechenden Werte in den größeren Ländern Lateinamerikas um das Vier- bis Fünffache übertraf. ${ }^{241}$ Wie schon aus dem Beispiel Ost- und Südeuropas ersichtlich wurde, gelang es den Unternehmen in den älteren Industrieländern offenbar besser als in den jüngeren, mit Hilfe ständig verbesserter Technologien und Produktinnovationen ihre industrielle Produktivität sowohl in quantitativer als auch in qualitativer Hinsicht in einem Tempo zu steigern, dass die anderen bestenfalls nachziehen, kaum jedoch gleichziehen konnten.

239 Maddison (Per Capita GDP).

240 Zum Vergleich mit Europa Tabelle.

241 Welt in Zahlen (Industrieproduktion) 
Grafik 15: Fernsehgeräte pro 1.000 Einwohner in Lateinamerika 1960-2006 (größere Länder)

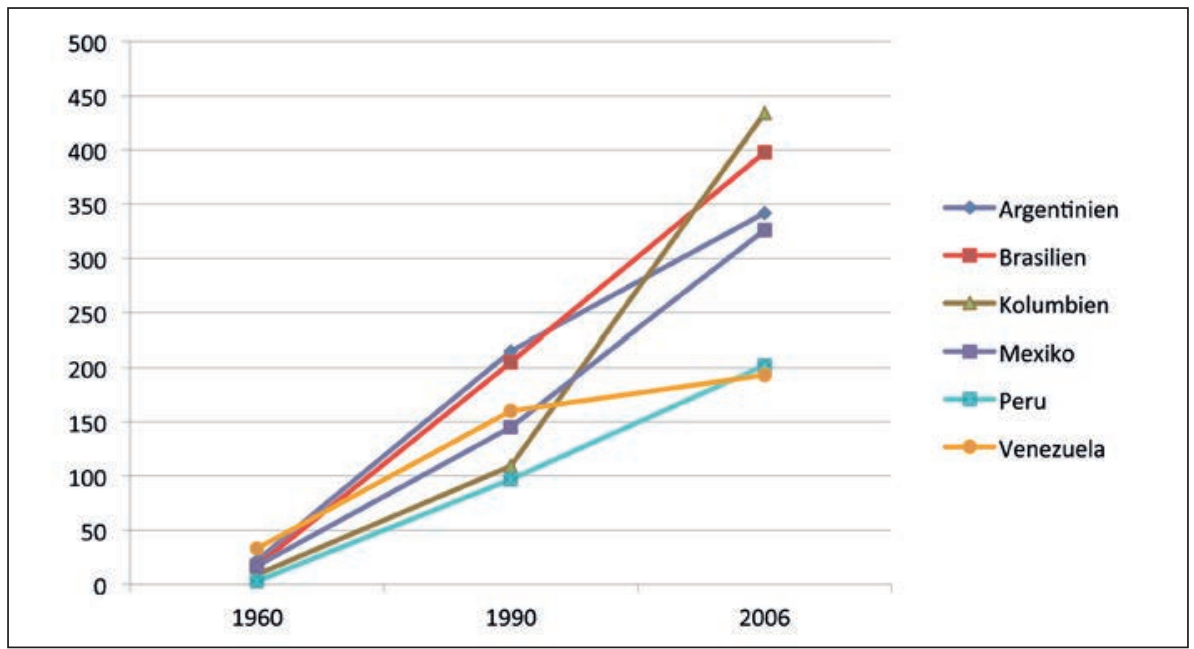

Vgl. Tabelle 19.

Grafik 16: PKW pro 1.000 Einwohner in Lateinamerika 1950-2006 (größere Länder)

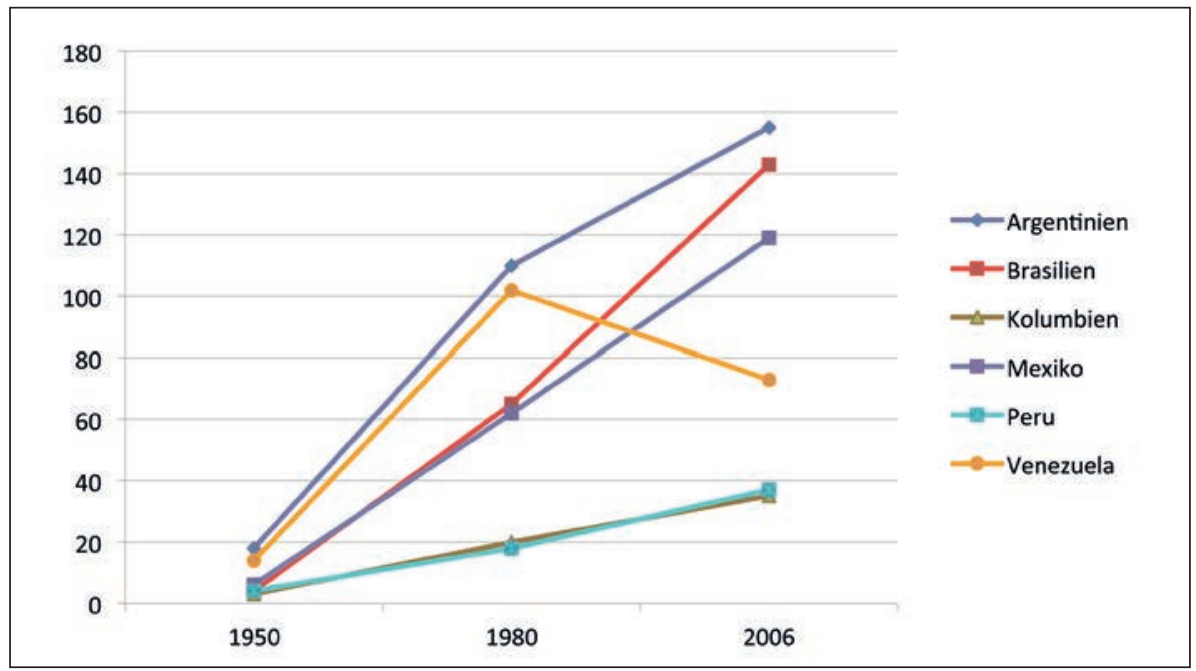

Vgl. Tabelle 19. 


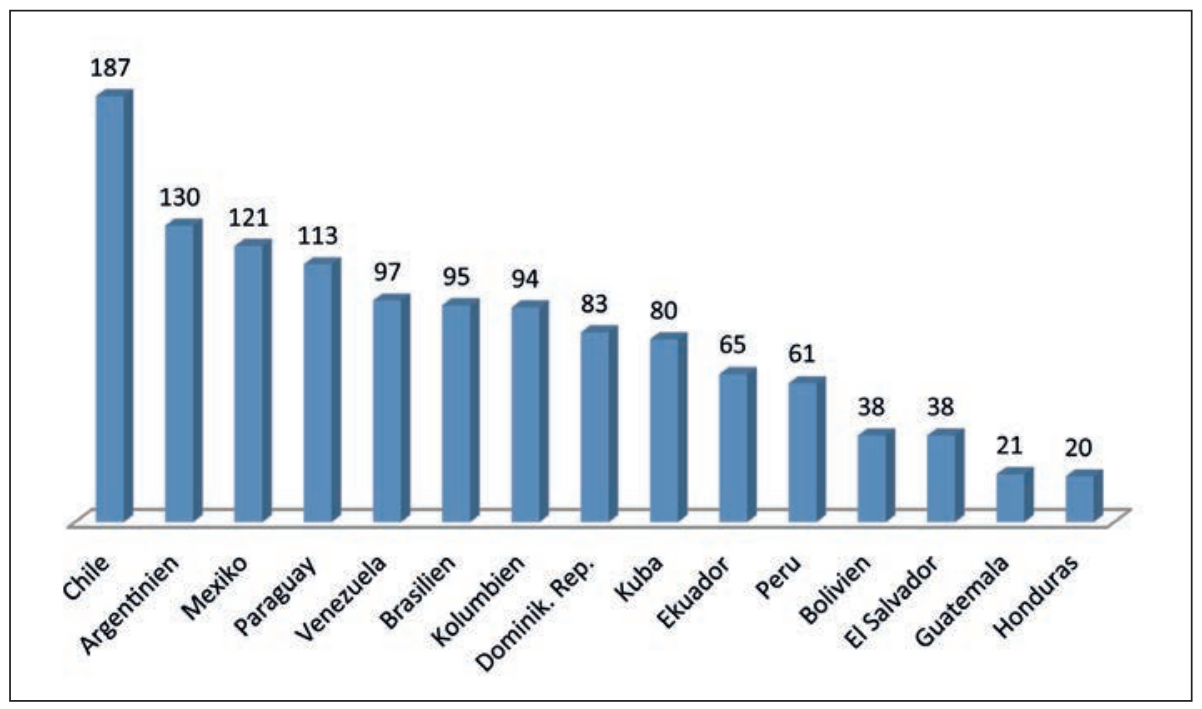

Welt in Zahlen (Computer).

Resümierend kann daher für Lateinamerika ähnlich wie für Ost- und Südeuropa festgehalten werden, dass dank eines zwar verspäteten, dann aber durchaus beachtlichen Industrialisierungsprozesses sowohl absolut als auch relativ Millionen von Menschen die lange Zeit vorherrschende, ländliche Armut hinter sich lassen konnten. Allerdings ist die Zahl der Menschen, denen dies bis heute nicht gelungen ist, noch immer wesentlich höher als in den breit industrialisierten Ländern Nordamerikas und des westlichen, mittleren und nördlichen Europa. Dies war zum einen dem späteren Beginn der Industrialisierung und zum anderen ihrer regionalen Konzentration auf wenige Zentren geschuldet. Beides war letztlich durch die Struktur der Urbanisierung bedingt. Dank einer lange Zeit relativ dünnen Bevölkerungsdichte entstanden großstädtische Ballungs- und Nachfragezentren später als in Nordamerika oder Europa, dank den Hauptquellen ihres Wachstums, nämlich Außenhandel und Verwaltung, blieben sie auf wenige Orte an den Küsten und die Landeshauptstädte beschränkt. Gleichzeitig kamen ihr Wachstum und die von ihnen ausgelöste Industrialisierung zumindest relativ auch deswegen nicht mehr Menschen zugute, weil sich die rasante Bevölkerungsvermehrung seit den 50er Jahren in hohem Maße in den ländlichen Gebieten außerhalb der Metropolen abspielte. Sie verhinderte, 
dass sich trotz der anhaltend starken Landflucht die Bevölkerungsstruktur rascher zugunsten der entwickelteren, d.h. industrialisierten, großstädtischen Regionen verschob. 



\section{Afrika}

In Afrika lassen sich mindestens drei Großregionen unterscheiden: die an das Mittelmeer grenzenden Länder des Nordens, die Länder des tropischen Afrika südlich der Sahara sowie Südafrika. Allen drei Großregionen war gemeinsam, dass in den jüngeren Jahrhunderten zwar noch viele Menschen als Jäger und Sammler oder als herumziehende Hirten lebten, die meisten jedoch zu einer sesshaften, landwirtschaftlichen Lebensweise übergegangen waren. Daneben gab es zahlreiche Handwerker und Kaufleute, und zwar - wie anderswo - vornehmlich in städtischen und stadtähnlichen Siedlungen. Allerdings blieben die Städte lange Zeit überaus klein und waren relativ weit voneinander entfernt. Noch um 1900 zählte man in ganz Afrika mit Kairo, Alexandria, Tunis, Algier und Fez im Norden, mit Kapstadt und Johannesburg im Süden sowie mit Ibadan im heutigen Nigeria erst acht Städte mit mehr als 100.000 Einwohnern; keine von ihnen hatte annähernd die Millionengrenze erreicht. ${ }^{242}$

Johannesburg um 1911

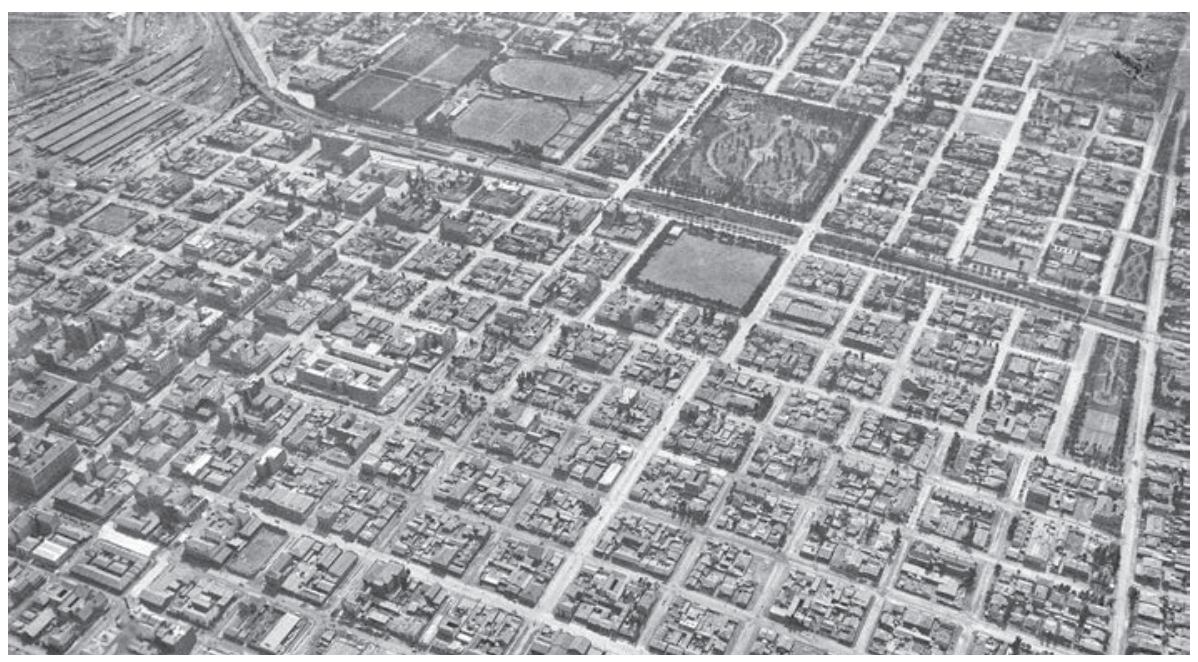

http://de.wikipedia.org/wiki/Johannesburg\#/media/File:CH-NB_-_Johannesburg_-_Eduard_Spelterini_-_EAD-WEHR-32110-B.tif

242 Mitchell (2007), 41. Vgl. auch Zeleza (1993), 75-77. 
Der überaus niedrige Urbanisierungsgrad war der dünnen Bevölkerungsdichte geschuldet. Obwohl die Schätzungen erheblich voneinander abweichen, dürften um 1600 auf dem ganzen Kontinent maximal um die 100 Millionen Menschen gelebt haben, also kaum mehr als in dem nur ein Drittel so großen Europa. ${ }^{243}$ Dank dem danach einsetzenden Sklavenhandel und der Verschleppung zahlreicher Afrikaner vor allem nach Amerika blieb auch in der Folge ein rascheres Wachstum der Bevölkerung aus. Im Gegenteil, nach manchen Einschätzungen ging sie sogar zurück ${ }^{244}$ und begann erst im 19. Jahrhundert wieder zu steigen - zunächst langsam, ab der Mitte des 20. Jahrhunderts jedoch rascher als auf jedem anderen Kontinent. ${ }^{245}$ Um 1900, als die Bevölkerung Europas auf über 400 Millionen angewachsen war, zählte man in Afrika noch immer erst etwas mehr als $100^{246}$ und um 1950 knapp 230 Millionen Menschen. ${ }^{247}$

In den Jahrzehnten danach „explodierte“ die Bevölkerung Afrikas in nur 50 Jahren auf rund 800 Millionen $^{248}$ und bis 2009 auf fast eine Milliarde Menschen (vgl. Tabelle 21). Der rasche Bevölkerungsanstieg der letzten Jahrzehnte resultierte fast ausschließlich aus den sinkenden Sterberaten und den lange Zeit gleich bleibenden, vormodernen und daher hohen Geburtenraten der einheimischen Bevölkerung. ${ }^{249}$ Die Zuwanderung aus Europa, die sich zunächst vor allem auf Südafrika und Algerien konzentrierte, seit dem Ende des 19. Jahrhunderts aber auch andere Teile Afrikas erfasste, machte lediglich einen Bruchteil der europäischen Auswanderung nach Amerika aus und trug nur unwesentlich zum Bevölkerungswachstum in Afrika bei. ${ }^{250}$

Dank des bis ins 20. Jahrhundert geringen Urbanisierungsgrades fand auch eine Industrialisierung vorerst nur in Ansätzen statt. ${ }^{251}$ Eine Marktwirtschaft größeren Zuschnittes, die über die Selbstversorgung hinausging, war vor allem im Außenhandel entstanden. Wie in Lateinamerika wurde er von in Europa nachgefragten Produkten der Landwirtschaft und des Bergbaus gespeist und brachte im Gegenzug europäische Fertigwaren

243 Bei Maddison (Population) sind 55, bei Mathieu (2011), 87, 113 Millionen angegeben.

244 Nach Mathieu (2011), 87 auf 102 Millionen im Jahre 1800.

245 Zur Bevölkerungsentwicklung vgl. ausführlich Zeleza (1993), 56-77.

246138 Millionen nach Mathieu (2011), 87 bzw. 110 Millionen nach Maddison (Population), zwischen 120 und 141 Millionen nach Zeleza (1993), 60.

247228 Millionen nach Maddison (Population).

248 Weniger als 800 nach Mathieu (2011), 87, über 800 Millionen nach Maddison (Population).

249 Vgl. Bairoch (1975), 5-12.

250 Vgl. Zeleza (1993), $73 \mathrm{f}$.

251 Zur Entwicklung von Industrie und Gewerbe im Detail vgl. Zeleza (1993), 175-251 und - etwas weniger - Austen (1987). 
nach Afrika. ${ }^{252}$ Ein etwas größeres Ausmaß erreichte die eigene industrielle Produktion im nördlichen und südlichen Afrika, wo die Dichte an Großstädten am höchsten war. 1950 entfielen mit Kapstadt, Johannesburg, Durban, Pretoria und Port Elizabeth allein fünf der inzwischen 30 Städte mit mehr als 100.000 Einwohnern auf Südafrika, obwohl die Republik nur rund 5 Prozent der Bevölkerung Afrikas stellte. 12 weitere Städte dieser Größenordnung fanden sich in den Anrainerstaaten des Mittelmeeres - also in Marokko, Algerien, Tunesien, Libyen und Ägypten -, mit Kairo als damals einziger Millionenstadt Afrikas.

Kairo um 2007

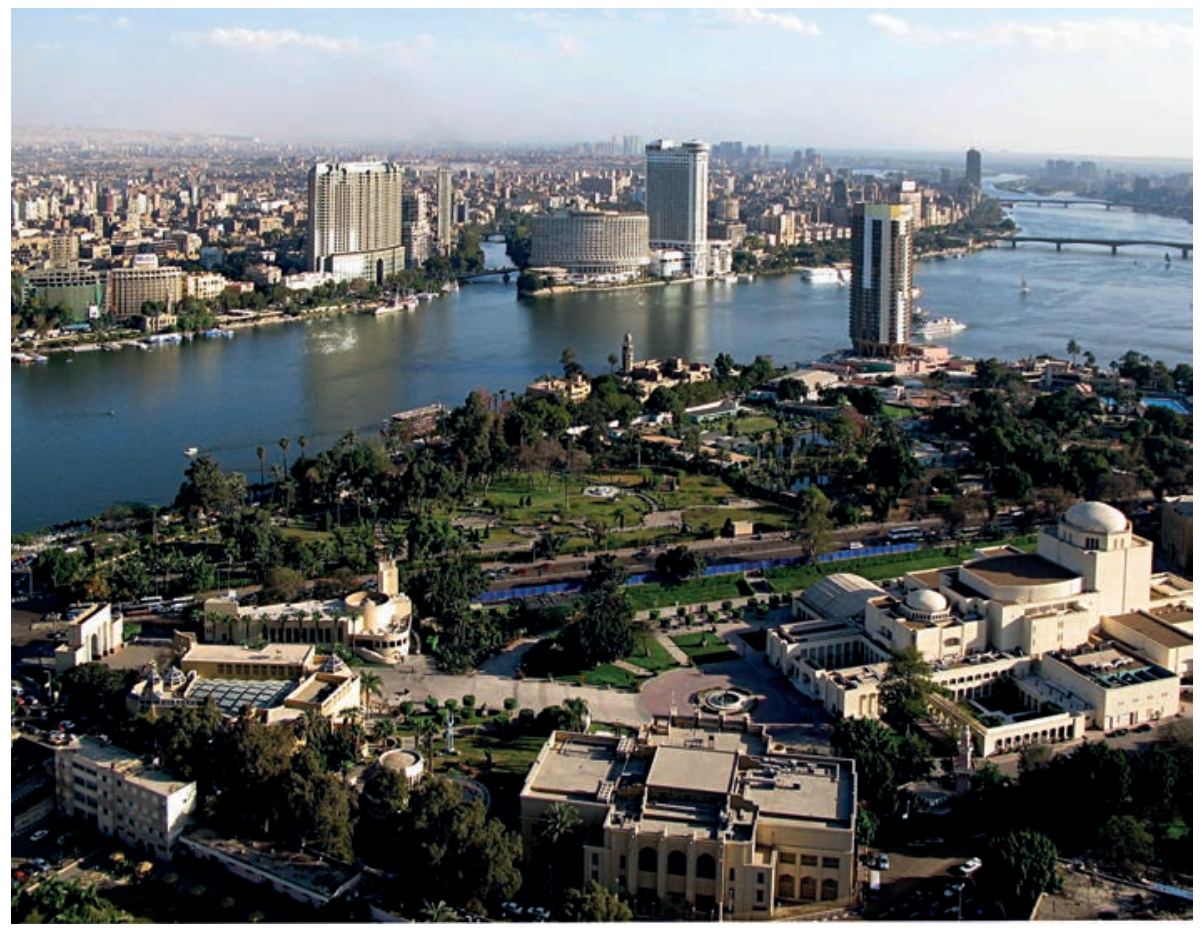

http://commons.wikimedia.org/wiki/File:View_from_Cairo_Tower_31march2007.jpg

252 Ausführlich bei Albertini (1985). 
Aber auch im urbanisierteren Süden und Norden des Kontinents blieb die Industrialisierung sehr bescheiden und ging zunächst kaum über größere Handwerksbetriebe hinaus. In Südafrika wurde nach dem starken Aufschwung des Edelmetallbergbaus seit dem letzten Viertel des 19. Jahrhunderts ein Teil der Gewinne auch in der Industrie investiert. ${ }^{253}$ Die Produktion von Industrie und verarbeitendem Gewerbe einschließlich Bau- und Energiewirtschaft stieg in der ersten Hälfte des 20. Jahrhunderts auf mehr als das Zehnfache, die der darin Beschäftigten auf mehr als das Fünffache. ${ }^{254}$ In Ägyten dauerte es nach den frühen, letztlich aber nur vorübergehenden Industrialisierungsversuchen, die um die Mitte des 19. Jahrhunderts vom Staat initiiert worden waren, weitere hundert Jahre, bis auf der Basis heimischer Rohbaumwolle eine größere Baumwollwarenindustrie entstand. ${ }^{255} \mathrm{Im}$ Zuge einer angestrebten Importsubstitution wurde ein Teil der geernteten Rohbaumwolle, die zuvor fast zur Gänze exportiert worden war, eigenen Baumwollfabriken zugeführt. 1960 verarbeitete mit 4,3 kg pro Kopf der Bevölkerung kein Land in Afrika annähernd so viel Rohbaumwolle zu Garnen und Stoffen wie Ägypten, das damit durchaus an kontinentaleuropäische Werte herankam; lediglich 1,2 kg waren es in Südafrika, immerhin etwa $2 \mathrm{~kg}$ auch im benachbarten Südrhodesien, dem heutigen Simbabwe. ${ }^{256}$ Innerhalb Ägyptens konzentrierte sich die Industrie, die durch einen relativ hohen Anteil staatlicher Unternehmen gekennzeichnet war und deren Produktion sich zwischen 1945 und 1970 etwa versechsfachte, auf die drei Großstadtzonen um Kairo, Alexandria und die Kanalzone mit Suez und Port Said. ${ }^{257}$

Eine nennenswerte Eisen- und Stahlproduktion zur zumindest teilweisen Abdeckung des heimischen Bedarfes entstand auf Initiative der Regierung und auf der Basis eigener Erze zunächst nur in Südafrika und Simbabwe sowie - in bescheidenerem Ausmaß - in Ägypten, Algerien und Tunesien. ${ }^{258}$ In diesem Fall war es Südafrika, dessen Roheisenproduktion sowohl absolut als auch pro Einwohner die der anderen Länder mit Ausnahme Simbabwes weit hinter sich ließ. 1961 lag die Pro-Kopf-Produktion in Südafrika bei etwa $140 \mathrm{~kg}$, im viel kleineren Simbabwe - es zählte damals weniger als 2 Millionen Einwohner - rund $122 \mathrm{~kg}$, in den nordafrikanischen Ländern dagegen bei kaum mehr als $10 \mathrm{~kg} .{ }^{259} \mathrm{Mit}$

253 Ausführlich zu Südafrika Feinstein (2005).

254 Feinstein (2005), 122 und Lal (1988), 201.

255 Mabro/Radwan (1978), 10-26; Albertini (1985), 187.

256 Eigene Berechnungen nach Mitchell (2007), 466 und Maddison (Population).

257 Mabro/Radwan (1978), 84 und 93-97.

258 Cooper (2002), 100; Feinstein (2005), 121.

259 Eigene Berechnungen nach Mitchell (2007), 440 und Maddison (Population). 
diesen Werten blieben Südafrika und Simbabwe zwar unter dem Niveau, das westeuropäische Länder am Vorabend des Ersten Weltkriegs erreicht hatten, übertrafen Ost- und Südeuropa jedoch deutlich (vgl. Grafik 3).

Dank der etwas breiteren Industrialisierung waren Südafrika und Ägypten damals auch die einzigen Länder, in denen der Anteil der Industrie und des verarbeitenden Gewerbes - gemessen an den statistisch erfassten Erwerbstätigen - über der 10-Prozent-Marke lag. Der Anteil der Landwirtschaft war in Südafrika auf rund 30 Prozent gesunken, während sie im restlichen Afrika - von kleineren Ländern wie Libyen und der Insel Mauritius abgesehen - zum Teil noch weit über die Hälfte aller Erwerbstätigen beschäftigte. ${ }^{260}$ Der höhere Industrialisierungsgrad Südafrikas spiegelte sich auch im gesamten Bruttoinlandsprodukt pro Einwohner wider. Mit Ausnahme Algeriens und Libyens sowie einiger kleinerer, atypischer Länder wie Gabun, Mauritius, Namibia, Réunion und den Seychellen mit zusammen lediglich 2 Millionen Einwohnern überstieg der von Angus Maddison errechnete Wert in Südafrika den der anderen Länder um mehr als das Doppelte, in der Mehrzahl der Fälle sogar um mehr als das Drei- bis Fünffache. ${ }^{261}$ Pro Einwohner produzierte die südafrikanische Wirtschaft um die Mitte des 20. Jahrhunderts ungefähr gleich viel wie Spanien, Portugal und Griechenland im südlichen oder Bulgarien und Polen im östlichen Europa. ${ }^{262}$

Die aktive Industrialisierungspolitik der südafrikanischen Regierungen, die außer vom Aufbau einer staatlichen Eisen- und Stahlproduktion von der Strategie der Importsubstitution getragen war, wurde in der zweiten Hälfte des 20. Jahrhunderts zum Teil auch von den Regierungen anderer, nunmehr unabhängiger Länder übernommen. ${ }^{263}$ Allerdings erzielten sie mangels ähnlicher struktureller Voraussetzungen nicht annähernd dieselben Ergebnisse wie Südafrika. Versuche, die geförderten Rohstoffe im eigenen Land einer industriellen Weiterverarbeitung zuzuführen, hielten sich in Grenzen. Stattdessen wurden sie zum größten Teil als Erze, Rohöl oder vereinzelt auch als Rohmetalle exportiert. ${ }^{264}$ Offenbar war die Aufnahmefähigkeit des Binnenmarktes für eine lohnende Weiterverarbeitung der Rohstoffe zu gering. Dank der raschen Bevölkerungszunahme nahm die Urbanisierung zwar auch in anderen Teilen des Kontinents stark zu - die Zahl der Groß-

260 Eigene Berechnungen nach Mitchell (2007), 96-102 und Maddison (Population).

261 Manche Länder lagen sogar noch weiter zurück. Maddison (Per Capita GDP) und Maddison (Population).

262 Maddison (Per Capita GDP).

263 Vgl. Cooper (2002), $100 \mathrm{f}$.

264 Helmschrott (1990), 16 und 135-160. 
stadtagglomerationen mit über einer Million Einwohner vervielfachte sich zwischen 1980 und 2010 von 11 auf über 50 (vgl. Karte 9 und Tabelle 22) (265 $^{2}$, doch handelte es sich meist um nur eine, und zwar in der Regel die Hauptstadt des jeweiligen Landes.

Karte 9: Millionenstädte in Afrika um 1980

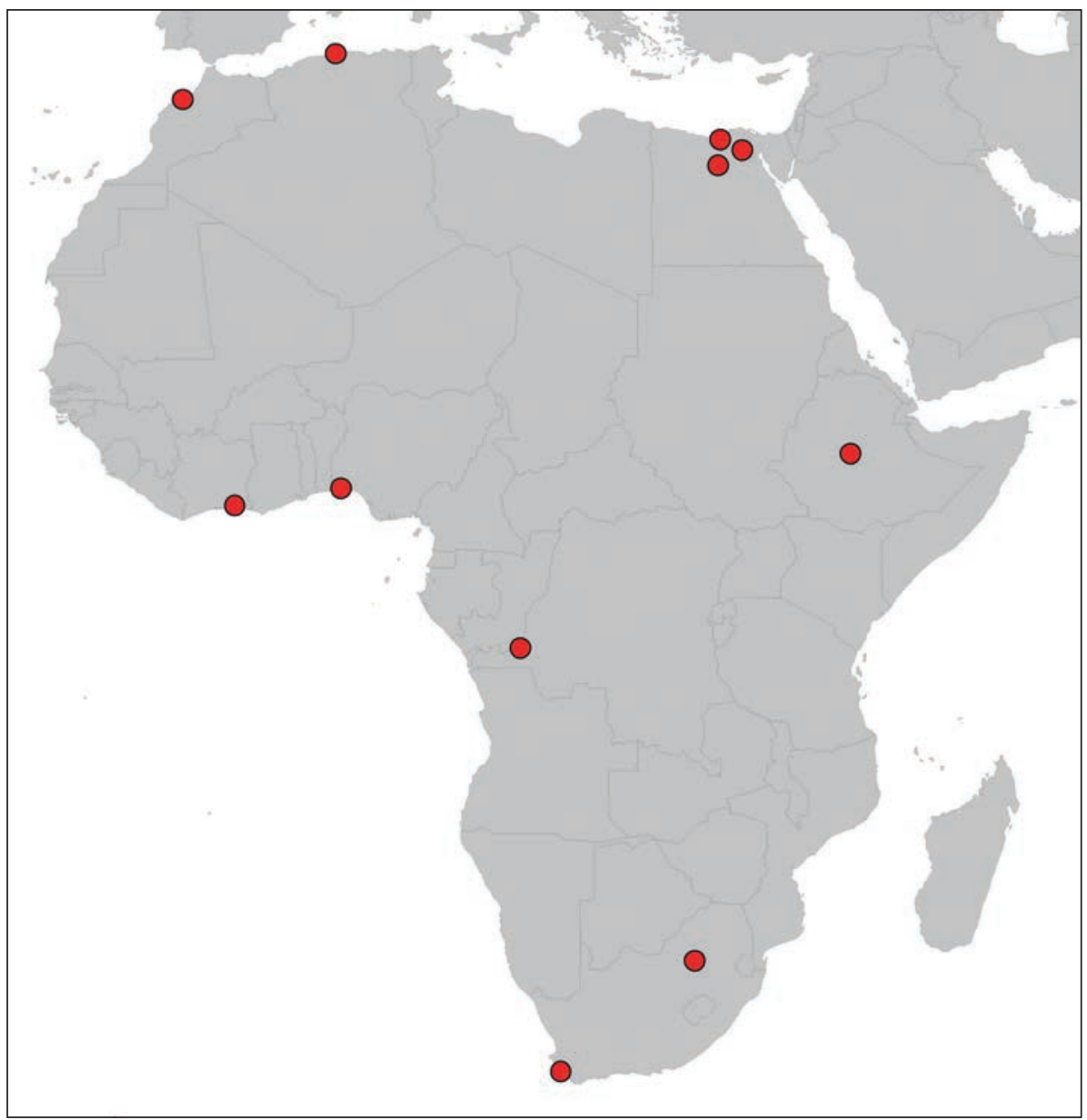

Tirol Atlas - Bearbeitung Klaus Förster nach Tabelle 22.

Kartenhintergrund: World Borders Dataset - http://thematicmapping.org/downloads/world_borders.php

265 Lions (2010), 18 und Liste der größten Städte Afrikas. 
Die von den Großstädten ausgehenden Industrialisierungsimpulse blieben weitgehend auf diese beschränkt und vielfach isoliert. Die nach wie vor umfangreichere, zum Teil weit verstreute und ebenfalls rasch wachsende Landbevölkerung wurde nur in beschränktem Maße miteinbezogen. Trotz einer gigantischen Landflucht, die die städtische Bevölkerung zwischen Nord- und Südafrika zuletzt um über 3 Prozent pro Jahr wachsen ließ, ${ }^{266}$ nahm auch die Landbevölkerung stark zu, zwischen 1950 und 2010 von etwa 200 auf rund 600 Millionen Menschen. ${ }^{267}$ Außerdem setzte sich die städtische Bevölkerung vor allem im Afrika südlich der Sahara in überdurchschnittlich hohem Maße aus wenig kaufkräftigen Slumbewohnern zusammen, was die positive Wirkung der Großstädte auf die wirtschaftliche Entwicklung reduzierte. Während der Anteil der Slumbevölkerung an den Städten Nordafrikas nach Berechnungen der UNO zwischen 1990 und 2005 von 38 auf 14,5 Prozent zurückging, lebten südlich der Sahara trotz sinkender Tendenz noch immer rund 200 Millionen oder 62 Prozent der Stadtbevölkerung in Slums. ${ }^{268}$ Sie siedelten sich zwar in und im Umfeld der großen Städte an, waren jedoch eher der wirtschaftlich wenig entwickelten, armen Landbevölkerung zuzurechnen.

So kam es, dass zwar in allen Ländern speziell in den größeren Städten sowohl die Industrieproduktion als auch die Industriebeschäftigung stark zunahmen, gleichzeitig aber ihr relatives Gewicht wegen der nach wie vor umfangreichen ländlichen Bevölkerung und der zahlreichen Slumbewohner überaus gering blieb. In den meisten der 30 Länder, für die von Brian Mitchell Statistiken erstellt wurden, stieg der Anteil der in der Industrie und im verarbeitenden Gewerbe beschäftigten Erwerbstätigen bis zur Jahrhundertwende auf maximal 10 oder weniger Prozent an. ${ }^{269}$ In den anderen erreichte der entsprechende Anteil am Höhepunkt ihrer Industrialisierung zwischen 11 Prozent in Ghana und 22 Prozent in Marokko (vgl. Grafik 18). ${ }^{270}$

266 Urbanisierung (2011), 4.

267 Eigene Berechnungen nach Urbanisierung (2011), 3 und Maddison (Population).

268 Urbanisierung (2011), 4.

269 Eigene Berechnungen nach Mitchell (2007), 96-102.

270 Lediglich im kleinen und atypischen Mauritius, wo zuletzt rund die Hälfte der rund eine Million Einwohner zählenden Bevölkerung in der Hauptstadtagglomeration von Port Louis lebte, fiel der Anteil mit im Jahre 1995 rund 43 Prozent deutlich höher aus. 
Nairobi, Slum Kibera, um 2000

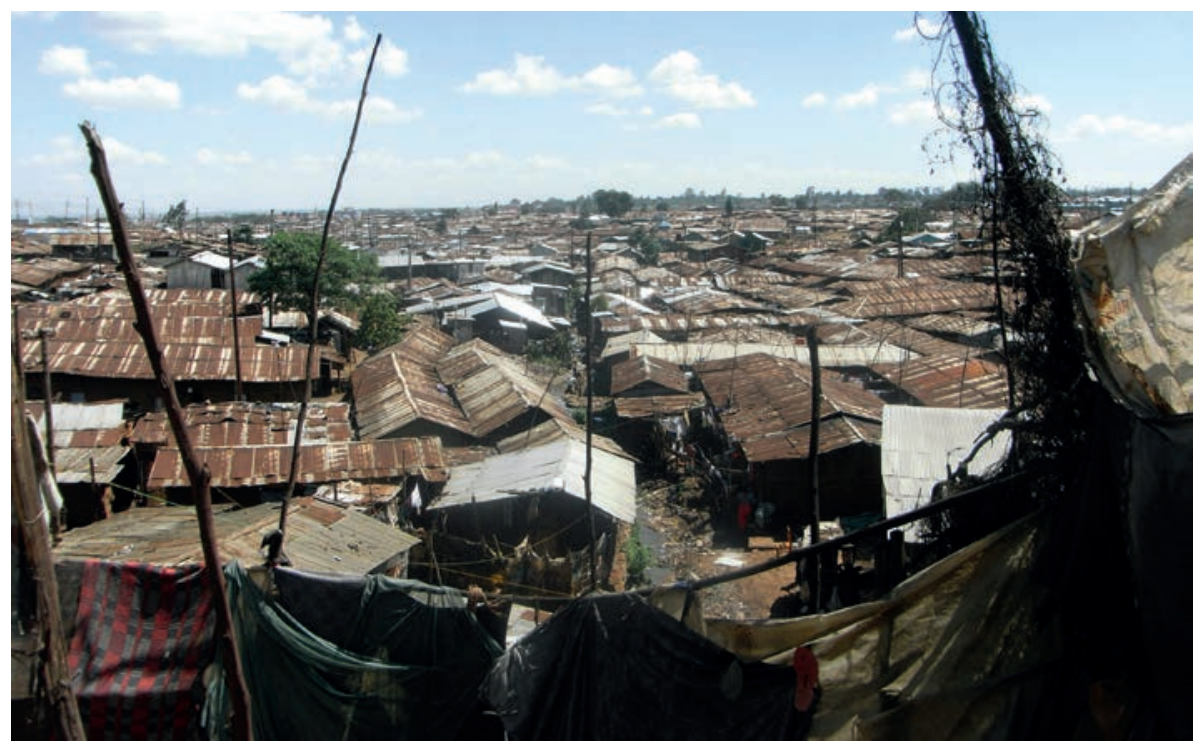

http://commons.wikimedia.org/wiki/File:Nairobi_Kibera_01.JPG

Grafik 18: Erwerbstätige in Industrie und verarbeitendem Gewerbe in Afrika 1980-1996

(Prozent aller Erwerbstätigen, Höchstwerte)

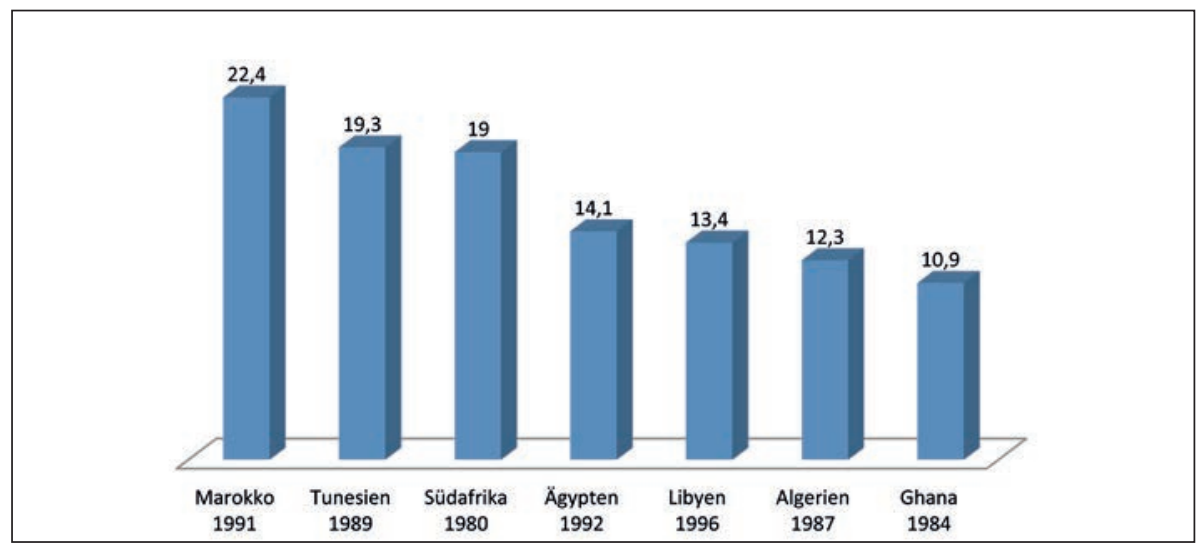

Eigene Berechnungen nach Mitchell (2007), 96-102. 
Ab den 80er und 90er Jahren begann der Anteil der Industriebeschäftigten wieder zu sinken, obwohl er noch weit von den Spitzenwerten der europäischen und nordamerikanischen Industrieländer entfernt war. Wie in diesen erfolgte der relative Rückgang der Industrie zugunsten des rasch wachsenden Dienstleistungssektors. ${ }^{271}$

Ein ähnliches, wenn auch nicht für alle Länder gleiches Bild wie die Beschäftigung liefert die industrielle Produktion. Im Zuge der überall zu beobachtenden Industrialisierung nahm sie zunächst bis in die 70er Jahre schneller zu als die Bevölkerung. ${ }^{272}$ Schon bald jedoch stieß die Strategie der Importsubstitution an ihre Grenzen. Während die industrielle Produktion in den Ländern südlich der Sahara ohne Südafrika zwischen 1965 und 1973 jährlich um durchschnittlich 10 Prozent gewachsen war, schwächte sie sich in den verbleibenden 70er Jahren auf 8 Prozent ab und lag zwischen 1980 und 1987 bei weniger als einem Prozent. ${ }^{273}$ Die Industrieproduktion hinkte in mehreren Ländern hinter dem Bevölkerungswachstum her und legte zum Teil erst in jüngerer Zeit wieder zu. In Südafrika etwa stieg die Industrieproduktion pro Einwohner nach einem Rückgang in den 80er und 90er Jahren erst nach der Jahrhundertwende wieder an. In Ghana war dies nach einem kurzen, aber heftigen Einbruch in den 70er Jahren ab etwa 1983 der Fall. Spätestens seit den 80er Jahren blieb die Industrieproduktion auch in Senegal, Simbabwe und Zaire hinter dem Bevölkerungswachstum zurück, in Algerien und Malawi etwas später. Dagegen setzte sich der Industrialisierungsprozess, gemessen an der Pro-Kopf-Produktion, in Ägypten zumindest bis zur Jahrhundertwende, in Marokko und Tunesien auch darüber hinaus fort. ${ }^{274}$

Der diskontinuierliche Industrialisierungsprozess der afrikanischen Länder spiegelt sich auch in der Entwicklung einzelner Branchen wider. Obwohl inzwischen auch in anderen Ländern eine Baumwollwarenindustrie entstanden war, konnte Ägypten bis zuletzt seine Spitzenposition behaupten, obwohl die Verarbeitung von Robbaumwolle pro Einwohner nach einem Rekordwert von knapp $8 \mathrm{~kg}$ im Jahre 1981 bis zum Ende des Jahrhunderts auf etwa $6 \mathrm{~kg}$ zurückfiel. Einen ähnlichen Wert erreichte Simbabwe 1995, wogegen sie sich in Südafrika seit Mitte der 60er Jahre zwischen 2 und $3 \mathrm{~kg}$ einpendelte, gefolgt von Algerien, Marokko und Nigeria mit zuletzt etwa 1,5 kg. Noch niedriger fielen die Werte aus, die in den 70er und 80er Jahren in Zaire, Äthiopien und im Sudan erzielt wurden. ${ }^{275}$

271 Mitchell (2007), 96-102.

272 Der Befund ergibt sich aus den Daten von 12 Ländern, dürfte aber auch für die anderen Länder zutreffen. Eigene Berechnungen nach Mitchell (2007), 365 f. und Maddison (Population).

273 Sub-Saharan Africa (1989), 223.

274 Eigene Berechnungen nach Mitchell (2007), 365 f. und Maddison (Population).

275 Eigene Berechnungen nach Mitchell (2007), 466 und Maddison (Population). 
In der Roheisenproduktion verzeichnete Südafrika um 1980 sowohl absolut als auch relativ den für ganz Afrika mit Abstand höchsten Wert von $302 \mathrm{~kg}$ Roheisen pro Einwohner. Es folgten Simbabwe mit etwas über 100 (1982) sowie Algerien mit circa 60 (1988), Tunesien mit 20 (2000) und Ägypten mit nur $12 \mathrm{~kg}$ (1973). ${ }^{276}$ Bezeichnend für die späte und nur schwach ausgeprägte Industrialisierung in Afrika war auch, dass keine eigenständige Automobilproduktion entstand. Stattdessen begnügte man sich mit dem Zusammenbau importierter Automobilteile, dem sog. Assembling. Die Stückzahlen der auf diese Weise hergestellten Autos entwickelten sich unregelmäßig und mit Ausnahme Südafrikas in sehr bescheidenem Rahmen. In Südafrika stieg die Zahl der zusammengebauten PKW von knapp 40.000 in den 50er Jahren auf über 300.000 zu Beginn des neuen Jahrhunderts. In Marokko als dem nächst größeren Herstellerland waren es in den 90er Jahren weniger als 100.000. Dies entsprach sieben bzw. drei PKW pro 1000 Einwohner in Ländern wie Deutschland, Frankreich oder Kanada waren es in den Spitzenzeiten über 50 Stück (vgl. Tabelle 7 und Tabelle 18). ${ }^{277}$

Neben dem Anteil der Industrieproduktion an der gesamten Wertschöpfung blieb auch die industrielle Produktivität als solche meist weit hinter den hoch entwickelten Industrieländern Europas und Nordamerikas zurück. Aus der Produktion des sekundären Sektors und der Zahl der darin Beschäftigten lässt sich für den Beginn des neuen Jahrhunderts eine Arbeitsproduktivität errechnen, die in den meisten Fällen mit den ärmeren und nur in wenigen Fällen wie Algerien, Libyen, Gabun und Südafrika mit den etwas produktiveren Ländern Osteuropas vergleichbar war. ${ }^{278}$

Wie aber lässt es sich erklären, dass trotz fortschreitender Urbanisierung der bescheidene Industrialisierungsprozess ins Stocken geriet, bevor er sich breiter entfalten konnte? Drei Antworten bieten sich an: Zunächst stieg auch in Afrika die industrielle Produktivität trotz ihrer relativen Rückständigkeit an, weshalb zuletzt weniger Arbeitskräfte als zuvor notwendig waren, um die im Wesentlichen auf die größeren Städte beschränkte Nachfrage nach Industriewaren zu decken. Zum zweiten wurde der großstädtische Markt zu einem guten Teil mit Importen beliefert, was die Absatzchancen für potentielle heimi-

276 Eigene Berechnungen nach Mitchell (2007), 440 und Maddison (Population).

277 Eigene Berechnungen nach Mitchell (2007), 501 und Maddison (Population).

278 Eigene Berechnungen nach Welt in Zahlen (Industrieproduktion) und Mitchell (2007), 96-102. Die nur beschränkte Industrialisierung verhinderte auch größere Fortschritte in der Bekämpfung des Hungers. Während die Zahl der unterernährten Menschen laut FAO trotz rasch wachsender Gesamtbevölkerung seit 1992 weltweit von über einer Milliarde auf rund 800 Millionen zurückging, stieg sie in Afrika von 182 auf 227 Millionen an. „Die Zeit“ vom 29. 04. 2015, 24. 
sche Industriebetriebe begrenzte. Zum dritten begann ein Teil der großstädtischen Konsumenten, dessen Bedarf an Industriegütern teilweise befriedigt war, wie in den hoch entwickelten Industrieländern in zunehmendem Maße Dienstleistungen nachzufragen.

Zur Bedeutung der Importe für die Deckung des großstädtischen Bedarfes eignet sich der wachsende und gut dokumentierte $P K W$-Bestand in den einzelnen Ländern besonders gut, da nur Südafrika, Marokko und Ägypten über eine nennenswerte, eigene Automobilproduktion verfügten. Die PKW-Dichte wuchs mit fortschreitender wirtschaftlicher Entwicklung insbesondere in den Metropolen, blieb aber, wenn sie auf das ganze Land berechnet wird, überaus bescheiden (vgl. Grafik 19 und Tabelle 23). Sogar in den entwickelteren Ländern Libyen, Algerien, Tunesien und Marokko im Norden sowie Südafrika und Simbabwe im Süden erreichten sie lediglich Werte wie in den ärmeren Ländern Osteuropas (vgl. Tabelle 10).

Grafik 19: PKW pro 1.000 Einwohner in Afrika 2006

(größere Länder, über 20 Stück)

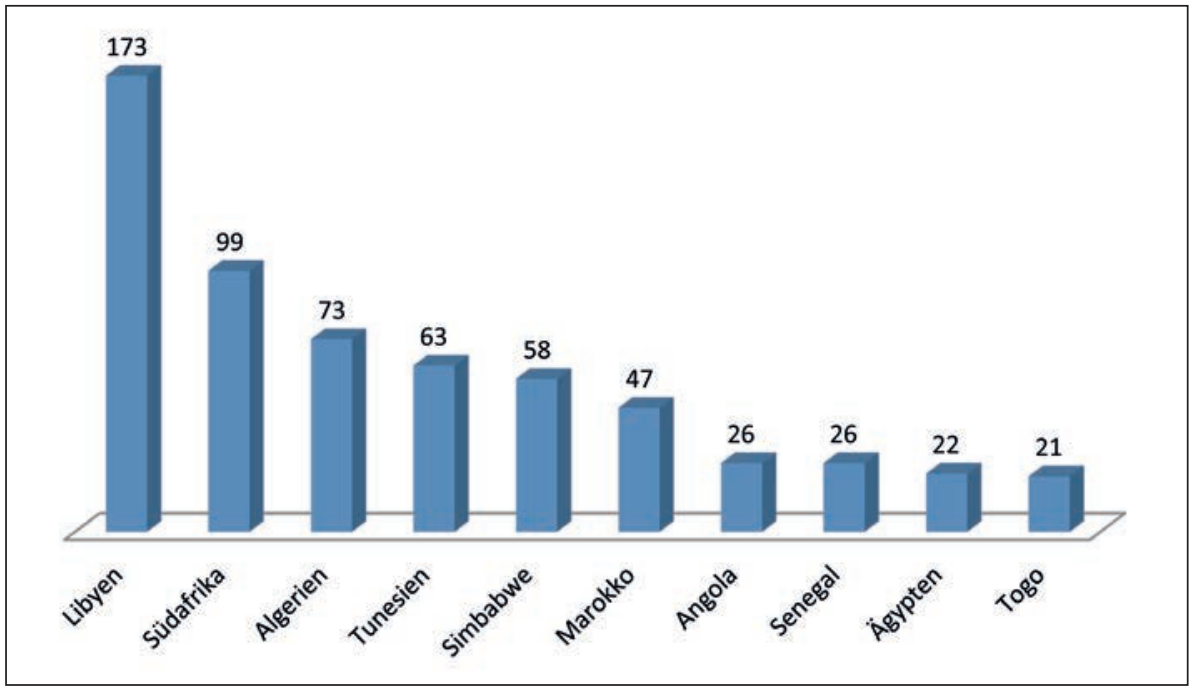

Welt in Zahlen (PKW).

Die niedrige PKW-Dichte ist nicht nur auf das statistisch geringe Gewicht zurückzuführen, das den Großstädten an der jeweiligen Gesamtbevölkerung zukam, 
sondern auch auf den relativ kleinen Teil der großstädtischen Bevölkerungen selbst, der über eine entsprechende Kaufkraft verfügte. Immerhin wuchs die Zahl der kaufkräftigen Konsumenten in einem Ausmaß, dass die Zahl importierter Autos in den meisten Ländern mit der Bevölkerungszunahme Schritt halten konnte und in manchen sogar deutlich über sie hinausging.

Ein ähnliches Bild bietet die Ausstattung mit weniger aufwändigen Konsumgütern wie Fernsehapparaten oder - in jüngerer Zeit - Computern. Abgesehen von einigen nicht ganz glaubwürdigen Zahlen bestätigen die in den Grafiken 20 und 21 sowie in der Tabelle 23 angeführten Werte einmal mehr den höheren Entwicklungsstand Südafrikas und der nordafrikanischen Länder. Von den kleineren Ländern erreichten neben Libyen zuletzt auch Gabun, Swasiland, Dschibuti und Togo sowie bei den Computern auch Namibia und Gambia ähnliche Werte. Wie bei den Autos kamen aber auch diese Länder bei den Fernsehgeräten mit Ausnahme von Bosnien-Herzegowina an keines und bei der ProKopf-Ausstattung mit Computern lediglich an die ärmsten der europäischen Länder heran (vgl. Tabelle 8). ${ }^{279}$ Typisch für den niedrigen Entwicklungsstand waren auch die bei allen drei Gütern feststellbaren, überaus großen Unterschiede zwischen den einzelnen Ländern, die sich in der Regel erst bei fortschreitender Entwicklung abschwächen.

Grafik 20: Fernsehgeräte pro 1.000 Einwohner in Afrika 2006

(größere Länder, über 100 Stück)

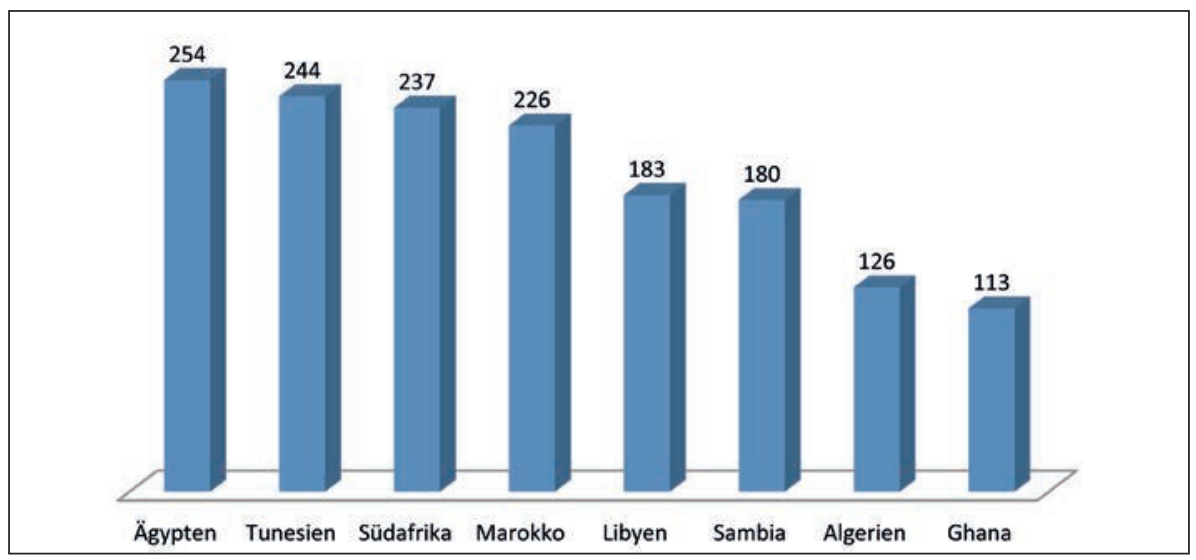

Welt in Zahlen (Fernsehgeräte).

279 Welt in Zahlen (Fernsehgeräte). 
Grafik 21: Computer pro 1.000 Einwohner in Afrika 2006

(größere Länder, über 20 Stück)

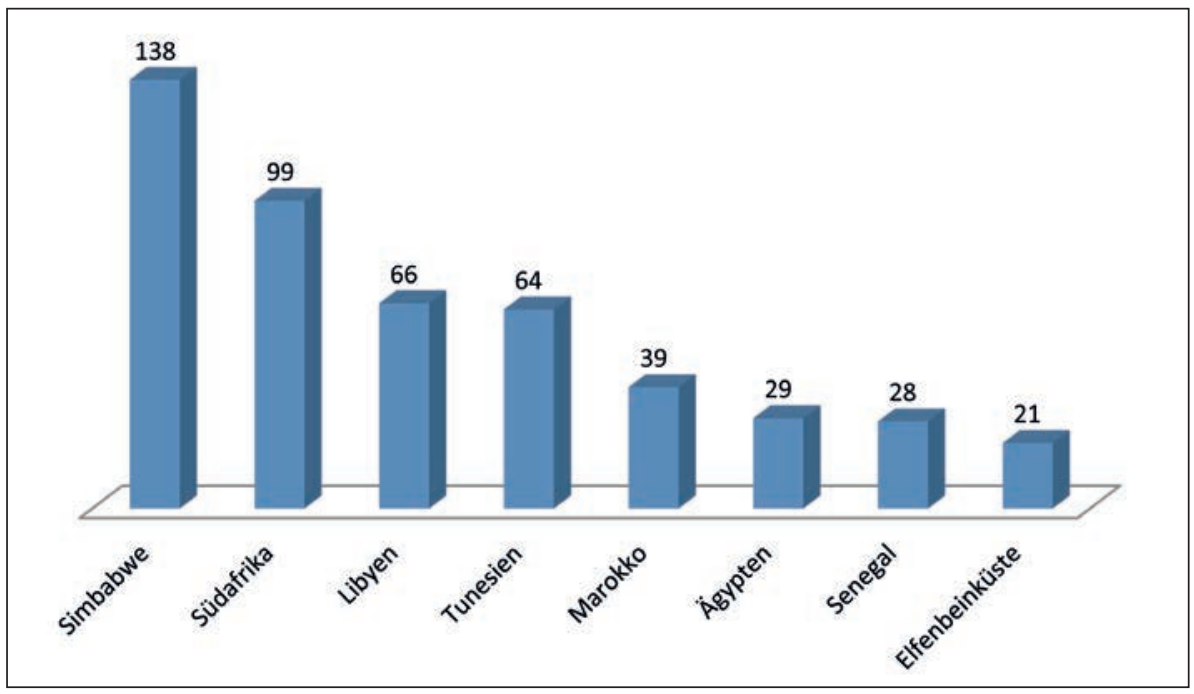

Welt in Zahlen (Computer).

Angesichts einer nur punktuellen Industrialisierung kam anderen Einkommensquellen wie dem Export landwirtschaftlicher Produkte oder mineralischer Rohstoffe einschließlich des Erdöls oder den Geldern aus Staatsanleihen und der Entwicklungshilfe eine entsprechend größere, wenn auch von Land zu Land unterschiedliche Bedeutung zu. ${ }^{280}$ Exportorientierte Landwirtschaft, Bergbau und Außenhandel verhalfen nicht nur privaten Wirtschaftstreibenden zu Einkommen und Löhnen, sondern auch den Regierungen sei es über direkte Beteiligungen des Staates etwa an Bergbauunternehmen, sei es über Steuern oder andere Abgaben - zu nicht unerheblichen Einnahmen. Die Einnahmen der Regierungen ermöglichten den Aufbau eines relativ umfangreichen öffentlichen Beschäftigungssektors sowie staatliche Investitionen etwa in die Infrastruktur, wodurch außer in privaten Unternehmen auch im staatlichen Bereich Einkommen und Kaufkraft geschaffen wurden. ${ }^{281}$

280 Moyo (2001), 114

281 Vgl. Helmschrott (1990), 17, wo die Staatsausgaben eher negativ beurteilt werden. 
Die auf diese Weise geschaffene Kaufkraft ermöglichte nicht nur den Import industrieller Fertigwaren, sondern ließ in den großstädtischen Zentren auch eine zunehmende Nachfrage nach privaten wie öffentlichen Dienstleistungen entstehen. So kam es, dass trotz relativ geringer Industrialisierung der tertiäre Sektor speziell in den Großstädten expandierte und zuletzt in den meisten Ländern Afrikas mehr zur formell gemessenen, gesamtwirtschaftlichen Wertschöpfung beitrug als die beiden anderen Wirtschaftssektoren (vgl. Tabelle 24).

Laut einer Studie zu 15 Ländern, die 80 Prozent der gesamtafrikanischen Wertschöpfung auf sich vereinigten, trugen Industrie und verarbeitendes Gewerbe zwischen 2002 und 2007 lediglich 9 Prozent zum gesamtwirtschaftlichen Wachstum bei, die Dienstleistungen hingegen 50 Prozent. Weitere 36 Prozent des Wachstums entfielen auf Rohstoffe und landwirtschaftliche Produkte, 5 Prozent auf das Bauwesen. ${ }^{282}$ Derselbe Trend lässt sich - wie bereits erwähnt - in der Struktur der Erwerbstätigen beobachten. In sechs der sieben Länder, für die entsprechende Zahlen vorliegen, ${ }^{283}$ nahm der relative Anteil des Dienstleistungssektors in den ersten Jahren des 21. Jahrhunderts rascher zu als der Anteil des sekundären Sektors. ${ }^{284}$

Auf diese Weise konnte sich abseits der von der Industrialisierung kaum erfassten Landbevölkerung eine großstädtische Dienstleistungsgesellschaft entwickeln. Es entstand eine dualistische Wirtschaftsstruktur mit einem relativ schmalen, großstädtischen Segment, das durchaus mit den urbanen Zentren der Industrieländer vergleichbar war, und einer nach wie vor großen und trotz anhaltender Landflucht wachsenden, ländlichen Bevölkerung. Letztere umfasste in einzelnen Ländern wie Burundi, Ruanda oder Botswana noch um die Jahrhundertwende zwischen 80 und gut 90 Prozent der Gesamtbevölkerung. ${ }^{285}$ Das städtische Segment war bereits durch einen hohen Anteil an Dienstleistungen gekennzeichnet, während die Mehrheitsbevölkerung am Land weitgehend in vorindustriellen Verhältnissen lebte.

Trotz der Fortschritte im modernen Segment war das Gewicht der weniger entwickelten Bevölkerungsteile derart groß, dass die durchschnittliche Wertschöpfung pro Einwohner deutlich hinter den breiter entwickelten Ländern zurückblieb und die Länder Afrikas als Ganze bis zuletzt nur einen sehr niedrigen Entwicklungsstand aufwiesen. 2008 erreichte

282 Lions (2010), 2.

283 Burkina Faso, Äthiopien, Mosambik, Ruanda, Tansania, Uganda, Nigeria.

284 Outlook (2013), 37.

285 Eigene Berechnungen nach Mitchell (2007), 96-102 und Maddison (Population). 
das Bruttoinlandsprodukt pro Einwohner sogar in den am weitesten entwickelten Ländern Tunesien, Südafrika, Namibia und Botswana lediglich ein Viertel bis ein Fünftel des west- und mitteleuropäischen Durchschnitts. ${ }^{286}$ Noch weiter zurück lagen naturgemäß die 18 ärmsten Länder des Kontinents, die zusammen etwa ein Drittel der afrikanischen Gesamtbevölkerung stellten. ${ }^{287}$ Ihre Wertschöpfung pro Einwohner machte nur ein Viertel oder weniger der ärmsten europäischen Länder am Balkan und im äußersten Osten Europas aus.

Der erhebliche Entwicklungsrückstand der afrikanischen Länder - dies gilt es resümierend noch einmal festzuhalten - ist weniger das Ergebnis einer ausbleibenden oder zu langsamen Industrialisierung, sondern liegt vielmehr darin begründet, dass die auch in Afrika stattgefundene Industrialisierung auf nur wenige „Inseln“ in der Form großstädtischer Zentren beschränkt blieb. Gemeinsam mit der nachhinkenden industriellen Produktivität hatte die nur schmale Industrialisierung zur Folge, dass sich die gesamtstaatliche Wertschöpfung pro Einwohner trotz einem viel niedrigeren Ausgangsniveau und einem dementsprechend stärkeren Nachholbedarf zwischen 1950 und 2008 lediglich verdoppelte, ${ }^{288}$ während sie sich in West-, Mittel- und Nordeuropa im selben Zeitraum mehr als vervierfachte. Auch in den USA und in Kanada stieg sie auf das Dreieinhalbfache an. Allerdings waren die Menschen in Afrika von der wachsenden Einkommenskluft zwischen ihrem Kontinent auf der einen und Europa bzw. Nordamerika auf der anderen Seite nicht - wie die staatlichen Durchschnittswerte vermuten lassen könnten - im selben Ausmaß betroffen. Vielmehr fiel der Abstand zwischen vorindustrieller Armut in Afrika auf der einen und postindustriellem Wohlstand in Europa und Nordamerika auf der anderen Seite bei der Mehrheit der Landbevölkerung und der großstädtischen Slumbevölkerung wesentlich größer aus als bei der relativ schmalen Minderheit der kaufkräftigen städtischen Mittel- und Oberschichten, die in ihrem Einkommen und ihrem Lebensstil durchaus an die in den entwickelten Ländern erreichten Standards herankamen.

286 Die deutlich höheren Werte der kleinen Länder Äquatorialguinea und Mauritius stellen kaum repräsentative Sonderfälle dar.

287 Burundi, Tschad, Niger, Äthiopien, Guinea, Guinea Bissau, Malawi, Tansania, Liberia, Madagaskar, Sierra Leone, Eritrea, Somalia, Sambia, Simbabwe, Togo, Zentralafrikanische Republik, Demokratische Rep. Kongo, die 2008 pro Einwohner ein Bruttoinlandsprodukt von weniger als 1.000 Dollar aufwiesen. Maddison (Per Capita GDP).

288 Unter den größeren Ländern wuchs sie lediglich in Tunesien und Ägypten deutlich rascher. Maddison (Per Capita GDP). 



\section{Asien}

Angesichts der Größe Asiens, das mit rund 45 Millionen Quadratkilometern fast ein Drittel der kontinentalen Landmasse und mit etwa 4 Milliarden Menschen mehr als die Hälfte der gesamten Erdbevölkerung auf sich vereinigt, empfiehlt es sich, den Kontinent bezüglich seiner wirtschaftlichen Entwicklung in mehrere Großregionen zu unterteilen. Unter Berücksichtigung geographischer Faktoren und der Bevölkerungsgröße lassen sich fünf solche Großregionen unterscheiden:

1. Nord- und Zentralasien mit rund 100 Millionen Menschen, die sich auf den asiatischen Teil Russlands östlich des Uralgebirges sowie auf die Mongolei, Kasachstan und das Gebiet zwischen Turkmenistan und Kirgisistan verteilen.

2. Westasien mit zuletzt knapp 300 Millionen Menschen zwischen dem Mittelmeer, dem Kaukasus und dem Arabischen Meer.

3. Südasien mit fast eineinhalb Milliarden Menschen, die vor allem in Afghanistan, Pakistan, Indien und Bangladesch leben.

4. Südostasien mit über einer halben Milliarde Menschen zwischen Myanmar, Indonesien und den Philippinen.

5. Ostasien mit der Volksrepublik China, Japan, den beiden Koreas und Taiwan mit zusammen gut eineinhalb Milliarden Einwohnern.

Wie in anderen Teilen der Welt gab es im 19. Jahrhundert auch in Asien noch viele Menschen, die wie ihre Vorfahren als Jäger und Sammler lebten. Die allermeisten jedoch waren - und zwar früher als anderswo - zu einer sesshaften Lebensweise übergegangen. Ebenfalls bereits vor mehreren tausend Jahren entstanden in manchen Regionen erste Städte, deren Bewohner nicht-landwirtschaftlichen, gewerblichen Tätigkeiten nachgingen. Allerdings variierten Urbanisierungsgrad und Bevölkerungsdichte sowohl innerhalb als auch zwischen den genannten Großregionen. 


\section{Nord- und Zentralasien}

Besonders dünn war die Bevölkerungsdichte bis zuletzt in Nord- und Zentralasien. Auf gut 40 Prozent der Fläche Asiens (18,7 Mio. $\mathrm{km}^{2}$ ) lebten mit rund 100 Millionen zuletzt weniger als 3 Prozent der Bevölkerung (vgl. Tabelle 25). ${ }^{289}$ Die daraus resultierende Bevölkerungsdichte entsprach etwa einem Vierzehntel des europäischen oder einem Sechstel des afrikanischen Wertes. Entsprechend niedrig fiel auch der Urbanisierungsgrad aus. Ein Großteil der Menschen in Nord- und Zentralasien lebte bis in die jüngere Vergangenheit und zum Teil bis heute als nomadische bis halb nomadische Viehzüchter, die meist saisonal von einem Weideplatz zum anderen zogen. In der Mongolei stellten sie Mitte der 80er Jahre rund 35 Prozent der knapp zwei Millionen Einwohner, ${ }^{290}$ in den ehemals zur Sowjetunion gehörenden Gebieten Nord- und Zentralasiens ging ihre Zahl infolge der von den Sowjets verfügten Kollektivierung von rund 20 Millionen auf nur noch zwei bis zweieinhalb Millionen zurück. ${ }^{291}$ Unter der restlichen Bevölkerung vorwiegend sesshafter Bauern hatten sich nur wenige größere Städte entwickelt, die zudem weit voneinander entfernt lagen.

Noch um die Wende zum 20. Jahrhundert gab es in dem riesigen Gebiet keine einzige Stadt mit mehr als 100.000 Einwohnern. Dementsprechend gering war das Produktionsvolumen des verarbeitenden Gewerbes. 1908 machte es im asiatischen Teil des Russischen Reiches pro Kopf der Bevölkerung lediglich ein Viertel des ohnehin niedrigen gesamtrussischen Durchschnittswertes aus. ${ }^{292} 1926$ lebten im sowjetischen Teil der Region östlich des Uralgebietes weniger als 15 Prozent der Menschen in Städten, 1939 waren es knapp 30 und 1959 über 40 Prozent. ${ }^{293}$

Mit zunehmendem Bevölkerungswachstum und als Folge der wirtschaftlichen ErschlieBung der Region durch die sowjetische Regierung stieg auch die Zahl der Großstädte. 1956 gab es in Nord- und Zentralasien einschließlich des Uralgebietes rund 20 Städte mit mehr als 200.000 Einwohnern, ${ }^{294}$ von denen allerdings nur vier, nämlich Novosibirsk, Swerdlowsk/Jekaterinburg, Tscheljabinsk und Omsk, die halbe Million überschritten hat-

\footnotetext{
289 Wikipedia (Asien).

290 Wikipedia (Mongolei).

291 Vgl. Köllmann (1965), 220.

292 Wagener (1972), 8.

293 Für Sibirien und den Fernen Osten, für die für 1959 keine Zahlen angeführt sind, wurden etwas höhere Werte als für die zentralasiatischen Sowjetrepubliken angenommen. Köllmann (1965), 222 und 229.

294 Einschließlich Omsk und Bischkek, die bei Köllmann (1965), 229 fehlen.
} 
ten. Sie lagen vorwiegend im Gebiet des mittleren und südlichen Uralgebirges sowie im südwestlichen Sibirien, wo sie seit den 30er Jahren und dem Zweiten Weltkrieg vom Abbau wichtiger Rohstoffe oder von ihrer Lage an der ab 1891 gebauten Transsibirischen Eisenbahn profitierten. ${ }^{295}$ Der Anteil der Ostgebiete ${ }^{296}$ an der Kohleförderung Russlands bzw. der Sowjetunion stieg zwischen 1913 und 1970 von 12 auf über 50 Prozent, jener der Stromerzeugung von 10 auf 38 Prozent. ${ }^{297}$ Auch das in der Sowjetunion geförderte Erdöl stammte 1970 zu einem Viertel aus dem Osten des Landes. Zwischen 1940 und 1956 zählten Westsibirien und das Uralgebiet sowie über einen längeren Zeitraum auch Kasachstan zu den Gebieten der Sowjetunion, in denen die industrielle Produktion am stärksten zulegte. ${ }^{298}$

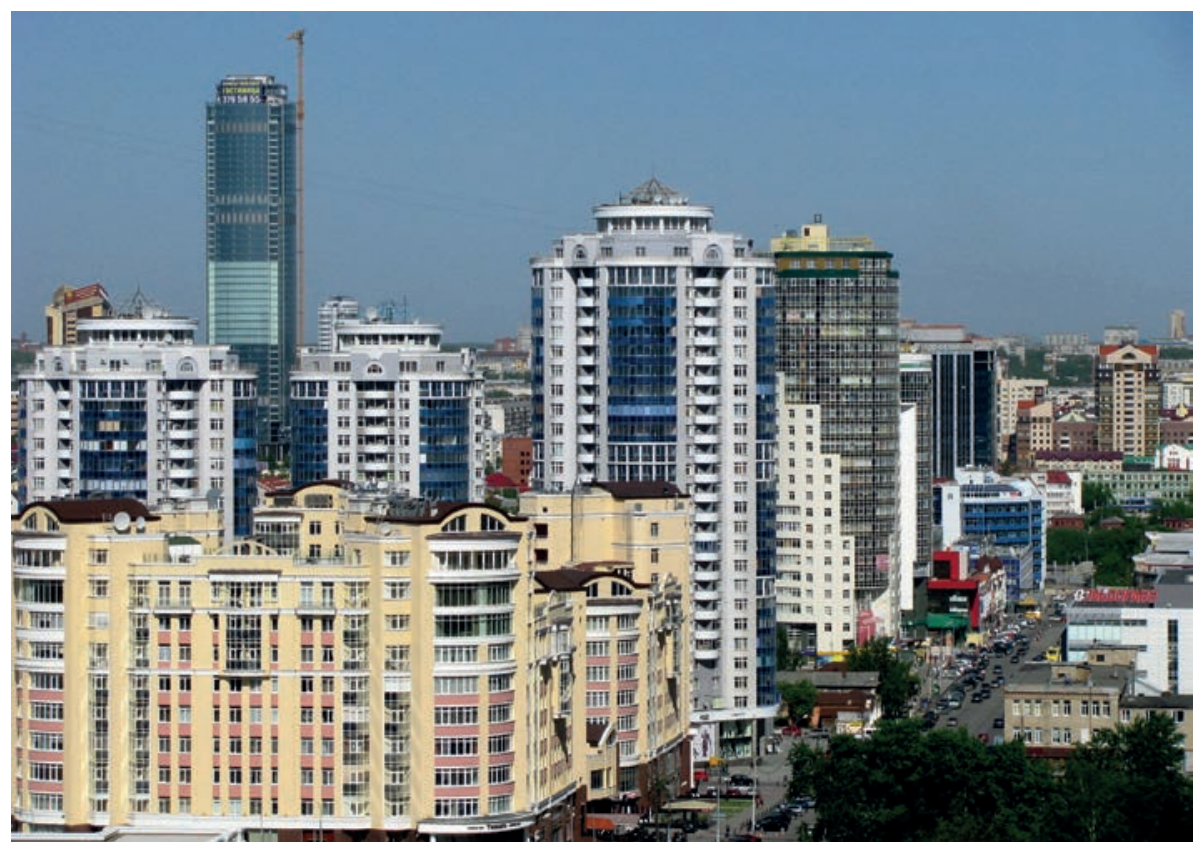

http://de.wikipedia.org/wiki/Jekaterinburg\#/media/File:Yekaterinburg_skyline2.jpg

295 Vgl. Mauro (1984), 173-176 und Köllmann (1965), 221.

296 Ural, West- und Ostsibirien, Ferner Osten, Mittelasien und Kasachstan

$297 \operatorname{Merl}(1987), 697$.

298 Hutchings (1971), 220. 
Obwohl im Zuge fortgesetzten Städtewachstums Novosibirsk, Jekaterinburg, Omsk und Tscheljabinsk sowie Alma Ata und Taschkent als rasch wachsende Hauptstädte Kasachstans und Usbekistans bis zum Ende der Sowjetunion zu Millionenstädten aufstiegen (vgl. Karte 11), ${ }^{299}$ war die Industrialisierung Nord- und Zentralasiens in diesem Fall weniger der Nachfrage nach Konsumgütern als vielmehr den Zielen der sowjetischen Wirtschaftsplanung geschuldet. Sie sah eine besondere Förderung der Erzeugung und Weiterverarbeitung von Eisen und Stahl vor. So diente die Verbindung der hochwertigen Eisenerzvorkommen des Urals mit der Kohle des Kusnezker Beckens zum Aufbau einer zweiten Stahlbasis der Sowjetunion, das als Ural-Kusnezk-Kombinat zu einem der weltweit bedeutendsten Zentren der Eisen- und Stahlerzeugung wurde. ${ }^{300}$ Um 1970 stammten rund 40 Prozent des in der Sowjetunion erzeugten Roheisens und Rohstahls, 20 Prozent der Traktoren und immerhin 12 Prozent der Werkzeugmaschinen, aber nur knapp 10 Prozent der Baumwollstoffe aus dem Osten des Landes, obwohl sich speziell in Usbekistan und Turkmenistan die Hauptanbaugebiete der Rohbaumwolle befanden. ${ }^{301}$ Gemessen am Bevölkerungsanteil von damals rund 30 Prozent lag die Pro-Kopf-Produktion bei Roheisen und Rohstahl über, bei den anderen drei Produktgruppen deutlich unter dem gesamtstaatlichen Durchschnitt. Der größte Teil speziell der Roheisen- und Stahlproduktion entfiel mit etwa drei Vierteln allein auf das Uralgebiet, während die Produktion von Baumwollstoffen fast ausschließlich außerhalb dieses Gebietes angesiedelt war.

Auch in den beiden folgenden Jahrzehnten bis zur Auflösung der Sowjetunion sah die staatliche Wirtschaftsplanung für die asiatischen Teile des Landes vor allem den Ausbau des Energie- und Rohstoffsektors und weniger die Förderung der verarbeitenden Industrie vor. So stieg die Elektrizitätserzeugung pro Kopf der Bevölkerung in der Russischen Sowjetrepublik, die neben dem europäischen auch den nordasiatischen Teil des Landes umfasste, zwischen 1970 und 1985 um 86 Prozent, in den zentralasiatischen Republiken Kasachstan und Usbekistan um 92 bzw. 72 Prozent sowie in den restlichen drei Republiken Kirgisistan, Tadschikistan und Turkmenistan sogar auf mehr als das Zwei-, Drei- und Vierfache des Ausgangswertes. ${ }^{302}$ Auch von der sowjetischen Rohstahlproduktion stammte ein Großteil aus dem Ural und den östlichen Regionen der Russischen Republik, im zentralasiatischen Kasachstan erreichte die Pro-Kopf-Produktion westeuropäische Werte.

299 Liste der Städte (einzelne Länder).

300 Raupach (1964), 93.

301 Merl (1987), 697, Hutchings (1971), 225 und Pomfret (1996), 4

302 Pockney (1991), 157. 
In Usbekistan blieb sie dagegen deutlich hinter diesen zurück, im restlichen Zentralasien war überhaupt keine nennenswerte Stahlindustrie entstanden. ${ }^{303}$

Im Bereich der Konsumgüterindustrie kam in der Herstellung von Baumwollstoffen Ende der 80er Jahre lediglich Usbekistan als wichtigster Produzent von Rohbaumwolle an den gesamtsowjetischen Durchschnitt und damit auch an west- und mitteleuropäische Werte heran. Nur etwa halb so hoch war die Pro-Kopf-Produktion im restlichen Zentralasien, ${ }^{304}$ und auch für Nordasien deuten die indirekt erschließbaren Daten darauf hin, dass die Baumwollindustrie bis zuletzt nur eine sehr geringe Rolle spielte. ${ }^{305}$ Eine eigene Produktion von Fernsehgeräten ist überhaupt nur für die Russische Republik und dort wohl fast ausschließlich für den europäischen Teil ausgewiesen. ${ }^{306}$

Insgesamt gingen von diesen Industrien zwar in einigen wenigen Regionen relativ starke, für eine breite Industrialisierung Nord- und Zentralasiens jedoch nur unzureichende Impulse aus. So dürfte der Anteil der im sekundären Sektor erwerbstätigen Menschen um 1970 lediglich im Uralgebiet die 40-Prozent-Marke überschritten und damit an westund mitteleuropäische Werte herangekommen sein. ${ }^{307}$ In Sibirien und im Fernen Osten lag er darunter, in Kasachstan und den restlichen Republiken Zentralasiens bei 21 bis 30 Prozent, woran sich auch in der Folge nichts Wesentliches ändern sollte. ${ }^{308}$ Dementsprechend niedrig waren die durchschnittlichen Pro-Kopf-Einkommen speziell in Zentralasien, wo sie 1965 rund 60 Prozent und 1989 zwischen 50 (Tadschikistan) und 75 Prozent (Kasachstan) des gesamtsowjetischen Wertes erreichten. ${ }^{309}$ Noch geringer fielen sie in der stark am sowjetischen Entwicklungsmodell ausgerichteten Mongolei aus, obwohl sich auch dort die Produktion des sekundären Sektors zwischen 1950 und 1989, ausgehend von einem sehr niedrigen Ausgangsniveau, vervielfachte. ${ }^{310}$

Die zumindest in Ansätzen zu beobachtende Industrialisierung Nord- und Zentralasiens nahm mit der Auflösung der Sonjetunion um 1990 ein abruptes Ende. An die Stelle ei-

303 Eigene Berechnungen nach Mitchell (1992), 460, Sowjetunion (1992), 78 und Pockney (1991), Table 3.

304 Eigene Berechnungen nach Mitchell (1992), 505, Sowjetunion (1992), 78 und Pockney (1991), Table 3.

305 In Ermangelung getrennter Daten zum europäischen und zum asiatischen Teil der Russischen Sowjetrepublik lässt sich letzteres nur indirekt aus einem Vergleich der zentralasiatischen und der gesamtsowjetischen Werte der Jahre 1970 und 1989 erschließen. Merl (1987), 697 und Sowjetunion (1992), 78.

306 Sowjetunion (1992), 78.

307 Zwar ist der Anteil für das Uralgebiet bei Wagener nicht eigens ausgewiesen, doch lässt er sich aus dem für die Russische Sowjetrepublik angeführtem Wert von 39,8 Prozent ermitteln, da deren industrielle Pro-Kopf-Produktion etwas unter dem Wert des Uralgebietes lag. Wagener (1972), 96 und 136.

308 Wagener (1972), 96 und 136.

309 Wagener (1972), 86 und Fischer Weltalmanach (1992), 547.

310 Pomfret (1996), 2 und 77 sowie Mitchell (2007), 367 und 370. 
ner zentral gelenkten Planwirtschaft trat die Marktwirtschaft. Sie unterbrach nicht nur die in Jahrzehnten etablierten Handelsbeziehungen zwischen den ehemaligen Sowjetrepubliken, sondern setzte die Unternehmen einem neuen Wettbewerb aus, dem viele nur unzureichend gewachsen waren. ${ }^{311}$ Besonders von der Krise betroffen waren die asiatischen Gebiete der ehemaligen Sowjetunion. Im Gebiet der neuen Russischen Föderation, zu der nach wie vor auch die nordasiatischen Regionen gehörten, ging die Industrieproduktion zwischen 1990 und 1994 um mindestens ein Viertel, nach anderen Angaben sogar um mehr als ein Drittel zurück, bevor sie anschließend wieder zu wachsen begann. ${ }^{312}$ Die Erzeugung von Rohstahl wurde fast halbiert, die Herstellung von Baumwollgarnen fiel bis 1996 auf ein Achtel des Wertes von 1990 zurück. Ähnlich dramatisch gestalteten sich die Einbrüche in Zentralasien, wo zwischen 1990 und 1993 im industriell-gewerblichen Sektor Produktionsrückgänge von gut 12 Prozent in Turkmenistan und Usbekistan, von fast 30 Prozent in Kasachstan, nicht ganz 40 Prozent in Tadschikistan und fast 45 Prozent in Kirgisistan zu verzeichnen waren. ${ }^{313}$

Erst in der zweiten Hälfte der 90er Jahre setzte ein neuerliches Wachstum der industriellen Produktion ein, das sich im neuen Jahrhundert fortsetzte. Die jährlichen Wachstumsraten des sekundären Sektors bewegten sich zwischen 2000 und 2004 zwischen 3,2 Prozent in Usbekistan und 11,8 Prozent in Kasachstan. Auch in der Mongolei, die von ähnlichen Problemen betroffen war wie die asiatischen Teile der Sowjetunion, wuchs der sekundäre Sektor pro Jahr um durchschnittlich 7,4 Prozent. Dennoch lag das reale Bruttoinlandsprodukt 2002 noch durchwegs und zum Teil erheblich unter dem Niveau von $1989 .^{314}$

Auch der Beschäftigungseffekt des jüngeren industriellen Wachstums blieb wegen der ebenfalls zunehmenden Produktivität hinter den Auswirkungen früherer Jahrzehnte zurück. Im Gegenteil, wie fast überall in der Welt ging der relative Anteil der im sekundären Sektor Erwerbstätigen zurück, und zwar fast durchwegs auf weniger als 20 Prozent. (vgl. Grafik 22 und Tabelle 26). Dabei fällt auf, dass der Rückgang der Industriebeschäftigung nicht nur zugunsten der Dienstleistungen erfolgte, sondern mit Ausnahme Usbekistans und der Mongolei zu Beginn des neuen Jahrhunderts auch in der Landwirtschaft wieder

311 Andrejew (1993), 19 und 23.

312 Eigene Berechnungen nach Andrejew (1993), 88, Fischer Weltalmanach (1995), 519 und Commander (1995), 148.

313 Eigene Berechnungen nach Fischer Weltalmanach (1995), 519. Vgl. auch Growth Amid Change (2007), 49 mit Angaben für den Zuwachs in den 80er und den Rückgang in den 90er Jahren.

314 Transition report (2003), 56 und Growth Amid Change (2007), 49. 
mehr Menschen beschäftigt waren als zuvor. Letzteres dürfte auch im asiatischen Teil der Russischen Föderation der Fall gewesen sein. In ihr nahm der Anteil der Landwirtschaft zunächst ebenfalls wieder zu und erst seit der Jahrhundertwende wieder ab. Außerdem arbeitete ein unterschiedlich großer Teil der Menschen in dem in Grafik 22 und Tabelle 26 nicht erfassten und meist schlecht bezahlten informellen Sektor. ${ }^{315}$

Grafik 22: Erwerbstätige im sekundären Sektor in Nord- und Zentralasien 1990-2004

(Prozent aller Erwerbstätigen, Jahresdurchschnitte)

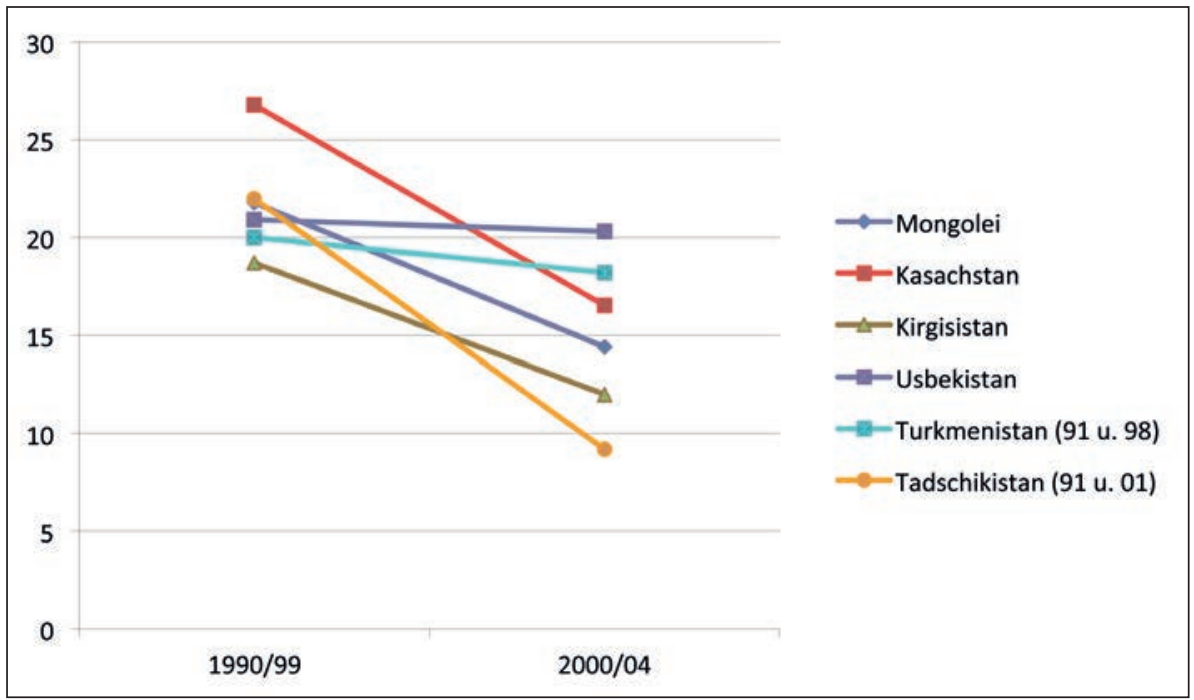

Vgl. Tabelle 26.

Wie Afrika war daher auch Nord- und Zentralasien von einer breiten Industrialisierung, wie sie die Industrieländer Europas und Nordamerikas in früheren Jahrzehnten erlebt hatten, weit entfernt. Zu Beginn des neuen Jahrhunderts lag die Produktion des sekundären Wirtschaftssektors pro Kopf der Bevölkerung in der Russischen Föderation und in Kasachstan zwischen einem Sechstel und einem Fünftel der west-, mittel- und nordeuropäischen Länder. ${ }^{316}$ Noch niedriger war sie in der Mongolei und den anderen

315 Johnson/Kaufmann (2001), 215.

316 Welt in Zahlen (Industrieproduktion). 
Ländern Zentralasiens. Nur ein kleiner Teil der Bevölkerung profitierte vom Aufbau relativ isolierter Industrien, was sich in den überaus niedrigen, durchschnittlichen ProKopf-Einkommen der einzelnen Länder niederschlug. Obwohl sie nach der Krise der 90er Jahre außer in der Mongolei und Kirgisistan nicht zuletzt dank steigender Rohstoffexporte wieder kräftig wuchsen, lag das Bruttoinlandsprodukt im Jahre 2008 mit großem Abstand hinter den hoch entwickelten Industrieländern zurück. ${ }^{317}$ Konkret kommt ihr niedriger Entwicklungsstand auch an der bescheidenen Ausstattung mit langlebigen Konsumgütern zum Ausdruck, die sich auf dem Niveau der ärmeren und ärmsten Länder im Osten und Südosten Europas bewegte. ${ }^{318}$

Grafik 23: Fernsehgeräte pro 1.000 Einwohner in Nord- und Zentralasien 2006

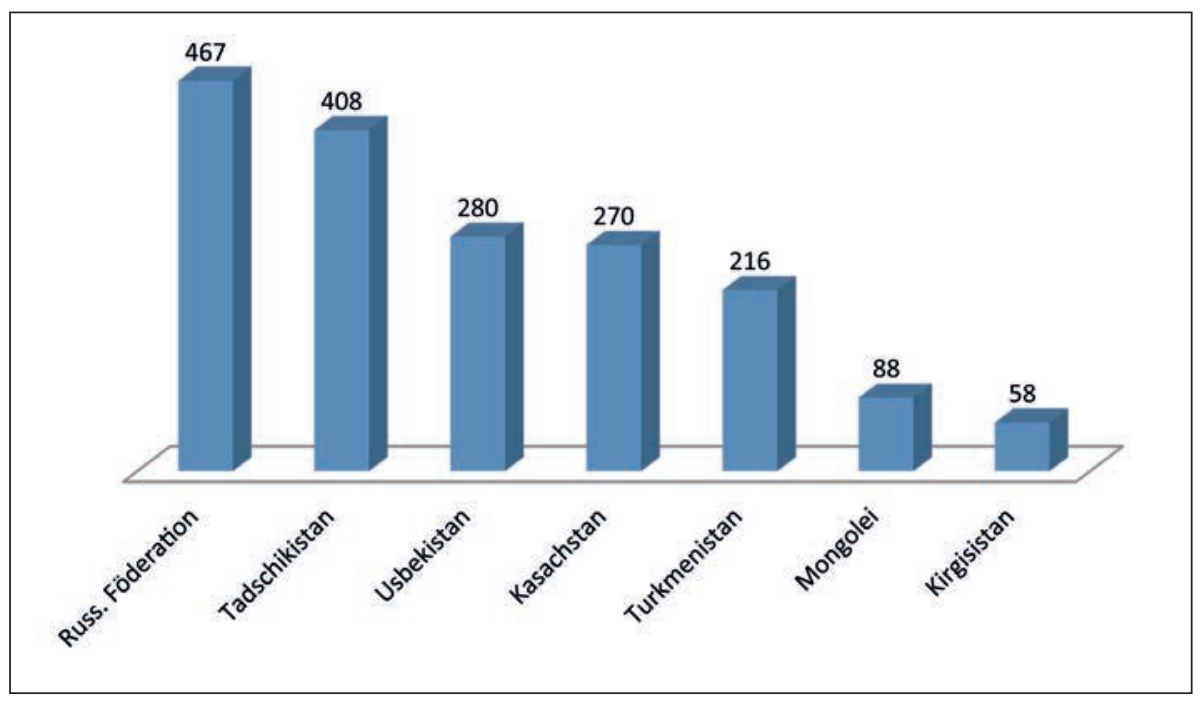

Welt in Zahlen (Fernsehgeräte).

317 Maddison (Per Capita GDP).

318 Vgl. Tabelle 8 und Tabelle 10 sowie Welt in Zahlen (Fernsehgeräte). 
Grafik 24: PKW pro 1.000 Einwohner in Nord- und Zentralasien 2006

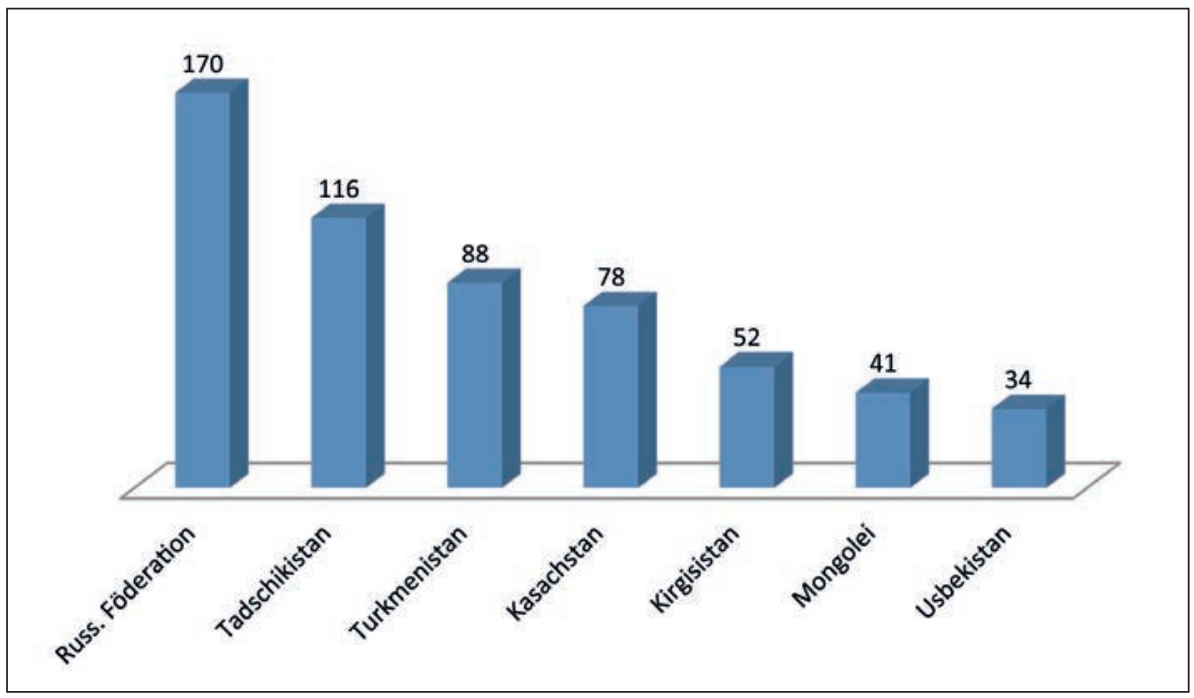

Welt in Zahlen (PKW).

Grafik 25: Computer pro 1.000 Einwohner in Nord- und Zentralasien 2006

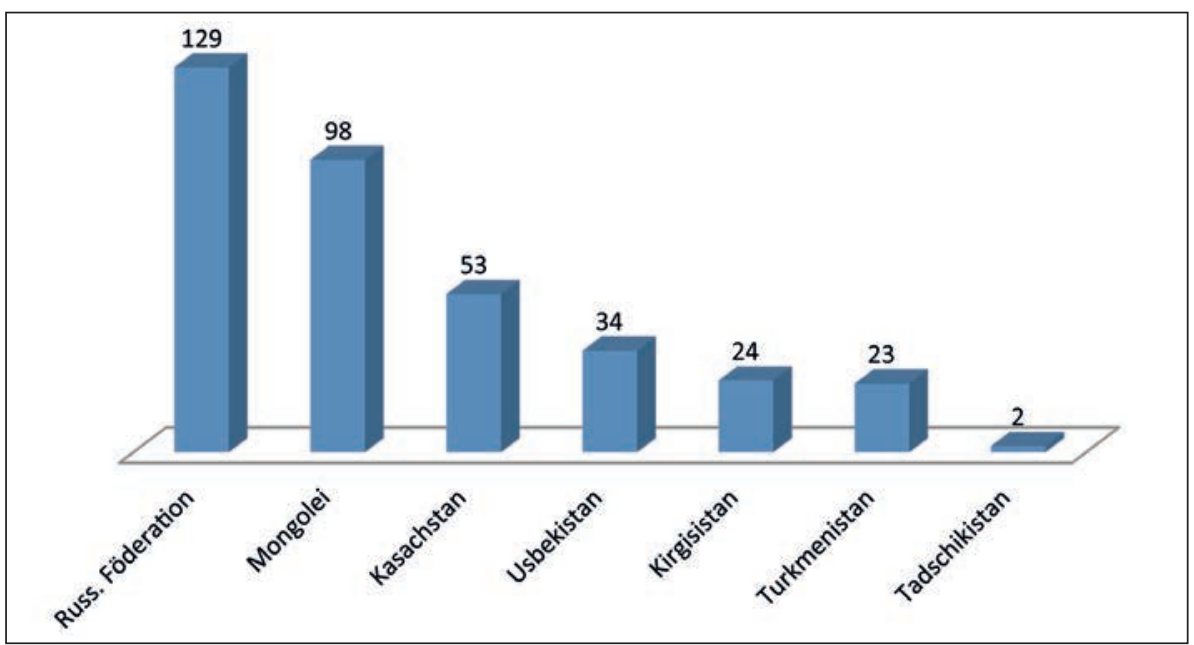

Welt in Zahlen (Computer). 


\section{Westasien}

Ginge es nach dem Alter städtischer Siedlungen, hätte die moderne Industrialisierung nicht in West- und Mitteleuropa, sondern in West- oder Vorderasien beginnen müssen. Im Gebiet des so genannten Fruchtbaren Halbmondes, das sich vom östlichen Mittelmeer über das heutige Syrien und den nördlichen Irak bis in das westliche Persien erstreckte, gingen die Menschen vor über 10.000 Jahren zum ersten Mal auf der Erde zu einer sesshaften, bäuerlichen Lebensweise über, und wenig später entstanden hier auch die ersten stadtähnlichen Siedlungen. Gleichzeitig lebten in anderen Teilen Westasiens viele Menschen bis weit ins 20. Jahrhundert als Vieh züchtende Nomaden. ${ }^{319}$ Außerdem blieben die Städte über tausende von Jahren relativ klein. Großstädte mit mehreren 100.000 Einwohnern, wie sie seit dem späten 18. und vor allem im 19. Jahrhundert beiderseits des Atlantiks in großer Zahl entstanden, gab es in Westasien lange Zeit keine.

Istanbul um 2005

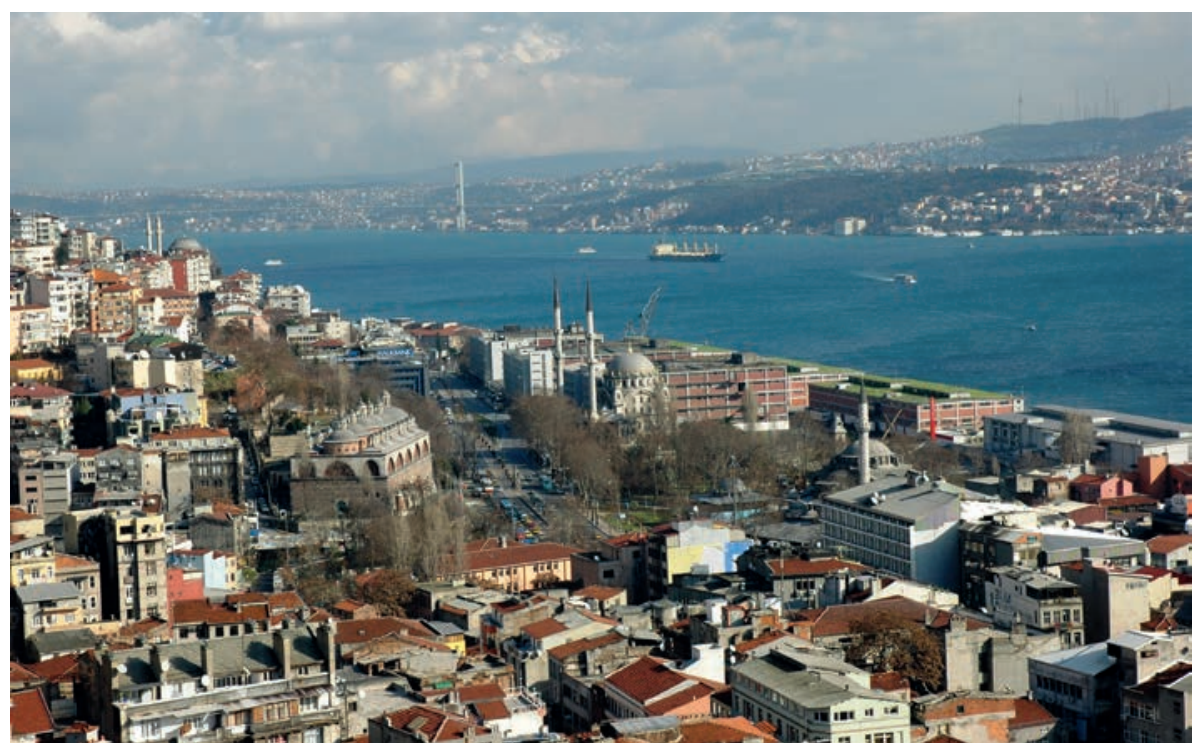

http://commons.wikimedia.org/wiki/File:Istanbul_-_Beyoglu_amb_el_B $\%$ C3\%B2sfor_al_fons.JPG

319 Köllmann (1965), 246 und 249 sowie Schuster (1979), 56 und 61-63. 
Noch 1920 zählten nur etwa 12 und 1950 bei einer sehr geringen Gesamtbevölkerung von knapp 70 Millionen Menschen erst etwa 25 Städte mehr als 100.000 Einwohner. ${ }^{320}$ Lediglich Istanbul hatte um die Jahrhundertwende vorübergehend die Millionengrenze überschritten, während Baku, Tiflis und Teheran die halbe Million erst in den 30er Jahren erreichten. Alle anderen lagen noch zur Mitte des 20. Jahrhunderts deutlich darunter.

Entsprechend schwach entwickelt waren Industrie und verarbeitendes Gewerbe. Ihr Anteil an der Gesamtzahl der Erwerbstätigen schwankte in den Ländern, für die Daten überliefert sind, zwischen 14 Prozent im Iran (1956) und nur 7 Prozent in der Türkei (1960), den mit Abstand größten Ländern der Region, die zusammen mehr als die Hälfte der Bevölkerung Vorderasiens auf sich vereinigten (vgl. Tabelle 27). Lediglich in Israel, das dank eines besonders starken Zuzuges von außen mit den drei Großstädten Tel Aviv, Jerusalem und Haifa einen überdurchschnittlich hohen Urbanisierungsgrad aufwies, arbeiteten damals gut 25 Prozent aller Erwerbstätigen in der Industrie und im verarbeitenden Gewerbe. ${ }^{321}$ Ähnlich viele waren es dank staatlicher Planung in den sowjetischen Republiken Aserbaidschan, Armenien und Georgien. 322

Die Baumwollverarbeitung als mehrfach herangezogener Indikator für die Anfänge einer maschinellen Industrieproduktion lag, soweit er erfasst wurde, mit rund $2 \mathrm{~kg}$ pro Einwohner deutlich unter den Werten, die die west- und mitteleuropäischen Länder bereits am Vorabend des Ersten Weltkrieges erreicht hatten. ${ }^{323}$ Die Pro-Kopf-Produktion an Roheisen machte in der Türkei mit $5 \mathrm{~kg}$ nur einen Bruchteil der west- und mitteleuropäischen Roheisenerzeugung zu Beginn des Jahrhunderts aus. ${ }^{324}$ Ähnlich bescheidene Anfänge einer Industrialisierung fanden in der ersten Jahrhunderthälfte auch in anderen Ländern Vorderasiens statt. ${ }^{325}$

Kräftigere Industrialisierungsschübe setzten erst in den Jahrzehnten nach dem Zweiten Weltkrieg ein. Neben wachsenden Märkten und staatlicher Industrialisierungspolitik stützten sie sich vor allem auf die in der Region nunmehr in großem Stil betriebene Erdölförderung. Im Iran als dem größten Öl produzierenden Land der Region „,explodierten“ die Ölexporte innerhalb weniger Jahre von 1,3 (1969/70) auf 21 Milliarden (1974/75)

320 Mitchell (2007), 42-46 und Köllmann (1965), 224 f. und 247-251.

321 Eigene Berechnungen nach Mitchell (2007), 105 und 112 sowie Wolffsohn (1991), 382.

322 Wagener (1972), 136.

323 Eigene Berechnungen nach Mitchell (2007), 467 f.

324 Eigene Berechnungen nach Mitchell (2007), 441-443.

325 Issawi (1982), 150-203. 
Barrel. ${ }^{326}$ Die Ölförderung ließ da und dort weiter verarbeitende Betriebe entstehen, erhöhte aber vor allem die Einnahmen der Regierungen, die sie für eine wirtschaftliche Entwicklungspolitik nutzen konnten. So stiegen die direkten Zahlungen der Ölgesellschaften an die Regierungen des Nahen Ostens zwischen 1961 und 1979 von 1,5 auf 135,6 Milliarden Dollar. ${ }^{327}$ Sie ermöglichten eine gigantische Steigerung der staatlichen Ausgaben, die sich etwa im Iran in nur sechs Jahren zwischen 1968 und 1974 fast verfünffachten, während sich die privaten Ausgaben im selben Zeitraum nicht einmal verdoppelten. ${ }^{328}$ An Erdöl verarbeitenden Industriebetrieben entstanden in Saudi-Arabien, Katar und Kuwait sowie im Irak, im Iran und in den Vereinigten Arabischen Emiraten bis 1980 insgesamt 39 Raffinerien und 16 Anlagen zur Erzeugung von Stickstoffdünger. An sonstigen Betrieben im Grundstoffbereich zählte man hingegen im selben Jahr lediglich vier Eisen- und Stahlwerke sowie fünf Aluminiumwerke. ${ }^{329}$

Teheran mit Elburs-Gebirge um 2007

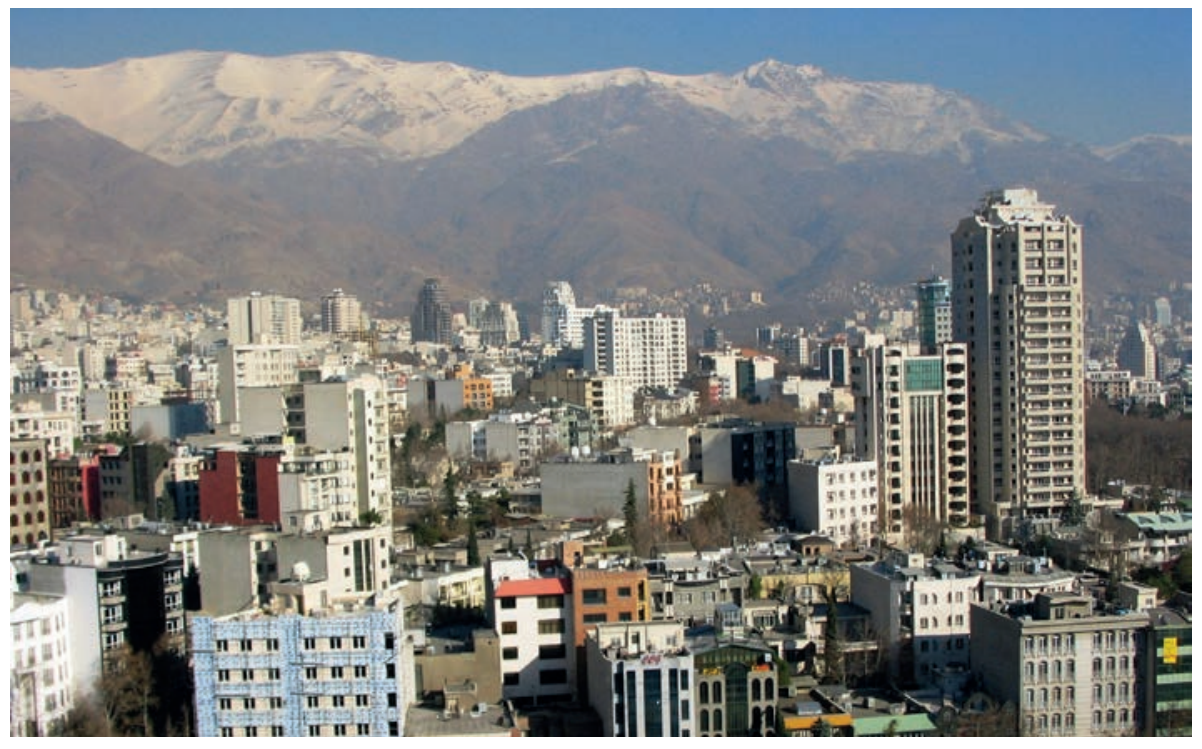

http://de.wikipedia.org/wiki/Teheran\#/media/File:Northern-Tehran.JPG

326 Looney (1977), 4.

327 Issawi (1982), 203.

328 Looney (1977), 16.

329 Ochel (1978), 45. 
Neben den direkten und indirekten Industrialisierungsimpulsen der Ölförderung war es auch in Westasien der jetzt rascher wachsende Binnenmark.t, der moderne Industriebetriebe in größerer Zahl entstehen ließ. Wie anderswo konzentrierten sie sich auf die Gebiete der an Bevölkerung und Zahl zunehmenden Groß- und meist auch Hauptstädte der einzelnen Länder. Vor dem Hintergrund eines explosionsartigen Bevölkerungswachstums - 2009 lebten in Westasien mehr als vier Mal so viele Menschen wie 1950 - und einer beschleunigten Landflucht zählte man 1980 in der Region bereits elf und zur Jahrhundertwende über 20 Städte mit mehr als einer Million Einwohner (vgl. Karte 11 und Tabelle 28). Wie sehr die Großstädte die Industrialisierung ihrer Länder anregten, geht beispielhaft daraus hervor, dass etwa 1964 im Libanon knapp 70 Prozent der Industriebetriebe im Großraum Beirut angesiedelt waren oder dass um dieselbe Zeit im Irak ein gleich hoher Anteil aller Fabrikbeschäftigten in Bagdad arbeiteten und sich in der Türkei in den 80er Jahren ein Großteil der Industrien im Westen des Landes im Umfeld von Istanbul, Bursa und Izmir sowie in Ankara und an der Schwarzmeerküste befanden. ${ }^{330} \mathrm{Zu}$ Beginn des neuen Jahrhunderts wurden fast drei Viertel des Umsatzes der 500 größten Unternehmen der Türkei in Istanbul und der angrenzenden Provinz Kocaeli erwirtschaftet, weitere 14 Prozent verteilten sich ziemlich gleichmäßig auf Ankara, Bursa und Izmir. ${ }^{331}$ Auch in Saudi-Arabien konzentrierten sich die Industriebetriebe auf die größten Städte des Landes, und zwar zunächst auf Dammam, Riad und Dschidda sowie später auch auf Mekka, Medina und Al-Khobar. ${ }^{332}$ In Israel arbeiteten in den 70er und 80er Jahren über die Hälfte aller Industriebeschäftigten in der Region Tel Aviv und im Zentralbezirk um Rischon LeZion. ${ }^{333}$

Wie stark die Industrieproduktion in einigen der größeren - und wohl auch in den anderen Ländern - zulegte, lassen Grafik 26 und Tabelle 29 erkennen. Ausgehend von einem niedrigen Niveau stieg sie im Iran, der Türkei, Syrien und Israel zwischen 1960 und 1980 auf das Fünf- bis Siebenfache des Ausgangswertes an und verdoppelte bis verdreifachte sich noch einmal in den folgenden 20 Jahren.

330 Lechleitner (1972), 87, Issawi (1982), 166 und Weitz (1987), 25.

331 Bronger/Trettin (2011), $278 \mathrm{f}$.

332 Schuster (1979), 87.

333 Wolffsohn (1991), 395. 
Grafik 26: Produktion von Industrie und verarbeitendem Gewerbe in Westasien 1960-1999 $(1980=100$, ausgewählte Länder $)$

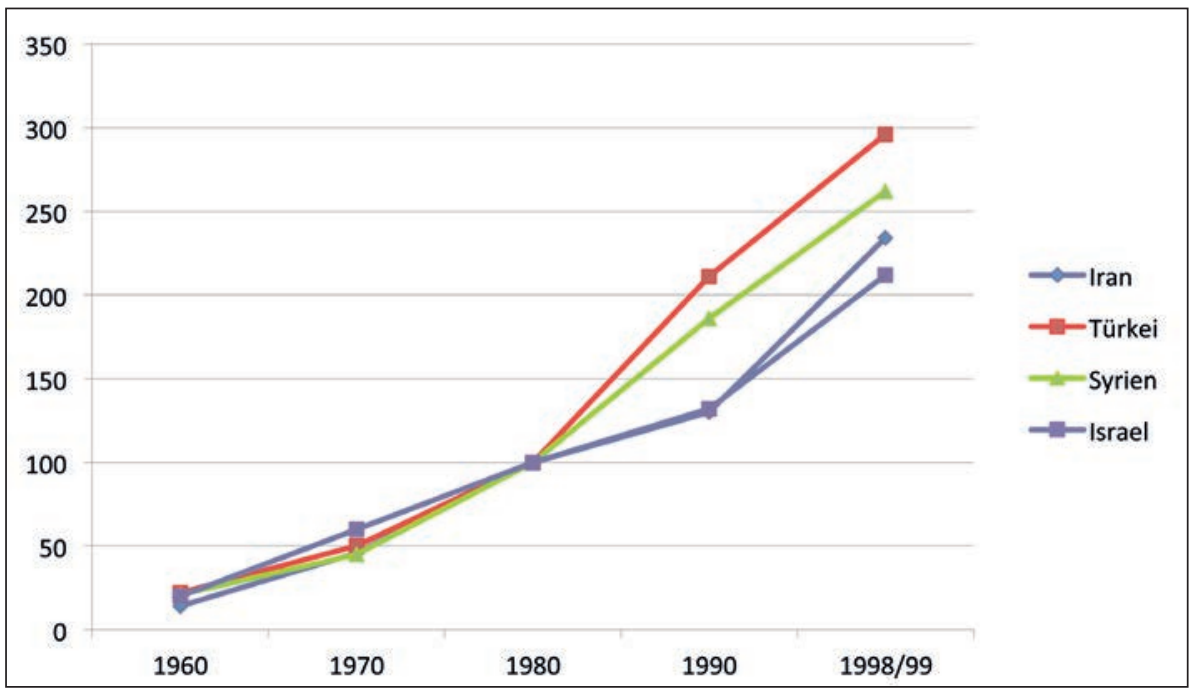

Vgl. Tabelle 29.

Allerdings verlief die Industrialisierung keineswegs kontinuierlich, sondern war vielmehr starken jährlichen Schwankungen und fallweise sogar Rückschlägen unterworfen. Zu solchen Produktionsrückgängen kam es etwa im Iran im Revolutionsjahr 1978/9 und in der zweiten Hälfte der 80er Jahre, in Syrien und Israel um die Mitte bzw. gegen Ende der 80er Jahre sowie in der Türkei Ende der 70er und Mitte der 90er Jahre sowie um die Wende zum neuen Jahrhundert. ${ }^{334}$

Noch stärkere jährliche Schwankungen lassen sich bei einzelnen Produktionszweigen wie etwa der Baumwollverarbeitung oder der Roheisenproduktion beobachten. Langfristig stieg die Verarbeitung von Rohbaumwolle pro Einwohner bis gegen Ende des Jahrhunderts im Iran auf gut 2, in Syrien auf etwa 5 und in der Türkei auf $10 \mathrm{~kg}$, während er in Israel nach ebenfalls rund $10 \mathrm{~kg}$ (1960) auf nur noch $6 \mathrm{~kg}$ zurückfiel. ${ }^{335}$ Damit kamen diese Länder an die Werte heran, die West- und Mitteleuropa einige Jahrzehnte zuvor erreicht

334 Mitchell (2007), 367-370 sowie OECD Turkey (1990/91), 13, (1996), 6 und (2002), 30.

335 Eigene Berechnungen nach Mitchell (2007), 467 f. und Maddison (Population). 
hatte. Eine über den Konsumgüterbereich hinaus gehende Industrialisierung erfolgte jedoch nur in Ansätzen. So lag die Produktion von Roheisen, die lediglich im Iran und in der Türkei ein nennenswertes Ausmaß erreichte, um die Wende zum 21. Jahrhundert mit knapp 35 und rund $80 \mathrm{~kg}$ pro Einwohner weit unter den Pro-Kopf-Werten, die in den west- und mitteleuropäischen Ländern bereits 100 Jahre zuvor verzeichnet worden waren (vgl. Grafik 3). ${ }^{336}$

Dennoch entstand in den beiden Ländern seit den 60er Jahren auch eine eigene $A u$ tomobilproduktion, die insbesondere in jüngerer Zeit stark expandierte. Zwischen 1990 und 2011 stieg die Produktion von Personenkraftwagen, Bussen und Lastkraftwagen im Iran von weniger als 50.000 auf 1,6 Millionen Einheiten, in der Türkei wuchs sie zwischen 1980 und 2007 von gut 30.000 auf über 600.000 Automobile. ${ }^{337}$ Sie bediente zum einen die wachsende, vor allem städtische Binnennachfrage, zum anderen die Nachfrage sowohl des entwickelten als auch des weniger entwickelten Auslandes nach preisgünstigen Automobilen. Gemessen an ihrer Bevölkerung standen sie in der Automobilproduktion auf einer Stufe mit anderen weniger entwickelten Ländern wie Russland, Rumänien, Mexiko, Brasilien, Argentinien oder Südafrika, wo zuletzt jährlich zwischen 10 und 20 Autos pro 1.000 Einwohner hergestellt wurden. ${ }^{338}$

Die bis ins neue Jahrhundert anhaltende Industrialisierung schlug sich in der Türkei und im Iran auch in der Struktur der Erwerbstätigen nieder. Allerdings stieg der relative Anteil der in Industrie und verarbeitendem Gewerbe beschäftigten Menschen dank zunehmender Produktivität deutlich langsamer als die Produktion. Um die Jahrhundertwende lag er bei weniger als 20 Prozent. ${ }^{339}$ Der größere Teil der Erwerbstätigen arbeitete inzwischen im Dienstleistungsbereich, ein immer noch großer Teil - nämlich rund 40 Prozent - in der Landwirtschaft. Ob die weitere Entwicklung zugunsten einer breiteren Industrialisierung oder wie in anderen entwickelten und weniger entwickelten Ländern in Richtung Dienstleistungsgesellschaft verlaufen wird, bleibt abzuwarten.

Die meisten anderen Länder Westasiens scheinen den Höhepunkt der Industrialisierung - gemessen am Anteil der in der Industrie Erwerbstätigen - bereits überschritten zu haben, und zwar die ehemaligen Sowjetrepubliken Armenien, Georgien und Aserbaidschan ebenso wie die Länder zwischen dem Mittelmeer und dem persischen Golf. In

336 Eigene Berechnungen nach Mitchell (2007), 442 und Maddison (Population).

337 Mitchell (2007), 502 f. und Wirtschaftszahlen zum Automobil.

338 Eigene Berechnungen nach Wirtschaftszahlen zum Automobil und Maddison (Population).

339 OECD Turkey (2002) sowie Mitchell (2007), 112. 
ersteren kam es nach der Auflösung des sowjetischen Wirtschaftsraumes und mit dem Übergang von der Planwirtschaft zur Marktwirtschaft sogar zu einer Art Reagrarisierung, stieg doch der Anteil der Landwirtschaft im ersten Jahrzehnt des neuen Jahrhunderts auf wieder über 40 Prozent aller Erwerbstätigen an. ${ }^{340}$ In letzteren hingegen fanden immer mehr Menschen eine Beschäftigung im Dienstleistungsbereich, dessen Expansion zu einem guten Teil auf den Einnahmen aus dem Export von Erdöl und Erdgas beruhte. Dem west-, mittel- und nordeuropäischen Muster, in dem die Ausweitung der Dienstleistungen auf einer zuvor statt gefundenen, breiten Industrialisierung basierte, folgten Israel und zum Teil auch der Libanon. Weder eine nennenswerte Industrie noch eine mit anderen Ländern vergleichbare Dienstleistungswirtschaft war im relativ bevölkerungsstarken Jemen entstanden, wo der Anteil der Landwirtschaft mit rund 50 Prozent um die Jahrhundertwende deutlich höher ausfiel als in den anderen Ländern der Region. ${ }^{341}$

Grafik 27: Fernsehgeräte pro 1.000 Einwohner in Westasien 1980-2006

(größere Länder)

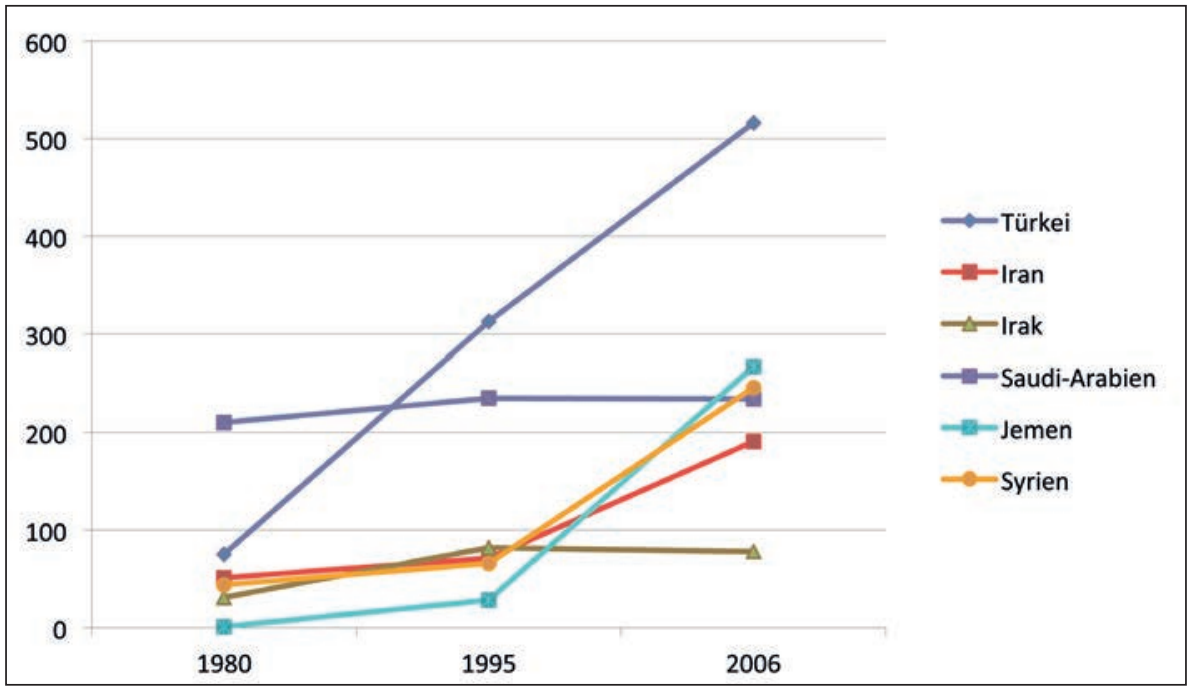

Vgl. Tabelle 30 .

340 Fischer Weltalmanach (2011). In Aserbaidschan arbeiteten zu Beginn des Jahrhunderts weniger als 6 Prozent aller Beschäftigten in Industrie und verarbeitendem Gewerbe. Growth Amid Change (2007), 52.

341 Fischer Weltalmanach (2005), 238. 
Insgesamt jedoch nahmen die durchschnittlichen Pro-Kopf-Einkommen mit Ausnahme des Irak, wo das Bruttoinlandsprodukt seit den späten 80er Jahren drastisch zurückging, in allen größeren Ländern zu - wenn auch unterschiedlich stark und zum Teil mit Rückschlägen und Unterbrechungen. ${ }^{342}$

Beides, das Wachstum und die zum Teil erheblichen regionalen Unterschiede, spiegeln sich auch in der Ausstattung mit langlebigen Konsumgütern wider (vgl. Grafik 27 bis Grafik 29 und Tabelle 30).

Grafik 28: PKW pro 1.000 Einwohner in Westasien 1970-2006

(größere Länder)

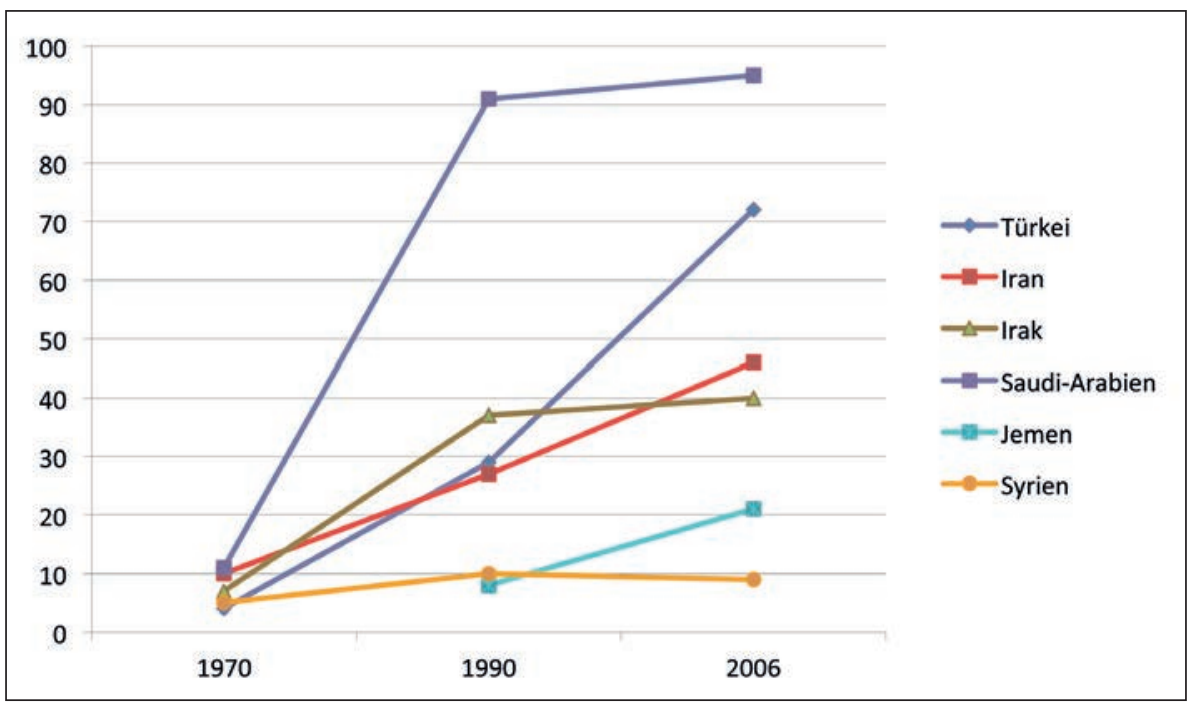

Vgl. Tabelle 30 .

342 Maddison (Per Capita GDP). 


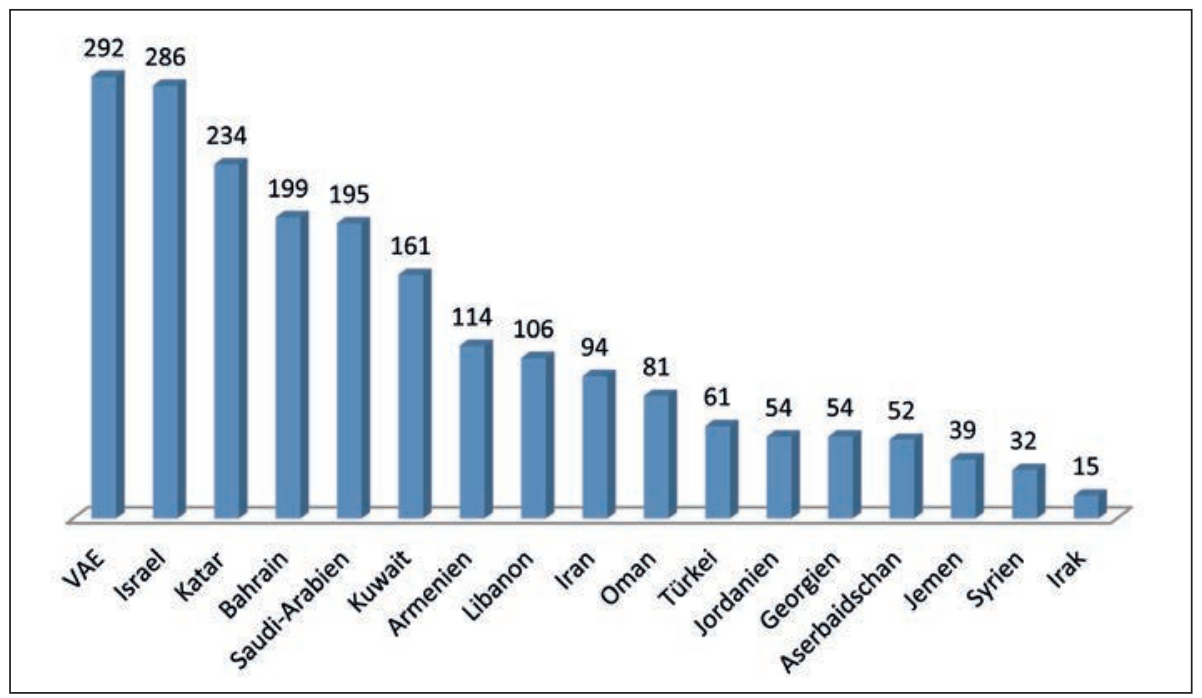

Welt in Zahlen (Computer).

Die Unterschiede resultieren, da es sich um rechnerische Durchschnittswerte handelt, aus dem verschieden starken Industrialisierungsgrad und den ebenfalls unterschiedlich hohen Exporterlösen aus der Öl- und Gasförderung auf der einen und aus der Bevölkerungszahl der einzelnen Länder auf der anderen Seite. Obwohl die PKW- und Computerdichte in sämtlichen Ländern der Region hinter den Werten der hoch entwickelten Industrieländer zurückblieben, schnitten die kleineren Länder Israel und der Libanon sowie Kuwait, Bahrain, Katar, die Vereinigten Arabischen Emirate und zum Teil auch der Oman tendenziell etwas besser ab als die größeren (vgl. Tabelle 30). In den größeren Ländern war der Anteil der Bevölkerung, der weder von der punktuellen Industrialisierung erfasst worden war noch von etwaigen Exporterlösen profitierte und daher bis zuletzt in vorindustriellen und vormodernen Verhältnissen lebte, entsprechend höher. Allerdings kamen auch die im Durchschnitt besser gestellten Länder sowohl in ihren Pro-KopfEinkommen als auch in der Ausstattung mit langlebigen Konsumgütern maximal an die ost- und zum Teil auch südeuropäischen Länder heran. Zwar hatte, angeregt durch die seit den 50er Jahren rasch wachsenden Großstädte, auch in Westasien eine Industrialisierung stattgefunden, doch verhalf sie - anders als in den breit industrialisierten Ländern West-, 
Mittel- und Nordeuropas - nur einer Minderheit zu einem ähnlich hohen Wohlstand, während der großen Mehrheit der Bevölkerung in Westasien ein solcher bis heute vorenthalten blieb.

\section{Südasien}

In Südasien zwischen Afghanistan und Sri Lanka waren speziell auf dem bevölkerungsreichen indischen Subkontinent neben einer agrarischen Subsistenzwirtschaft schon früh auch städtische Siedlungen entstanden. Allerdings blieben sie lange Zeit relativ klein. Um 1900 gab es bei einer Gesamtbevölkerung von rund 300 Millionen Menschen erst 25 Städte mit mehr als 100.000 Einwohnern, von denen fünf, nämlich die Hafenstädte Kalkutta, Bombay, Madras und Karatschi sowie Lahore als politisches Zentrum und Eisenbahnknotenpunkt bis 1950 die Millionengrenze überschritten. ${ }^{343}$ Als Handelsstädte und zum Teil auch als Verwaltungsmittelpunkte waren sie dank der Einbindung in den von den Briten dominierten Welthandel stärker gewachsen als die Städte im Landesinneren (vgl. Karte 10 und Tabelle 32).

Im Bereich der Großstädte entwickelten sich auch die ersten Industrien. Nachdem die traditionelle Baumwollverarbeitung durch die maschinell hergestellten und daher billigeren Baumwollwaren aus Großbritannien verdrängt worden war, errichteten indische Unternehmer noch in der zweiten Hälfte des 19. Jahrhunderts in und um Bombay eine moderne Baumwollindustrie zur Verarbeitung der heimischen Rohbaumwolle. Indien stieg bis 1914 zum größten Baumwollwarenproduzenten Asiens und zum viertgrößten der Welt auf und belieferte neben dem Binnenmarkt auch eine Reihe anderer Länder. Weitere Zentren der Baumwollindustrie entstanden in der Folge in Ahmedabad und im nordindischen Kampur sowie in kleinerem Ausmaß in Madras, Madurai und Solapur. ${ }^{344}$

343 Köllmann (1965), 114-116 und Mitchell (2007), 42-46.

344 Rothermund (1985), 69-72. 


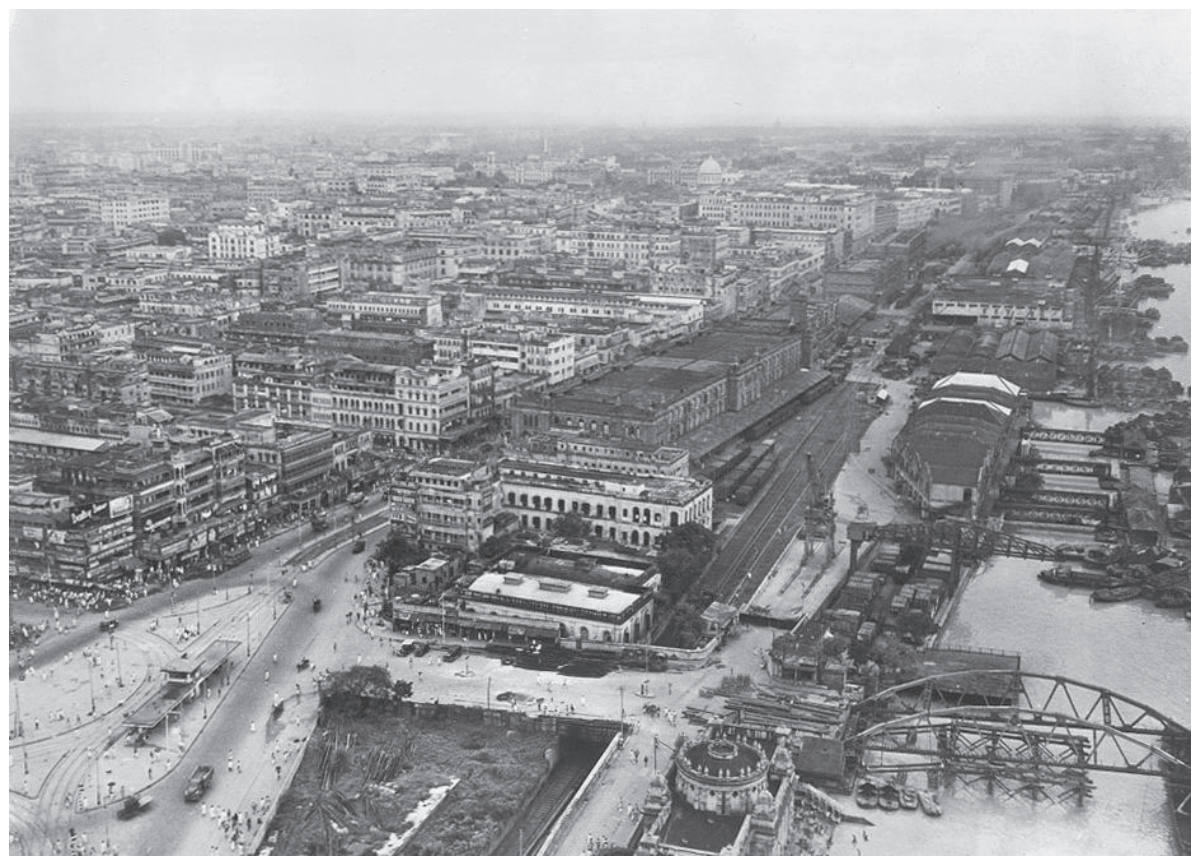

http://de.wikipedia.org/wiki/Kalkutta\#/media/File:AerialKolkata1945.jpg

Von vorneherein auf den Export ausgerichtet war die Juteindustrie in und um Kalkutta. Sie entwickelte sich auf Initiative britischer Unternehmer in der Nähe des in der Region angebauten Rohstoffes und stellte einen rasch wachsenden Ableger der schottischen Jutewarenproduktion dar. 1914 rangierte die indische Juteindustrie unter den Jutewaren produzierenden Ländern an zweiter Stelle. Neben diesen beiden Hauptindustriezweigen wurden auch in mehreren anderen Branchen Fabriken gegründet, 1907 auch das erste größere Eisen- und Stahlwerk. ${ }^{345}$ Insgesamt stieg die industrielle Wertschöpfung zwischen 1868 und 1900 um nicht weniger als 10 Prozent pro Jahr an, zwischen 1900 und 1913 um

345 Arbeiteten im ersten Jahrzehnt des 20. Jahrhunderts noch 44 Prozent aller Industriebeschäftigten in der Baumwollund Juteindustrie, so waren es zu Beginn der 40er Jahre nur noch 30 Prozent. Sivasubramonian (2002), 109 f. Vgl. auch Rothermund (1985), 74 und Lal (1988 ), 200. 
6 Prozent und zwischen 1919 und 1939 um jährlich fast 4 Prozent. ${ }^{346} 1946$ produzierte die indische Industrie ohne das Handwerk rund sieben Mal so viel wie zu Beginn des Jahrhunderts. Etwas langsamer nahm die Zahl der darin Beschäftigten zu. ${ }^{347}$

Karte 10: Millionenstädte in Asien um 1950

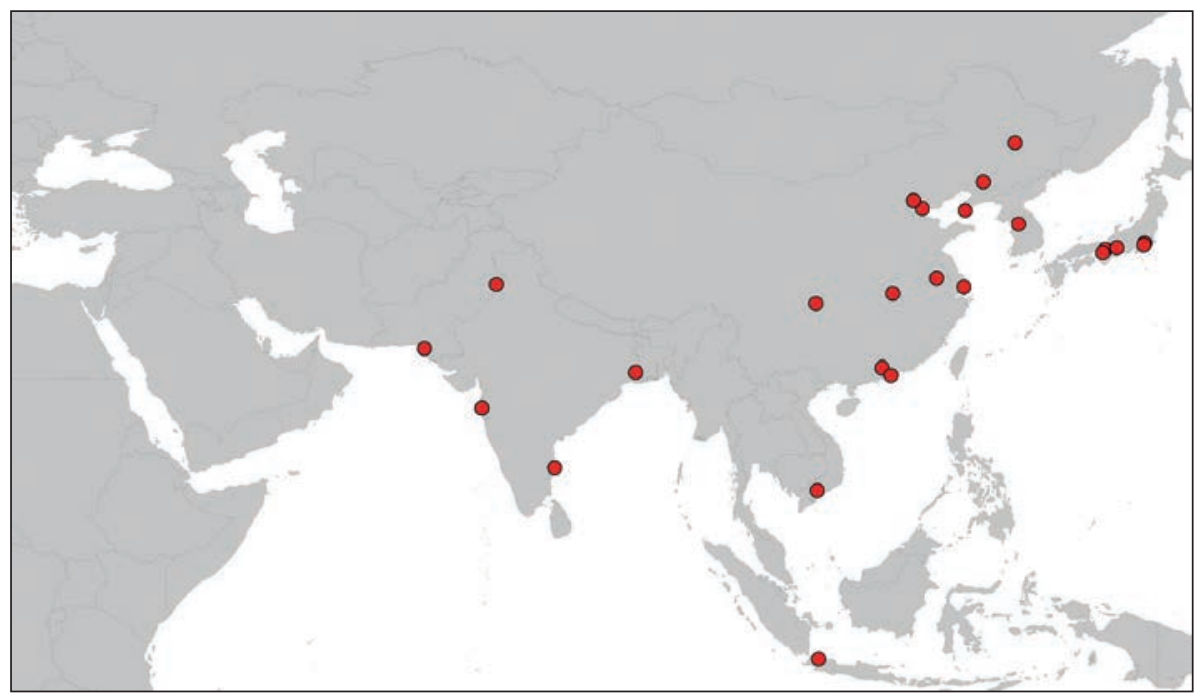

Tirol Atlas - Bearbeitung Klaus Förster nach Tabelle 32, Tabelle 35 und Tabelle 40.

Kartenhintergrund: World Borders Dataset - http://thematicmapping.org/downloads/world_borders.php

Dennoch war wegen der weit auseinander liegenden Großstädte und der weitgehend auf diese beschränkten Massennachfrage nach Industriewaren erst ein sehr kleiner Teil der indischen Bevölkerung - sie zählte um die Jahrhundertmitte etwa 360 Millionen Menschen - von der Industrialisierung erfasst worden (vgl. Tabelle 31 und Karte 10). Speziell Kalkutta wies den Charakter einer „Industrieinsel“ inmitten eines auf landwirtschaftliche Exporte ausgerichteten Gebietes auf. Auch die inzwischen auf mehrere Gebiete verteilte Baumwollindustrie schlug trotz ihrer beachtlichen Produktionsmengen gemessen an der indischen Gesamtbevölkerung nur in bescheidenem Maße zu Buche. ${ }^{348}$ Am Vorabend des

$346 \mathrm{Lal}(1988), 196$.

347 Sivasubramonian (2002), 106 und 109 sowie Lal (1988), 196 und 200).

348 Rothermund (1985), 72-83. 
Ersten Weltkrieges lag die Verarbeitung von Rohbaumwolle pro Einwohner in BritischIndien bei lediglich 1,2 kg, 1950 in dem inzwischen unabhängigen Indien bei $2 \mathrm{~kg}$. Noch isolierter waren die wenigen Eisen- und Stahlwerke, deren Produktion pro Einwohner weniger als 1 bzw. $5 \mathrm{~kg}$ ausmachte. Insgesamt waren um die Mitte des Jahrhunderts nur etwa 10 Prozent aller Erwerbstätigen im sekundären Sektor beschäftigt. ${ }^{349}$

Ähnliches gilt für die anderen Länder Südasiens, und zwar für die größeren Länder Pakistan und das spätere Bangladesch ebenso wie für die kleineren Länder Sri Lanka, Afghanistan und Nepal. Speziell in den beiden letzteren lebten noch viele Menschen als nomadische bis halbnomadische Viehzüchter, ${ }^{350}$ größere Städte waren neben den genannten Millionenstädten Karatschi und Lahore kaum entstanden.

Karte 11: Millionenstädte in Asien um 1980

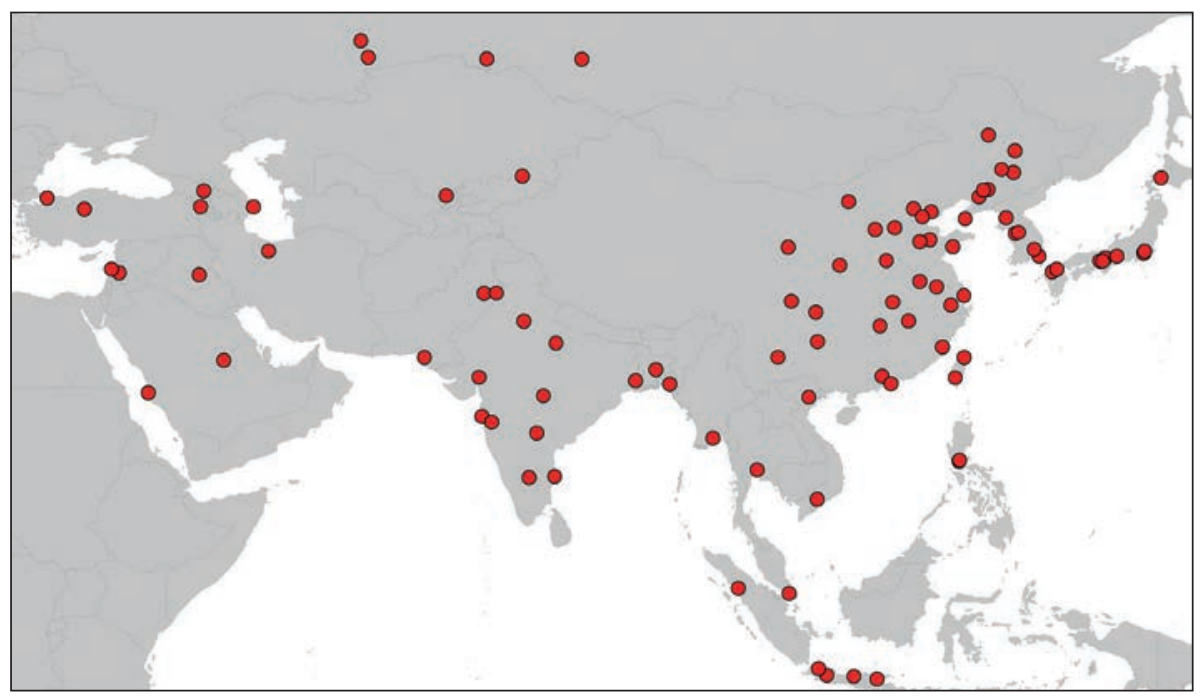

Tirol Atlas - Bearbeitung Klaus Förster nach Tabelle 28, Tabelle 32, Tabelle 35 und Tabelle 40.

Kartenhintergrund: World Borders Dataset - http://thematicmapping.org/downloads/world_borders.php

349 Eigene Berechnungen nach Mitchell (2007), 442, 467, 103 f. und Maddison (Population).

350 In Afghanistan waren es nach einer Schätzung der UNO Ende der 60er Jahre rund zwei und später nach einer offiziellen Schätzung der afghanischen Regierung sechs Millionen. Noor (1974), 28 und Kuchis (Afghanistan). 
Erst in der zweiten Hälfte des 20. Jahrhunderts kam es auch in Südasien dank sinkender Sterblichkeit zu einer geradezu explosionsartigen Zunahme der Gesamtbevölkerung und der Großstädte (vgl. Tabelle 31 und Tabelle 32). In Indien, wo seit der Jahrtausendwende über eine Milliarde Menschen leben, stieg die Zahl der Millionenstädte bis 1980 auf 10 und bis zur Jahrhundertwende auf 25 an, von denen das inzwischen auf Mumbai umbenannte Bombay und Kalkutta zuletzt über 10 Millionen Einwohner zählten. Allerdings verteilten sich die Großstädte nicht gleichmäßig auf das ganze Land. Westlich einer Linie zwischen Delhi und Madras, dem heutigen Chennai, lagen etwa doppelt so viele und mit Ausnahme Kalkuttas auch die größeren Millionenstädte als östlich davon (vgl. Karte 11).

Dementsprechend verlief auch der Industrialisierungsprozess, der nunmehr von den indischen Regierungen weit stärker gefördert wurde als zuvor von den Briten, im westlichen Teil des Landes mit mehr Dynamik als im Osten. Neben der Gegend zwischen Ahmedabad und Pune einschließlich des Großraumes von Bombay und dem Punjab mit der Hauptstadt Delhi entwickelten sich auch der Bundesstaat Tamil Nadu mit der Metropole Madras und die Industriestadt Bangalore im Süden zu wichtigen Industriegebieten des Landes. Obwohl in diesen Regionen weniger als ein Viertel der Gesamtbevölkerung lebte, vereinigten sie um die Mitte der 70er Jahre weit mehr als die Hälfte der industriellen Produktion auf sich. Ein weiteres Viertel der Industrieproduktion entfiel auf die östlichen Bundesstaaten West-Bengalen, Bihar und Orissa, dem heutigen Odisha. ${ }^{351}$ Hier befanden sich neben der alten Industriestadt Kalkutta die Zentren der Schwerindustrie, die im Umfeld großer Erz- und Kohlevorräte entstanden. Im Unterschied zur relativ breiten Industrialisierung im Westen blieben sie allerdings „Enklaven industriellen Fortschritts“ in einer überwiegend landwirtschaftlichen Umgebung. ${ }^{352}$

Wie sehr es auch in Indien gerade die Großstädte waren, die Industriegründungen anzogen, lässt sich am Beispiel Bombays besonders gut zeigen. 1961 arbeiteten fast zwei Drittel aller Industriebeschäftigten des zweitgrößten Bundesstaates Maharashtra allein in Bombay; zusammen mit der nahe gelegenen Großstadt Pune und ihrer beiden Umfeld waren es sogar 89 Prozent. Der große Rest war mit Ausnahme des weiter östlich gelegenen, ebenfalls großstädtischen Industriezentrums Nagpur weitgehend industriefrei. ${ }^{353}$ Obwohl in der Folge in anderen Teilen des Bundesstaates viele meist kleinere und mittlere

351 Tischner (1981), 192. Vgl. auch Schmidt (1974), 89.

352 Rothermund (1985), 194-199.

353 Bronger (2004), 108. 
Industriebetriebe entstanden, entfiel 1998 noch immer ein knappes Drittel aller Industriebeschäftigten auf Bombay, wo nur etwa 10 Prozent der Einwohner Maharashtras lebten. ${ }^{354}$ Insgesamt verzeichnete die industrielle Entwicklung in Indien in der zweiten Jahrhunderthälfte ein beachtliches Wachstum, wobei neben der traditionellen Textilindustrie nun auch andere Branchen vor allem im Bereich der Investitionsgüter eine größere Rolle spielten. Das gesamte Produktionsvolumen der Industrie und des verarbeitenden Gewerbes stieg zwischen 1947 und 1997 um mehr als das Fünfzehnfache, während sich die landwirtschaftliche Produktion lediglich verdreifachte. ${ }^{355}$ Unter Berücksichtigung des Bevölkerungswachstums ergaben sich daraus für die Landwirtschaft praktisch stagnierende Pro-Kopf-Werte, während in der Industrie und im verarbeitenden Gewerbe vor der Jahrtausendwende pro Einwohner mehr als fünf Mal so viel produziert wurde wie 50 Jahre zuvor. ${ }^{356}$ In keinem anderen Bereich wuchsen die Arbeitsproduktivität, gemessen an der Wertschöpfung pro Erwerbstätigem, und damit potentiell auch die Einkommen so schnell wie in der Industrie. ${ }^{357}$

Der Industrialisierungsprozess sollte sich in diesem halben Jahrhundert nicht nur beschleunigen, sondern auch auf andere Produktionszweige erweitern. Während sich zwischen 1960 und 1980 die Produktion von Roheisen, Rohstahl und Kraftfahrzeugen verdoppelte bis verdreifachte, die von Fahrrädern und Radiogeräten vervier- bis versechsfachte und sich die Herstellung von Stickstoff- und Phosphatdünger sogar verzwanzigfachte, legte die Produktion von Jute- und Baumwollwaren nur noch um etwa ein Viertel zu. ${ }^{358}$ Dementsprechend verschoben sich auch die relativen Anteile der einzelnen Branchen an der industriellen Gesamtproduktion zugunsten einer ausgewogeneren, weniger einseitigen Struktur. Im größeren Zeitraum zwischen 1951 und 1994 fiel der Anteil der Textilindustrie von rund 40 auf wenig mehr als 10 Prozent, während der Anteil von Chemie, Metallen und des Maschinenbaus von circa 20 auf etwa 69 Prozent anstieg. ${ }^{359}$ Während sich die Verarbeitung von Rohbaumwolle pro Einwohner bis gegen Ende des Jahrhunderts nur unwesentlich auf 2,6 kg erhöhte, wuchs die Roheisenproduktion bis 2011 auf das fast Siebenfache des Wertes von $1950 .{ }^{360}$ Dennoch blieb Indien dank der

354 Vgl. auch Bronger/Trettin (2011), 287.

355 Sivasubramonian (2002), 117.

356 Eigene Berechnungen nach Sivasubramonian (2002), 117 und Maddison (Population).

357 Sivasubramonian (2001), 120.

358 Rothermund (1985), 170.

359 Sivasubramonian (2002), 126.

360 Eigene Berechnungen nach Mitchell (2007),442, 467 und Maddison (Population) 
überaus hohen Bevölkerungszahl mit $32 \mathrm{~kg}$ pro Einwohner in der Pro-Kopf-Erzeugung weit hinter den hoch entwickelten Industrieländern zurück, obwohl es nach der Gesamtmenge unter den fünf größten Roheisenerzeugern der Welt rangierte. ${ }^{361}$

Grafik 30: Erwerbstätige in Industrie und verarbeitendem Gewerbe in Südasien 1981-2002

(Prozent aller Beschäftigten, Höchstwerte)

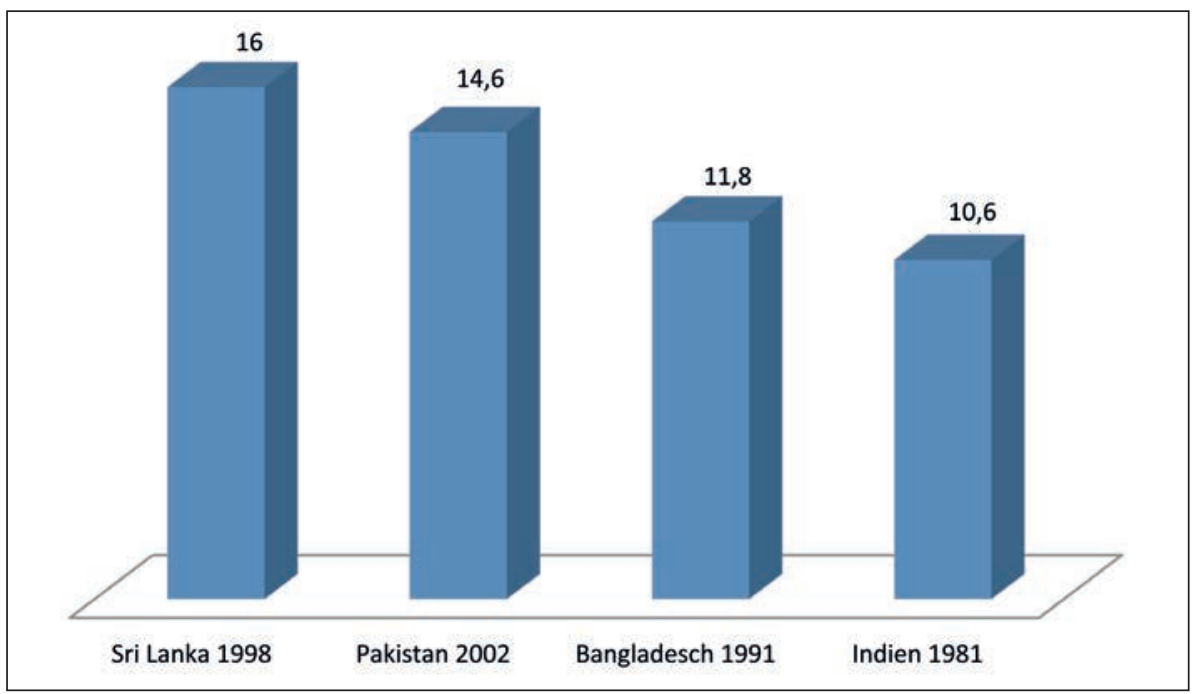

Eigene Berechnungen nach Mitchell (2007), 103 f. und 109 f.

Somit lässt sich für Indiens Industrialisierung Ähnliches resümieren wie für andere weniger entwickelte Länder. Trotz erheblicher Industrialisierungsfortschritte in den letzten Jahrzehnten beschränkten sie sich vorerst auf einen in relativer Hinsicht nur kleinen Teil der Bevölkerung speziell in und im Umfeld der großen Städte. Da es trotz ihrer großen Zahl an einer den Industrieländern vergleichbaren, großstädtischen Dichte mangelte, kam es zu keinem breiteren, das gesamte Land erfassenden Industrialisierungsprozess. Noch zu Beginn des neuen Jahrhunderts arbeiteten wie zuvor ${ }^{362}$ nur etwa 11 Prozent der Beschäftigten in Industrie und verarbeitendem Gewerbe. ${ }^{363}$ Dank der über die industrielle

361 Liste der größten Roheisenerzeuger.

362 Mitchell (2007), $103 \mathrm{f}$.

363 Growth Amid Change (2007), 52. 
Produktion geschaffenen Wertschöpfung konnten zwar direkt und indirekt in den Ober- und Mittelschichten der größeren Städte Millionen von Menschen ähnlich hohe Einkommen erzielen wie in den Industrieländern, gleichzeitig blieb eine noch größere Zahl von Menschen, und zwar auf dem Land ebenso wie in den durch Zuwanderung wachsenden Elendsvierteln der Großstädte, von diesem Prozess ausgeschlossen. Noch 2003 arbeiteten fast 60 Prozent aller Erwerbstätigen in der Landwirtschaft, ${ }^{364}$ und für die Metropolregion Mumbai geht die amtliche Statistik von einem Anteil von knapp 50 Prozent Slumbevölkerung aus. ${ }^{365}$

Dharavi Slum in Mumbai um 2008

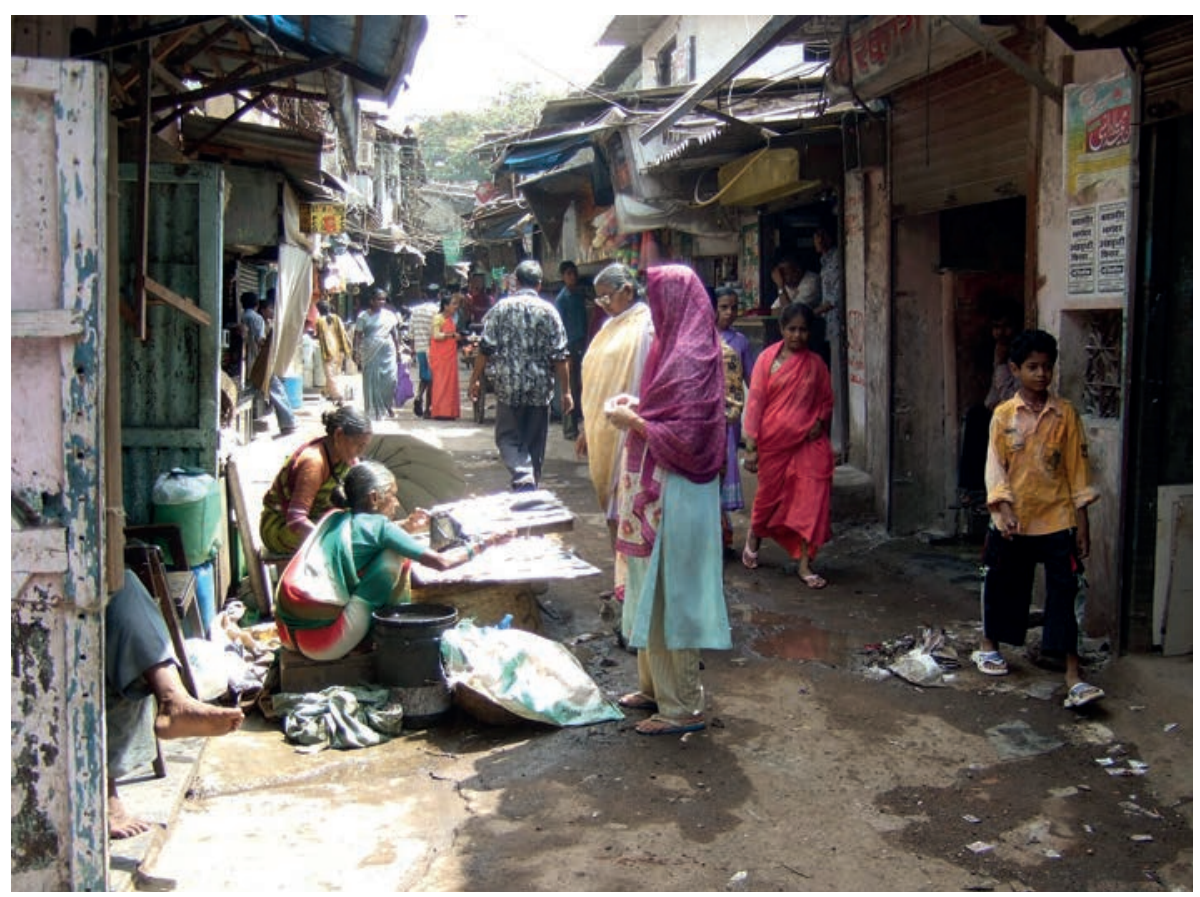

http://de.wikipedia.org/wiki/Mumbai\#/media/File:Dharavi_Slum_in_Mumbai.jpg

364 Fischer Weltalmanach (2008), 218.

365 Bronger (2004), 163. 
Grafik 31: Fernsehgeräte pro 1.000 Einwohner in Südasien 1985-2006

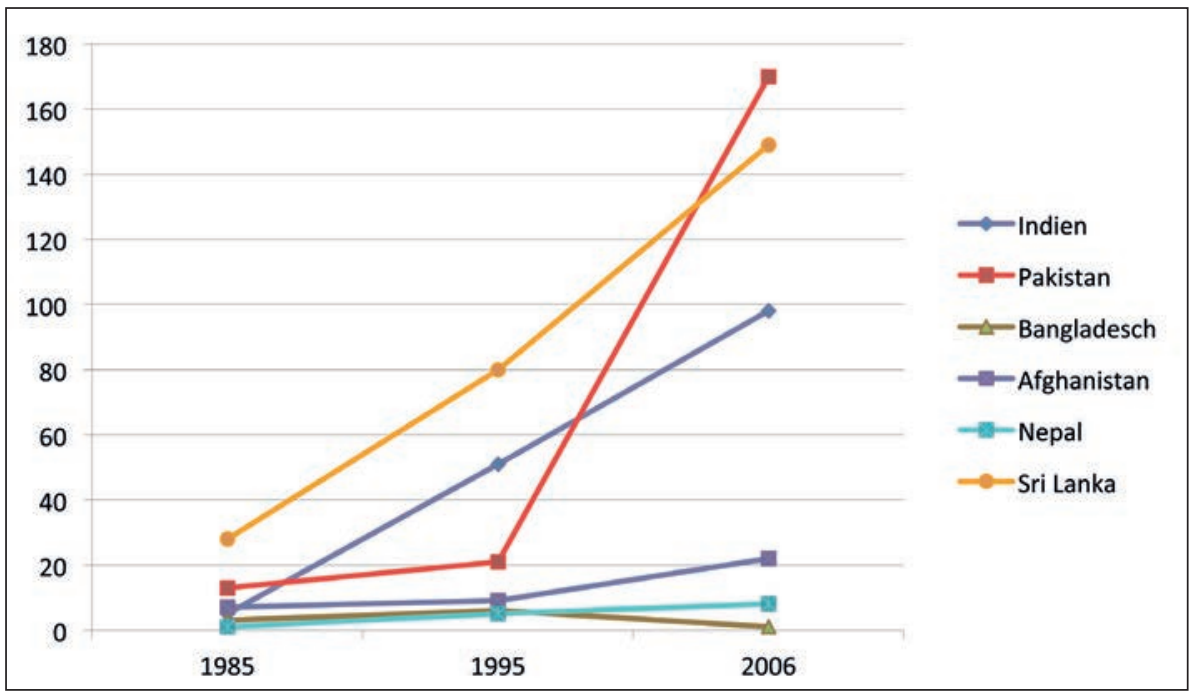

Vgl. Tabelle 33.

Dementsprechend niedrig fielen die Werte für die Dichte an Fernsehgeräten, Personenkraftwagen und Computern aus, die schon mehrfach als Gradmesser wirtschaftlichen Woblstandes herangezogen wurden (vgl. Grafik 31 bis Grafik 33). Trotz regional zum Teil weit höheren Werten rangierte Indien als Ganzes um 2006 mit einem Bestand von knapp 98 TV-Geräten, 10 PKW und 14 Computern pro 1.000 Einwohnern unter den ärmsten Ländern der Welt, obwohl das Land inzwischen unter die größten PKW-Produzenten der Welt aufgestiegen war. ${ }^{366}$ Fast ein Drittel aller PKW entfielen auf die vier Megastädte Mumbai, Kalkutta, Delhi und Chennai, in denen zusammen nur 5 Prozent der indischen Bevölkerung lebten. ${ }^{367}$ Kaum weniger dramatisch fiel der Rückstand in der durchschnittlichen wirtschaftlichen Wertschöpfung pro Einwohner aus, die 2008 weniger als ein Siebtel der west-, mittel- und nordeuropäischen Industrieländer ausmachte. Allerdings resultierte der niedrige Wert nicht so sehr aus einer mangelnden wirtschaftlichen Entwicklung des gesamten Landes, sondern vielmehr aus ihrer

366 Wirtschaftszahlen zum Automobil.

367 Bronger/Trettin (2011), 281. 
Beschränkung auf relativ wenige, hauptsächlich großstädtische Regionen, während viele andere Regionen in vorindustrieller Armut verharrten. ${ }^{368}$

Grafik 32: PKW pro 1.000 Einwohner in Südasien 1970-2006

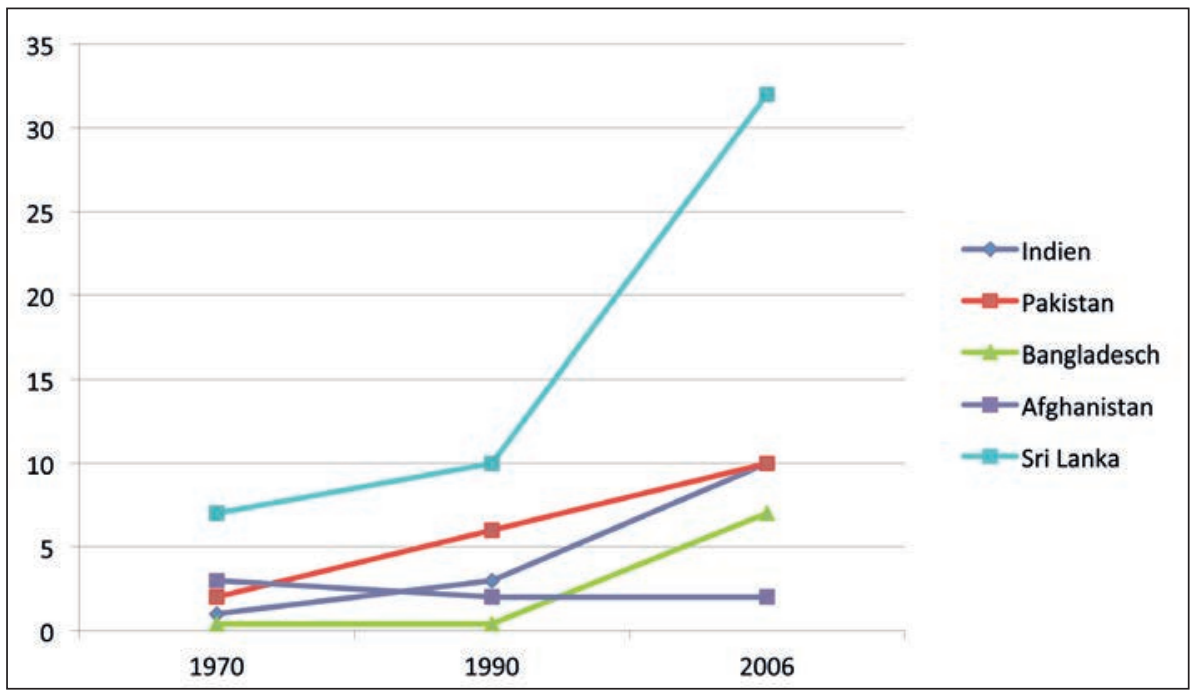

Vgl. Tabelle 33.

Auch in den anderen Nachfolgestaaten Britisch-Indiens, in Pakistan und dem 1971 davon abgetrennten Bangladesch mit um die Jahrtausendwende sieben bzw. drei Millionenstädten, erfuhr die Industrialisierung in den letzten Jahrzehnten eine deutliche Beschleunigung. ${ }^{369}$ In Pakistan produzierte der gesamte sekundäre Sektor um die Jahrtausendwende 24 Mal so viel wie 1955, was pro Einwohner mehr als dem Siebenfachen entsprach. ${ }^{370}$ Ein überdurchschnittlich großer Teil entfiel auf die Baumwollindustrie, die sich auf eine umfangreiche eigene Rohstoffproduktion stützen konnte. Obwohl sie erst nach 1947 von privaten Unternehmern aufgebaut wurde, erlebte sie in der Folge ein besonders rasches Wachstum und machte Pakistan hinter China und Indien zum weltweit drittgrößten

368 Vgl. Lal (1988), 216.

369 Zur Konzentration der Industrialisierung auf die Großstädte vgl. Zingel (1979), 279 und Heimat und Welt (Südasien - Wirtschaft).

370 Eigene Berechnungen nach Mitchell (2007), 368 und 370 sowie Maddison (Population). 
Produzenten von Baumwollwaren. Um die Jahrtausendwende lag die Verarbeitung von Rohbaumwolle pro Einwohner bei fast $14 \mathrm{~kg}$ und damit über dem Niveau, das die meisten europäischen Länder mit Ausnahme Großbritanniens jemals erreicht hatten. ${ }^{371}$ Vor allem die neue, wenn auch nur vorübergehende Hauptstadt Karatschi entwickelte sich zum zentralen Industriezentrum des Landes, gefolgt vom Punjab mit den Industrieund Millionenstädten Lahore, Faisalabad, Multan, Gujranwala und Rawalpindi sowie der südlichen Industriestadt Hyderabad. Dagegen gab es im nach wie vor ländlich geprägten und dünn besiedelten Belutschistan, in der Nordwestlichen Grenzprovinz und in den nördlichen Bergregionen nur wenig Industrie, so dass zu Beginn des Jahrtausends noch immer über 40 Prozent der Erwerbstätigen in der Landwirtschaft und nur knapp 15 Prozent in der Industrie und im verarbeitenden Gewerbe arbeiteten (vgl. Grafik 30). ${ }^{372}$

Grafik 33: Computer pro 1.000 Einwohner in Südasien 2006

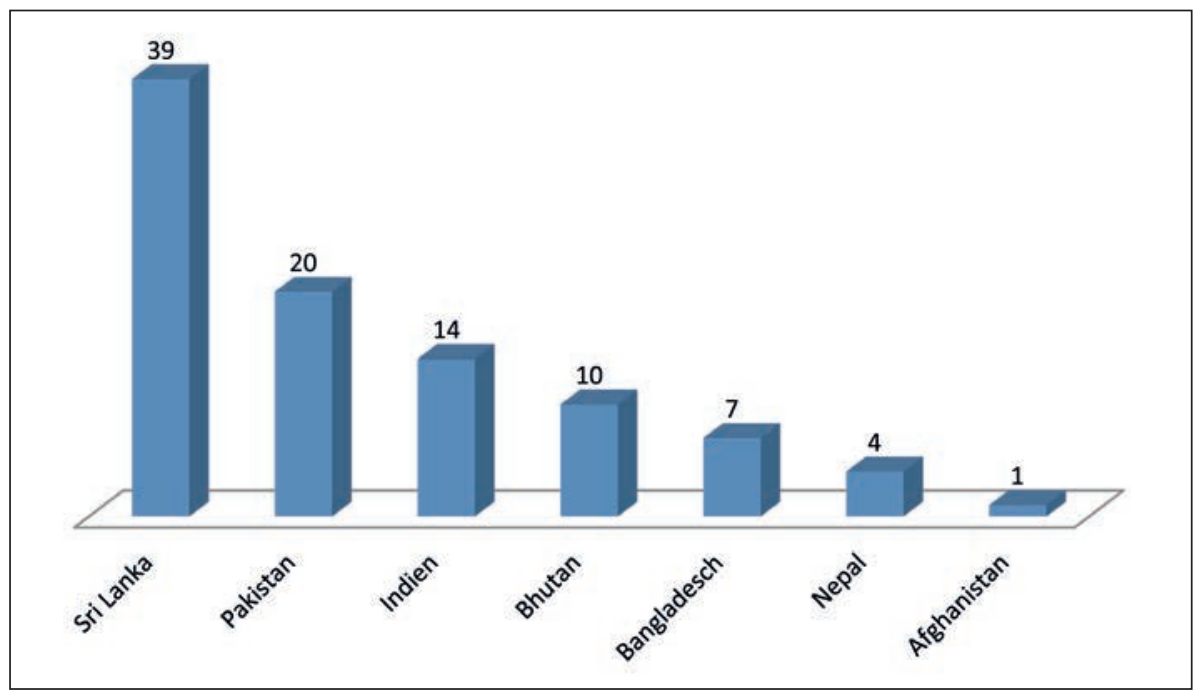

Welt in Zahlen (Computer).

371 Eigene Berechnungen nach Mitchell (2007), 468 und Maddison (Population), sowie Fischer (1987), 135.

372 Zingel (1979), 233-248, 290-297 und 374-523; Hübner-Schmid (2004), 11; Mitchell (2007), 109. 
Sowohl den nach wie vor hohen Anteil der Landwirtschaft als auch die überragende Stellung der Textilindustrie hatte Pakistan mit dem früheren Ostpakistan, dem heutigen Bangladesch gemeinsam, das in jüngster Zeit nach China zum weltweit zweitgrößten Textilproduzenten der Welt aufstieg. ${ }^{373}$ Allerdings stand hier weniger die Verarbeitung von Rohbaumwolle - sie lag um die Jahrtausendwende bei nur gut einem Kilogramm pro Kopf der Bevölkerung -, ${ }^{374}$ sondern vielmehr die Bekleidungsindustrie im Vordergrund. In beiden Ländern spielte die Binnennachfrage für die außergewöhnliche Expansion ihrer Textilindustrie allerdings nur eine relativ geringe Rolle. Viel wichtiger war die ausländische Nachfrage nach Baumwollgarnen und -stoffen im einen sowie nach Bekleidung im anderen Fall. ${ }^{375}$ Wie in anderen Ländern das Erdöl oder andere mineralische Rohstoffe stellten in Pakistan und Bangladesch Textilwaren die wichtigsten Exportgüter dar. Eine auf den heimischen Markt ausgerichtete Industrialisierung erreichte nicht zuletzt wegen der umfangreichen Industriewarenimporte nur bescheidene Ausmaße. In Bangladesch arbeiteten 1991 am Höhepunkt der Industrialisierung lediglich 12 Prozent der Erwerbstätigen in der Industrie und im verarbeitenden Gewerbe (vgl. Grafik 30). ${ }^{376}$

Der niedrige Industrialisierungsgrad wirkte sich wie in anderen Ländern ungünstig auf die gesamtnationalen Durchschnittswerte aus. Dabei schnitt Pakistan etwas besser ab als Bangladesch, dessen Bruttoinlandsprodukt pro Einwohner 2008 nur etwa die Hälfte von Pakistan und ein gutes Drittel des indischen Wertes ausmachte. ${ }^{377}$ Auch die Ausstattung mit langlebigen Konsumgütern fiel in beiden Ländern überaus bescheiden aus (vgl. Grafik 31 bis Grafik 33).

Ähnlich schwach entwickelt blieben die weitgehend landwirtschaftlich geprägten Länder Afghanistan, Nepal und das kleine Bhutan. Noch zu Beginn des neuen Jahrtausends arbeiteten in Afghanistan rund 70 Prozent - zum Teil als Nomaden - und in den beiden Himalayastaaten über 90 Prozent aller statistisch erfassten Erwerbstätigen in der großteils auf Selbstversorgung ausgerichteten Landwirtschaft. ${ }^{378}$ An Großstädten hatte lediglich Kabul die Millionengrenze überschritten, Kathmandu kam nahe an die Millionengrenze heran. Ansätze einer Industrialisierung, die in Afghanistan speziell in der

373 Textilindustrie in Bangladesch

374 Eigene Berechnung nach Mitchell (2007), 467 und Maddison (Population).

375 Wikipedia (Pakistan) und Wikipedia (Bangladesch).

376 Mitchell (2007), 103 und Growth Amid Change (2007), 50.

377 Maddison (Per Capita GDP).

378 Fischer Weltalmanach (2008), 44, 79 und 345 sowie Kafle (2007), 1-9. 
Herstellung von Baumwollstoffen seit den 50er Jahren zu beobachten waren, wurden durch die kriegerischen Auseinandersetzungen seit den späten 70er Jahren unterbrochen. $^{379}$

Deutlich besser verlief die Entwicklung in Sri Lanka, der früheren Insel Ceylon. Neben einer exportorientierten Landwirtschaft, die das relativ kleine Land zum drittgrößten Teeexporteur der Welt aufsteigen ließ, entwickelte sich speziell im Umfeld der Metropolregion um die faktische Hauptstadt Colombo eine eigene Industrie, die zusammen mit dem verarbeitenden Gewerbe gegen Ende des Jahrhunderts 16 Prozent aller Erwerbstätigen beschäftigte. ${ }^{380}$ Der Anteil der Landwirtschaft war auf zuletzt weniger als 40 Prozent gesunken. Nach den Berechnungen von Maddison erwirtschaftete Sri Lanka 2008 pro Einwohner ein Bruttoinlandsprodukt, das Pakistan um mehr als das Doppelte und Nepal um mehr als das Vierfache übertraf und an die Werte der ärmeren Länder Südosteuropas herankam. ${ }^{381}$

\section{Südostasien}

Obwohl die Länder Südostasiens bezüglich Urbanisierung und Industrialisierung mit den Ländern Südasiens viel gemeinsam haben, weisen sie mit Singapur eine bemerkenswerte Ausnahme auf. Wenn Singapur in den letzten Jahrzehnten den Anschluss an die höchst entwickelten Industrieländer gefunden hat - 2008 war die Wertschöpfung pro Einwohner etwa gleich hoch wie in Norwegen und wurde nur von den USA übertroffen $-{ }^{382}$ ist dies vor allem seiner Struktur als einem räumlich eng begrenzten Stadtstaat zu verdanken. Als günstig gelegener Umschlagplatz und Handelsstadt auf dem Seeweg zwischen Europa und China überschritt Singapur bereits in den 50er Jahren des 20. Jahrhunderts die Grenze zur Millionenstadt und zählte um die Jahrtausendwende über vier Millionen Einwohner. ${ }^{383}$

379 Vgl. Fischer (1968), 20.

380 Mitchell (2007), 110, Wikipedia (Sri Lanka) und Sri Lanka Industry Country Studies.

381 Maddison (Per Capita GDP).

382 Maddison (Per Capita GDP).

383 Mitchell (2007), 45. 


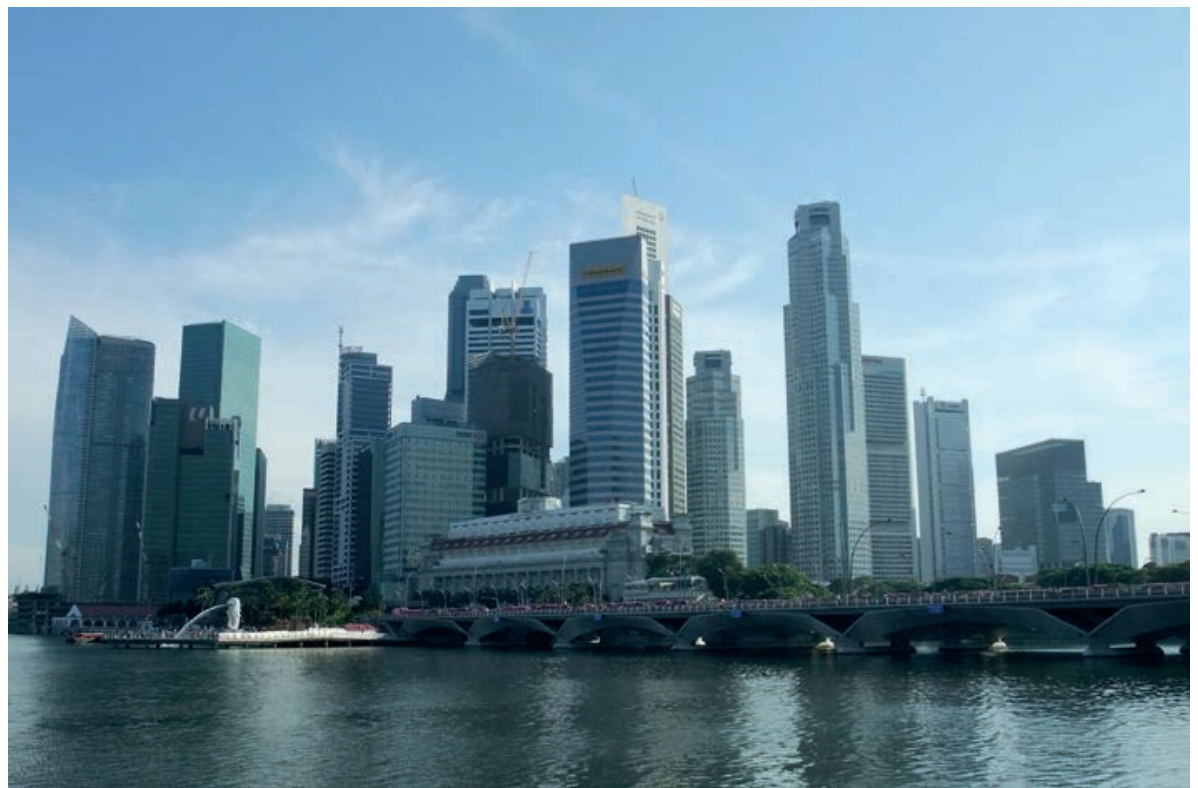

http://de.wikipedia.org/wiki/Singapur\#/media/File:Singapore_Skyline_2009.jpg

Damit waren wie in anderen Großstädten günstige Voraussetzungen für eine Industrialisierung gegeben, die wie in diesen auch genutzt wurden. Allerdings unterschied sich Singapur insofern, als es Stadt und Staat in einem war, während die anderen Großstädte in größere Flächenstaaten mit einem hohen Anteil ländlicher Bevölkerung eingebettetwaren. Dementsprechend höherfielen diegesamtstaatlichen Durchschnittswerte Singapurs bei Industrialisierungsgrad, Wertschöpfung oder langlebigen Konsumgütern aus. Außerdem verhinderten die nationalen Grenzen eine unkontrollierte Massenzuwanderung aus den ländlichen Gebieten umliegender Regionen und damit eine anderen Großstädten vergleichbare Slumbildung. Auf diese Weise wurde Singapur sowohl Industriestadt als auch Industriestaat, in dem der Anteil einer wenig entwickelten und daher wenig kaufkräftigen Bevölkerung verschwindend klein war: 1957 arbeiteten knapp 10 und 1987 weniger als 1 Prozent der Erwerbstätigen in der Landwirtschaft. ${ }^{384}$

384 Mitchell (2007), 110 und Pascha (1990), 99. 
Grafik 34: Erwerbstätige in Industrie und verarbeitendem Gewerbe in Südostasien 1989-2004

(Prozent aller Erwerbstätigen, Höchstwerte)

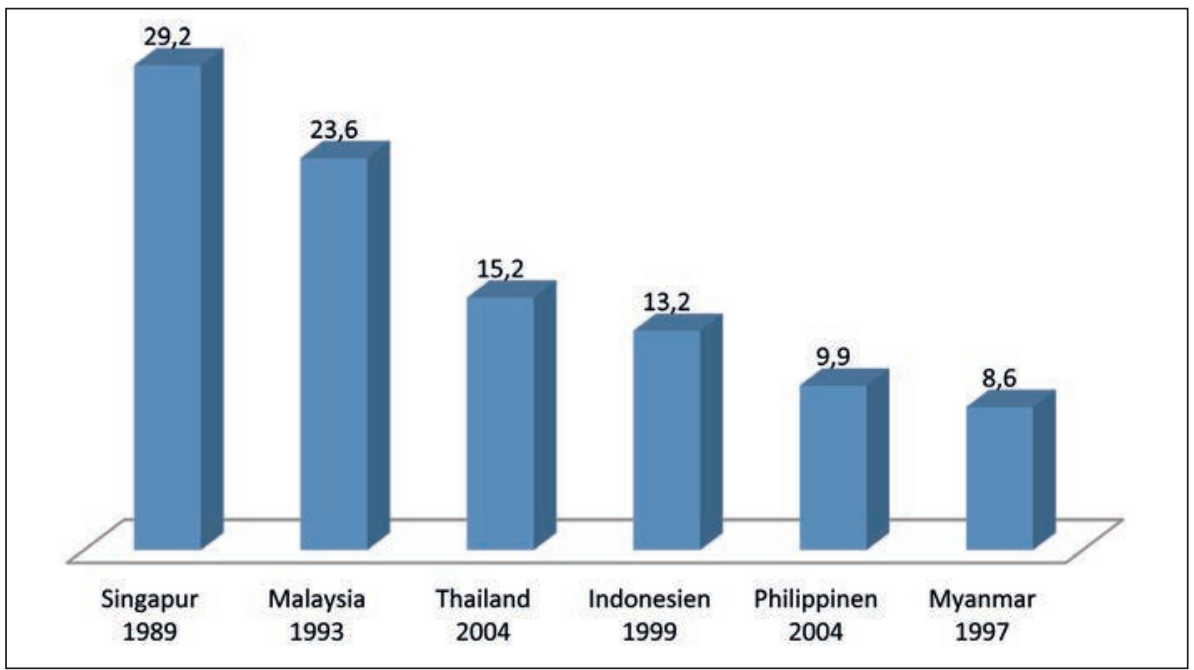

Eigene Berechnungen nach Mitchell (2007), 105 und 109-111.

Zunächst hatte der wachsende städtische Binnenmarkt neben dem für eine Handelsstadt typischen Dienstleistungssektor ein verarbeitendes Gewerbe und eine Industrie entstehen lassen, die 1959, als sich Singapur aus der britischen Herrschaft löste, rund 17 Prozent der Erwerbstätigen beschäftigten. ${ }^{385}$ In der Folge war es in wachsendem Ausmaß auch der Weltmarkt, der zusätzliche Industrieinvestitionen anregte, wobei sich sowohl die gewerblichen Strukturen der Stadt als auch attraktive wirtschaftspolitische Rahmenbedingungen als Standortvorteile erwiesen. ${ }^{386}$ Zahlreiche Unternehmen aus entwickelten Industrieländern wie den USA, dem Vereinigten Königreich, den Niederlanden und Japan oder auch aus Hongkong und dem benachbarten Malaysia siedelten sich in Singapur an. Gemeinsam mit den heimischen Unternehmen trugen sie dazu bei, dass die reale Wertschöpfung der Industrie und des verarbeitenden

385 Mitchell (2007), 110.

$386 \operatorname{Kim}$ (1990), 178, Woronoff(1992), 129 und Agrawal (1995), 56. 
Gewerbes zwischen 1960 und 1989 im Durchschnitt um 10 Prozent pro Jahr wuchs. ${ }^{387}$ Obwohl dank zunehmender Produktivität die Beschäftigung nicht im selben Ausmaß zulegte, arbeiteten um 1990 knapp 30 Prozent aller Erwerbstätigen in Industrie und verarbeitendem Gewerbe (vgl. Grafik 34).

Danach ging ihr Anteil wie in anderen Industrieländern zugunsten des Dienstleistungssektors zurück: 2003 waren es noch 18 Prozent. ${ }^{388}$ Im Zuge der positiven wirtschaftlichen Entwicklung reduzierte sich der Anteil der Haushalte, die in absoluter Armut lebte, zwischen den frühen 50er und den frühen 80er Jahren von 19,2 auf lediglich 0,3 Prozent. Wie wohlhabend der Stadtstaat inzwischen geworden war, wird auch daraus ersichtlich, dass es 2006 pro Einwohner nur in den USA und in Australien sowie in Schweden, Luxemburg und der Schweiz mehr Computer gab als in Singapur. ${ }^{389}$

Abgesehen vom Stadtstaat Singapur bieten die Länder Südostasiens in ihrer überwiegenden Mehrheit dasselbe Bild wie die meisten anderen, weniger entwickelten Länder der Dritten Welt:

- $\quad$ eine bis weit ins 20. Jahrhundert vorherrschende, ländlich geprägte Bevölkerungsstruktur mit relativ wenig Handel und Gewerbe in den kleinen bis mittelgroßen Städten;

- $\quad$ ein rasches, geradezu explosionsartiges Bevölkerungswachstum in der zweiten Hälfte des 20. Jahrhunderts;

- $\quad$ eine noch raschere Zunahme der städtischen Bevölkerung speziell in den Großstädten;

- $\quad$ eine damit verbundene, allerdings weitgehend auf die Metropolen und ihre Umgebung beschränkte Industrialisierung mit ersten Anzeichen eines Überganges in eine Dienstleistungsgesellschaft;

- $\quad$ eine nach wie vor umfangreiche, von der Industrialisierung nur marginal erfasste Bevölkerung am Land und in den aus der Landflucht gespeisten Elendsvierteln der großen Städte;

3872005 wurde im sekundären Wirtschaftssektor mehr als $20 \mathrm{Mal}$ so viel produziert wie 40 Jahre zuvor. Eigene Berechnung nach Mitchell (2007), 368 und 370. Der Anteil von Industrie und verarbeitendem Gewerbe am Bruttoinlandsprodukt stieg zwischen 1960 und 1982 von 12 auf 26 Prozent. Harberger (1988), 167.

388 Agrawal (1995), 98, Mitchell (2007), 210 und Growth Amid Change (2007), 52.

389 Welt in Zahlen (Computer). 
- $\quad$ eine daraus resultierende, dualistische Gesellschaft mit durchschnittlichen ProKopf-Einkommen, die nicht nur den tatsächlichen Wohlstand der inzwischen besser gestellten, wenn auch relativ schmalen Bevölkerungsschichten, sondern auch die tatsächliche Armut der restlichen Bevölkerung nur unzureichend widerspiegeln.

Am relativ breitesten fiel die Industrialisierung in Malaysia aus (vgl. Grafik 34). Speziell im Westen der Malaysischen Halbinsel, wo auf einem Fünftel der Landesfläche der Großteil der Bevölkerung lebte, war neben der Hauptstadt Kuala Lumpur eine relativ große Zahl von kleineren und mittelgroßen Städten und damit eine Städtedichte entstanden, die als günstige Basis für eine Industrialisierung dienen konnte. Parallel zum raschen Wachstum der Gesamtbevölkerung (vgl. Tabelle 34) nahm die städtische Bevölkerung weiter zu, mit der Folge, dass Malaysia um die Jahrtausendwende neben der Millionenstadt Kuala Lumpur nicht weniger als 32 weitere Großstädte mit über 100.000 Einwohnern zählte. ${ }^{390}$ Sie befanden sich zu zwei Dritteln in dem relativ schmalen und nur etwa $700 \mathrm{~km}$ langen Landstreifen im Westen des Landes zwischen den Bundesstaaten Perlis im Norden und Johor im Süden. Einige von ihnen lagen in unmittelbarer Nachbarschaft zur Hauptstadt, mit der sie die rund sechs Millionen Einwohner zählende Metropolregion von Kuala Lumpur bildeten.

Hier entstanden auch die ersten Industrieansiedlungen. Auf private und staatliche Initiative wurde bereits 1952, also noch unter britischer Kolonialherrschaft, in Petaling Jaya in unmittelbarer Nähe zu Kuala Lumpur eine erste Industriezone errichtet, der bis in die 70er Jahre viele weitere derartige Industrieparks vor allem in den größeren Städten der Westküste wie etwa Butterworth und Ipoh im Norden oder Johor Bahru im Süden folgten. ${ }^{391}$ Erst danach ging man dazu über, solche von Seiten der Regierung mit günstigen Bedingungen geförderte Industriezonen auch in kleineren Städten und in den schwächer entwickelten Regionen im Osten des Landes anzulegen, nicht zuletzt infolge neu entdeckter Erdöl- und Erdgasfelder. Im Unterschied zu den schon früher entstandenen Betrieben zur Aufarbeitung der eigenen Zinnerze und des seit der Jahrhundertwende produzierten Kautschuks waren die Industrieparks anfangs vorwiegend auf den Binnenmarkt ausgerichtet. Sie blieben es auch, als später eine Reihe Freier Industriezonen

390 Liste der Städte (Malaysia).

391 Vgl. Vorlaufer (2009), 186 und Fessen/Kubitschek (1984), 174-177. 
hinzukamen, in denen sowohl von heimischen als auch von zahlreichen ausländischen Unternehmen insbesondere für den Export produziert wurde. ${ }^{392}$ Die Bedeutung traditioneller Konsumgüter speziell der Nahrungs- und Genussmittelindustrie ging - typisch für den zunehmenden Industrialisierungsgrad - zugunsten der Maschinen-, Elektro- und Automobilindustrie zurück, wobei anstelle einer bloßen Montage importierter Teile in zunehmendem Maße die Vollproduktion eigener Fahrzeuge aufgenommen wurde. ${ }^{393}$

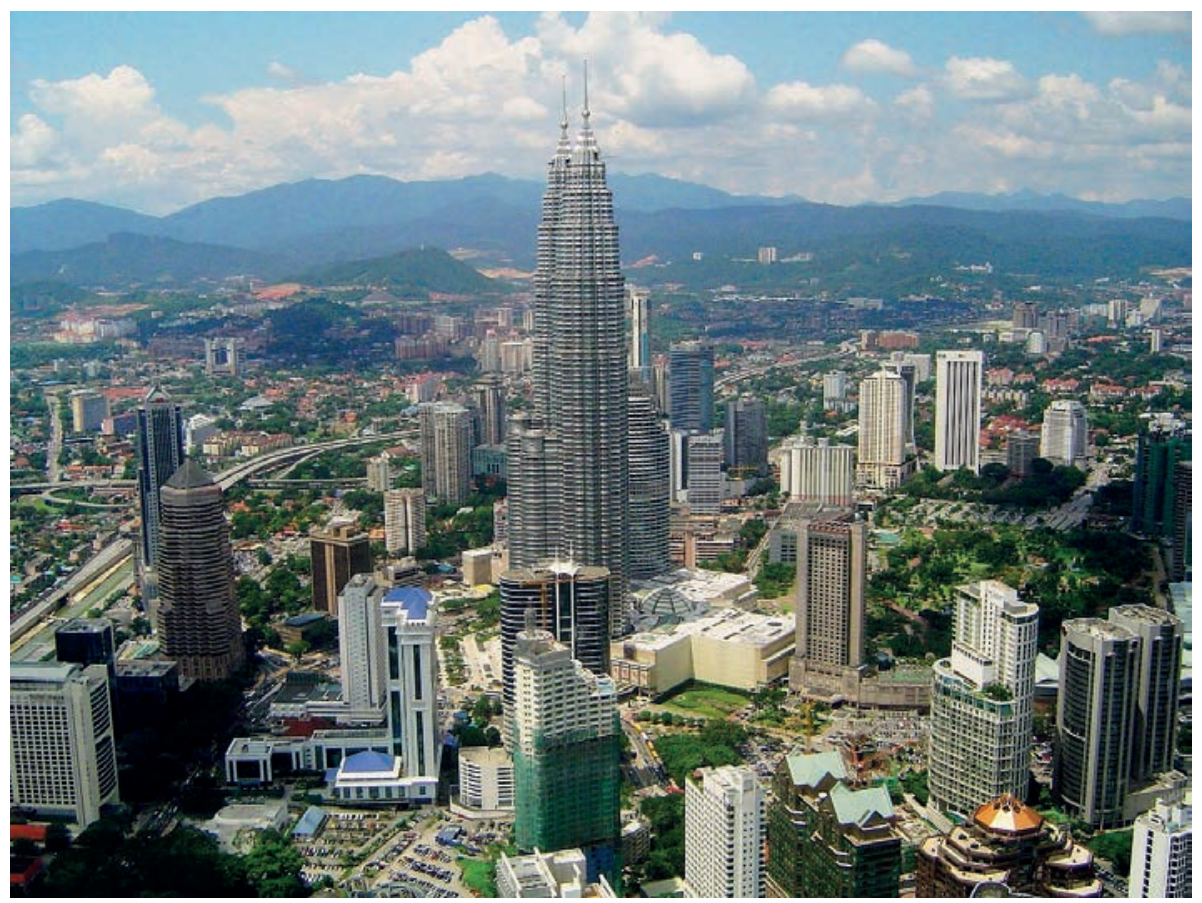

http://upload.wikimedia.org/wikipedia/commons/thumb/7/74/View_on_Petronas_Towers. JPG/1280px-View_on_Petronas_Towers.JPG

392 Kratoska (1998), 20-22

393 Tucher (1999), 52 und 82-89. 
Auch wenn die angeführten Zahlen nicht immer übereinstimmen, spiegeln sie alle eine bis zuletzt anhaltende, rasche Zunahme sowohl der industriellen Produktion als auch der in der Industrie Beschäftigten wider. Und da die Industriebetriebe vornehmlich in Gebieten angesiedelt waren, in denen die Mehrheit der malaysischen Bevölkerung lebte, schlugen sich die maßgebenden Kennzahlen auch im nationalen Durchschnitt nieder. Der Anteil von Industrie und verarbeitendem Gewerbe an der gesamten Wertschöpfung stieg zwischen 1970 und 1993 von 15 auf 40 Prozent. ${ }^{394}$ Pro Einwohner produzierte die Industrie mehr als zwei Mal so viel wie in Thailand, fünf Mal so viel wie in Indonesien und fast zehn Mal so viel wie auf den Philippinen. Fast ein Viertel aller Erwerbstätigen waren inzwischen in der Industrie und im verarbeitenden Gewerbe beschäftigt - zu Beginn der Unabhängigkeit im Jahre 1957 waren es lediglich 7 Prozent gewesen. ${ }^{395}$ Mit Ausnahme des Stadtstaates Singapur und des kleinen, atypischen Ölstaates Brunei arbeiteten zuletzt in keinem Land Südostasiens relativ so wenige Menschen in der Landwirtschaft wie in Malaysia (vgl. Tabelle 36). ${ }^{396}$ Die Folge des breiten Industrialisierungsprozesses war eine Wertschöpfung pro Einwohner, die zwar nicht an die Werte der west-, mitteloder auch südeuropäischen Länder herankam, jedoch die Produktionsleistung mancher osteuropäischer Länder ebenso übertraf wie die der anderen größeren Länder der Region. ${ }^{397}$ Und dasselbe trifft außer bei den Fernsehgeräten auch für die Ausstattung mit langlebigen Konsumgütern zu (vgl. Grafik 35 bis Grafik 37). Als weitere Folge der besseren wirtschaftlichen Entwicklung lebten in Malaysia auch deutlich weniger Menschen in den Elendsvierteln der Großstädte als mit Ausnahme Thailands in den anderen Ländern Südostasiens. ${ }^{398}$

394 Chowdhury (1997), 49.

395 Eigene Berechnungen nach Mitchell (2007), 109; vgl. Growth Amid Change (2007), 52.

396 Das kleine Sultanat Brunei stellte insofern einen Sonderfall dar, als sich wie in einigen ebenfalls kleinen Emiraten am Persischen Golf die Wirtschaft auf die Förderung und den Export von Erdöl und Erdgas konzentrierte, die den wenigen Einwohnern des Sultanats (um 2009 knapp 400.000) zu einem gewissen Wohlstand verhalfen. Maddison (Population) und Siddiqui (1997), 1-3.

397 Maddison (Per Capita GDP).

$398 \mathrm{Zu}$ Beginn des neuen Jahrhunderts waren es laut Vorhofer lediglich 2 Prozent der städtischen Bevölkerung. Vorlaufer (2009), 106. Zur positiven Entwicklung in Malaysia vgl. auch Chowdhury (1997), 43-50 
Grafik 35: Fernsehgeräte pro 1.000 Einwohner in Südostasien 1985-2006 (größere Länder)

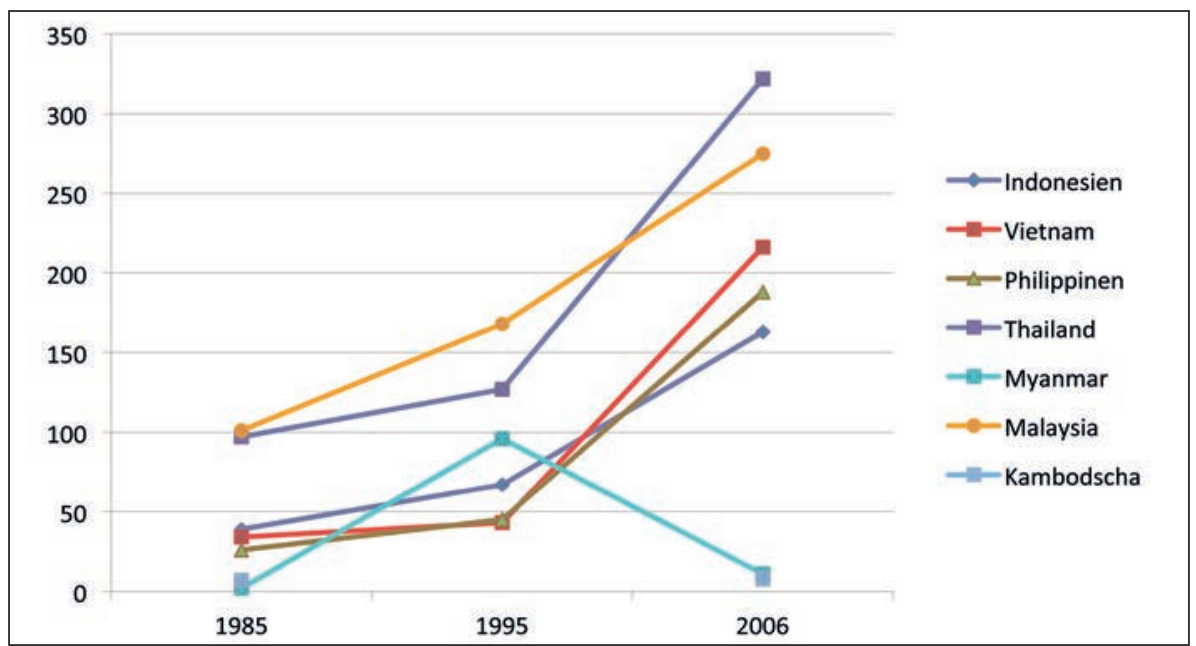

Vgl. Tabelle 37.

Grafik 36: PKW pro 1.000 Einwohner in Südostasien 1970-2006 (größere Länder)

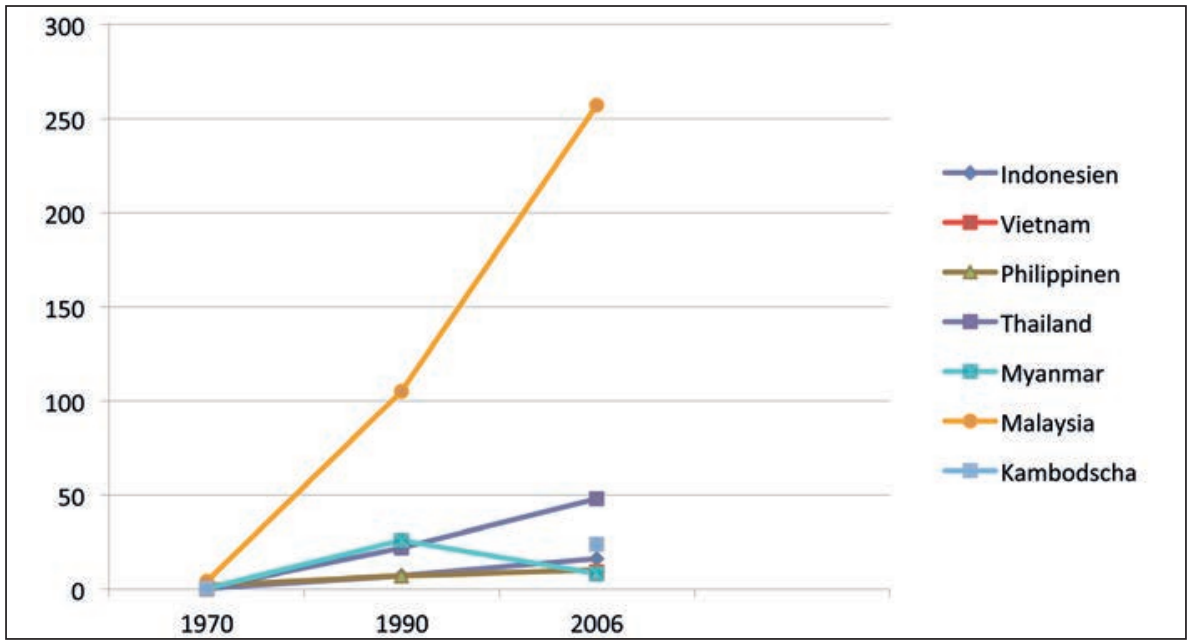

Vgl. Tabelle 37. 


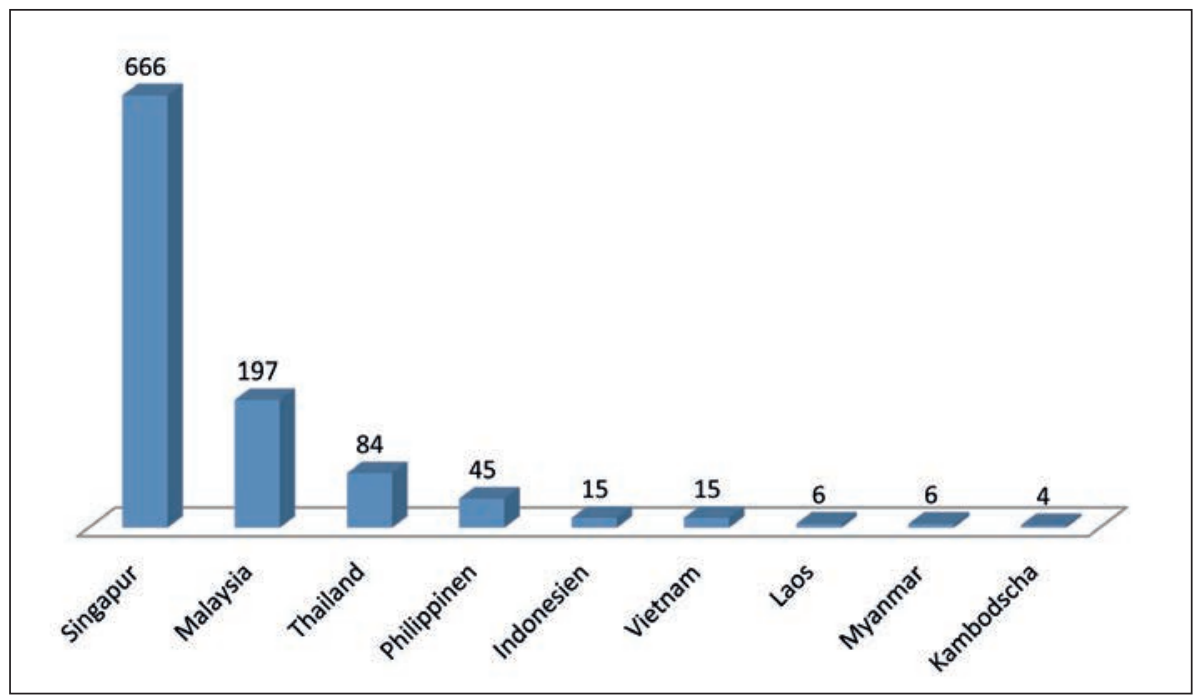

Welt in Zahlen (Computer).

In Thailand lässt sich in der zweiten Hälfte des 20. Jahrhunderts ein ähnlich starker Industrialisierungsprozess wie in Malaysia beobachten. Allerdings konzentrierte er sich hier in viel stärkerem Maße auf die Hauptstadtregion Bangkok und kam daher in der Breite relativ weniger Menschen zugute als in Malaysia. Während es in Malaysia um die Jahrtausendwende neben der Millionenstadt Kuala Lumpur noch drei weitere Großstädte mit über einer halben Million Einwohner gab, zählten in Thailand die nach Bangkok größten Städte Samut Prakan und Nonthaburi weniger als 400.000 Einwohner. ${ }^{399}$

Nach ersten Anfängen einer bescheidenen Industrialisierung, in deren Rahmen seit den 30er Jahren einige kleinere Betriebe etwa in der Papier-, Textil-, Zucker- oder Alkoholindustrie entstanden waren, dauerte es bis 1950, als mit der Bangkok Cotton Mills eine erste größere Baumwollspinnerei mit gut 1.000 Mitarbeiterinnen gegründet wurde. ${ }^{400}$ Weitere Unternehmen folgten und ließen Thailand zu einem der größeren Produzenten von Baumwollwaren aufsteigen. Weniger Verbreitung fand dagegen die Eisen- und

399 Liste der Städte (Malaysia) und Liste der Städte (Thailand).

400 Ingram (1971), 121. 
Stahlerzeugung, die erst 1965 in größerem Umfang aufgenommen wurde und noch zu Beginn des neuen Jahrhunderts weniger Stahl produzierte als etwa das sehr viel kleinere Österreich. ${ }^{401}$ So beschränkte sich auch die in den 70er Jahren begonnene, eigene Automobilproduktion im Wesentlichen auf die Montage importierter Teile, obwohl manche von ihnen in zunehmendem Maße in Thailand selbst hergestellt wurden. ${ }^{402}$ Insgesamt wuchs die industrielle Produktion, die zunächst insbesondere auf den Binnenmarkt und seit den 80er Jahren auch auf den Export ausgerichtet war, bis zuletzt schneller als die anderen Wirtschaftssektoren, so dass der sekundäre Sektor 2005 für knapp die Hälfte der gesamten wirtschaftlichen Wertschöpfung des Landes aufkam. ${ }^{403}$

Allerdings blieb die Industrialisierung in Thailand, wie bereits erwähnt, in überdurchschnittlich hohem Maße auf die Hauptstadt und deren Umland konzentriert. Auch die seit den 70er Jahren eröffneten Industrieparks wurden zunächst im Großraum Bangkok und seit 1989 in den angrenzenden Gebieten errichtet. Speziell in der Entwicklungszone Eastern Seabord im südöstlichen Großraum von Bangkok entstanden eine Reihe großer und leistungsstarker Betriebe, vielfach in ausländischem Besitz und mit staatlicher Förderung. Zahlreiche weitere Industrieansiedlungen schlossen sich südlich davon in der Provinz Rayong an, die zur überragenden Industrieregion des Landes wurde. Dagegen blieb der große Rest des Landes von solchen Entwicklungen weitgehend unberührt. ${ }^{404}$ Um 1980 stammte mehr als die Hälfte der thailändischen Industrieproduktion aus Bangkok und seinen Nachbarprovinzen, mehr als drei Viertel aus der gesamten Zentralregion, die damals nur etwa ein Drittel der Gesamtbevölkerung stellte. ${ }^{405}$ Gegen Ende des 20. Jahrhunderts arbeiteten über 40 Prozent aller Industriebeschäftigten des Landes allein in Bangkok, wo nur 10 Prozent der Bevölkerung lebten. ${ }^{406}$ Die Konzentration auf die Hauptstadtregion schlug sich auch in der gesamten Wertschöpfung nieder, die in Bangkok und seinem Umfeld deutlich rascher anstieg als im Rest des Landes. 2005 fiel das Bruttoinlandsprodukt pro Einwohner nirgends so hoch aus wie in der Metropolregion Bangkok und in den sich nördlich, östlich und südöstlich anschließenden Provinzen Ayutthaya, Chachoengsao, Chon Buri

401 Stahl (Tabellen und Grafiken).

402 Buchmann (1980a), 443-445.

403 Buchmann (1980a), 442 und Schmid (2013), 92.

404 Vorlaufer (2009), 186.

405 Buchmann (1980a), 443. In den 80er Jahren trug allein die Metropolregion Bangkok fast 70 Prozent zur industriellen Wertschöpfung des Landes bei. Amin (1997), 118. Vgl. auch Schmid (2013), 74.

406 Bronger/Trettin (2011), 306. 
und Rayong. ${ }^{407}$ In der Großregion Bangkok wurden von gut 20 Prozent der thailändischen Bevölkerung fast zwei Drittel der gesamten Wirtschaftsleistung erwirtschaftet. ${ }^{408}$ Dank der dynamischen Entwicklung dieser Region blieb auch der Anteil der in Elendsvierteln lebenden Menschen wie in Malaysia relativ niedrig. ${ }^{409}$

Auf der anderen Seite hatte die einseitige Ausrichtung der thailändischen Industrialisierung auf den Großraum Bangkok und damit auf eine Minderheit der Gesamtbevölkerung zur Folge, dass ein Großteil der Menschen nur in sehr beschränktem Ausmaß daran teilhatte. Der Anteil der in der Industrie und im verarbeitenden Gewerbe Erwerbstätigen wuchs bis 2004 lediglich auf rund 15 Prozent, die Landwirtschaft beschäftigte noch immer über 40 Prozent. ${ }^{410}$ Wie in anderen Entwicklungsländern blieb die Industrialisierung trotz erheblicher Fortschritte eine punktuelle, auf einen kleinen Teil der Gesamtbevölkerung begrenzte Erscheinung. ${ }^{411}$

Dies gilt erst recht für die restlichen Länder der südostasiatischen Halbinsel, in denen zu Beginn des 21. Jahrhunderts noch immer zwei Drittel und mehr der Bevölkerung auf dem Land lebten. In ganz Indochina hatte es 1950 mit Saigon, dem heutigen Ho-ChiMinh-Stadt, lediglich eine Millionenstadt gegeben (vgl. Karte 10). ${ }^{412}$ Sie war seit dem 17. Jahrhundert zu einer Handelsstadt mit überregionaler Bedeutung aufgestiegen und von der französischen Kolonialregierung zu einer ihrer regionalen Hauptstädte erhoben worden. Dagegen überschritten Rangun und Phnom Penh als Hauptstädte von Myanmar und Kambodscha sowie im geteilten Vietnam nun auch Hanoi erst in den folgenden Jahrzehnten die Millionengrenze. Vientiane als Hauptstadt von Laos zählte bis zuletzt weniger als eine Million Einwohner. ${ }^{413}$ Außerdem wurde die wirtschaftliche Entwicklung, die durch das Wachstum der Großstädte hätte angeregt werden können, durch die jahrelangen Unabhängigkeits- und Bürgerkriege behindert, so dass sie erst in jüngerer Zeit einen etwas stärkeren Industrialisierungsprozess erlebten. ${ }^{414}$

Speziell in Vietnam, wo sich bis zum Ende des Krieges in jedem der beiden getrennten Landesteile nur eine bescheidene und vielfach ineffiziente Industrie entwickelt hatte,

407 Bronger/Trettin (2011), 215.

408 Bronger/Trettin (2011), 278, 310 und 428.

409 Laut Vorlaufer (2009), 106 machten sie nur 2 Prozent der städtischen Bevölkerung aus.

410 Eigene Berechnungen nach Mitchell (2007), 112; vgl. Growth Amid Change (2007), 52.

411 Vgl. Bronger/Trettin (2011), 321.

412 Mitchell (2007), 42-46.

413 Mitchell (2007), 42-46.

414 Vgl. Vorlaufer (2009), 9 f., 84-88 und 96. 
entstanden seit den 80er Jahren mehrere Industriezonen, die ersten und größten unter ihnen in den Großstädten Ho-Chi-Minh-Stadt, Hanoi, Haiphong und Da Nang samt ihrer Umgebung. ${ }^{415}$ Außer von der Massennachfrage ihrer Bevölkerung profitierten sie auch von der städtischen Infrastruktur in Form großer See- und Flughäfen, die insbesondere den stark auf den Export ausgerichteten, ausländischen Unternehmen zugute kamen. Allein zwischen 1991 und 2003 wurden in 62 Industriezonen rund 1.300 inländische und etwa 1.600 ausländische Betriebe gegründet, obwohl insgesamt die heimischen Betriebe, die sich zu einem großen Teil noch immer in Staatsbesitz befanden, überwogen. ${ }^{416}$ 2007 stammten gut zwei Drittel der Industrieproduktion aus den beiden metropolitanen Großregionen von Ho-Chi-Minh-Stadt und Hanoi einschließlich der dritten Millionenstadt Haiphong, obwohl in ihnen nicht einmal ein Viertel der Bevölkerung lebte. ${ }^{417}$ Trotz starkem Wachstum in den letzten Jahren fehlte der Industrialisierung somit auch in Vietnam - ebenso wie in Myanmar, Laos und Kambodscha - die regionale Breite. Der Großteil ihrer Bevölkerungen - am Land ebenso wie in den Elendsvierteln der Großstädte - blieb von der Industrialisierung nicht oder nur am Rande erfasst, so dass sie trotz dem in den städtischen Zentren geschaffenen Wohlstand als Ganze noch immer zu den ärmsten Ländern der Welt zählten. ${ }^{418}$ Nach Angaben der Asian Development Bank lebten zu Beginn des Jahrhunderts in Vietnam, Laos und Kambodscha zwischen 47 und 72 Prozent der städtischen Bevölkerungen in Slums. ${ }^{419}$

44 bzw. 23 Prozent waren es in den beiden großen Inselstaaten der Philippinen und Indonesiens. ${ }^{420}$ Auch hier konzentrierte sich die bis heute entstandene Industrie in starkem Ausmaß auf die beiden Hauptstadtregionen und ihre Umgebung. Auf den Philippinen gilt dies vor allem für Metro Manila sowie die nördlich und südlich angrenzenden Regionen Central Luzon und Calabarzon, in denen in den 80er Jahren rund drei Viertel aller Industriebeschäftigten des Landes arbeiteten. ${ }^{421}$ Auf die Region Metro Manila allein, die neben der Hauptstadt selbst auch die beiden Millionenstädte Quezon City und Caloocan City umfasste, entfielen bereits seit den 60er Jahren rund die Hälfte und mehr aller

415 Schmid (2013), 76-80.

416 Vorlaufer (2009), 187 und Pomfret (1996), 63.

417 Bronger/Trettin (2011), 312.

418 Maddison (Per Capita GDP). Vgl. Pomfret (1996), 2 und 70.

419 Vorlaufer (2009), 106.

420 Vorlaufer (2009), 106.

421 Bauer (1988), 110. 
Industriebeschäftigten, obwohl sie um 2007 nur etwa ein Achtel der Gesamtbevölkerung auf sich vereinigte. ${ }^{422}$

Manila war im Rahmen des spanischen Kolonialreiches ein wichtiger Umschlagsplatz zwischen Amerika und Asien, wo unter anderem Silber aus Mexiko gegen Seide und Gewürze aus China gehandelt wurde. ${ }^{423}$ Ihr überdurchschnittliches Wachstum verdankte die Stadt allerdings ihrer Stellung als Hauptstadt der spanischen und später von den USA beherrschten Philippinen. Obwohl sie den Hauptstadtcharakter zwischen 1948 und 1976 vorübergehend an das benachbarte Quezon City abgeben musste, überschritt sie um 1950 die Millionengrenze und zog dank ihrer Massennachfrage einen Großteil der zuvor in bescheidenem Ausmaß in mehreren Landesteilen entstandenen Industrie an. ${ }^{424}$ Die Betriebe, die vor allem landwirtschaftliche Produkte verarbeitet hatten, traten in ihrer Bedeutung hinter die neuen Industrien zurück, die sich nunmehr vor allem auf die Hauptstadtregion konzentrierten und speziell in den 50er Jahren eine besonders dynamische Entwicklung erlebten.

Nach einer anfänglichen Phase der Importsubstituierung gewann auch die Produktion für den Export an Bedeutung, wobei es außer in der Hauptstadtregion auch in den urbanisierteren Gegenden auf den Visayas und auf Mindanao, wo mit Davao City eine weitere Millionenstadt entstanden war, zu einer Industrialisierung kam. ${ }^{425}$ Dazu trugen die großräumigen Spezialwirtschaftszonen bei, die seit 1995 geschaffen wurden und zu einem weiteren stürmischen Produktionsanstieg führten. ${ }^{426}$ Die meisten Beschäftigten arbeiteten nach wie vor in der Nahrungs- und Genussmittel- sowie in der Textil- und Lederindustrie, viele aber auch in der Elektroindustrie, während die Eisen- und Stahlindustrie, die Metallwarenindustrie und der Maschinen- und Fahrzeugbau deutlich weniger Menschen beschäftigten. Insgesamt handelte es sich auch auf den Philippinen um eine nur punktuelle Industrialisierung. Zu Beginn des neuen Jahrhunderts entfielen noch immer fast 40 Prozent aller Erwerbstätigen auf die Landwirtschaft und nur rund 10 Prozent auf Industrie und verarbeitendes Gewerbe. ${ }^{427}$

In Indonesien, dem mit Abstand bevölkerungsreichsten Land der Region, konzentrierten sich Urbanisierung und Industrialisierung ebenfalls auf nur wenige Regionen.

422 Bronger/Trettin (2011), 306, Bauer (1988), 43 und 100 sowie Vorlaufer (2009), 89 f. und 96.

$423 \operatorname{Kim}(1990), 123$.

424 Bauer (1988), 30 f. und Mitchell (2007), 44.

425 Bauer (1988), 44 und 110.

426 Vorlaufer (2009), 188.

427 Eigene Berechnungen nach Mitchell (2007), 110. Vgl. Growth Amid Change (2009), 52. 
Allein auf Java, der am weitaus dichtesten besiedelten Insel, befanden sich um 1930 sechs der sieben Großstädte mit mehr als 100.000 Einwohnern. Obwohl hier schon früh eine industrielle Verarbeitung der für den Export angebauten, landwirtschaftlichen Produkte einsetzte, ${ }^{428}$ schufen erst die Großstädte den Massenmarkt, der eine umfangreichere Industrialisierung auslösen sollte. Im Zuge des raschen Bevölkerungswachstums überschritten fünf von ihnen, nämlich die Hauptstadt Jakarta sowie Surabaya, Bandung und Semarang auf Java sowie Medan auf Sumatra, bis 1980 die Millionengrenze (vgl. Karte 11 und Tabelle 35), denen bis zur Jahrtausendwende das ebenfalls auf Sumatra gelegene Palembang, die unweit von Jakarta gelegenen Städten Bekasi und Tangerang sowie die süd-sulawesische Hauptstadt Makassar auf Celebes bzw. Sulawesi folgten. ${ }^{429}$

Bis 1970 entstanden auf Java, und zwar speziell im westlichen Teil der Insel einschließlich der Hauptstadt, rund 78 Prozent aller Mittel- und Großbetriebe des Landes, weitere 11 Prozent auf Sumatra. ${ }^{430}$ Bis zur Jahrtausendwende waren in den großen javanischen Agglomerationen von Jakarta, Surabaya, Semarang und Bandung fast sämtliche Industriezweige vertreten, während sich auf Sumatra in den Agglomerationen Medan, Palembang und Padang vor allem eine differenzierte Verbrauchsgüter- und Lebensmittelindustrie entwickelt hatte. Deutlich bescheidener fiel dagegen die Industrialisierung auf den restlichen, viel dünner besiedelten und weniger urbanisierten Inseln des Landes aus, wo sie nach wie vor in engem Zusammenhang mit der Nutzung vorhandener Rohstoffe stand. Insgesamt beschäftigten wie auf den Philippinen auch in Indonesien die Nahrungs- und Genussmittel-, die Textil- und die Holzwarenindustrien bis zuletzt deutlich mehr Menschen als die Eisen- und Stahl-, die Maschinen- und die Erdöl- und Erdgasindustrie, obwohl gerade letztere einen überdurchschnittlich hohen Beitrag zur gesamtindustriellen Wertschöpfung leistete. ${ }^{431}$ Und obwohl die Industrie auch in Indonesien die meiste Zeit rascher wuchs als andere Wirtschaftszweige, beschäftigte sie zusammen mit dem verarbeitenden Gewerbe zu Beginn des neuen Jahrhunderts noch immer erst 13 Prozent aller Erwerbstätigen. Über 40 Prozent arbeiteten nach wie vor in der Landwirtschaft. ${ }^{432}$

428 Um 1930 gab es auf Java und Madura 180 Zuckerfabriken. Röpke (1982), 185.

429 Mitchell (2007), $42-46$ und Liste der Städte (Indonesien). Vgl. Zimmermann (2003), 90-266 und Vorlaufer (2009), 88 f. und 96.

430 Zimmermann (2003), 397. Vgl. Kötter (1979), 448-452 und zur Bedeutung des Binnenmarktes auch Vorlaufer (2009), 189 und 213-215 sowie Hossain (1997), 71.

431 Zimmermann (2003), 400-402, Mishra (1995), 103 und Röpke (1982), 267.

432 Errechnet aus Mitchell (2007), 105. Vgl. Zimmermann (2003), 268 und Growth Amid Change (200), 52. 


\section{Ostasien}

Deutlich früher als in den meisten anderen, außereuropäischen Ländern setzte der Industrialisierungsprozess in Japan ein. Wie in Europa, Kanada und den USA wurde er durch die relativ frühe und dichte Großstadtbildung und die von ihr ausgehende Massennachfrage angeregt. ${ }^{433}$ Die Großstädte waren ihrerseits die Folge einer besonders hohen Bevölkerungsdichte in vor allem zwei Regionen. Im südlichen Teil der heutigen Region Kantō und im nordwestlichen Teil der Region Kinki lebte auf lediglich 7,5 Prozent der Fläche ein Großteil der japanischen Bevölkerung - heute sind es über 40 Prozent. ${ }^{434}$

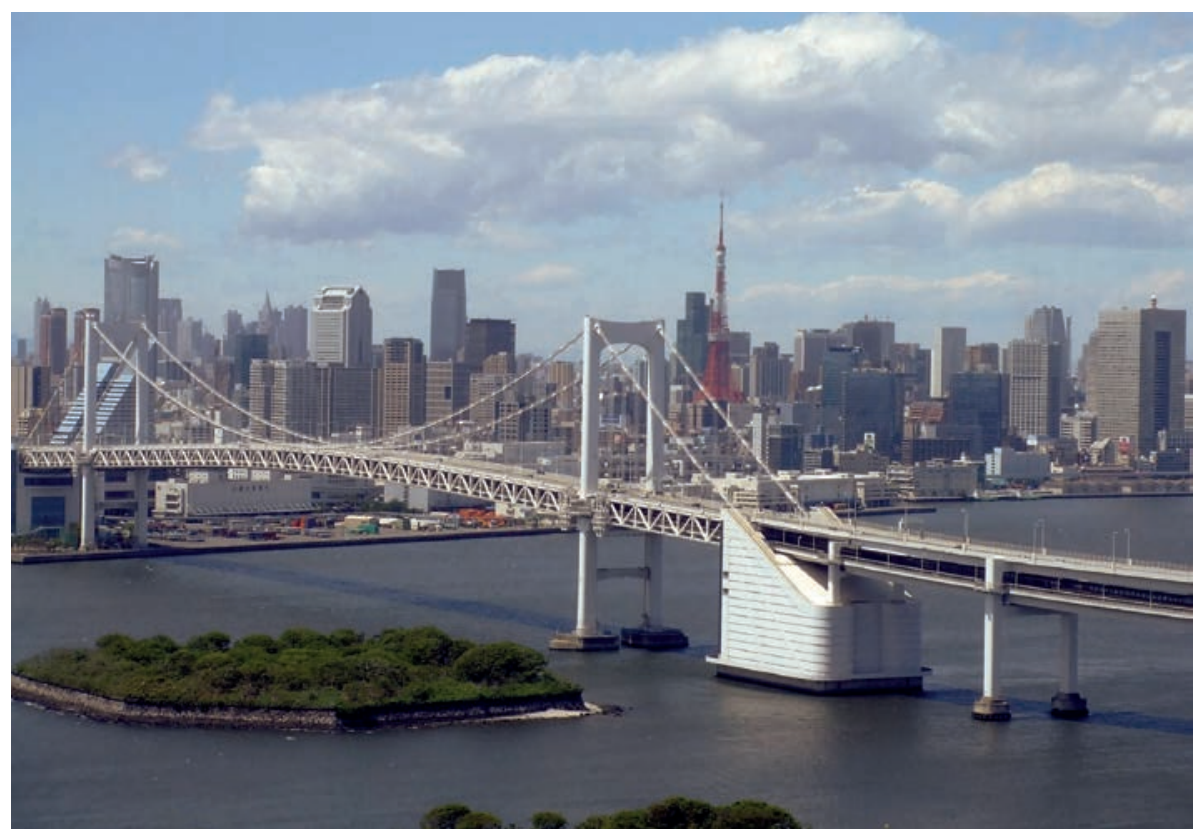

http://de.wikipedia.org/wiki/Tokio\#/media/File:Tokyo_Oka2.JPG

433 Vgl. Mathis (2006), 228-233.

434 Errechnet für die vier Präfekturen Tokio, Kanagawa, Saitama und Chiba in Kantō und die drei Präfekturen Osaka, Kyoto und Hyōgo in Kinki. Japan (Präfekturen). 
Hier wuchsen bereits um die Wende vom 19. zum 20. Jahrhundert die nur etwa $400 \mathrm{~km}$ auseinander liegenden Städte Tokio, das frühere Edo, und die Handelsstadt Osaka zu Millionenstädten heran, die von drei weiteren Großstädten, nämlich Yokohama, Kyoto und Kōbe, mit jeweils rund 400.000 Einwohnern umgeben waren. Ähnlich groß war das zwischen Tokio und Osaka gelegene Nagoya (vgl. Karte 10 und Tabelle 40). ${ }^{435}$

Grafik 38: Verarbeitung von Rohbaumwolle in Japan und den USA 1900-1969

(Kilogramm pro Einwohner, Jahresdurchschnitte)

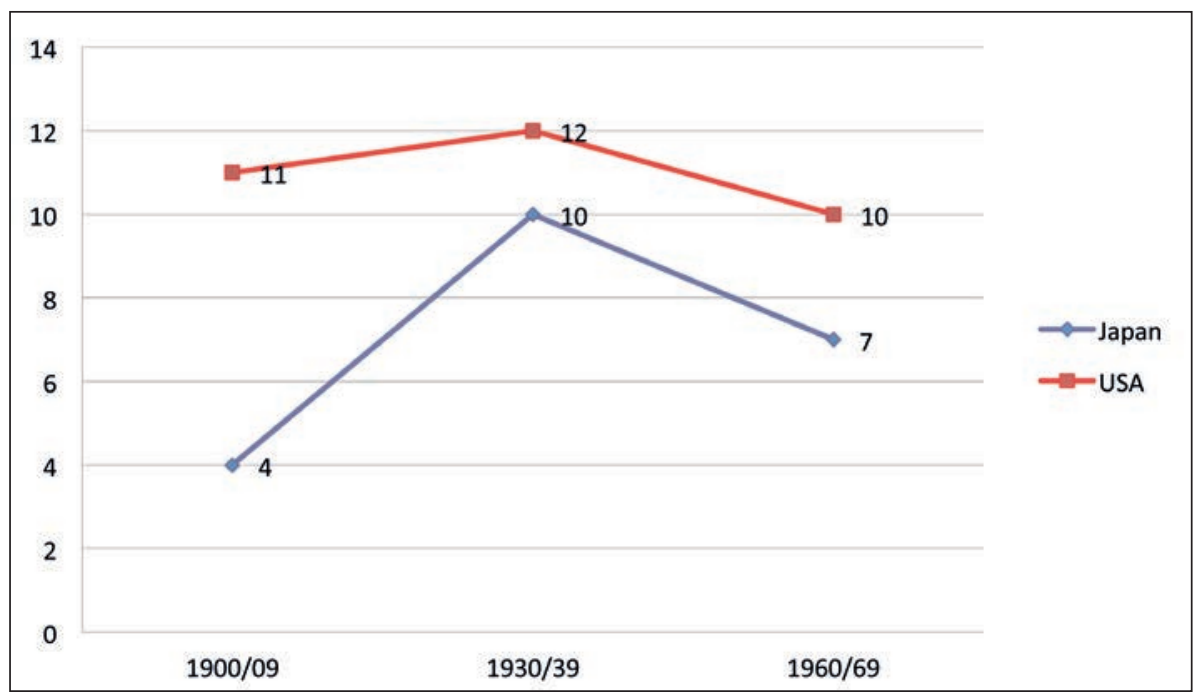

Eigene Berechnungen nach Mitchell (2007), 467 f. und Mitchell (1998), 374 f.

Wie anderswo begann die Industrialisierung in Japan mit der Mechanisierung der Textilindustrie, die auf einer langen, protoindustriellen Tradition aufbauen konnte. Neben der stark exportorientierten Seidenindustrie war es die anfangs auf den Binnenmarkt ausgerichtete Baumwollindustrie, deren Produktion sich zum Teil mit Hilfe staatlicher Unterstützung in nur wenigen Jahren vervielfachte. ${ }^{436}$ Seit der Gründung der Osaka Spinning Company (1880) und anderer Baumwollfabriken sollte sich allein zwischen 1886

435 Mitchell (2007), 44-46.

$436 \operatorname{Kim}(1990), 140$. 
und 1897 der Gesamtwert der Garnproduktion vervierzehnfachen. ${ }^{437}$ Statt lediglich 6.000 beschäftigten die Baumwollspinnereien am Vorabend des Ersten Weltkrieges mehr als 100.000 Menschen. ${ }^{438}$ Pro Einwohner verarbeiteten sie zu Beginn des 20. Jahrhunderts rund $4 \mathrm{~kg}$ Rohbaumwolle, womit Japan zwar nicht an Großbritannien oder die USA, sehr wohl jedoch an andere west- und mitteleuropäische Länder herankam (vgl. Grafik 2 und Grafik 38).

Grafik 39: Produktion von Roheisen in Japan und den USA 1912-1979

(Kilogramm pro Einwohner, Jahresdurchschnitte)

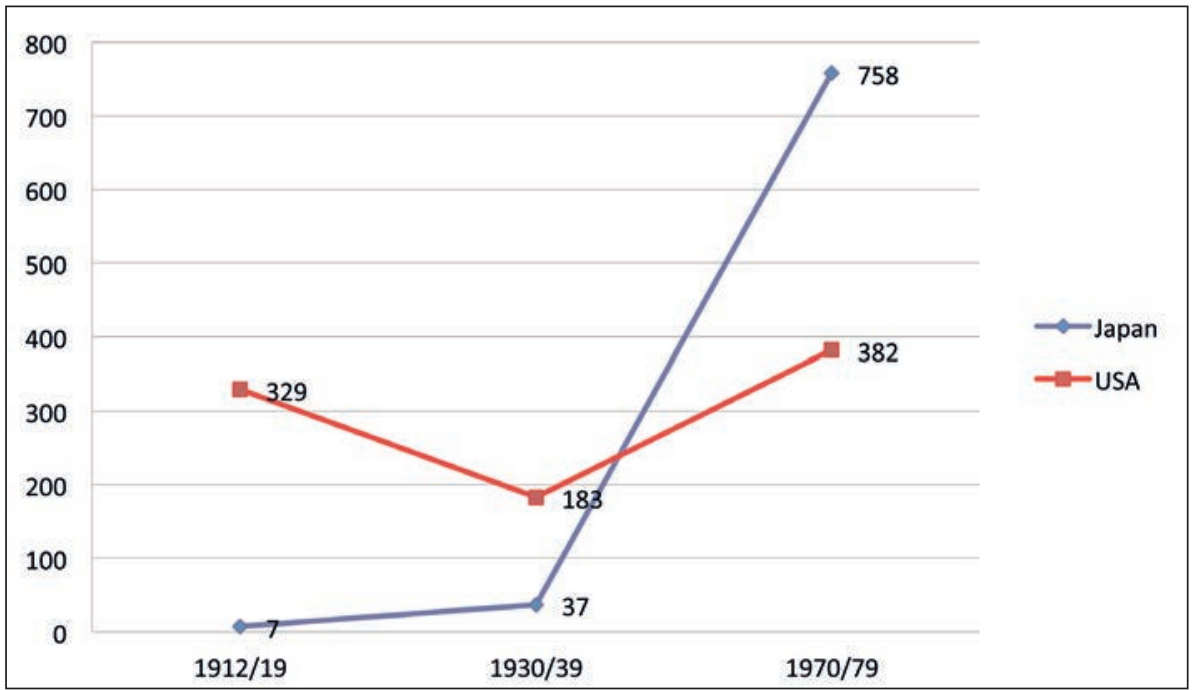

Eigene Berechnungen nach Mitchell (2007), 441 f. und Mitchell (1998), 359 f.

Etwas langsamer entwickelten sich eine eigene Eisen- und Stahlindustrie sowie im Anschluss daran auch ein eigener Maschinen- und Schiffsbau, deren Produkte zuvor fast zur Gänze importiert worden waren. Wegen des späteren Beginns produzierte Japan mit $7 \mathrm{~kg}$ pro Einwohner zwar deutlich weniger Roheisen als die USA oder Europa, aber wesentlich mehr als sämtliche übrigen Länder Asiens, Afrikas oder Lateinamerikas (vgl.

437 Mathis (2006), 228. Die Zahl der mechanischen Baumwollspindeln stieg zwischen 1887 und 1929 von bescheidenen 72.000 auf fast 6,7 Millionen an. Kim (1990), 138.

438 Hentschel (1986), I, 134. 
Grafik 3 und Grafik 39). Insgesamt arbeiteten 1910 bereits 14 Prozent aller Erwerbstätigen in Industrie und verarbeitendem Gewerbe. ${ }^{439}$

In den folgenden Jahrzehnten des 20. Jahrhunderts setzte sich das Wachstum sowohl der großstädtischen Bevölkerung als auch der industriellen Produktion fort. Obwohl die Gesamtbevölkerung zwischen 1910 und 1940 nur um etwa die Hälfte zunahm, lebten in den inzwischen fast sechs Millionenstädten ${ }^{440}$ mit gut 14 Millionen Einwohnern mehr als vier Mal so viele Menschen wie in den beiden Millionenstädten Tokio und Osaka 30 Jahre zuvor. Ihr Anteil an der Gesamtbevölkerung hatte sich auf ein knappes Fünftel verdreifacht. ${ }^{441}$ Die Produktion von Industrie und verarbeitendem Gewerbe stieg zwischen 1913 und dem Vorabend des Zweiten Weltkrieges auf mehr als das Fünffache, die Zahl der darin Beschäftigten auf das Doppelte. ${ }^{42}$ In den 30er Jahren lag die Verarbeitung von Rohbaumwolle, deren Produkte inzwischen auch in andere Länder Asiens exportiert wurden, bei rund $10 \mathrm{~kg}$ pro Einwohner und damit über den Werten West- und Mitteleuropas (vgl. Grafik 4). Dagegen blieb die Erzeugung von Roheisen, obwohl sie sich gegenüber dem Beginn des Jahrhunderts auf fast $40 \mathrm{~kg}$ pro Einwohner vervielfachte, hinter diesen und den USA zurück (vgl. Grafik 39). ${ }^{443}$

Die Zerstörungen des Zweiten Weltkrieges konnten die zuvor begonnene Industrialisierung nur vorübergehend stoppen. Zwar fiel die industrielle Produktion im letzten Kriegsjahr auf 10 Prozent des Mitte der 30er Jahre erreichten Wertes, doch lag sie bereits 1950 wieder bei 84 und 1954 bei 167 Prozent der Vorkriegswerte. ${ }^{444}$ Bis 1991 stieg sie noch einmal auf mehr als das 17 -fache an. ${ }^{445}$ Wie in anderen Industrieländern ging die Bedeutung der traditionellen Industriezweige wie etwa der Textilindustrie zugunsten des Maschinenbaus, der Fahrzeug- und der Elektroindustrie und der ihnen zugrunde liegenden Eisen- und Stahlindustrie zurück. Obwohl Japan über keine nennenswerten Eisenerz- und nur wenige Kohlenlager verfügte, produzierte das Land seit den späten 70er Jahren mehr Rohstahl und in den 80er Jahren auch mehr Automobile als die doppelt so großen USA, obwohl Japan erst nach dem Krieg mit einer umfangreicheren Automo-

439 Mitchell (2007), 107.

440 Neben den Millionenstädten Tokio, Osaka, Nagoya und Kyoto zählten Yokohama und Kōbe 1940 knapp 970.000 Einwohner. Mitchell (2007), 44-46.

441 Eigene Berechnungen nach Mitchell (2007), 44-46 und Maddison (Population).

$442 \mathrm{Lal}$ (1988), 201 für die Produktion und Mitchell (2007), 107 für die Beschäftigten (errechnet für 1910 und 1940).

443 Für West- und Mitteleuropa eigene Berechnungen nach Mitchel (1992), $450 \mathrm{f}$. und Maddison (Population).

$444 \operatorname{Kim}(1990), 147-149$.

445 Eigene Berechnungen nach Mitchell (2007), $368 \mathrm{f}$. 
bilherstellung begann (vgl. Grafik 40). ${ }^{446}$ Noch früher hatte Japan die USA in der Herstellung von Fernsehgeräten hinter sich gelassen. ${ }^{447}$ Insgesamt beschäftigten Industrie und verarbeitendes Gewerbe bereits in den 70er Jahren über ein Viertel aller Erwerbstätigen (vgl. Grafik 41), bevor ihr Anteil wie in anderen hoch entwickelten Industrieländern zugunsten der Dienstleistungen auf unter 20 Prozent zurückfiel. In der Landwirtschaft arbeiteten zuletzt weniger als 5 Prozent aller Erwerbstätigen, 1950 waren es noch fast 50 Prozent gewesen. ${ }^{448}$

Grafik 40: Produktion von Automobilen in Japan und den USA 1950-1989

(Jahresdurchschnitte pro 1.000 Einwohner)

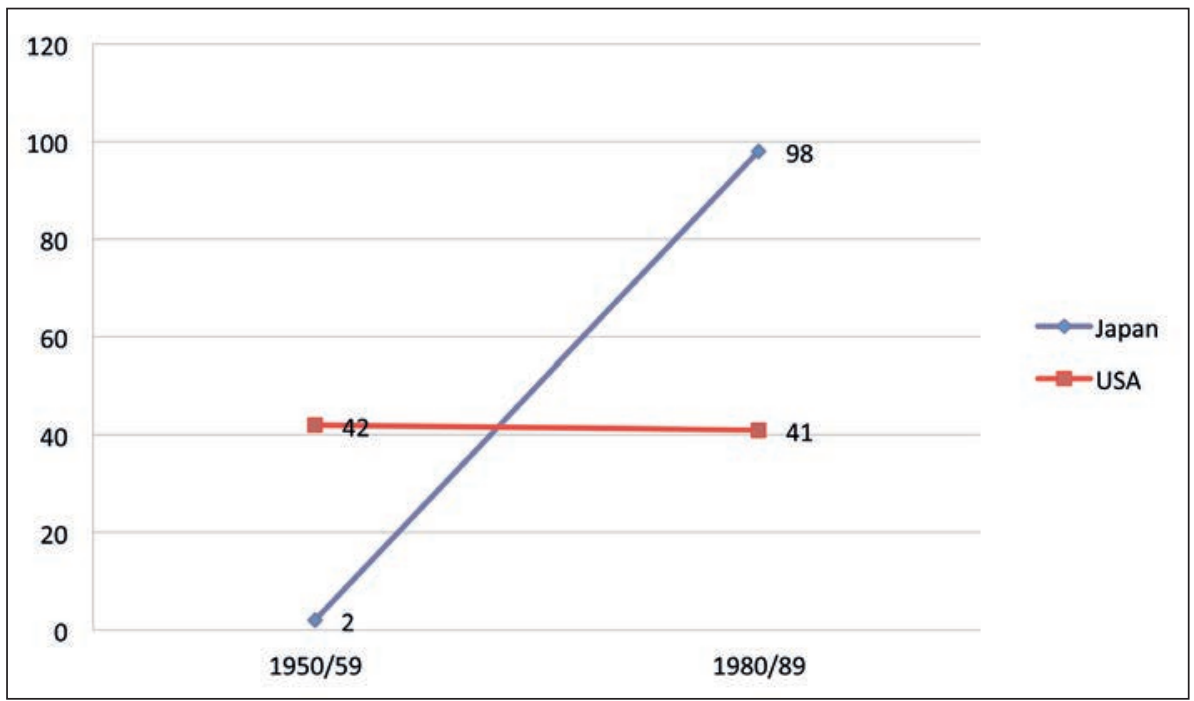

Eigene Berechnungen nach Mitchell (2007), 503 und Mitchell (1998), 395 f.

446 Stahl (Tabellen und Grafiken) und Wirtschaftszahlen zum Automobil.

447 Statistisches Jahrbuch (2003), 571.

448 Mitchell (2007), 107. 


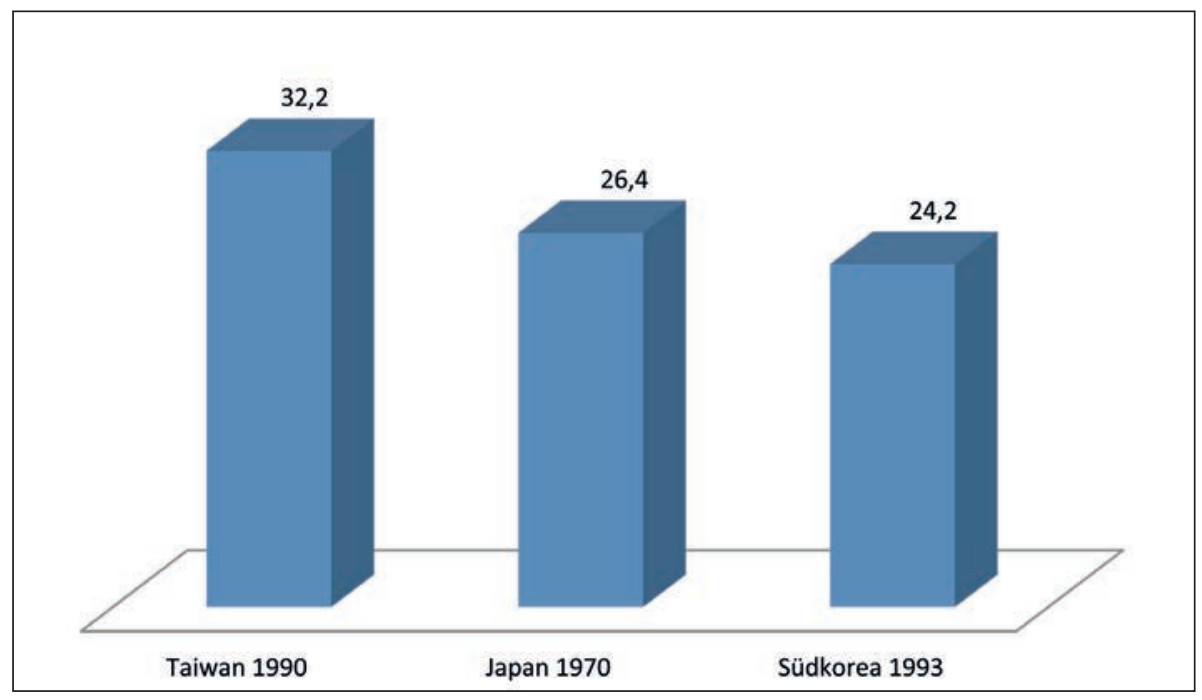

Eigene Berechnungen nach Mitchell (2007), 107 und 111.

Die überaus erfolgreiche und vor allem breite Industrialisierung ging in Japan mit einer weiteren Zunahme der Großstädte und ihrer Bevölkerung einher. Um die Jahrtausendwende gab es in Japan 13 Millionenstädte. ${ }^{449}$ Allein in den drei traditionellen Agglomerationen um Tokio, Osaka und Nagoya lebten zu Beginn des Jahres 2006 rund 63 Millionen und damit etwa die Hälfte aller Japanerinnen und Japaner, weitere 7 Millionen in den nächst größeren Agglomerationen um Fukuoka und Kitakyūshū im Südwesten und um die Millionenstadt Sapporo im Norden des Landes. ${ }^{450}$ Auf diese Regionen konzentrierte sich auch die Industrie des Landes. ${ }^{451}$ Da gleichzeitig die Gesamtbevölkerung und damit auch die nicht-städtische Bevölkerung wie in anderen Industrieländern dank sinkender Geburtenraten deutlich langsamer wuchs als in den meisten anderen außereuropäischen Ländern (vgl. Tabelle 38), profitierte ein relativ größerer Teil der japanischen Bevölkerung von der Großstadtbildung und der von

449 Mitchell (2007), 42-46.

450 Liste der Städte (Japan).

451 Japan-Perspektiven (1990), 98. 
ihr stimulierten Industrialisierung. Dementsprechend rangierte Japan nicht nur in der Wertschöpfung pro Einwohner, sondern auch in der Ausstattung mit langlebigen Konsumgütern durchwegs an führender Stelle. Unter den größeren Ländern lag es 2008 beim Bruttoinlandsprodukt pro Einwohner hinter den USA, Australien, Kanada und dem Vereinigten Königreich an fünfter Stelle. ${ }^{452}$ Ähnliches gilt für die PKW- und die Computerdichte, obwohl sich gerade bei letzteren die ostasiatischen Nachbarstaaten Südkorea und Taiwan inzwischen vor Japan einreihten (vgl. Grafik 42 bis Grafik 44).

Grafik 42: Fernsehgeräte pro 1.000 Einwohner in Ostasien 1985-2006

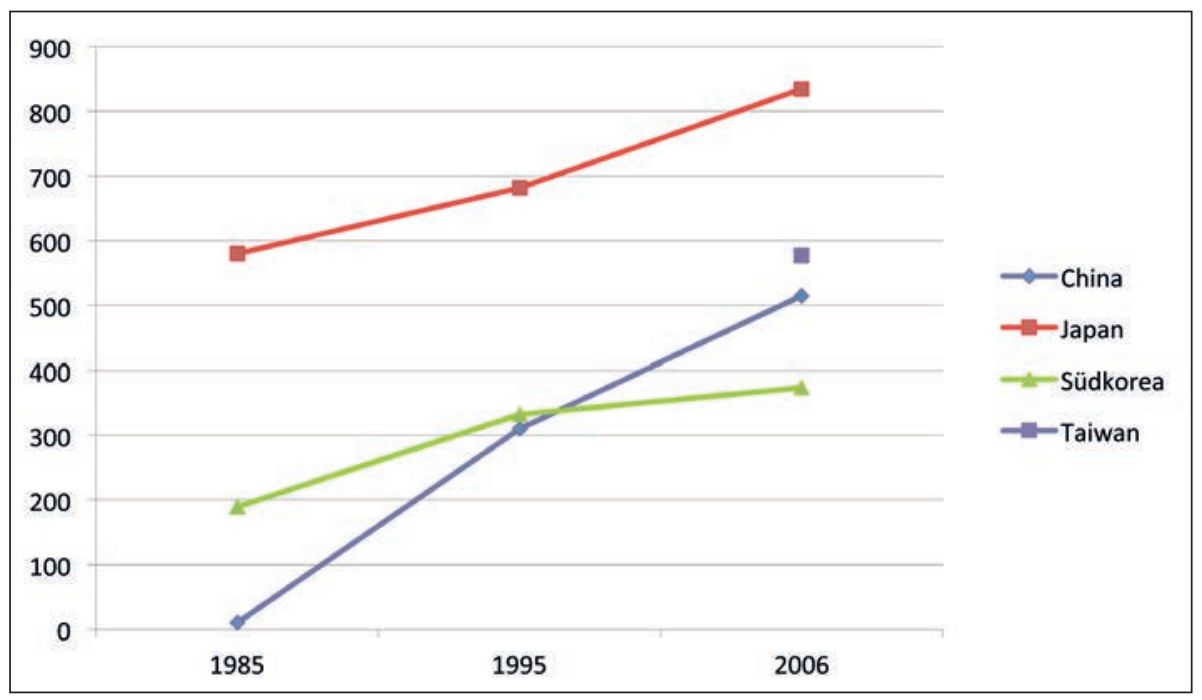

Vgl. Tabelle 39.

452 Maddison (Per Capita GDP). 
Grafik 43: PKW pro 1.000 Einwohner in Ostasien 1970-2006

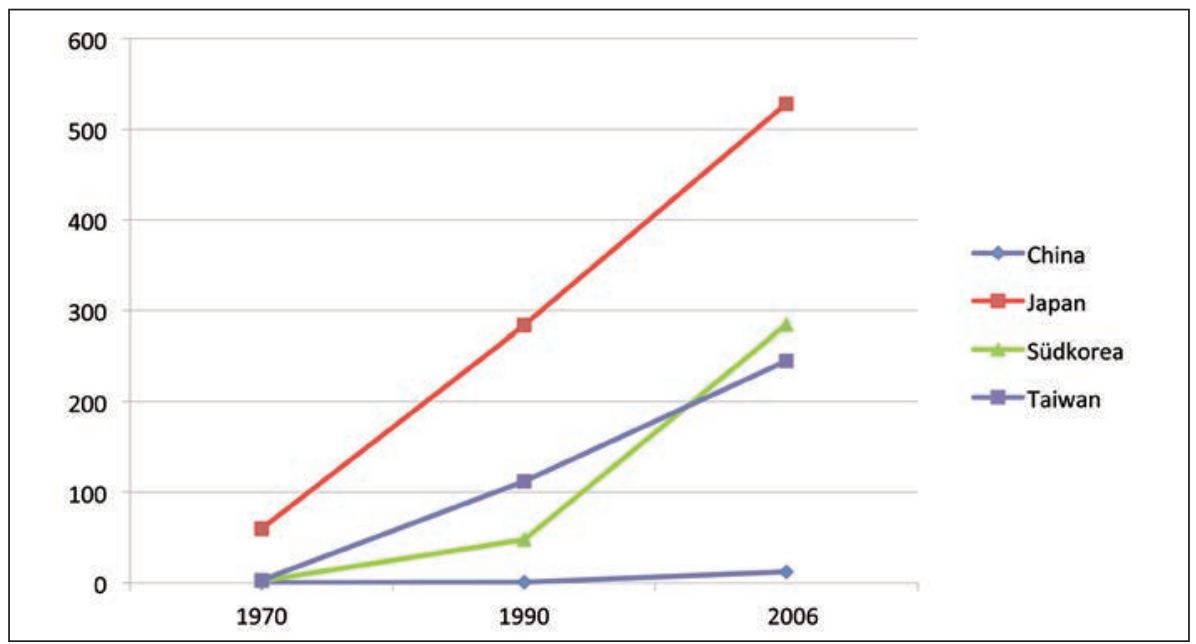

Vgl. Tabelle 39.

Grafik 44: Computer pro 1.000 Einwohner in Ostasien 2006

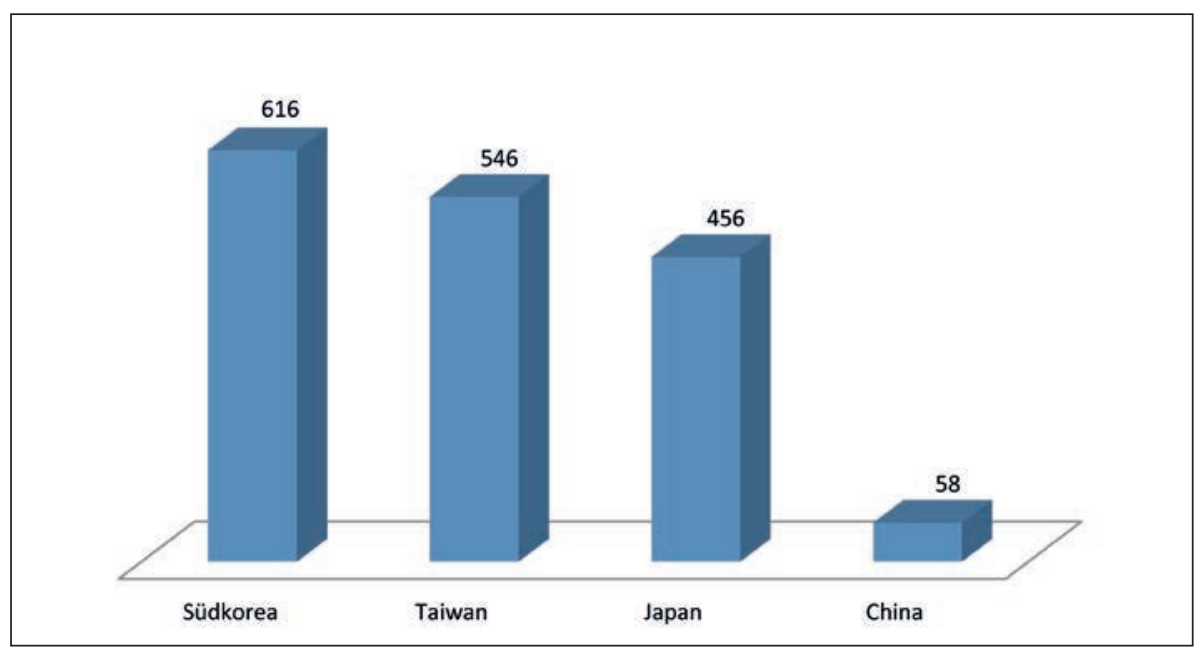

Welt in Zahlen (Computer). 
In Korea hatte eine bescheidene Industrialisierung noch unter japanischer Kolonialherrschaft in der ersten Hälfte des 20. Jahrhunderts begonnen. Obwohl es sich bei der Mehrzahl der Betriebe um traditionelle und meist kleinere Unternehmen zur Verarbeitung landwirtschaftlicher Rohstoffe handelte, wurde ein wachsender Teil der industriell-gewerblichen Produktion bereits in größeren Firmen mit über 100 Beschäftigten hergestellt. ${ }^{453} \mathrm{Im}$ Süden entstanden vor allem Konsumgüterindustrien wie die Nahrungsmittel- oder die Textilindustrie, während im Norden im Zuge der japanischen Aufrüstungspolitik seit den 30er Jahren eine beachtliche Schwerindustrie einschließlich der Herstellung chemischer Produkte aufgebaut wurde, die auf den reichlich vorhandenen, mineralischen Rohstoffen und der für die Stromerzeugung nutzbaren Wasserkraft beruhte. ${ }^{454} 1940$ entfielen auf den Süden rund 86 Prozent der Textil- und 65 Prozent der Nahrungsmittelindustrie, auf den Norden dagegen zwischen 80 und 90 Prozent der Chemie- und Metallindustrie sowie der Gas- und Stromerzeugung. ${ }^{455}$

In jedem der beiden Landesteile hatten der Zweite Weltkrieg und der nachfolgende Krieg zwischen dem Norden und dem Süden erhebliche Zerstörungen der industriellen Produktionskapazitäten und der zuvor aufgebauten Infrastruktur zur Folge. ${ }^{456}$ AnschlieBend richteten die Regierungen des insgesamt stärker industrialisierten Nordkorea ihre zentralwirtschaftliche Planung nach dem Beispiel der Sowjetunion an der Förderung der Schwerindustrie aus, wobei sie anfangs beachtliche Industrialisierungserfolge erzielten. ${ }^{457}$ Die Konsumgüterindustrien wurden wie die Landwirtschaft stark vernachlässigt. Im Gegensatz zur Schwerindustrie, deren Produktion zwischen 1953 und 1965 um das 21-fache wuchs, legte die Textilproduktion nur um das Siebenfache zu. ${ }^{458}$ Dies führte gemeinsam mit der ab den späten 60er Jahren zunehmenden Isolierung von der restlichen Welt zu deutlich langsameren Wachstumsraten und ließ Nordkorea immer weiter hinter andere Länder zurückfallen. ${ }^{459} \mathrm{Zu}$ Beginn des neuen Jahrhunderts arbeiteten in Nordkorea noch immer fast 30 Prozent der Erwerbstätigen in der Landwirtschaft, im Süden waren es nur noch 8 Prozent. ${ }^{460}$ Das von Angus Maddison errechnete Bruttoinlandsprodukt pro Ein-

453 Suh (1978), 109 und 139-141.

454 Reichart (1993), 187-189 und Frank (2005a), 235.

455 Wontroba/Menzel (1978), 213.

456 Bronger/Trettin (2011), 173 und Hughes (1988), 27.

457 Frank (2005a), 238 und Frey (1986), 51.

458 Frey (1986), 54.

459 Engelhard (2004), 343.

460 Fischer Weltalmanach (2008), 289 und 293. 
wohner machte 2008 in Nordkorea lediglich den 18ten Teil des südkoreanischen Wertes aus. ${ }^{461}$

Südkorea hingegen, dessen Bevölkerung sich zwischen 1960 und 2010 von 25 auf rund 50 Millionen Einwohner verdoppelte, entwickelte sich von einem armen Agrarland, in dem 1965 über die Hälfte der Erwerbstätigen in der Landwirtschaft arbeiteten, in wenigen Jahrzehnten zu einem der führenden Industrieländer der Welt. ${ }^{462}$ Nachdem gegen Ende der 50er Jahre die jährliche Wirtschaftsleistung der 40er Jahre wieder erreicht worden war, sollte sich die Wertschöpfung pro Einwohner bis 2008 auf das 16-fache vervielfachen. ${ }^{463}$ Die Produktion des sekundären Sektors wuchs durchwegs rascher als die der anderen Wirtschaftssektoren und lag 2005 um das rund 100-fache über dem Wert des Jahres 1965. ${ }^{464}$ Statt weniger als 10 Prozent beschäftigten die Industrie und das verarbeitende Gewerbe 1990 rund 27 Prozent aller Erwerbstätigen. ${ }^{465}$ Erst danach fiel ihr relativer Anteil wie in anderen hoch entwickelten Industrieländern zugunsten des Dienstleistungssektors auf knapp 20 Prozent zurück. ${ }^{466}$

Wie in den traditionellen Industrieländern verschob sich das Gewicht der Industrieproduktion schon bald von den anfänglich dominierenden, arbeitsintensiven Leichtindustrien wie der Baumwollindustrie zu den kapitalintensiveren Schwerindustrien wie etwa der Automobilindustrie. ${ }^{467}$ Erstere erreichte ihren Höhepunkt 1989, als sie pro Einwohner knapp $11 \mathrm{~kg}$ Rohbaumwolle verarbeitete und damit die west- und mitteleuropäischen Spitzenwerte zum Teil übertraf (vgl. Grafik 2, Grafik 4 und Grafik 45). Letztere begann 1967 mit einer Assemblingfabrik für den lokalen Markt, entwickelte in der Folge eigene Modelle und produzierte zuletzt über 4 Millionen Autos - ein Wert, der nur von China, den USA, Japan und Deutschland übertroffen wurde (vgl. Grafik 46). ${ }^{468}$ Ähnliches gilt für die Eisen- und Stahlindustrie, die in größerem Ausmaß ebenfalls erst in den 70er Jahren entstand, 2005 jedoch hinter China, Japan, den USA und der Russischen Föderation bereits an der fünften Stelle aller Stahl erzeugenden Länder rangierte (vgl. Grafik 47). ${ }^{469}$

461 Maddison (Per Capita GDP)

462 Engelhard (2004), 21.

463 Bronger/Trettin (2001), 173 und Maddison (Per Capita GDP).

$464 \mathrm{Kim}$ (2001), 19 und eigene Berechnungen nach Mitchell (2007), $368 \mathrm{f}$.

$465 \mathrm{Kim}$ (2001), 127 und eigene Berechnungen nach Mitchell (2007), $107 \mathrm{f}$.

466 Eigene Berechnungen nach Mitchell (2007), $107 \mathrm{f}$.

467 Vgl. Kim (1990), 180 f. und Gokarn (1995), 27.

$468 \mathrm{Kim}$ (2001), 74 und Wirtschaftszahlen zum Automobil.

469 Stahl (Tabellen und Grafiken). 
Grafik 45: Verarbeitung von Rohbaumwolle in Ostasien 1937-1998

(Kilogramm pro Einwohner, Höchstwerte)

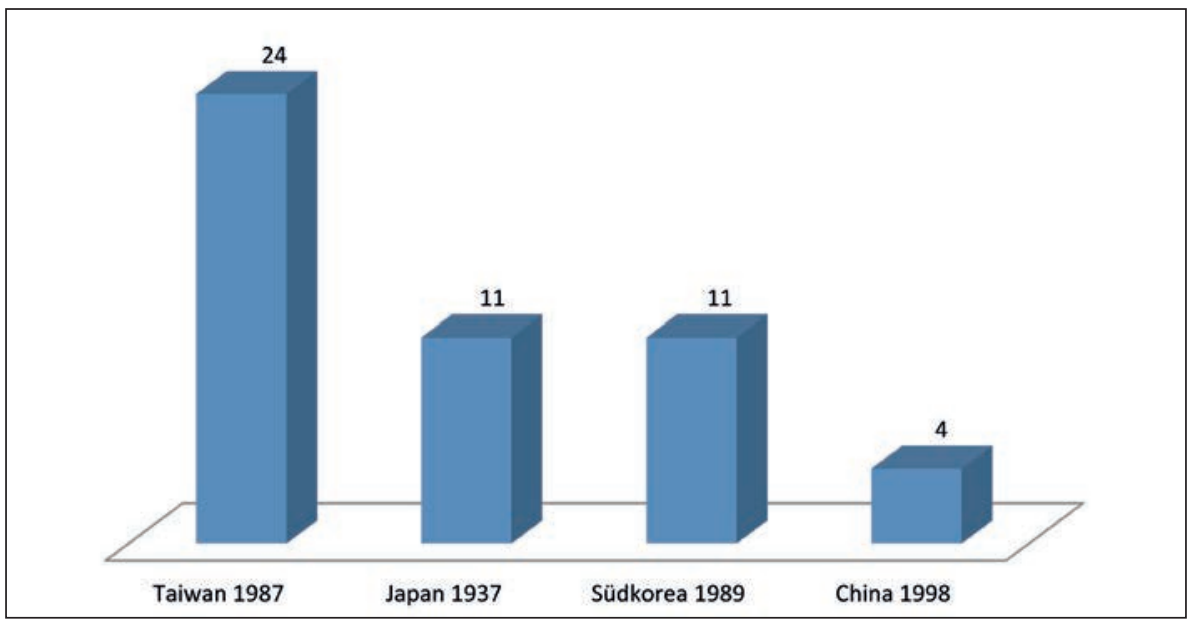

Eigene Berechnungen nach Mitchell (2007), $467 \mathrm{f}$.

Grafik 46: Produktion von Automobilen in Ostasien 1990-2003

(pro 1.000 Einwohner, Höchstwerte)

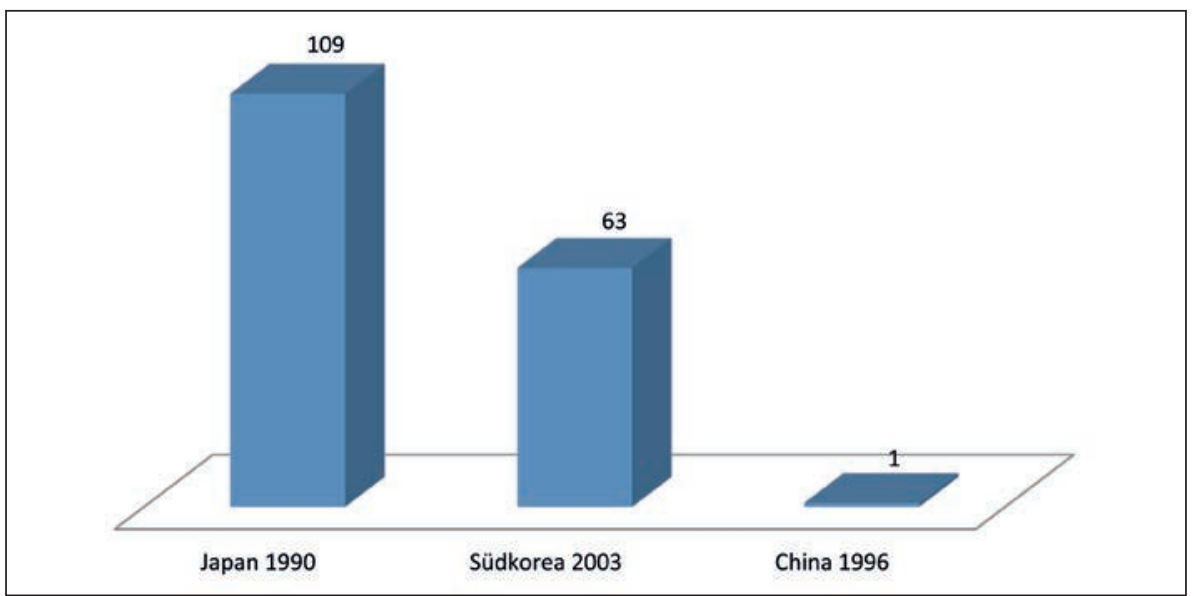

Eigene Berechnungen nach Mitchell (2007), $502 \mathrm{f}$. 


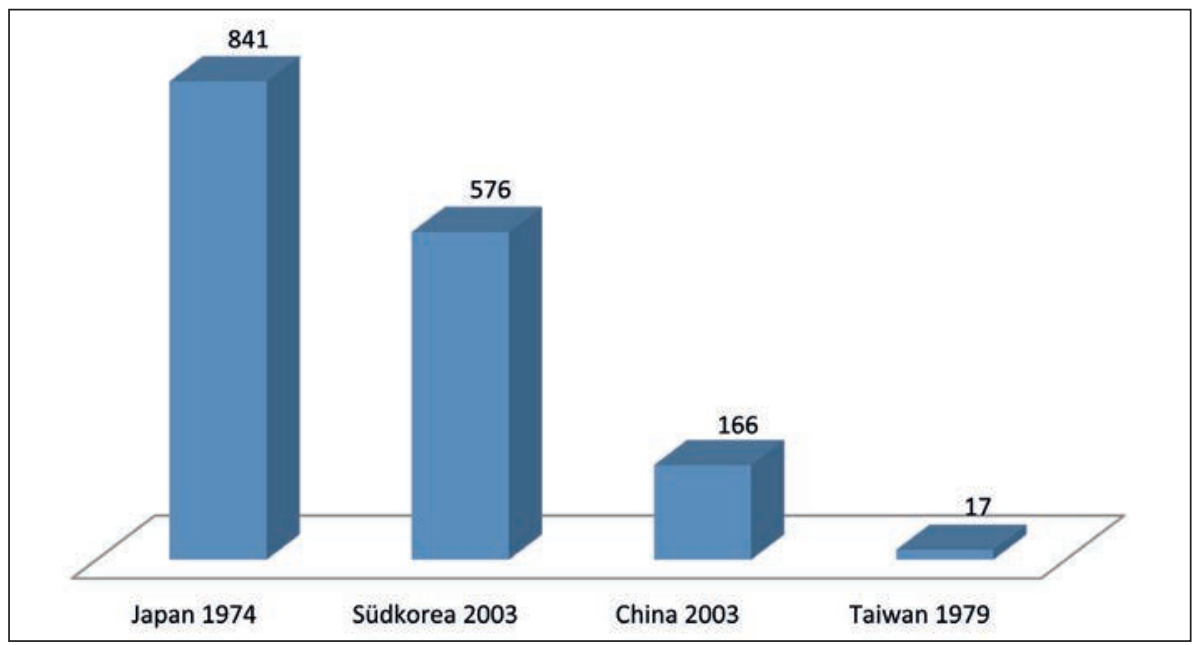

Eigene Berechnungen nach Mitchell (2007), $441 \mathrm{f}$.

Obwohl die rasante Industrialisierung des Landes in einem hohen Maß der gewaltigen Steigerung der südkoreanischen Exporte zu verdanken war, zeigt sich bei genauerem Hinsehen, dass auch in Südkorea die Nachfrage des Binnenmarktes am Beginn der Entwicklung stand. ${ }^{470}$ Bereits die erste koreanische Baumwollspinnerei und -weberei war 1917 zur Deckung des heimischen Bedarfes an Baumwollwaren gegründet worden. ${ }^{471}$ Noch 1968, als die Produktion den inländischen Bedarf bereits seit einiger Zeit übertraf, wurden weniger als 20 Prozent der Baumwollgarne und nur knapp die Hälfte der Baumwollstoffe exportiert, was sich erst in der Folge wegen des beschränkten Binnenmarktes rasch zugunsten der Exporte änderte. Auch die später so erfolgreiche und ebenfalls in die Anfänge des Jahrhunderts zurückreichende Herstellung von Elektrogeräten begann in den späten 50er Jahren mit der Produktion von Radiogeräten und anderen elektrotechnischen Produkten für den heimischen Markt, bevor sie wenig später aus denselben Gründen wie die Baumwollindustrie in den Export drängte. ${ }^{472}$

$470 \operatorname{Kim}(1990), 180$.

$471 \operatorname{Suh}(1978), 99-103$.

472 Hasan (1976), 169 und 177. 
Wie in Japan hatten sich in dem überaus dicht besiedelten und stark urbanisierten Südkorea zwei Zentren der Bevölkerungsverdichtung herausgebildet, die ebenfalls nur wenige hundert Kilometer auseinander lagen. 1960 zählten die langjährige Hauptstadt Seoul im Nordwesten bereits 2,4 und die durch die Anbindung an Japan gewachsene, rund $300 \mathrm{~km}$ südöstlich gelegene Hafenstadt Busan 1,2 Millionen Einwohner. Bis 1980 überschritten auch die der Hauptstadt vorgelagerte Hafenstadt Incheon und das auf der zunehmend belebteren Achse zwischen Seoul und Busan gelegene Daegu die Millionengrenze (vgl. Karte 10, Karte 11 und Tabelle 40). 2005 zählte man bereits sieben Millionenstädte sowie neun weitere Großstädte mit über einer halben Million Einwohner. ${ }^{473}$

Wie anderswo entwickelten sich die koreanischen Großstädte dank ihrer geballten Kaufkraft zu frühen Zentren der Industrialisierung, die sich schon bald über die Stadtgrenzen hinaus auf die benachbarten Provinzen erstreckte. Zwischen 1963 und 1986 verteilte sich die industrielle Produktion des Landes zu über 40 Prozent auf Seoul und die umliegende Provinz Gyeonggi-do einschließlich Incheons und zu rund 27 Prozent auf Busan und die anschließende Provinz Gyeongsangnam-do. Gemeinsam mit der im Osten angrenzenden Provinz Gyeongsangbuk-do mit der Millionenstadt Daegu vereinigten sie 1980 vier Fünftel der gesamten Industrieproduktion auf sich. ${ }^{474}$

Und da in denselben Regionen rund drei Fünftel der südkoreanischen Bevölkerung lebten, ${ }^{475}$ schlug sich ihre und die Industrialisierung einiger weiterer Großstädte in den gesamtstaatlichen Werten entsprechend positiv nieder. ${ }^{476}$ Das Bruttoinlandsprodukt pro Einwohner lag zuletzt nur knapp unter den west- und mitteleuropäischen Werten und damit deutlich über den Werten der anderen, lange Zeit weniger entwickelten Ländern der Welt. ${ }^{477}$ Bei der Industrieproduktion pro Einwohner rangierte Südkorea um 2006 unter den größeren Ländern (über 20 Millionen Einwohner) an der zehnten, bei der PKW-Dichte an der elften und an der Ausstattung mit Computern sogar an der dritten Stelle. ${ }^{478}$ Immer weniger Menschen lebten in absoluter Armut: Seit 1980 waren es weniger als 10 Prozent. $^{479}$

473 Mitchell (2007), 43-46 und Liste der Städte (Südkorea).

474 Reichart (1993), 307 f. Vgl. Engelhard (2004), 22 und 149.

475 Engelhard (2004), 91 und Maddison (Population).

476 Der Anteil der städtischen Bevölkerung insgesamt stieg von 18 (1950) auf 89 (2002) Prozent. Engelhard (2004), 79 92.

477 Maddison (Per Capita GDP).

478 Welt in Zahlen (Industrieproduktion), Welt in Zahlen (PKW) und Welt in Zahlen (Computer).

$479 \operatorname{Kim}(2001), 20$. 
Ähnlich wie in Südkorea verlief der Industrialisierungsprozess in Taiwan. Auch hier begann eine bescheidene Industrialisierung während der japanischen Kolonialherrschaft, als vor allem landwirtschaftliche Produkte wie Reis und Zucker für den japanischen Markt weiterverarbeitet wurden. ${ }^{480}$ Der eigentliche Durchbruch zu einem modernen Industriestaat erfolgte nach dem Zweiten Weltkrieg. Trotz der schweren Zerstörungen im Krieg wurde die Vorkriegsproduktion des sekundären Sektors um 1955 wieder erreicht, bevor in der Folge eine gewaltige, zunächst auf den Binnenmarkt und seit den 60er Jahren in zunehmendem $\mathrm{Maß}$ auf den Export ausgerichtete Expansion der Industrieproduktion einsetzte. ${ }^{481} 1993$ produzierte der sekundäre Sektor der taiwanesischen Wirtschaft mehr als $60 \mathrm{Mal}$ so viel wie 40 Jahre zuvor. ${ }^{482}$

Zwar gab es auf Taiwan, wo um 1950 erst etwa 7,5 Millionen Menschen lebten, vorerst noch keine Millionenstädte, doch nahm die Einwohnerzahl der beiden Großstädte Taipeh im Norden und Kaohsiung im Süden, die nur etwa $300 \mathrm{~km}$ auseinanderlagen, rasch zu. Erstere überschritt die Millionengrenze in den 60er, letztere spätestens in den 80er Jahren. Kurz danach war dies auch bei den beiden dazwischen liegenden Großstädten Taichung und Tainan der Fall. In ihnen und in der aus dem Landkreis Taipeh geschaffenen Millionenstadt Neu-Taipeh lebten zuletzt bei einer Gesamtbevölkerung von inzwischen 23 rund 14 Millionen Menschen. ${ }^{483}$

Ihre auf ein relativ kleines Gebiet konzentrierte Nachfrage nach Industriegütern wurde schon bald von eigenen Industrieunternehmen gedeckt. Während 1937 fast zwei Drittel des Bedarfes an Textilien und Bekleidung importiert wurden, waren es 1954 weniger als zehn Prozent. ${ }^{484}$ Vom gesamten Angebot an Konsumgütern stammten Ende der 50er Jahre über 90 Prozent aus inländischen Produktionsstätten. ${ }^{485}$ Umgekehrt lag der Anteil der Exporte - damals noch vorwiegend landwirtschaftliche Produkte - am gesamten Bruttosozialprodukt bei unter fünf Prozent und stieg erst danach auf rund 40 Prozent in den 80 er Jahren an. ${ }^{486}$ Die anfängliche Industrialisierung wurde daher auch in Taiwan von der Binnennachfrage und erst später von den Auslandsmärkten getragen. ${ }^{487} 1970$

480 Woronoff (1992), 81. Vgl. Menzel (1985), 156.

481 Frey (1986), 28 f., Kim (2001), 13 und Hughes (1988), 27.

482 Eigene Berechnung nach Mitchell (2007), 367 f. und 370.

483 Mitchell (2007), 44-46, Liste der Städte (Taiwan) und Maddison (Population).

484 Ranis (1979), 210.

485 Ranis (1979), $211 .$.

486 Menzel (1985), 64 und 200.

$487 \operatorname{Kim}(1990), 180$. 
war ein Drittel aller Betriebe in Industrie und verarbeitendem Gewerbe in den genannten Großstädten angesiedelt, die damals etwa ein Fünftel der Gesamtbevölkerung stellten. ${ }^{488}$ Weitere Betriebe waren zur Deckung des heimischen Bedarfes in großer Zahl am Land entstanden.

In der Folge stieg der Anteil der fünf Millionenstädte auf rund 60 Prozent der Gesamtbevölkerung an, wodurch die von ihnen ausgelöste Industrialisierung einen deutlich größeren Teil der taiwanesischen Bevölkerung erfasste, als dies in vielen anderen Ländern der Dritten Welt der Fall war. ${ }^{489}$ Dementsprechend höher waren die nationalen Durchschnittswerte. Mit $24 \mathrm{~kg}$ wurde 1987 in Taiwan pro Einwohner deutlich mehr Rohbaumwolle verarbeitet als in jedem anderen Land Asiens und sogar mehr als in den führenden europäischen Industrieländern am Vorabend des Ersten Weltkrieges (vgl. Grafik 2 und Grafik 45). Bescheidener blieb dagegen der Aufbau einer eigenen Eisen- und Stahlindustrie, obwohl auch in Taiwan in den letzten Jahrzehnten eine Verschiebung der Industriestruktur in Richtung Schwer- und Investitionsgüterindustrie erfolgte (vgl. Grafik 47). ${ }^{490}$ Insgesamt arbeitete bereits 1970 mit 20 Prozent ein fast gleich großer Teil der Beschäftigten in Industrie und verarbeitendem Gewerbe wie im Stadtstaat Singapur. In den 80er Jahren waren es bis zu 35 und danach nur wenig unter 30 Prozent. ${ }^{41}$ Das Bruttoinlandsprodukt pro Einwohner lag 2008 über dem an sich schon hohen Wert von Südkorea und etwa auf dem Niveau Deutschlands. ${ }^{492}$ Nur wenige Plätze hinter Südkorea rangierte das Land bei der Ausstattung mit Computern und dem Bestand an PKW (vgl. Grafik 43 und Grafik 44).

Im Unterschied zu Taiwan und Südkorea, wo dank einer städtischen Mehrheitsbevölkerung der Großteil der Menschen von der Industrialisierung profitieren konnte, ist China der Gruppe jener Länder zuzuordnen, in denen wegen ihrer mehrheitlich ländlichen Bevölkerung vorerst nur eine Minderheit von der Industrialisierung erfasst wurde. Allerdings umfasste die Minderheit bei einer Gesamtbevölkerung von über einer Milliarde Einwohner - wie in Indien - mehrere Millionen Menschen.

Wie Indien blieb auch China lange Zeit ein Agrarland. In den 80er Jahren des 19. Jahrhunderts steuerten Industrie und Handwerk geschätzte vier Prozent zum Brutto-

488 Ranis (1979) 223 und eigene Berechnung nach Mitchell (2007), 44-46 und Maddison (Population).

489 Vgl. Myers (1986), 22.

490 Vgl. Cheng (2002), $9 \mathrm{f}$.

491 Mitchell (2007), $110 \mathrm{f}$.

492 Maddison (Per Capita GDP). 
inlandsprodukt bei. ${ }^{493}$ Nach ersten bescheidenen Anfängen einer Industrialisierung, die vor allem den staatlichen Rüstungsbedarf deckte, setzte eine größere Zahl von Fabrikgründungen erst seit der Jahrhundertwende ein. Sie wurden zu einem Großteil in den über den Außenhandel gewachsenen, weit auseinander liegenden Hafenstädten Shanghai, Tientsin, Kanton und dem über den Yangtsekiang an das Meer angeschlossenen Wuhan vorgenommen. ${ }^{494}$ Sie zählten zu den größten der insgesamt 25 Großstädte Chinas, die um 1900 bei einer Gesamtbevölkerung von 400 Millionen über 100.000 Einwohner zählten. In der Folge verzeichnete vor allem Shanghai ein besonders starkes Wachstum auf über 5 Millionen Einwohner im Jahre 1950, gefolgt vom damals britischen Hongkong mit über zwei Millionen und neun weiteren Millionenstädten mit weniger als zwei Millionen Einwohnern (vgl. Karte 10 und Tabelle 40). ${ }^{495}$

Shanghai, Nanjing Road, um 1930

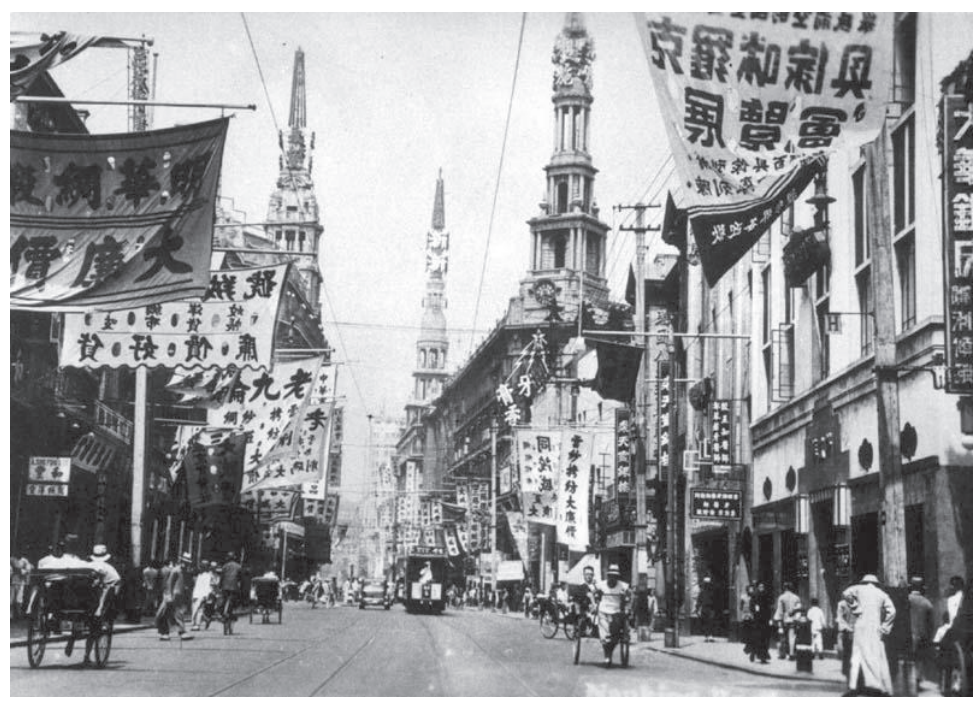

http://de.wikipedia.org/wiki/Shanghai\#/media/File:Shanghai_Nanking_Road_1930s.jpeg

493 Goswin (1996), 19.

494 Goswin (1996), 23.

495 Neben den genannten Großstädten auch Peking, Shenyang, Harbin, Dalian, Chongqing und Nanking. Vgl. Tabelle 40. 
Im Vordergrund der chinesischen Industrieproduktion standen zunächst die Konsumgüter, die in zunehmendem $\mathrm{Maß}$ die zuvor importierten Baumwollwaren und Baumwollgarne ersetzten. ${ }^{496}$ Die Verarbeitung von Rohbaumwolle kam in den 30er Jahren zwar nicht pro Einwohner, aber immerhin in absoluten Werten an Indien und Japan heran. ${ }^{497}$ Dagegen blieb eine eigene Eisen- und Stahlproduktion deutlich hinter den beiden Ländern zurück. An Roheisen stellte China im Schnitt der 30er Jahre weniger als die Hälfte von Britisch-Indien und nur etwa ein Drittel Japans her. ${ }^{498}$

In der Folge wurde der Industrialisierungsprozess durch den chinesisch-japanischen Krieg und den innerchinesischen Bürgerkrieg unterbrochen. ${ }^{499}$ Der Neubeginn, der nach der Gründung der Volksrepublik China im Jahre 1949 einsetzte, wurde weniger von marktwirtschaftlichen Impulsen bestimmt als vielmehr von staatlicher Seite zentral geplant. Die Planung sah nach dem Vorbild des sowjetischen Modells vor allem die Förderung der Schwerindustrie vor. Parallel zu den wechselnden politischen Zielsetzungen - wie etwa während der so genannten Kulturrevolution in der zweiten Hälfte der 60er Jahre - war sie starken Schwankungen unterworfen. ${ }^{500}$ Sie konnte zum Teil auf der Basis aufbauen, die von der japanischen Besatzungsmacht in der südlichen Mandschurei im Bereich der Metallverarbeitung und der chemischen Industrie errichtet worden war.

Trotz zum Teil divergierender Angaben in der Fachliteratur bleibt unbestritten, dass der Anteil der Leichtindustrie an der industriellen Gesamtproduktion zugunsten der Schwerindustrie deutlich zurückging und sich die relativen Anteile an der industriellen Gesamtproduktion geradezu umkehrten. ${ }^{501}$ Die Verarbeitung von Rohbaumwolle nahm zwischen 1950 und 1978 pro Einwohner um das Dreieinhalbfache zu, die Pro-KopfProduktion an Roheisen um mehr als das 20 -fache. ${ }^{502}$ Letztere übertraf den indischen Wert um mehr als das Doppelte, machte aber noch immer nur einen Bruchteil der viel rascher wachsenden, japanischen Pro-Kopf-Produktion aus (vgl. Grafik 45 und Grafik 47). Dasselbe gilt für das relativ junge Konsumgut Fernsehapparat: Das sehr viel kleinere Japan stellte etwa fünf Mal so viele Fernsehgeräte her wie China. ${ }^{503}$ Erst mit den

496 Goswin (1996), 35.

497 Mitchell (2007), 467.

498 Mitchell (2007), 441.

499 Kraus (1979), 31 und Goswin (1996), 28.

500 Goswin (1996), 40-55.

501 Goswin (1996), 40 und Wu (2002), 92.

502 Eigene Berechnungen nach Mitchell (2007), 442 und 467.

503 Statistisches Jahrbuch (2003), 571. 
wirtschaftspolitischen Reformen der späten 70er Jahre, die eine Öffnung nach außen und einen allmählichen Übergang zur Marktwirtschaft vorsahen, konnten die Impulse, die von den rasch wachsenden Großstädten auf die Industrialisierung ausgingen, wieder verstärkt wirksam werden. ${ }^{504}$

Sie hatten ein überaus rasches Wirtschaftswachstum zur Folge, das sich wie zu Beginn der Industrialisierung auf die küstennahen Großstadtregionen konzentrierte und nur in beschränktem Maß auf die stark ländlich geprägten Regionen im Landesinneren ausstrahlte. ${ }^{505}$ Insgesamt stieg die Wertschöpfung pro Einwohner, die sich zwischen 1950 und 1978 etwas mehr als verdoppelt hatte, bis 2008 auf fast das Siebenfache an. ${ }^{506}$ Die jährlichen Wachstumsraten des Bruttonationalproduktes lagen häufig über 10 Prozent. Die geschätzte Industrieproduktion allein, die sich zwischen 1960 und 1978 etwas mehr als verdoppelt hatte, stieg bis Mitte der 90er Jahre um mehr als das Vierfache und zwischen 2000 und 2014 noch einmal um das Sechsfache an. ${ }^{507}$ Davon entfiel ein Großteil auf die Herstellung von Automobilen, die China bis 2009 zwar nicht pro Einwohner, aber immerhin in absoluten Zahlen zum größten Automobilproduzenten der Welt machte. ${ }^{508}$ Im Bereich der Stahlproduktion wurde dieselbe Spitzenposition schon vor der Jahrhundertwende erreicht, ${ }^{509}$ und auch an Fernsehgeräten wurden um die Jahrhundertwende 20 Mal so viele produziert wie 20 Jahre zuvor und damit mehr als in jedem anderen Land der Welt. ${ }^{510}$

Allerdings wäre es in China wie in den meisten Ländern verfehlt, die rasante wirtschaftliche Entwicklung der letzten Jahrzehnte als gesamtstaatliches Phänomen anzusehen. Sie konzentrierte und beschränkte sich auf wenige, vornehmlich an der Küste gelegene Regionen, von denen allerdings jede für sich mehr Einwohner zählte als manche Länder als Ganze. ${ }^{511}$ Neben der Provinz Liaoning mit den drei Millionenstädten Shenyang, dem früheren Mukden, Anshan und Dalian, früher Lüta, sowie der Hauptstadt Peking samt dem nahen Tientsin waren es vor allem das Yangste-Delta um Shanghai, Nanking und Hangzhou sowie das Perlfluss-Delta mit Hongkong, Shenzhen und Kanton. Letztere entwickelten sich in den letzten Jahrzehnten zu den dynamischsten Wirtschaftsregio-

504 Goswin (1996), 56-74.

505 Schon 1952 stammten knapp drei Viertel der industriellen Wertschöpfung aus den sieben Küstenprovinzen. Kraus (1979), 101.

506 Maddison (Per Capita GDP).

507 Wu (2002), 89 und Quest Trend Magazin.

508 Wirtschaftszahlen zum Automobil.

509 Stahl (Tabellen und Grafiken).

510 Statistisches Jahrbuch (2003), 571.

511 Vgl. Bronger (2004), $92 \mathrm{f}$. 
nen Chinas und den größten Industriezonen der Welt, mit einer wirtschaftlichen Wertschöpfung, die durchaus mit jener Südkoreas vergleichbar war. ${ }^{512}$ In den vier küstennahen Großregionen lagen 1980 die Hälfte der inzwischen 34 chinesischen Millionenstädte und 30 Jahre später neben den im Landesinneren gelegenen Großstädten Chongqing, Xi'an bzw. Sian und Harbin sieben der zehn größten Metropolregionen. ${ }^{513}$

Wie sehr sie zu Zentren der modernen wirtschaftlichen Entwicklung geworden waren, geht auch daraus hervor, dass etwa 1993 das Sozialprodukt pro Einwohner in den sieben Provinzen, zu denen sie gehörten, durchwegs und zum Teil deutlich über dem Wert der restlichen 23 Provinzen des Landes lag. ${ }^{514} 2012$ steuerten sie fast 40 Prozent zum gesamtchinesischen Bruttoinlandsprodukt bei, obwohl sie nur ein Viertel der inzwischen auf über 1,3 Milliarden Menschen angestiegenen Gesamtbevölkerung stellten. ${ }^{515}$ Dazu trugen neben den in den städtischen Metropolregionen selbst angesiedelten Industrien auch zahlreiche kleinere Gewerbebetriebe auf dem Land bei, deren Produktion seit den Reformen der späten 70er Jahre - und zwar wiederum speziell im Umfeld der großen Städte entlang der Küste von Peking und Tientsin bis Hongkong und Macau - besonders rasch wuchs. ${ }^{516}$

Hongkong um 2008

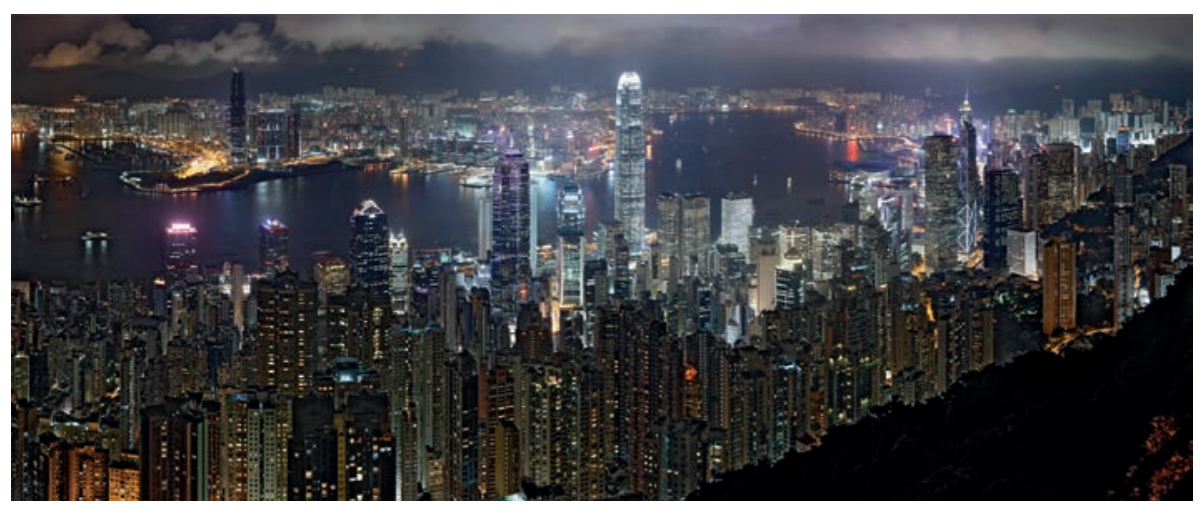

http://de.wikipedia.org/wiki/Hongkong\#/media/File:Hong_Kong_Night_Skyline_non-HDR.jpg

512 Brink (2013), 13 und Bronger/Trettin (2011), $293 \mathrm{f}$.

513 Mitchell (2007), 42-46 und Liste der Städte (China).

514 Herrmann-Pillath (1995), 29.

515 Eigene Berechnungen nach China (2012a) und China (2012b).

516 Pomfret (1996), 16. 
Als Folge der räumlich sehr einseitigen Entwicklung ergeben sich auch für China trotz des spektakulären Wachstums einiger Zentren relativ niedrige, in Anbetracht des riesigen Landes allerdings nur wenig aussagekräftige, gesamtstaatliche Durchschnittswerte. So errechnete Angus Maddison für 2008 ein Bruttoinlandsprodukt pro Einwohner, das zwar über dem Wert Indiens und vieler anderer weniger entwickelter Länder lag, aber nur ein Drittel bis ein Viertel der Werte ausmachte, die von ihm für die Industrieländer West-, Nord- und Mitteleuropas sowie für Kanada und die USA, aber auch für Japan, Südkorea und Taiwan ermittelt wurden. ${ }^{517}$ Ähnliches gilt für die zu Beginn des neuen Jahrhunderts errechnete Industrieproduktion pro Einwohner, die im Durchschnitt nur auf ein Achtel bis ein Zehntel der Industrieländer kam. ${ }^{518}$ Auch bei der Ausstattung mit Computern oder mit Autos lag China trotz in einzelnen Regionen viel höheren Werten als Ganzes weit zurück (vgl. Grafik 43 und Grafik 44). Wenn das Land auf der anderen Seite bei all diesen Parametern zum Teil deutlich besser abschnitt als das von der Größe her vergleichbare Indien, lässt sich dies kaum aus gesamtstaatlichen Unterschieden erklären, sondern in erster Linie aus dem Umstand, dass die hoch entwickelten Teilregionen in China einen größeren und die noch weitgehend ländlich geprägten Regionen einen kleineren Teil der Gesamtbevölkerung umfassten, als dies in Indien der Fall war.

517 Maddison (Per Capita GDP).

518 Welt in Zahlen (Industrieproduktion). 


\section{Ozeanien}

Außer in den größeren Ländern Australien und Neuseeland blieben sowohl die Bevölkerungszahl als auch die Verstädterung auf den pazifischen Inseln derart gering, dass es dort bis zuletzt zu keiner nennenswerten Industrialisierung kam. ${ }^{519}$ Letzteres gilt auch für Papua-Neuguinea mit seinen rund 7 Millionen Einwohnern, wo nur die Hauptstadt mehr als 100.000 Einwohner zählt und der überwiegende Teil der Bevölkerung nach wie vor weit verstreut in einer Subsistenzwirtschaft lebt. ${ }^{520}$

\section{Australien und Neuseeland}

Ganz anders gestaltete sich die Entwicklung im heutigen Australien und in ähnlicher Form auch in Neuseeland, obwohl beide Länder lange Zeit ebenfalls nur sehr dünn besiedelt waren. ${ }^{521}$ Noch um die Wende zum 20. Jahrhundert, als die bis dahin getrennten britischen Kolonien in Australien zu einem einzigen Staat vereinigt wurden, zählte das Land erst etwa 3,7 Millionen Einwohner - in Neuseeland waren es weniger als eine Million. ${ }^{52}$ Schon damals jedoch hatte sich etwa ein Drittel der australischen Bevölkerung, die sich neben einer kleinen Minderheit indigener Aborigines hauptsächlich aus Zuwanderern und ihren Nachkommen zusammensetzte, in einigen wenigen Großstädten niedergelassen. ${ }^{523}$

In Australien verdankten die so genannten „Port Capitals“"524 ihr Wachstum der Doppelfunktion als Hafenstädte auf der einen und als Verwaltungsmittelpunkte der jeweiligen Kolonien und späteren Provinzen auf der anderen Seite. Zwei von ihnen, Sydney in New South Wales und Melbourne in Victoria, wuchsen besonders schnell und überschritten zwischen den beiden Weltkriegen die Grenze zur Millionenstadt. Brisbane, Adelaide und Perth als Hauptstädte von Queensland, South Australia und Western Australia folgten in den 80er Jahren des 20. Jahrhunderts (vgl. Karte 12 und Tabelle 41). ${ }^{525}$

519 Kreisel (2009), 256.

520 Wikipedia (Papua-Neuguinea).

521 Vgl. Fitzpatrick (1969).

522 Maddison (Population).

523 Mitchell (2007), 47.

524 Hofmeister (2002), 24.

525 Mitchell (2007), 47. Zu den Großstädten mit über 100.000 Einwohnern zählte um 1950 auch Newcastle. 


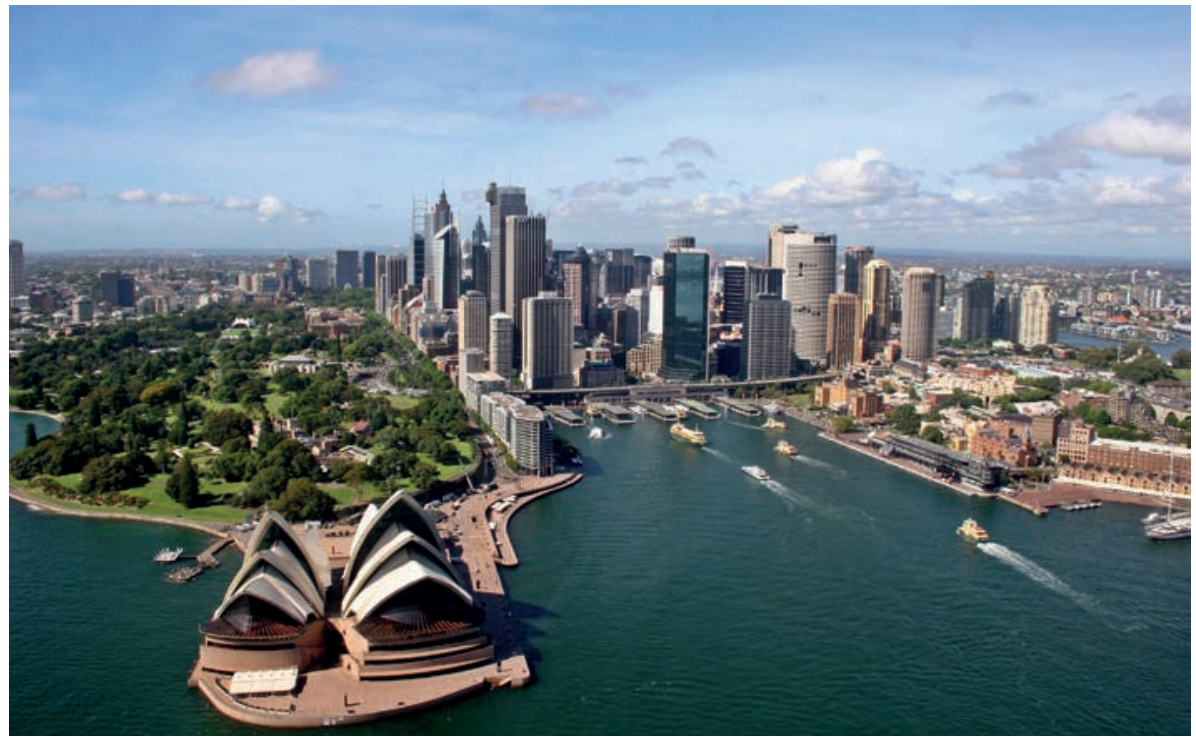

http://de.wikipedia.org/wiki/Sydney\#/media/File:Sydney_skyline_from_the_north_aerial_2010.jpg

Auf diese Großstädte konzentrierte sich von Anfang an die Industrialisierung des Landes, die nach bescheidenen Anfängen zuvor in der ersten Hälfte des 20. Jahrhunderts ein größeres Ausmaß annahm. ${ }^{526}$ In den 1960er Jahren, als Industrie und verarbeitendes Gewerbe rund 30 Prozent aller Erwerbstätigen und damit weit mehr als die zuvor dominierenden Sektoren der Landwirtschaft und des Bergbaus beschäftigten, arbeiteten fast drei Viertel aller Fabrikbeschäftigten in den fünf Großstädten, die meisten von ihnen allein in Sydney und Melbourne. ${ }^{527}$ Auch 30 Jahre später, als der Anteil von Industrie und verarbeitendem Gewerbe wie in anderen Industrieländern auf weniger als 15 Prozent der Erwerbstätigen gefallen war, vereinigten die fünf Großstädte knapp 70 Prozent aller Industriebeschäftigten auf sich. ${ }^{528}$

526 Zwischen 1913 und 1938 stieg die Produktion von Industrie und verarbeitendem Gewerbe auf fast das Doppelte an. Lal (1988), 201. Vgl. Hofmeister (2002), 24.

527 Eigene Berechnungen nach Mitchell (2007), 113 und Boehm (1971), 140.

528 Eigene Berechnungen nach Braun/Grotz (2002), 185 und Mitchell (2007), 113. 
Karte 12: Großstädte mit über 100.000 Einwohnern in Australien und Neuseeland um 1950

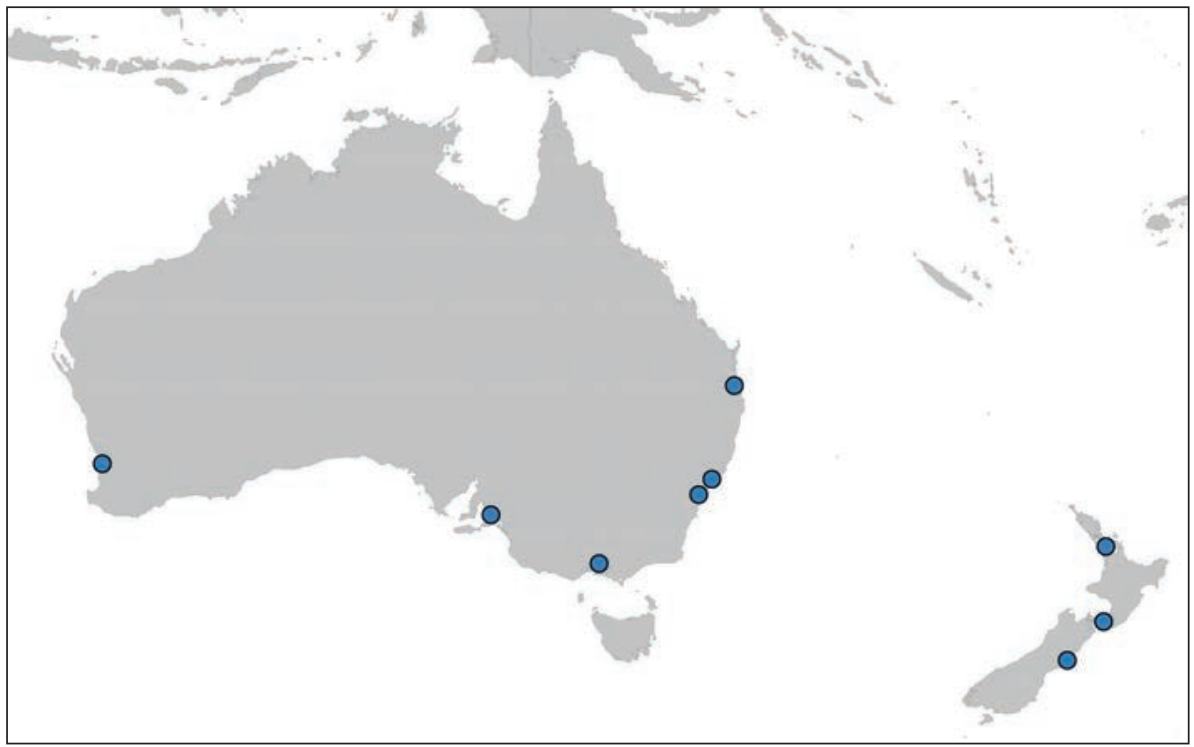

Tirol Atlas - Bearbeitung Klaus Förster nach Mitchell (2007), 47.

Kartenhintergrund: World Borders Dataset - http://thematicmapping.org/downloads/world_borders.php

Im Unterschied zur Landwirtschaft und zum Bergbau, die von Anfang an in großem Ausmaß für den Export produzierten, war die Industrie auf den in den Großstädten konzentrierten Binnenmarkt ausgerichtet. Zwischen 1927/28 und 1936/37 wurden weniger als 4 Prozent der gesamten Produktion aus Industrie und verarbeitendem Gewerbe exportiert. Speziell die Produkte der Textil- und Bekleidungsindustrie waren fast zur Gänze für den Binnenmarkt bestimmt. ${ }^{529}$ Erst später, als die Industrie weiter zulegte, ging ein zunehmender Teil der Industriewaren auch in den Export. ${ }^{530}$

Angeregt durch den Massenmarkt der Großstädte wurde Australien auf diese Weise $\mathrm{zu}$ einem hoch industrialisierten Industrieland, das sich wie andere Industrieländer in den letzten Jahrzehnten in zunehmendem Maße zu einer Dienstleistungsgesellschaft entwickelte. Die ungebremst steigende Produktivität seiner Industrie und die damit fortge-

529 Fitzpatrick (1969), 287 und 311.

$530 \mathrm{Vgl}$. OECD Australia (2001). 
setzte Steigerung der Einkommen auf der einen sowie eine partielle Bedarfssättigung bei Industriewaren auf der anderen Seite ließen ab Mitte der 70er Jahre die Zahl der Industriebeschäftigten zugunsten hochwertiger Beschäftigungen im Dienstleistungsbereich zurückgehen. Und da die fünf größten Städte, auf die sich diese Entwicklung bis zuletzt konzentrierte, um 1960 über die Hälfte und um die Jahrhundertwende über 60 Prozent der australischen Gesamtbevölkerung von inzwischen rund 19 Millionen Einwohnern auf sich vereinigten, ${ }^{531}$ fielen die nationalen Durchschnittswerte entsprechend positiv aus. Das Bruttoinlandsprodukt pro Einwohner lag sowohl 1960 als auch in den Jahrzehnten danach in etwa auf dem Niveau Kanadas oder der west-, mittel- und nordeuropäischen Länder. ${ }^{532}$

Eine ähnliche Entwicklung erlebte das mit rund 4 Millionen Einwohnern deutlich kleinere Neuseeland, dessen Wirtschaft ebenfalls lange Zeit vom Export landwirtschaftlicher Produkte wie insbesondere Wolle, Fleisch und Milchprodukte bestimmt war. ${ }^{53}$ Seine größte Stadt Auckland zählte in den 60er Jahren über eine halbe Million Einwohner und überschritt als Agglomeration die Millionengrenze gegen Ende des 20. Jahrhunderts (vgl. Karte 12 und Tabelle 41). ${ }^{534}$ Parallel dazu entwickelte sich vor allem in den Jahrzehnten nach dem Zweiten Weltkrieg eine Industrie, die gemeinsam mit dem verarbeitenden Gewerbe in den 60er und 70er Jahren 25 und mehr Prozent aller Erwerbstätigen beschäftigte und wesentlich zur wachsenden Wertschöpfung beitrug. ${ }^{535}$ Pro Einwohner lag sie lange Zeit auf etwa demselben Niveau wie in Australien und fiel erst im Zuge des Übergangs zur Dienstleistungsgesellschaft, die in Neuseeland mit niedrigeren Wachstumsraten verbunden war, hinter Australien zurück. ${ }^{536}$ Dennoch zählte Neuseeland zuletzt zu den reicheren Ländern der Welt, was unter anderem auch in der hohen PKW- oder Computerdichte von jeweils über 500 Stück pro 1.000 Einwohner zum Ausdruck kam. ${ }^{537}$

531 Eigene Berechnungen aus Maddison (Population) und Mitchell (2007), 47.

532 Maddison (Per Capita GDP).

533 Fellmeth/Rohde (1999), 26.

534 Mitchell (2007), 47. Zu den Großstädten mit über 100.000 Einwohnern zählten um 1950 auch Wellington und Christchurch.

535 Mitchell (2007), 114 und Kreisel (2009), 255.

536 Maddison (Per Capita GDP). Zur zuletzt niedrigeren Industrieproduktion pro Einwohner vgl. Welt in Zahlen (Industrieproduktion),

537 Welt in Zahlen (PKW) und Welt in Zahlen (Computer). 


\section{Resümee}

Die Ergebnisse des wirtschaftshistorischen Rundgangs durch die Länder der Welt lassen sich in 30 Punkten zusammenfassen.

1. Tausende von Jahren waren die einzelnen Regionen der Welt derart dünn besiedelt, dass sich die Menschen damit begnügten, sich selbst und ihre Haushalte sei es als Jäger und Sammler, sei es als sesshafte Bauern - mit den notwendigsten Bedarfsgütern zu versorgen. Ein überlokaler Austausch war weder notwendig noch profitabel und fand, wenn überhaupt, nur in sehr bescheidenem Ausmaß statt.

2. Mit der Sesshaftwerdung der Menschen, die vor gut 10.000 Jahren in dem aus europäischer Sicht als „Vorderer Orient“ bezeichneten Gebiet einsetzte und in der Folge zu unterschiedlichen Zeiten fast alle Teile der Welt erfasste, nahm die Bevölkerung etwas schneller, obwohl im Vergleich zu den jüngsten Entwicklungen noch immer überaus langsam zu.

3. Die Bevölkerungsverdichtung ließ sowohl die Zahl der Siedlungen als auch ihre Größe anwachsen. Es lohnte sich, außer für sich selbst auch für andere Menschen, und zwar innerhalb wie außerhalb der eigenen Siedlungen zu produzieren, wodurch der lokale, regionale und sogar überregionale Handel stimuliert wurde.

4. Die damit einhergehende Arbeitsteilung war umso stärker ausgeprägt, je größer die Siedlungen wurden. Ihr Wachstum resultierte sowohl aus der Differenz zwischen Geburten und Sterbeziffern als auch aus dem Zuzug aus der näheren und weiteren Umgebung.

5. Der Zuzug fiel in verkehrsgünstig gelegenen Siedlungen stärker aus als in anderen. Sie lagen entweder an häufig frequentierten Handelsrouten am Wasser und am Land oder an Orten, die sich zur Herrschafts- und Verwaltungsausübung besonders gut eigneten. In vielen Fällen vereinigten sie beide Funktionen, die eines Handelsplatzes und die eines Herrschafts- und Verwaltungsmittelpunktes, auf sich.

6. Derartige, meist größere und zum Teil dank ihrer besonderen Rechtsstellung als Städte bezeichnete Siedlungen entstanden in den einzelnen Regionen der Welt in unterschiedlich großer Zahl und zu verschiedenen Zeiten. 
7. Dank fortschreitender Arbeitsteilung stellten sie sowohl für die eigenen Bewohner als auch für die Bewohner anderer Städte einen Markt dar, der einzelne Produzenten zur Herstellung konkurrenzfähiger Produkte sowie Detail- und Fernhändler zur Verteilung dieser Produkte anregen konnte.

8. Um auf den Märkten konkurrenzfähig zu bleiben, war es notwendig, die Produktivität in quantitativer und/oder qualitativer Hinsicht zu steigern.

9. Eine höhere Produktivität hatte höhere individuelle Einkommen zur Folge und verhalf städtischen Siedlungen ebenso wie den marktorientierten Bauern, die sie belieferten, zu einem Lebensstandard, der tendenziell höher war als in einer allein auf Selbstversorgung ausgerichteten, ländlichen Subsistenzwirtschaft.

10. Eine besonders drastische Steigerung der Produktivität erfolgte in jüngerer Zeit mit der Umstellung auf Massenproduktion. Sie wurde maschinell betrieben und stützte sich statt auf die lange Zeit übliche, menschliche wie tierische Energie auf die leblosen und damit weit effizienteren Energieträger wie Kohle, Erdöl oder elektrische Energie.

11. Angesichts der Größenordnung der technischen Neuerungen werden die Umgestaltung der gewerblichen Produktion als Industrielle Revolution und die damit einhergehenden Veränderungen als Industrialisierung bezeichnet.

12. Um eine Massenproduktion lohnend und profitabel werden zu lassen, bedurfte es einer entsprechenden Massennachfrage, die zudem - um verteuernde Transportkosten zu vermeiden - in möglichst konzentrierter Form vorliegen sollte.

13. Eine derartige Konzentration der Nachfrage war tendenziell in größeren, mehrere 100.000 bis über eine Million Einwohner zählenden Großstädten eher anzutreffen als in den kleineren Städten.

14. Die erste Stadt, die um 1800 die Millionengrenze überschritt, war London, gefolgt von mehreren Großstädten in Kontinentaleuropa und im zunächst östlichen Nordamerika. Gegen Ende des 19. und vor allem in der zweiten Hälfte des 20. Jahrhunderts kamen vor dem Hintergrund rasch wachsender Gesamtbevölkerungen eine Reihe weiterer Millionenstädte hinzu.

15. Sie alle lösten in ihrem Umfeld einen Industrialisierungsprozess aus, der fast durchwegs mit der Umstellung der Konsumgüterproduktion begann und in der Folge in unterschiedlich starkem Ausmaß auch andere Industriezweige speziell der Investitionsgüter- und Schwerindustrie erfasste. 
16. In den jüngeren Jahrzehnten kam es insbesondere in den stärker industrialisierten Ländern zu einer partiellen Bedarfssättigung bei Industriewaren.

17. Sie hatte zur Folge, dass die Nachfrage nach Industriegütern - anders als früher langsamer zunahm als die nach wie vor anhaltende Steigerung der Produktivität.

18. Wo immer dies der Fall war, ging die Zahl der in der Industrie beschäftigten Menschen zunächst relativ und in manchen Ländern schließlich auch absolut zurück.

19. Gleichzeitig wuchsen dank steigernder Produktivität sowohl die privaten Einkommen als auch die Abgaben an die öffentliche Hand tendenziell weiter an.

20. Dadurch nahm die private wie die öffentliche Nachfrage nach Dienstleistungen weiter $\mathrm{zu}$, wodurch im Dienstleistungsbereich neue und bei entsprechender Kaufkraft auch hochwertige Arbeitsplätze geschaffen werden konnten.

21. Die Großstadtregionen, die den genannten Entwicklungen zugrunde lagen und sie vielfach erst auslösten, entstanden weniger als Folge politischer Entscheidungen oder politischer Grenzziehungen, sondern vielmehr aufgrund regionaler Bevölkerungsdichten, Handelsströme und Wanderungsbewegungen. Sie waren in aller Regel von den Bedürfnissen und Beweggründen der einzelnen Menschen und nur in Ausnahmefällen von der Wirtschaftspolitik der Regierungen bestimmt.

22. Da die Großstadtregionen meist unabhängig von staatlichen Grenzziehungen entstanden, fiel ihre Zahl, ihre Verteilung und ihr relatives Gewicht innerhalb eines Landes unterschiedlich aus.

23. Auf diese Weise bestimmte die relative Verteilung einer Bevölkerung auf tendenziell weiter entwickelte, großstädtische Regionen auf der einen und eher ländlich geprägte, weniger entwickelte Regionen auf der anderen Seite in hohem Maße die Durchschnittswerte und das Gesamtbild eines Landes.

24. Es macht daher wenig Sinn, von weniger oder höher entwickelten, von armen oder reichen Ländern als Ganze zu sprechen. Sie unterscheiden sich nicht dadurch voneinander, dass in den einen eine Industrialisierung stattfand und in den anderen nicht, sondern vielmehr dadurch, dass sich innerhalb der einzelnen Länder industrialisierte und weniger industrialisierte Regionen unterschiedlich verteilen.

25. Es wäre daher sinnvoller, die Welt nicht nach armen und reichen Ländern zu unterscheiden und nach länderspezifischen Unterscheidungsmerkmalen zu 
suchen, sondern sie stattdessen in industrialisierte und weniger industrialisierte Regionen einzuteilen, die unabhängig von länderspezifischen Merkmalen entstanden.

26. Industrialisierung war weder ein europäisches noch ein außereuropäisches Phänomen. Sie fand sowohl in der Ersten als auch in der Dritten Welt statt und lässt sich auf jedem Kontinent beobachten.

27. Sie bedurfte keiner vor Ort vorhandener Rohstoffe und hing weder von gewissen Religionen noch von historisch gewachsenen Kulturen ab.

28. Außer in den wenigen und nur vorübergehenden Fällen einer zentralen Planwirtschaft war Industrialisierung zum überwiegenden Teil von den Kräften des Marktes und dem individuellen Streben der Menschen nach wirtschaftlicher Besserstellung bestimmt.

29. Die Regierungen der einzelnen Länder konnten sie mittels einer Importsubstitutionspolitik oder der Einrichtung von Industriezonen zwar fördern, nicht jedoch auslösen oder den Prozess auf andere als die ohnehin erfassten Regionen und damit auf das ganze Land ausdehnen.

30. Industrialisierung fand stattdessen überall dort statt, wo es aus dem Streben der Menschen nach einer Verbesserung ihrer Lebenssituation zur Entstehung von Großstädten kam, deren konzentrierte Nachfrage nach Gütern aller Art die Gründung von Industrieunternehmen lohnend und profitabel erscheinen ließ. ${ }^{538}$

Abschließend stellt sich die Frage, welche Schlüsse sich aus der historischen Erfahrung für künftige Entwicklungen ziehen lassen und welche Empfehlungen sich daraus ergeben könnten. Die ungebremst anhaltende Landflucht in fast allen Teilen der Welt lässt erwarten, dass sich der Prozess der Urbanisierung und speziell das Wachstum der Großstädte fortsetzen wird. Daraus ergeben sich für eine Entwicklungspolitik vor allem zwei Konsequenzen, eine kurzfristige und eine langfristige. Kurzfristig geht es darum,

538 Einer der nur vereinzelten Hinweise auf die positive Rolle der Großstadt in der wirtschaftlichen Entwicklung zumindest der Gegenwart stammt vom kanadischen Geographen Michael D. Mehta, der von Dirk Bronger mit der von ihm nicht unbedingt geteilten Aussage zitiert wird, dass die Metropole „has the advantage of a large and concentrated labour and consumer market; it is the focus of transportation routes; it has the economics of scale and juxtaposition of industries and specialists; it is a fertile ground for social and cultural change necessary for development; it is a centre from which these innovations or new adoptions, artefacts and technologies ... diffuse into the country side, and it is an area that receives migrants from the country side thus relieving the farming areas of the burden excess population." Bronger (2004), 107. Wie sehr all dies auch für die Vergangenheit und insbesondere für den Industrialisierungsprozess in den verschiedenen Teilen der Welt gilt, konnte in der vorliegenden Studie vollinhaltlich bestätigt werden. 
mittels entsprechender Hilfe zur Selbsthilfe möglichst viele Menschen am Land wie in den Städten aus der absoluten Armut herauszuführen. Für eine langfristige Entwicklung hingegen ist es notwendig, die großstädtische Kaufkraft, die in der Vergangenheit als entscheidender Entwicklungsmotor wirkte, nicht nur zu erhalten, sondern auf zusätzliche Bevölkerungsschichten auszudehnen. Neben der Förderung privater Investitionstätigkeit kämen dafür öffentliche Investitionen in die großstädtische Infrastruktur und in soziale Dienstleistungen im weitesten Sinn in Frage. Über beides würde zusätzliche Kaufkraft geschaffen, die eine steigende Nachfrage nach Industriegütern und Dienstleistungen zur Folge hätte. Sie könnte weitere Investitionen anregen und hätte auf diese Weise die Entstehung neuer Arbeitsplätze für die in die Großstädte strömenden Menschen zur Folge. 



\section{Tabellen}

Tabelle 1: Städte mit über 20.000 Einwohnern in Europa um 1300

\begin{tabular}{|c|c|c|c|c|c|}
\hline \multicolumn{3}{|c|}{ West- und Mitteleuropa } & \multicolumn{3}{|c|}{ Ost- und Südeuropa } \\
\hline London & Köln & Aachen & Novgorod & Pskow & Twer \\
\hline Brügge & Gent & Löwen & Wladimir & Moskau & Smolensk \\
\hline Tournai & Ypern & Saint-Omer & Polazk & Vilnius & Bolgar \\
\hline Lille & Valenciennes & Douai & Sudak & Feodossija & Suceava \\
\hline Arras & Amiens & Rouen & Preslav & Plowdiw & Belgrad \\
\hline Laon & Paris & Troyes & Sofia & Weliko Tar & \\
\hline Metz & Mainz & Speyer & Durrës & & \\
\hline \multicolumn{6}{|l|}{ Worms } \\
\hline Tours & Angers & Bordeaux & Saloniki & Korinth & Athen \\
\hline Lyon & Toulouse & Narbonne & Neapel & Messina & Palermo \\
\hline Montpellier & Marseille & & & & \\
\hline Erfurt & Prag & Wien & Barcelona & Burgos & León \\
\hline Augsburg & Lübeck & & Valladolid & Valencia & Córdoba \\
\hline Genua & Pavia & Mailand & Toledo & Granada & Málaga \\
\hline Brescia & Cremona & Piacenza & Sevilla & Medina del & apo \\
\hline Parma & Mantua & Verona & Lissabon & & \\
\hline Vicenza & Padua & Venedig & & & \\
\hline Ferrara & Bologna & Pisa & & & \\
\hline Florenz & Arezzo & Siena & & & \\
\hline Perugia & L'Aquila & Rom & & & \\
\hline
\end{tabular}

Bairoch/Batou/Chèvre (1988). 
Tabelle 2: Städte mit über 20.000 Einwohnern in Europa um 1750

\begin{tabular}{|c|c|c|c|c|}
\hline Frankreich & Spanien & Italien & Deutschland & Rußland \\
\hline Aix-en-Provence & Antequera & Bergamo & Aachen & Feodossija \\
\hline Amiens & Barcelona & Bologna & Augsburg & Kaliningrad \\
\hline Angers & Cádiz & Brescia & Berlin & Kasan \\
\hline Arles & Cartagena & Cagliari & Braunschweig & Kiew \\
\hline Avignon & Córdoba & Catania & Bremen & Lemberg \\
\hline Besançon & Écija & Cremona & Dresden & Moskau \\
\hline Bordeaux & Granada & Ferrara & Frankfurt/Main & St.Petersburg \\
\hline Brest & Jaén & Florenz & Hamburg & Polen \\
\hline Caen & Jerez de la Frontera & Genua & Köln & Breslau \\
\hline Clermont-Ferrand & Lorca & Livorno & Leipzig & Danzig \\
\hline Dijon & Madrid & Lucca & Lübeck & Krakau \\
\hline Douai & Málaga & Mailand & Mainz & Posen \\
\hline Grenoble & Murcia & Mantua & Mannheim & Warschau \\
\hline Lille & Palma de Mallorca & Messina & München & Litauen \\
\hline Lyon & Santiago de Comp. & Modena & Nürnberg & Vilnius \\
\hline Marseille & Saragossa & Modica & Regensburg & Tschechien \\
\hline Metz & Sevilla & Neapel & Großbritannien & Prag \\
\hline Montpellier & Toledo & Padua & Birmingham & Slowakei \\
\hline Nancy & Valencia & Palermo & Bristol & Pressburg \\
\hline Nantes & Portugal & Parma & Edinburgh & Ungarn \\
\hline Nîmes & Lissabon & Pavia & Glasgow & Debrecen \\
\hline Orléans & Porto & Piacenza & Liverpool & Budapest \\
\hline Paris & Griechenland & Rom & London & Serbien \\
\hline Reims & Saloniki & Turin & Newcastle/Tyne & Belgrad \\
\hline Rennes & Malta & Venedig & Norwich & Rumänien \\
\hline Rouen & La Valletta & Verona & Irland & Bukarest \\
\hline Saint-Étienne & Schweiz & Vicenza & Downpatrick & Jassy \\
\hline Straßburg & Genf & & Dublin & \\
\hline
\end{tabular}




\begin{tabular}{|c|c|c|c|c|}
\hline Toulon & Belgien & Österreich & Dänemark & Bulgarien \\
\hline Toulouse & \multirow{12}{*}{$\begin{array}{l}\text { Antwerpen } \\
\text { Brügge } \\
\text { Brüssel } \\
\text { Gent } \\
\text { Lüttich } \\
\text { Tournai }\end{array}$} & Graz & Kopenhagen & \multirow{12}{*}{$\begin{array}{l}\text { Schumen } \\
\text { Plowdiw } \\
\text { Russe } \\
\text { Silistra } \\
\text { Sofia }\end{array}$} \\
\hline Versailles & & Wien & Schweden & \\
\hline Niederlande & & Albanien & \multirow[t]{10}{*}{ Stockholm } & \\
\hline Amsterdam & & Shkodra & & \\
\hline Gouda & & Kosovo & & \\
\hline Groningen & & Prizren & & \\
\hline Haarlem & & & & \\
\hline Leiden & & & & \\
\hline Middelburg & & & & \\
\hline Rotterdam & & & & \\
\hline Den Haag & & & & \\
\hline Utrecht & & & & \\
\hline
\end{tabular}

Bairoch/Batou/Chèvre (1988).

Tabelle 3: Bevölkerung Europas 1820-1950 in Millionen (Grenzen von 1950)

\begin{tabular}{|l|l|l|l|l|}
\hline & 1820 & 1850 & 1900 & 1950 \\
\hline Sowjetunion & 54,8 & 73,8 & 124,5 & 179,6 \\
Deutschland & 24,9 & 33,7 & 54,4 & 68,4 \\
Vereinigtes Königreich & 14,1 & 20,3 & 36,7 & 50,1 \\
Italien & 20,2 & 24,5 & 33,7 & 47,1 \\
Frankreich & 31,3 & 36,4 & 40,6 & 42,5 \\
Spanien & 12,2 & 14,9 & 18,6 & 28,1 \\
Polen & 10,4 & 13,0 & 24,8 & 24,8 \\
Rumänien & 6,4 & 8,0 & 11,0 & 16,3 \\
Jugoslawien & 5,2 & 6,0 & 11,2 & 16,3 \\
Tschechoslowakei & 7,7 & 9,3 & 12,1 & 12,4 \\
Niederlande & 2,3 & 3,1 & 5,1 & 10,1 \\
Ungarn & 4,1 & 5,2 & 7,1 & 9,3 \\
Belgien & 3,4 & 4,4 & 6,7 & 8,6 \\
Portugal & 3,3 & 3,8 & 5,4 & 8,4 \\
Griechenland & 2,3 & 3,0 & 4,0 & 7,6 \\
Bulgarien & 2,2 & 2,5 & 7,0 & \\
\hline
\end{tabular}




\begin{tabular}{|l|l|l|l|l|}
\hline Schweden & 2,6 & 3,5 & 5,1 & 7,0 \\
Österreich & 3,4 & 4,0 & 6,0 & 6,9 \\
Schweiz & 2,0 & 2,4 & 3,3 & 4,7 \\
Dänemark & 1,2 & 1,5 & 2,6 & 4,3 \\
Finnland & 1,2 & 1,6 & 2,6 & 4,0 \\
Norwegen & 1,0 & 1,4 & 2,2 & 3,3 \\
Irland & 7,1 & 4,5 & 3,0 \\
Albanien & 0,4 & 0,9 & 0,8 & 1,2 \\
\hline
\end{tabular}

Maddison (Population).

Tabelle 4: Großstädte mit über 100.000 Einwohnern in Europa 1800 und 1850 (Einwohner in 1.000)

\begin{tabular}{|l|l|l|l|l|l|}
\hline & 1800 & 1850 & & 1800 & 1850 \\
\hline London & 948 & 2.236 & Paris & 550 & 1.053 \\
St. Peterburg & 220 & 524 & Moskau & 300 & 440 \\
Berlin & 172 & 437 & Wien & 247 & 431 \\
Neapel & 430 & 409 & Glasgow & 70 & 345 \\
Manchester & 84 & 303 & Madrid & 168 & 281 \\
Dublin & 200 & 262 & Lissabon & 195 & 240 \\
Birmingham & 71 & 233 & Amsterdam & 217 & 225 \\
Barcelona & 100 & 220 & Mailand & 135 & 209 \\
Marseille & 101 & 195 & Edinburgh & 83 & 194 \\
Lyon & 109 & 177 & Rom & 153 & 175 \\
Leeds & 53 & 172 & Palermo & 139 & 168 \\
Warschau & 63 & 167 & Budapest & 50 & 161 \\
Hamburg & 130 & 149 & Bristol & 64 & 137 \\
Turin & 82 & 137 & Sheffield & 46 & 135 \\
Brüssel & 66 & 132 & Bordeaux & 96 & 130 \\
Kopenhagen & 101 & 130 & Genua & 90 & 128 \\
Venedig & 138 & 127 & Prag & 76 & 118 \\
Breslau & 60 & 114 & Sevilla & 96 & 113 \\
Köln & 41 & 110 & Bradford & 13 & 110 \\
Gent & 55 & 107 & Bukarest & 50 & 104 \\
Rouen & 80 & 101 & Odessa & 15 & 100 \\
\hline
\end{tabular}

Bairoch/Batou/Chèvre (1988). 
Tabelle 5: Millionenstädte in Europa 1910/11 und 1950/51 (Einwohner in 1.000)

\begin{tabular}{|l|l|l|l|l|l|}
\hline & $1910 / 11$ & $1950 / 51$ & & $1910 / 11$ & $1950 / 51$ \\
\hline London & 7.256 & 8.348 & Moskau & 1.533 & 5.600 \\
Paris & 2.888 & $4.823(1954)$ & Berlin & 2.071 & 3.337 \\
Leningrad & 1.962 & 3.000 & Wien & 2.031 & 1.766 \\
Rom & 542 & 1.652 & Madrid & 600 & 1.618 \\
Hamburg & 931 & 1.606 & Budapest & 880 & 1.571 \\
Athen & $167(1907)$ & 1.379 & Barcelona & 587 & 1.280 \\
Mailand & 579 & 1.260 & Kopenhagen & 559 & 1.168 \\
Birmingham & 840 & 1.113 & Glasgow & 1.000 & 1.090 \\
Neapel & 723 & 1.011 & & & \\
\hline
\end{tabular}

Mitchell (1980), 425 f., für Leningrad und Moskau Fischer (1987), 52.

Tabelle 6: Produktion von Rohstahl in Europa 1920-1998

(Kilogramm pro Einwohner, Jahresdurchschnitte)

\begin{tabular}{|l|l|l|l|l|l|l|}
\hline & $1920 / 29$ & $1950 / 59$ & $1960 / 60$ & $1970 / 79$ & $1980 / 1988$ & $89 / 98$ \\
\hline West- und Mitteleuropa & 147 & 284 & 453 & 545 & 473 & 429 \\
Nordeuropa & 32 & 137 & 278 & 380 & 375 & 393 \\
Sowjetunion & 13 & 220 & 388 & 538 & 561 & 442 \\
& & & & & & $(89 / 93)$ \\
Russ. Föderation & & & & & & 327 \\
& & & & & & $(94 / 98)$ \\
Restliches Osteuropa & 20 & 93 & 194 & 339 & 407 & 237 \\
Südeuropa & 16 & 27 & 79 & 214 & 250 & 279 \\
\hline
\end{tabular}

West- und Mitteleuropa: Belgien, Deutschland, Frankreich, Irland, Italien, Luxemburg, Niederlande, Österreich, Schweiz, Tschechoslowakei, Vereinigtes Königreich.

Nordeuropa: Dänemark, Norwegen, Finnland, Schweden.

Restliches Osteuropa: Polen, Ungarn, Jugoslawien, Rumänien, Bulgarien.

Südeuropa: Griechenland, Portugal, Spanien.

Eigene Berechnungen nach Fischer (1987), 12 f. und 124, Mitchell (1992), 460, Mitchell (2003), 471-473 und Maddison (Population). 
Tabelle 7: Produktion von Automobilen (PKW und Lastkraftwagen) in Europa 1950-2009 (Jahresdurchschnitte pro 1.000 Einwohner)

\begin{tabular}{|l|l|l|l|l|l|l|}
\hline & $1950 / 59$ & $1960 / 69$ & $1970 / 70$ & $1980 / 88$ & $1989 / 98$ & $2007 / 09$ \\
\hline BRD & 17 & 49 & 62 & 68 & 59 & 71 \\
Frankreich & 17 & 37 & 68 & 64 & 60 & 40 \\
Ver. Kgr. & 20 & 37 & 34 & 23 & 28 & 25 \\
Italien & 6 & 23 & 31 & 30 & 28 & 18 \\
Schweden & 7 & 24 & 43 & 51 & 27 & \\
Spanien & 1 & 7 & 24 & 35 & 55 & 63 \\
DDR & 2 & 6 & 11 & 15 & & \\
Tschechosl. & 3 & 7 & 13 & 15 & ca.11 (89/92) & 95 \\
Polen & 1 & 2 & 8 & 9 & 10 & 23 \\
Rumänien & 0,3 & 1 & 5 & 6 & 4 & 14 \\
Jugoslawien & 0,3 & 2 & 8 & 10 & 3 & 10 \\
UdSSR/Russ. Föd. & 2 & 4 & 7 & 8 & 10 & \\
\hline
\end{tabular}

Eigene Berechnungen nach Fischer (1987), 12 f. und 128, Mitchell (1992), 537, Mitchell (2003), 552 f., Wirtschaftszahlen zum Automobil und Maddison (Population).

Tabelle 8: Computer pro 1.000 Einwohner in Europa 2006

\begin{tabular}{|l|l|l|l|l|l|}
\hline Schweiz & 757 & Luxemburg & 737 & Schweden & 710 \\
Island & 637 & Dänemark & 616 & Deutschland & 602 \\
Norwegen & 602 & Irland & 548 & Finnland & 533 \\
Niederlande & 529 & Österreich & 502 & Großbrit.. & 495 \\
Slowenien & 417 & Slowakei & 417 & Kroatien & 402 \\
Malta & 399 & Frankreich & 385 & Zypern & 344 \\
Belgien & 336 & Italien & 313 & Spanien & 312 \\
Tschech. Rep. & 307 & Estland & 305 & Lettland & 250 \\
Portugal & 203 & Weißrussland & 192 & Rumänien & 184 \\
Polen & 168 & Litauen & 161 & Ungarn & 156 \\
Russ. Föd. & 129 & Mazedonien & 126 & Bulgarien & 111 \\
\hline
\end{tabular}




\begin{tabular}{|l|l|l|l|l|l|}
\hline Griechenland & 107 & Bosnien-Herzeg. & 57 & Serbien-Mont. & 46 \\
Ukraine & 35 & Albanien & 28 & Moldawien & 27 \\
\hline
\end{tabular}

Welt in Zahlen (Computer).

Tabelle 9: Großstädte mit über 100.000 Einwohnern in den USA 1850 und 1900

(Einwohner in 1.000)

\begin{tabular}{|l|l|l|l|l|l|}
\hline & 1850 & 1900 & & 1850 & 1900 \\
\hline New York City & 696 & 3.437 & Chicago & 30 & 1.699 \\
Philadelphia & 340 & 1.294 & St. Louis & 78 & 575 \\
Boston & 137 & 561 & Cleveland & 17 & 382 \\
Baltimore & 169 & 509 & Pittsburgh & 68 & 452 \\
Detroit & 21 & 286 & Buffalo & 42 & 352 \\
San Francisco & 35 & 343 & Milwaukee & 20 & 285 \\
Cincinnati & 115 & 326 & Newark & 39 & 246 \\
New Orleans & 116 & 287 & Washington & 40 & 279 \\
Jersey City & 7 & 206 & Louisville & 43 & 205 \\
Minneapolis & & 203 & Providence & 42 & 176 \\
Indianapolis & 8 & 169 & Kansas City & & 164 \\
Rochester & 36 & 163 & St. Paul & 1 & 163 \\
Denver & 18 & 134 & Toledo & 4 & 132 \\
Columbus & 22 & 126 & Worcester & 17 & 118 \\
Syracuse & 11 & 108 & Fall River & 12 & 105 \\
Paterson & 9 & 105 & Omaha & 103 \\
Memphis & & Los Angeles & 2 & 102 \\
\hline
\end{tabular}

Mitchell (1998), 46-53. 
Tabelle 10: PKW pro 1.000 Einwohner in Europa 1949-2006

\begin{tabular}{|c|c|c|c|c|}
\hline & 1949 & 1969 & 1988 & 2006 \\
\hline Italien & 6 & 166 & 428 & 605 \\
\hline Österreich & 6 & 151 & 366 & 573 \\
\hline Schweiz & 27 & 208 & 421 & 526 \\
\hline Belgien & 26 & 196 & 366 & 517 \\
\hline Spanien & 3 & 50 & 276 & 516 \\
\hline Schweden & 28 & 274 & 413 & 514 \\
\hline Deutschland (BRD) & 7 & 207 & 418 & 510 \\
\hline Frankreich & 37 & 235 & 393 & 500 \\
\hline Portugal & 7 & 54 & 196 & 497 \\
\hline Finnland & 6 & 137 & 363 & 472 \\
\hline Slowenien & & & & 466 \\
\hline Ver. Königreich & 42 & 208 & 322 & 465 \\
\hline Niederlande & 11 & 178 & 356 & 458 \\
\hline Norwegen & 18 & 181 & 385 & 448 \\
\hline Griechenland & 1 & 22 & 150 & 441 \\
\hline Irland & 24 & 122 & 212 & 416 \\
\hline Dänemark & 26 & 209 & 311 & 411 \\
\hline Tschechoslowakei & 10 & 49 & 193 & $395 / 253$ \\
\hline Estland & & & & 393 \\
\hline Kroatien & & & & 353 \\
\hline Bulgarien & & & & 337 \\
\hline Litauen & & & & 334 \\
\hline Polen & 2 & 45 & 118 & 318 \\
\hline Ungarn & 1 & 19 & 171 & 313 \\
\hline Lettland & & & & 267 \\
\hline Serbien-Montenegro & & & & 195 \\
\hline Weißrussland & & & & 185 \\
\hline Sowjetunion/Russ. Föd. & & 5 & $40(1983)$ & 170 \\
\hline Rumänien & & 2 & & 170 \\
\hline
\end{tabular}




\begin{tabular}{|l|l|l|l|l|}
\hline Mazedonien & & & & 162 \\
Ukraine & & & & 118 \\
Moldawien & 0,4 & 28 & 137 & 71 \\
Jugoslawien & 4 & 54 & & \\
DDR & 4 & & \\
\hline
\end{tabular}

Mitchell (1992), 718-721; Fischer (1987), 143; Statistisches Jahrbuch (2013), 614; Welt in Zahlen (PKW).

Tabelle 11: Bevölkerung und Urbanisierung in den USA nach Regionen 1900 und 1990

\begin{tabular}{|l|l|l|l|l|l|l|}
\hline \multirow{2}{*}{} & \multicolumn{3}{|c|}{ Bevölkerung in Millionen und \% } & \multicolumn{2}{c|}{ Städtische Bevölkerung in \% } \\
\cline { 2 - 7 } & 1900 & $\%$ & 1990 & $\%$ & 1900 & 1990 \\
\hline Nordosten & 21,0 & 27,6 & 50,8 & 20,4 & 66,1 & 78,9 \\
Mittlerer Westen & 26,3 & 34,6 & 59,7 & 24,0 & 38,6 & 71,1 \\
Süden & 24,5 & 32,2 & 85,4 & 34,4 & 18,0 & 68,6 \\
Westküste & 2,6 & 3,5 & 39,1 & 15,7 & 44,7 & 88,6 \\
\hline USA & 76,2 & 100,0 & 248,7 & 100,0 & 39,6 & 75,2 \\
\hline
\end{tabular}

Heim (2000), 101 und 141.

Tabelle 12: Millionenstädte in den USA 1950 und 1980 (Einwohner in 1.000)

\begin{tabular}{|l|l|l|l|l|l|}
\hline & 1950 & 1980 & & 1950 & 1980 \\
\hline New York & 9.556 & 8.275 & Los Angeles & 4.368 & 7.478 \\
Chicago & 5.495 & 6.060 & Philadelphia & 3.671 & 4.717 \\
Detroit & 3.016 & 4.488 & San Francisco & 2.241 & 3.251 \\
Washington & 1.464 & 3.251 & Dallas & 615 & 2.931 \\
Boston & 2.370 & 2.806 & Houston & 807 & 2.736 \\
St. Louis & 1.681 & 2.377 & Baltimore & 1.337 & 2.200 \\
Pittsburgh & 2.213 & 2.219 & Atlanta & 672 & 2.138 \\
Minneapolis & 1.117 & 2.137 & Anaheim & 15 & 1.933 \\
Cleveland & 1.466 & 1.899 & Newark & 439 & 1.879 \\
San Diego & 557 & 1.862 & Miami & 495 & 1.626 \\
Denver & 564 & 1.618 & Tampa & 409 & 1.614 \\
Seattle & 733 & 1.607 & San Bernardino & 282 & 1.558 \\
\hline
\end{tabular}




\begin{tabular}{|l|l|l|l|l|l|}
\hline Phoenix & 332 & 1.509 & Kansas City & 814 & 1.433 \\
Cincinnati & 904 & 1.401 & Milwaukee & 871 & 1.397 \\
Portland & 705 & 1.298 & San José & 291 & 1.295 \\
New Orleans & 685 & 1.256 & Columbus & 503 & 1.244 \\
Buffalo & 1.089 & 1.243 & Indianapolis & 552 & 1.167 \\
Norfolk & 446 & 1.160 & Sacramento & 277 & 1.100 \\
San Antonio & 500 & 1.072 & Fort Lauderdale & 36 & 1.018 \\
\hline
\end{tabular}

Mitchell (1998), 50-53.

Tabelle 13: Erwerbstätige in Industrie und verarbeitendem Gewerbe in den USA 1900-1990 (Prozent aller Erwerbstätigen)

\begin{tabular}{|l|l|l|l|l|l|l|l|}
\hline & 1900 & 1940 & 1950 & 1960 & 1970 & 1980 & 1990 \\
\hline New England & 34,6 & 38,8 & 38,4 & 37,2 & 30,9 & 28,0 & 19,3 \\
Mideast & 22,9 & 30,3 & 31,9 & 32,2 & 27,2 & 22,7 & 15,8 \\
Great Lakes & 15,2 & 31,9 & 35,5 & 36,2 & 33,4 & 28,7 & 22,8 \\
Plains & 6,9 & 12,5 & 15,6 & 18,9 & 19,2 & 18,8 & 16,7 \\
Southeast & 6,9 & 17,3 & 19,5 & 22,9 & 24,4 & 21,8 & 18,0 \\
Southwest & 3,4 & 9,3 & 11,9 & 14,8 & 16,4 & 16,3 & 13,6 \\
Rocky Mountains & 7,6 & 9,0 & 10,4 & 13,9 & 13,0 & 12,8 & 12,4 \\
Far West & 11,8 & 17,4 & 19,0 & 23,2 & 19,9 & 18,7 & 15,9 \\
\hline USA & 14,6 & 23,7 & 25,7 & 27,4 & 25,2 & 22,1 & 17,4 \\
\hline
\end{tabular}

Heim (2000), 106-112.

Tabelle 14: Bevölkerung Lateinamerikas 1820-2009 in Millionen

\begin{tabular}{|l|l|l|l|l|}
\hline & 1820 & 1900 & 1950 & 2009 \\
\hline Brasilien & 4,5 & 18,0 & 53,4 & 198,7 \\
Mexiko & 6,6 & 13,6 & 28,5 & 111,2 \\
Kolumbien & 1,2 & 4,0 & 11,6 & 43,7 \\
Argentinien & 0,5 & 4,7 & 17,2 & 40,9 \\
Peru & 1,3 & 3,6 & 7,6 & 29,5 \\
Venezuela & 0,7 & 2,5 & 5,0 & 26,8 \\
Chile & 0,8 & 3,0 & 6,1 & 16,6 \\
\hline
\end{tabular}




\begin{tabular}{|l|l|l|l|l|}
\hline Ekuador & 0,5 & 1,4 & 3,4 & 14,6 \\
Bolivien & 1,1 & 1,7 & 2,8 & 9,8 \\
Paraguay & 0,1 & 0,4 & 1,5 & 6,3 \\
Uruguay & 0,1 & 0,9 & 2,2 & 3,5 \\
Mittelamerika & 1,2 & 3,6 & 9,2 & 40,8 \\
Karibische Inseln & 2,1 & 5,7 & 15,7 & 38,2 \\
\hline Lateinamerika & 21,6 & 64,6 & 165,5 & 584,0 \\
\hline
\end{tabular}

Mittelamerika: Guatemala, El Salvador, Honduras, Costa Rica, Nicaragua, Panama.

Karibische Inseln: Kuba, Puerto Rico, Haiti, Dominikanische Republik, Jamaica, Trinidad und Tobago. Maddison (Population).

Tabelle 15: Großstädte mit über 100.000 Einwohnern in Lateinamerika 1900 und 1920 (Einwohner in 1.000)

\begin{tabular}{|l|l|l|l|l|l|}
\hline & 1900 & 1920 & & 1900 & 1920 \\
\hline Buenos Aires & 664 & 1.663 & Rio de Janeiro & 811 & 1.158 \\
Mexico City & 345 & 615 & São Paulo & 240 & 579 \\
Santiago de Chile & 256 & 507 & Montevideo & 268 & 385 \\
Havanna & 236 & 364 & Salvador & 206 & 283 \\
Rosario & 92 & 250 & Recife & 113 & 239 \\
Belém & 97 & 236 & Valparaíso & 122 & 182 \\
Porto Alegre & 73 & 180 & Lima & 130 & 176 \\
La Plata & 45 & 151 & Bogotá & 100 & 144 \\
Guadalajara & 101 & 143 & Córdoba & 48 & 140 \\
Guatemala City & 74 & 116 & Campinas & 45 & 116 \\
La Paz & 53 & 107 & Santos & 30 & 103 \\
\hline
\end{tabular}

Mitchell (1998), 50-57. 
Tabelle 16: Millionenstädte in Lateinamerika 1950 und 1980

(Einwohner in 1.000, * Agglomeration)

\begin{tabular}{|l|l|l|l|l|l|}
\hline & 1950 & 1980 & & 1950 & 1980 \\
\hline Mexico City & $3.050^{*}$ & $12.932^{*}$ & São Paolo & 2.198 & $12.273^{*}$ \\
Buenos Aires & 4.722 & $9.948^{*}$ & Rio de Janeiro & 2.377 & $9.619^{*}$ \\
Lima & 835 & $4.669^{*}$ & Bogotá & 648 & 4.177 \\
Santiago de Chile & $1.348^{*}$ & $3.899^{*}$ & Caracas & $694^{*}$ & $2.944^{*}$ \\
Recife & 525 & $2.307^{*}$ & Belo Horizonte & 353 & $2.279^{*}$ \\
Guadalajara & 377 & $2.245^{*}$ & Porto Alegre & 394 & $2.133^{*}$ \\
Havanna & $1.218^{*}$ & $1.929^{*}$ & Monterrey & 333 & $1.916^{*}$ \\
Salvador & 417 & $1.563^{*}$ & Medellín & 358 & $1.452^{*}$ \\
Cali & 284 & $1.369^{*}$ & Fortaleza & 270 & $1.340^{*}$ \\
Santo Domingo & 182 & 1.313 & Montevideo & 784 & 1.252 \\
Guayaquil & 250 & 1.199 & Brasília & & 1.177 \\
Nova Iguaçu & 59 & 1.095 & Curitiba & 181 & $1.093^{*}$ \\
San Juan & $466^{*}$ & $1.086^{*}$ & & & \\
\hline
\end{tabular}

Mitchell (1998), 50-57.

Tabelle 17: Produktion von Industrie und verarbeitendem Gewerbe in Lateinamerika im 20. Jahrhundert (Vervielfachung pro Einwohner)

\begin{tabular}{|l|l|l|l|}
\hline & Faktor & & Faktor \\
\hline Argentinien 1935-1979 & 3,2 & Nicaragua 1953-1976 & 3,7 \\
Brasilien 1920-1981 & 5,1 & Panama 1958-1987 & 3,3 \\
Chile 1927-1993 & 1,6 & Peru 1945-1980 & 3,7 \\
Ekuador 1953-1993 & 7,1 & Uruguay 1953-1980 & 1,3 \\
Kolumbien 1948-1993 & 3,5 & Venezuela 1948-1987 & 18,5 \\
Mexiko 1920-1981 & 3,2 & & \\
\hline
\end{tabular}

Eigene Berechnungen nach Mitchell (1998), 307-310 und Maddison (Population). 
Tabelle 18: Verarbeitung von Rohbaumwolle, Produktion von Rohstahl und PKW in Amerika 1940-1993 (Kilogramm pro Einwohner bzw. Einheiten pro 1.000 Einwohner, Höchstwerte)

\begin{tabular}{|l|l|l|l|}
\hline & Rohbaumwolle & Rohstahl & PKW \\
\hline Argentinien & $5.0(1948)$ & $120(1989)$ & $8(1993)$ \\
Brasilien & $5,3(1992)$ & $159(1993)$ & $6(1986)$ \\
Chile & $3,1(1970)$ & $77(1993)$ & $2(1980)$ \\
Kolumbien & $3,2(1992)$ & $24(1988)$ & $2(1993)$ \\
Kuba & $4,6(1986)$ & $41(1986)$ & \\
Mexiko & $2,9(1976)$ & $97(1990)$ & $9(1993)$ \\
Peru & $4,0(1987)$ & $25(1987)$ & $1(1976)$ \\
Uruguay & $3,9(1960)$ & $17(1993)$ & \\
Venezuela & $2,4(1989)$ & $208(1987)$ & $7(1978)$ \\
\hline USA & $20,4(1942)$ & $645(1973)$ & $45(1973)$ \\
Kanada & $9,8(1940)$ & $662(1979)$ & $54(1973)$ \\
\hline
\end{tabular}

Eigene Berechnungen nach Mitchell (1998), 362 f., 374 f., 395-397 und Maddison (Population).

Tabelle 19: Langlebige Konsumgüter pro 1.000 Einwohner in Amerika 1950-2006

\begin{tabular}{|l|l|l|l|l|l|l|l|}
\hline & \multicolumn{3}{|c|}{ TV-Geräte } & \multicolumn{3}{c|}{ PKW } & Computer \\
\cline { 2 - 8 } & 1960 & 1990 & 2006 & 1950 & 1980 & 2006 & 2006 \\
\hline Brasilien & 17 & 205 & 398 & 4 & 65 & 143 & 95 \\
Mexiko & 17 & 145 & 326 & 6 & 62 & 119 & 121 \\
Kolumbien & 9 & 109 & 434 & 3 & 20 & 35 & 94 \\
Argentinien & 22 & 215 & 342 & 18 & 110 & 155 & 130 \\
Peru & 3 & 97 & 202 & 4 & 18 & 37 & 61 \\
Venezuela & 33 & 160 & 193 & 14 & 102 & 73 & 97 \\
Chile & 1 & 205 & 281 & 6 & 40 & 89 & 187 \\
Ekuador & 1 & 85 & 263 & 1 & 12 & 30 & 65 \\
Guatemala & 8 & 53 & 65 & 3 & 25 & 57 & 21 \\
Kuba & 71 & 168 & 409 & 1 & 16 & 27 & 80 \\
Bolivien & & 111 & 126 & 1 & 9 & 33 & 38 \\
Dominikan. Rep. & 5 & 85 & 99 & 2 & 16 & 82 & 83 \\
Haiti & 0,5 & 5 & 6,5 & 1 & 4 & 6,5 & \\
Honduras & 0,7 & 77 & 166 & 1 & 8 & 60 & 20 \\
\hline
\end{tabular}




\begin{tabular}{|l|l|l|l|l|l|l|l|}
\hline Paraguay & & 71 & 226 & 1 & 18 & 58 & 113 \\
El Salvador & 8 & 93 & 252 & 3 & 16 & 31 & 38 \\
Nicaragua & 3 & 65 & 84 & 1 & 14 & 21 & 39,5 \\
Costa Rica & 3 & 139 & 233 & 5 & 38 & 101 & 289 \\
Puerto Rico & 71 & 263 & 354 & 17 & 296 & 302 & 211 \\
Uruguay & 10 & 20 & 565 & 76 & 122 & 204 & 186 \\
Panama & 9 & 167 & 229 & 22 & 50 & 106 & 50 \\
Jamaica & 6 & 132 & 307 & 9 & 15 & 77 & 70 \\
\hline USA & 254 & 368 & 950 & 265 & 546 & 535 & 794 \\
Kanada & 215 & 612 & 682 & 136 & 417 & 551 & 541 \\
\hline
\end{tabular}

Welt in Zahlen (Fernsehgeräte), Welt in Zahlen (PKW) und Welt in Zahlen (Computer) sowie eigene Berechnungen nach Mitchell (1998), 626, 631, 588-598 und Maddison (Population).

Tabelle 20: Erwerbstätige in Industrie und verarbeitendem Gewerbe in Lateinamerika um 1990 (Prozent aller Erwerbstätigen)

\begin{tabular}{|l|l|l|l|}
\hline Argentinien (1980) & 20,9 & Bolivien (1991) & 17,0 \\
Brasilien (1990) & 16,2 & Chile (1994) & 16,6 \\
Ekuador (1990) & 11,2 & Kolumbien (1992) & 23,7 \\
Mexiko (1990) & 18,6 & Paraguay (1994) & 17,5 \\
Peru (1991) & 10,0 & Uruguay (1992) & 21,6 \\
Venezuela (1991) & 16,6 & & \\
\hline
\end{tabular}

Eigene Berechnungen nach Mitchell (1998), 105-110. 
Tabelle 21: Bevölkerung Afrikas 1950-2009 in Millionen (größere Länder)

\begin{tabular}{|c|c|c|c|}
\hline & 1950 & 1980 & 2009 \\
\hline Nigeria & 31,8 & 74,8 & 149,2 \\
\hline Äthiopien & 20,2 & 36,0 & 85,2 \\
\hline Ägypten & 21,2 & 42,6 & 78,9 \\
\hline Dem. Republik Kongo & 13,6 & 29,0 & 68,7 \\
\hline Südafrika & 13,6 & 29,3 & 49,1 \\
\hline Sudan & 8,1 & 19,1 & 41,1 \\
\hline Tansania & 7,9 & 18,7 & 41,0 \\
\hline Kenia & 6,1 & 16,3 & 39,0 \\
\hline Algerien & 8,9 & 18,8 & 34,2 \\
\hline Uganda & 5,5 & 12,4 & 32,4 \\
\hline Marokko & 9,3 & 19,5 & 31,3 \\
\hline Ghana & 5,3 & 11,0 & 23,9 \\
\hline Mosambik & 6,3 & 12,1 & 21,7 \\
\hline Madagaskar & 4,6 & 8,7 & 20,7 \\
\hline Elfenbeinküste & 2,9 & 8,6 & 20,6 \\
\hline Kamerun & 4,9 & 8,8 & 18,9 \\
\hline Burkina Faso & 4,4 & 6,3 & 15,7 \\
\hline Niger & 3,3 & 6,1 & 15,3 \\
\hline Malawi & 2,8 & 6,3 & 15,0 \\
\hline Senegal & 2,7 & 5,8 & 13,7 \\
\hline Mali & 3,7 & 6,8 & 13,4 \\
\hline Angola & 4,1 & 6,7 & 12,8 \\
\hline Sambia & 2,6 & 5,7 & 11,9 \\
\hline Simbabwe & 2,9 & 7,2 & 11,4 \\
\hline Ruanda & 2,4 & 5,1 & 10,7 \\
\hline Tunesien & 3,5 & 6,4 & 10,5 \\
\hline Tschad & 2,6 & 4,5 & 10,3 \\
\hline Guinea & 2,6 & 4,4 & 10,1 \\
\hline Afrika & 227,9 & 478,1 & 990,4 \\
\hline
\end{tabular}

Maddison (Population). 
Tabelle 22: Millionenstädte in Afrika 1950 und 1980 (Einwohner in 1.000)

\begin{tabular}{|l|l|l|l|l|l|}
\hline & 1950 & 1980 & & 1950 & 1980 \\
\hline Kairo & 2.091 & 5.875 & Alexandria & 919 & 2.705 \\
Casablanca & 682 & 2.409 & Kinshasa & 209 & 2.174 \\
Algier & 498 & 1.740 & Gizeh & 66 & 1.640 \\
Johannesburg & 884 & 1.536 & Kapstadt & 578 & 1.440 \\
Abidjan & 56 & 1.423 & Addis Abeba & 400 & 1.277 \\
Lagos & 267 & 1.061 & & & \\
\hline
\end{tabular}

Mitchell (2007), 41.

Tabelle 23: Langlebige Konsumgüter pro 1.000 Einwohner in Afrika 1970-2006 (größere Länder)

\begin{tabular}{|l|l|l|l|l|l|l|l|}
\hline \multirow{2}{*}{} & \multicolumn{3}{|c|}{ TV-Geräte } & \multicolumn{3}{c|}{ PKW } & Computer \\
\cline { 2 - 8 } & 1985 & 1995 & 2006 & 1970 & 1990 & 2006 & 2006 \\
\hline Nigeria & 6 & 56 & 81 & 1 & 4 & 7 & 8 \\
Ägypten & 77 & 108 & 254 & 4 & 19 & 22 & 29 \\
Äthiopien und Eritrea & 2 & 4 & 7 & 1 & 1 & 1 & 6 \\
Dem. Rep. Kongo & 0,4 & 2 & 146 & 3 & 2 & 17 & 2 \\
Südafrika & 87 & 106 & 237 & 68 & 88 & 99 & 99 \\
Sudan & 47 & 74 & $400(?)$ & 2 & 8 & 9 & 16 \\
Tansania & 0,4 & 2 & 31 & 2 & 2 & 2 & 13 \\
Kenia & 5 & 18 & 36 & 5 & 7 & 10 & 10 \\
Algerien & 68 & 89 & 126 & 10 & 29 & 73 & 19 \\
Uganda & 6 & 12 & 31 & 3 & 1 & 3 & 6 \\
Marokko & 53 & 91 & 226 & 14 & 27 & 47 & 39 \\
Ghana & 11 & 90 & 113 & 5 & 5 & 7 & 6 \\
Mosambik & 1 & 4 & 25 & 8 & 7 & 4 & 7 \\
Madagaskar & 5 & 22 & 29 & 7 & 4 & 4 & 13 \\
Elfenbeinküste & 48 & 57 & 59 & 10 & 12 & 12 & 21 \\
Kamerun & $12(88)$ & 23 & 34 & 5 & 5 & 10 & 16 \\
Burkina Faso & 5 & 6 & 17 & 1 & $2(87)$ & 3 & 3 \\
Niger & 2 & 11 & 77 & 1 & 5 & 4 & 16 \\
Malawi & 0,5 & 2 & 6 & 2 & 2 & 3 & 2 \\
\hline
\end{tabular}




\begin{tabular}{|c|c|c|c|c|c|c|c|}
\hline Senegal & 29 & 34 & 38 & 9 & 8 & 26 & 28 \\
\hline Mali & & & 70 & 1 & 2 & 4 & 3 \\
\hline Angola & 5 & 10 & 22 & 15 & 15 & 26 & 7 \\
\hline Sambia & 13 & 28 & 180 & 14 & 9 & 18 & 12 \\
\hline Simbabwe & 21 & 29 & 219 (?) & 24 & 19 & 58 & 138 \\
\hline Ruanda & & & 13 & 1 & 1 & 4 & 5 \\
\hline Tunesien & 54 & 89 & 244 & 13 & 23 & 63 & 64 \\
\hline Tschad & & & 3 & 1 & $1(91)$ & 3 & 2 \\
\hline Guinea & 2 & 9 & 47 & 3 & $3(95)$ & & 7 \\
\hline Libyen & 64 & 118 & 183 & 50 & 108 & 173 & 66 \\
\hline
\end{tabular}

Welt in Zahlen (Fernsehgeräte), Welt in Zahlen (PKW) und Welt in Zahlen (Computer) sowie eigene Berechnungen nach Mitchell (2007), 788, 795, 854-857 und Maddison (Population).

Tabelle 24: Wertschöpfung (BIP) in Afrika nach Wirtschaftssektoren 1965-2008

(Prozent des BIP, größere Länder)

\begin{tabular}{|l|l|l|l|l|l|l|}
\hline \multirow{2}{*}{} & \multicolumn{3}{|c|}{ Sekundär } & \multicolumn{3}{c|}{ Tertiär } \\
\cline { 2 - 7 } & 1965 & 1987 & 2008 & 1965 & 1987 & 2008 \\
\hline Nigeria & 13 & 43 & 24 & 33 & 27 & 34 \\
Äthiopien & 14 & 18 & 13 & 28 & 40 & 42 \\
Ägypten & & & 38 & & & 49 \\
Dem. Rep. Kongo & 26 & 33 & 28 & 53 & 35 & 32 \\
Südafrika & & & 34 & & & 63 \\
Sudan & 9 & 15 & 34 & 37 & 48 & 40 \\
Tansania & 14 & 8 & 17 & 40 & 31 & 38 \\
Kenia & 18 & 19 & 19 & 47 & 50 & 54 \\
Algerien & & & 62 & & & 31 \\
Uganda & 13 & 5 & 26 & 35 & 19 & 51 \\
Marokko & & 19 & 24 & & & 63 \\
Ghana & 19 & 25 & 38 & 33 & 41 \\
Mosambik & 16 & 16 & 17 & 53 & 42 & 47 \\
Madagaskar & 19 & 25 & 26 & 33 & 39 & 49 \\
Elfenbeinküste & 20 & 32 & 31 & 47 & 45 & 49 \\
Kamerun & 20 & 25 & 22 & 27 & 38 & 45 \\
Burkina Faso & & 12 & 24 & & 38 & \\
\hline
\end{tabular}




\begin{tabular}{|l|l|l|l|l|l|l|}
\hline Malawi & 13 & 18 & 21 & 37 & 45 & 45 \\
Senegal & 18 & 27 & 22 & 56 & 52 & 62 \\
Mali & 9 & 12 & 24 & 25 & 35 & 39 \\
Angola & 7 & 23 & 67 & 42 & 31 & 26 \\
Sambia & 54 & 36 & 46 & 32 & 52 & 33 \\
Tunesien & 15 & 18 & 49 & 43 & 39 & 37 \\
Tschad & & & 70 & & & 27 \\
Libyen & & & 35 & & & 54 \\
\hline
\end{tabular}

Sub-Saharan Africa (1989), S. 224 f. und Fischer Weltalmanach (2011).

Tabelle 25: Bevölkerung Nord- und Zentralasiens 1950-2009 in Millionen

\begin{tabular}{|l|l|l|l|}
\hline & 1950 & 1980 & 2009 \\
\hline Russische Föderation (asiatischer Teil einschl. Ural) & ca. 27,6 & ca. 37,7 & 38,0 \\
Usbekistan & 6,3 & 16,0 & 27,6 \\
Kasachstan & 6,7 & 15,0 & 15,4 \\
Tadschikistan & 1,5 & 4,0 & 7,3 \\
Kirgisistan & 1,7 & 3,6 & 5,4 \\
Turkmenistan & 1,2 & 2,9 & 4,9 \\
Mongolei & 0,8 & 1,7 & 3,0 \\
\hline Nord- und Zentralasien & ca. 45,8 & ca. 80,9 & 101,6 \\
\hline
\end{tabular}

Maddison (Population) sowie Wikipedia (Asien) und Wikipedia (Russland). 
Tabelle 26: Erwerbstätige in Nord- und Zentralasien nach Wirtschaftssektoren 1990-2004 (Prozent aller Erwerbstätigen, Jahresdurchschnitte)

\begin{tabular}{|l|l|l|l|l|l|l|}
\hline & \multicolumn{3}{|l|}{ Primär } & \multicolumn{2}{l|}{ Sekundär } & \multicolumn{2}{l|}{ Tertiär } \\
\cline { 2 - 7 } & $1990-99$ & $2000-04$ & $1990-99$ & $2000-04$ & $1990-99$ & $2000-04$ \\
\hline Mongolei & 47,1 & 45,9 & 21,8 & 14,4 & 31,1 & 39,7 \\
Kasachstan & 23,2 & 35,4 & 26,8 & 16,5 & 50,0 & 48,0 \\
Kirgisistan & 43,1 & 49,6 & 18,7 & 12,0 & 38,2 & 38,5 \\
Usbekistan & 42,5 & 34,4 & 20,9 & 20,3 & 36,6 & 45,3 \\
Turkmenistan (1991 und 1998) & 43,0 & 48,5 & 20,0 & 18,2 & 37,0 & 33,2 \\
Tadschikistan (1991 und 2001) & 43,0 & 66,0 & 22,0 & 9,2 & 35,0 & 24,8 \\
\hline
\end{tabular}

Growth Amid Change (2007), 50 sowie Fischer Weltalmanach (1995) und Fischer Weltalmanach (2008).

Tabelle 27: Bevölkerung Westasiens 1950-2009 in Millionen

\begin{tabular}{|l|l|l|l|}
\hline & 1950 & 1980 & 2009 \\
\hline Türkei & 21,1 & 45,0 & 76,8 \\
Iran & 16,4 & 39,4 & 66,4 \\
Irak & 5,2 & 13,2 & 28,9 \\
Saudi-Arabien & 3,9 & 10,0 & 28,7 \\
Jemen & 4,8 & 9,1 & 22,9 \\
Syrien & 3,5 & 8,8 & 21,8 \\
Aserbaidschan & 2,9 & 6,2 & 8.2 \\
Israel & 1,3 & 3,7 & 7,2 \\
Jordanien & 0,6 & 2,2 & 6,3 \\
Vereinigte Arab. Emirate & 0,1 & 1,0 & 4,8 \\
Georgien & 3,5 & 5,0 & 4,6 \\
Libanon & 1,4 & 3,1 & 4,1 \\
Westiordanland u. Gaza & 1,0 & 1,5 & 4,0 \\
Armenien & 1,4 & 3,1 & 3,0 \\
Oman & 0,5 & 1,2 & 2,9 \\
\hline
\end{tabular}




\begin{tabular}{|l|l|l|l|}
\hline Kuwait & 0,1 & 1,4 & 2,7 \\
Katar & 0,03 & 0,2 & 0,8 \\
Bahrain & 0,1 & 0,3 & 0,7 \\
\hline Westasien & 67,6 & 154,5 & 294,9 \\
\hline
\end{tabular}

Maddison (Population).

Tabelle 28: Millionenstädte in Westasien 1950 und 1980

(Einwohner in 1.000)

\begin{tabular}{|l|l|l|l|l|l|}
\hline & 1950 & 1980 & & 1950 & 1980 \\
\hline Teheran & 619 & 4.530 & Bagdad & 352 & 3.206 \\
Istanbul & 983 & 2.773 & Ankara & 289 & 1.878 \\
Damaskus & 335 & 1.112 & Riad & 120 & 1.300 \\
Baku & ca. 600 & 1.022 & Jerewan & $509(1959)$ & 1.019 \\
Beirut & 201 & ca. 1.000 & Dschidda & 60 & ca. 1.000 \\
Tiflis & & ca. 1.000 & & & \\
\hline
\end{tabular}

Mitchell (2007), 42-46 und Liste der Städte (einzelne Länder).

Tabelle 29: Produktion von Industrie und verarbeitendem Gewerbe in Westasien 1960-1999 (1980 = 100, ausgewählte Länder $)$

\begin{tabular}{|l|l|l|l|l|l|}
\hline & 1960 & 1970 & 1980 & 1990 & 1999 \\
\hline Iran & 14 & 46 & 100 & 130 & $234(1998)$ \\
Israel & 20 & 60 & 100 & 132 & 212 \\
Syrien & 21 & 45 & 100 & 186 & $262(1998)$ \\
Türkei & 22 & 50 & 100 & 211 & 296 \\
\hline
\end{tabular}

Eigene Berechnungen nach Mitchell (2007), 367-370. 
Tabelle 30: Langlebige Konsumgüter pro 1.000 Einwohner in Westasien 1970-2006

\begin{tabular}{|l|l|l|l|l|l|l|l|}
\hline & \multicolumn{3}{|c|}{ TV-Geräte } & \multicolumn{3}{c|}{ PKW } & Computer \\
\cline { 2 - 8 } & 1980 & 1995 & 2006 & 1970 & 1990 & 2006 & 2006 \\
\hline Türkei & 75 & 313 & 516 & 4 & 29 & 72 & 61 \\
Iran & 51 & 71 & 191 & 10 & 27 & 46 & 94 \\
Irak & 31 & 82 & 78 & 7 & 37 & 40 & 15 \\
Saudi-Arabien & 210 & 235 & 234 & 11 & 91 & 95 & 195 \\
Jemen & 1 & 28 & 267 & & 8 & 21 & 39 \\
Syrien & 44 & 66 & 246 & 5 & 10 & 9 & 32 \\
Aserbaidschan & & & 308 & & & 53 & 52 \\
Israel & 241 & 299 & 416 & 52 & 181 & 290 & 286 \\
Jordanien & 79 & 102 & 154 & 10 & 53 & 49 & 54 \\
VAE & 93 & 93 & 511 & & & 95 & 292 \\
Georgien & & & 496 & & & 97 & 54 \\
Libanon & 243 & 330 & 369 & 74 & 347 & 418 & 106 \\
Armenien & & & 343 & & & 62 & 114 \\
Oman & 29 & 680 & 529 & & & 167 & 81 \\
Kuwait & 258 & 438 & 554 & 151 & 257 & 340 & 161 \\
Katar & 338 & 422 & 830 & & & 346 & 234 \\
Bahrain & 216 & 468 & 454 & 45 & 198 & 279 & 199 \\
\hline
\end{tabular}

Welt in Zahlen (Fernsehgeräte), Welt in Zahlen (PKW) und Welt in Zahlen (Computer) sowie eigene Berechnungen nach Mitchell (2007), 796-803, 858-861 und Maddison (Population).

Tabelle 31: Bevölkerung Südasiens 1950-2009 in Millionen

\begin{tabular}{|l|l|l|l|}
\hline & 1950 & 1980 & 2009 \\
\hline Indien & 359,0 & 679,0 & $1.156,9$ \\
Pakistan & 39,4 & 85,2 & 174,6 \\
Bangladesch & 45,6 & 87,9 & 156,1 \\
Afghanistan & 8,2 & 15,1 & 38,4 \\
Nepal & 9,0 & 14,7 & 28,6 \\
Sri Lanka & 15,1 & 21,3 \\
Bhutan & 7,5 & 0,4 & 0,7 \\
Malediven & 0,2 & 0,2 & 0,4 \\
\hline Südasien & 0,1 & 897,6 & $1.576,9$ \\
\hline
\end{tabular}

Maddison (Population). 
Tabelle 32: Millionenstädte in Südasien 1950 und 1980 (Einwohner in 1.000)

\begin{tabular}{|l|l|l|l|l|l|}
\hline & 1950 & 1980 & & 1950 & 1980 \\
\hline Kalkutta & 4.578 & 9.194 & Bombay & 2.839 & 8.227 \\
Karatschi & 1.068 & 5.208 & Delhi & 914 & 4.884 \\
Dhaka & 336 & 3.459 & Madras & 1.416 & 3.277 \\
Lahore & 1.068 & 2.953 & Faisalabad & 179 & 2.953 \\
Bangalore & 779 & 2.629 & Haiderabad (I) & 803 & 2.093 \\
Ahmedabad & 788 & 2.060 & Kampur & 636 & 1.428 \\
Chittagong & 290 & 1.388 & Nagpur & 449 & 1.219 \\
Pune & 481 & 1.203 & & & \\
\hline
\end{tabular}

Mitchell (2007), 42-46.

Tabelle 33: Langlebige Konsumgüter pro 1.000 Einwohner in Südasien 1970-2006

\begin{tabular}{|l|l|l|l|l|l|l|l|}
\hline & \multicolumn{3}{|c|}{ TV-Geräte } & \multicolumn{3}{c|}{ PKW } & Computer \\
\cline { 2 - 8 } & 1985 & 1995 & 2006 & 1970 & 1990 & 2006 & 2006 \\
\hline Indien & 5 & 51 & 98 & 1 & 3 & 10 & 14 \\
Pakistan & 13 & 21 & 170 & 2 & 6 & 10 & 20 \\
Bangladesch & 3 & 6 & 1 & 0,4 & 0,4 & 7 & 7 \\
Afghanistan & 7 & 9 & 22 & 3 & 2 & 2 & 1 \\
Nepal & 1 & 5 & 8 & & & 3 & 4 \\
Sri Lanka & 28 & 80 & 149 & 7 & 10 & 32 & 39 \\
\hline
\end{tabular}

Welt in Zahlen (Fernsehgeräte), Welt in Zahlen (PKW) und Welt in Zahlen (Computer) sowie eigene Berechnungen nach Mitchell (2007), 798 f., 801 f., 858, 860 und Maddison (Population). 
Tabelle 34: Bevölkerung Südostasiens 1950-2009 in Millionen

\begin{tabular}{|l|l|l|l|}
\hline & 1950 & 1980 & 2009 \\
\hline Indonesien & 82,6 & 147,5 & 230,6 \\
Philippinen & 21,1 & 50,9 & 98,0 \\
Vietnam & 25,3 & 53,7 & 88,6 \\
Thailand & 20,0 & 47,0 & 66,0 \\
Myanmar & 19,5 & 33,1 & 52,2 \\
Malaysia & 6,4 & 13,8 & 25,7 \\
Kambodscha & 4,5 & 6,9 & 14,5 \\
Laos & 1,9 & 3,3 & 6,8 \\
Singapur & 1,0 & 2,4 & 4,7 \\
\hline Südostasien & 182,4 & 358,6 & 587,7 \\
\hline
\end{tabular}

Maddison (Population).

Tabelle 35: Millionenstädte in Südostasien 1950 und 1980 (Einwohner in 1.000)

\begin{tabular}{|l|l|l|l|l|l|}
\hline & 1950 & 1980 & & 1950 & 1980 \\
\hline Jakarta & 1.861 & 6.503 & Bangkok & 621 & 4.697 \\
Saigon & 1.179 & 3.420 & Hanoi & 238 & 2.571 \\
Rangun & 712 & 2.513 & Singapur & 680 & 2.414 \\
Surabaya & $1.008(1960)$ & 2.028 & Manila & 984 & 1.630 \\
Bandung & 686 & 1.463 & Medan & 250 & 1.379 \\
Quezon City & 108 & 1.166 & Semarang & $503(1960)$ & 1.027 \\
\hline Kuala Lumpur & 176 & 920 & & & \\
\hline
\end{tabular}

Mitchell (2007), 42-46. 
Tabelle 36: Erwerbstätige in Südostasien um 2000 (Prozent aller Erwerbstätigen)

\begin{tabular}{|l|l|l|}
\hline & Landwirtschaft & Sekundärer Sektor \\
\hline Philippinen & 39 & 16 \\
Indonesien & 44 & 19 \\
Vietnam & 63 & 13 \\
Thailand & 42 & 25 \\
Myanmar & 70 & $12(1996)$ \\
Malaysia & 15 & 37 \\
Kambodscha & 74 & 8 \\
Laos & 76 & \\
Singapur & 0,3 & 25 \\
\hline
\end{tabular}

Fischer Weltalmanach (2000) und Fischer Weltalmanach (2005).

Tabelle 37: Langlebige Konsumgüter pro 1.000 Einwohner in Südostasien 1970-2006

\begin{tabular}{|l|l|l|l|l|l|l|l|}
\hline & \multicolumn{3}{|c|}{ TV-Geräte } & \multicolumn{3}{c|}{ PKW } & Computer \\
\cline { 2 - 8 } & 1985 & 1995 & 2006 & 1970 & 1990 & 2006 & 2006 \\
\hline Indonesien & 39 & 67 & 163 & 0,4 & 7 & 16 & 15 \\
Philippinen & 26 & 45 & 188 & 2 & 7 & 10 & 45 \\
Vietnam & $34(88)$ & 43 & 216 & 0,2 & & 9 & 15 \\
Thailand & 97 & 127 & 322 & 0,5 & 22 & 48 & 84 \\
Myanmar & $2(88)$ & 96 & 11 & 0,4 & $26(94)$ & 8 & 6 \\
Malaysia & 101 & 168 & 275 & 4 & 105 & 257 & 197 \\
Kambodscha & 7 & & 8 & 0,3 & & 24 & 4 \\
Laos & & & 12 & 0,2 & & 8 & 6 \\
Singapur & 182 & 339 & 314 & 18 & 94 & 98 & 666 \\
Brunei & 160 & 243 & 682 & 2 & 423 & 643 & 105 \\
\hline
\end{tabular}

Welt in Zahlen (PKW), Welt in Zahlen (Fernsehgeräte) und Welt in Zahlen (Computer) sowie eigene Berechnungen nach Mitchell (2007), 796-803, 858-861 und Maddison (Population). 
Tabelle 38: Bevölkerung Ostasiens 1950-2009 in Millionen

\begin{tabular}{|l|l|l|l|}
\hline & 1950 & 1980 & 2009 \\
\hline China & 546,8 & 981,2 & $1.331,4$ \\
Japan & 83,8 & 116,8 & 127,1 \\
Südkorea & 20,8 & 38,1 & 48,5 \\
Nordkorea & 9,5 & 17,1 & 22,7 \\
Taiwan & 7,5 & 17,8 & 23,0 \\
\hline Ostasien & 668,4 & $1.171,1$ & $1.552,7$ \\
\hline
\end{tabular}

Maddison (Population).

Tabelle 39: Langlebige Konsumgüter pro 1.000 Einwohner in Ostasien 1970-2006

\begin{tabular}{|l|l|l|l|l|l|l|l|}
\hline \multicolumn{3}{|l|}{ TV-Geräte } & \multicolumn{2}{l|}{ PKW } & Computer \\
\hline & 1985 & 1995 & 2006 & 1970 & 1990 & 2006 & 2006 \\
\hline China & 10 & 310 & 515 & $0,3(78)$ & 1 & 12 & 58 \\
Japan & 580 & 682 & 835 & 60 & 284 & 528 & 456 \\
Südkorea & 189 & 332 & 374 & 2 & 48 & 285 & 616 \\
Taiwan & & & 577 & 3 & 112 & 245 & 546 \\
\hline
\end{tabular}

Welt in Zahlen (Fernsehgeräte), Welt in Zahlen (PKW) und Welt in Zahlen (Computer) sowie eigene Berechnungen nach Mitchell (2007), 798, 800, 803, 858 f. und Maddison (Population). 
Tabelle 40: Millionenstädte in Ostasien 1950 und 1980 (Einwohner in 1.000)

\begin{tabular}{|l|l|l|l|l|l|}
\hline & 1950 & 1980 & & 1950 & 1980 \\
\hline Shanghai & 5.407 & 11.185 & Peking & 1.940 & 9.180 \\
Seoul & 1.446 & 8.364 & Tokio & 6.778 & 8.352 \\
Tientsin & 1.786 & 5.152 & Hongkong & 2.265 & 5.110 \\
Shenyang & 1.551 & 5.055 & Dalian & 1.054 & 4.619 \\
Wuhan & 1.008 & 3.288 & Kanton & 1.496 & 3.182 \\
Busan & 474 & 3.160 & Yokohama & 951 & 2.774 \\
Chongqing & 1.039 & 2.673 & Osaka & 1.956 & 2.648 \\
Harbin & 1.163 & 2.519 & Chengdu & 750 & 2.499 \\
Xi'an & 559 & 2.252 & Taipeh & 503 & 2.220 \\
Zibo & 184 & 2.198 & Nanking & 1.020 & 2.519 \\
Nagoya & 1.031 & 2.088 & Changchun & 855 & 1.747 \\
Taiyuan & 721 & 1.746 & Daegu & 314 & 1.605 \\
Kyoto & 1.102 & 1.473 & Kunming & 309 & 1.419 \\
Tangshan & 693 & 1.408 & Zhengzhou & 595 & 1.404 \\
Sapporo & 314 & 1.402 & Kōbe & 765 & 1.367 \\
Lanzhou & 224 & 1.364 & Jinan & 680 & 1.359 \\
Guiyang & 242 & 1.350 & Piöngjang & 388 & 1.280 \\
Qiqihar & 345 & 1.209 & Anshan & 185 & 1.196 \\
Fushun & 679 & 1.185 & Qingdao & 884 & 1.172 \\
Hangzhou & 697 & 1.171 & Fuzhou & 553 & 1.112 \\
Fukuoka & 393 & 1.089 & Jilin & 435 & 1.088 \\
Incheon & 266 & 1.084 & Nanchang & 508 & 1.076 \\
Baotou & 149 & 1.076 & Shijiazhuang & 373 & 1.069 \\
Changsha & 651 & 1.066 & Kitakyūshū & 711 & 1.065 \\
Kawasaki & 319 & 1.041 & Huainan & 287 & 1.029 \\
\hline
\end{tabular}

Mitchell (2007), 42-46. 
Tabelle 41: Millionenstädte in Australien und Neuseeland 1950-2012 (Einwohner in 1.000)

\begin{tabular}{|l|l|l|l|}
\hline & 1950 & 1980 & 2012 \\
\hline Sydney & 1.484 & 2.877 & 4.667 \\
Melbourne & 1.226 & 2.578 & 4.246 \\
Brisbane & 402 & 942 & 2.190 \\
Perth & 273 & 809 & 1.898 \\
Adelaide & 382 & 883 & 1.277 \\
Auckland & 329 & 770 & $1.208(2006)$ \\
\hline
\end{tabular}

Mitchell (2007), 47 und Liste der Städte (Australien und Neuseeland). 



\section{Bibliographie ${ }^{539}$}

Acemoglu/Robinson (2014) = Acemoglu, Daron/Robinson, James A.: Warum Nationen scheitern. Die Ursprünge von Macht, Woblstand und Armut. Frankfurt am Main: Fischer Taschenbuch 2014.

Agrawal (1995) = Agrawal, Pradeep: „Singapore: Export-Oriented Industrialization“, in: Agraval, Pradeep u.a. (Hg.): Economic Restructuring in East Asia and India. Perspectives and Policy Reform. Basingstoke: Macmillan 1995, 54-102.

Agrawal (1995 a) = Agrawal, Pradeep: „Crisis and Response“, in: Agraval, Pradeep u.a. (Hg.): Economic Restructuring in East Asia and India. Perspectives and Policy Reform. Basingstoke: Macmillan 1995, 159-216.

Albertini (1985) = Albertini, Rudolf von: Europäische Kolonialherrschaft: 1880-1940 (Beiträge zur Kolonial- und Überseegeschichte 14). Stuttgart: Steiner 1985.

Allen $(2009)=$ Allen, Robert C.: The British Industrial Revolution in Global Perspective. Cambridge: Cambridge University Press 2009.

Amin (1997) = Amin, A. T. M. Nural: „An enduring lesson from Thailand's economic performance", in: Wahid, Abu N. (Hg.): The ASEAN Region in Transition. Aldershot: Ashgate 1997, 109-130.

Amin (1997a) = Amin, Samir: Die Zukunft des Weltsystems. Herausforderungen der Globalisierung. Hamburg: VSA-Verlag 1997.

Andrejew (1993) = Andrejew, Wladislaw/Sarafanov, Michail/Oreskin, Valerij: Stand und Perspektiven der Wirtschaftsreform in der Russischen Föderation. Köln: Deutscher InstitutsVerlag 1993.

Austen (1987) = Austen, Ralph A.: African Economic History. Internal Development and External Dependency. London: Heinemann Education Books 1987.

Bairoch (1975) = Bairoch, Paul: The Economic Development of the Third World since 1900. London: Methuen 2975.

Bairoch (1982) = Bairoch, Paul: „International Industrialization Levels from 1750 to 1980“, in: Journal of European Economic History 11 (1982), 269-310.

539 Aus der Fülle einschlägiger Untersuchungen und Statistiken zur wirtschaftlichen Entwicklung sind hier nur diejenigen angeführt, die für die vorliegende Arbeit herangezogen wurden. Bei mehreren Erscheinungsorten ist jeweils nur der erste genannt. 
Bairoch(1991) = Bairoch, Paul: Cities and Economic Development. From the Dawn of History to the Present. Chicago: University of Chicago Press 1991.

Bairoch/Batou/Chèvre (1988) = Bairoch, Paul/Batou, Jean/Chèvre, Pierre: La Population des villes européennes. Banque de donnés et analyse sommaire des résultats. Genf: Librairie Droz 1988.

Barbero/Rocchi (2003) = Barbero, Maria Ines/Rocchi, Fernando: „Industriy“, in: Paolera, Gerardo della/Taylor, Alan M. (Hg.): A New Economic History of Argentina. Cambridge: Cambridge University Press 2003, 261-294.

Bauer (1988) = Bauer, Michael: Die Entwicklung der Industrie in ibrer räumlichen Differenzierung auf den Philippinen (Europäische Hochschulschriften, Reihe V, 883). Frankfurt am Main: Lang 1988.

Bayly (2006) = Bayly, Christopher A.: Die Geburt der modernen Welt. Eine Globalgeschichte 1780-1914. Frankfurt am Main: Campus 2006.

Berend (2006) = Berend, Ivan T.: An Economic History of Twentieth Century Europe. Economic Regimes from Laissez-Faire to Globalization. Cambridge: Cambridge University Press 2006.

Berend/Ránki (1985) = Berend, Iván T./Ránki, György: „Ungarn, Rumänien, Bulgarien, Serbien und Montenegro 1850-1914“, in: Fischer, Wolfram (Hg.): Handbuch der europäischen Wirtschafts- und Sozialgeschichte, Bd. 5 (Europäische Wirtschafts- und Sozialgeschichte von der Mitte des 19. Jahrhunderts bis zum Ersten Weltkrieg). Stuttgart: KlettCotta 1985, 601-648.

Bernecker/Segura (1985) = Bernecker, Walther L./Segura, Francisco Simón: „Spanien 1850-1914“, in: Fischer, Wolfram (Hg.): Handbuch der europäischen Wirtschafts- und Sozialgeschichte, Bd. 5 (Europäische Wirtschafts- und Sozialgeschichte von der Mitte des 19. Jabrhunderts bis zum Ersten Weltkerieg). Stuttgart: Klett-Cotta 1985, 665-686.

Bértola/Ocampo (2012) = Bértola, Luis/Ocampo, José Antonio: The Economic Development of Latin America since Independence. Oxford: Oxford University Press 2012.

Bértola/Williamson (2006) = Bértola, Luis/Williamson, Jeffrey G.: „Globalization in Latein America before 1940“, in: Bulmer-Thomas, Victor u.a. (Hg.): The Cambridge Economic History of Latin America, vol. 2 (The Long Twentieth Century). Cambridge: Cambridge University Press 2006, 11-56.

Beschäftigungsstruktur 2013 = wko.at/statistik/eu/europa-beschaeftigungsstruktur.pdf Blanchard (1995) = Blanchard, Oliver u.a.: „Unemployment and Restructuring in Eastern Europe and Russia“, in: Commander, Simon/Coricelli, Fabrizio (Hg.): Unemployment, 
Restructuring, and the Labor Market in Eastern Europe and Russia. Washington, D.C.: World Bank 1995, 289-329.

Boehm (1971) = Boehm, E.A.: Twentieth Century Economic Development in Australia. Camberwell: Longman 1971.

Braun/Grotz (2002) = Braun, Boris/Grotz, Reinhold: „Die Wirtschaft“, in: Bader, Rudolf (Hg.): Australien. Eine interdis₹iplinäre Einführung. Trier: WVT 2002, 163-203.

Brink (2013) = Brink, Tobias ten: Chinas Kapitalismus. Entwicklung, Verlauf, Paradoxien (Schriften aus dem Max-Planck-Institut für Gesellschaftsforschung 78). Frankfurt am Main: Campus 2013

Broadberry/O'Rourke (2010a) = Broadberry, Stephen/O'Rourke, Kevin H. (Hg.): The Cambridge Economic History of Modern Europe, vol. 1 (1700-1870). Cambridge: Cambridge University Press 2010.

Broadberry/O'Rourke $(2010 \mathrm{~b})=$ Broadberry, Stephen/O'Rourke, Kevin H. (Hg.): The Cambridge Economic History of Modern Europe, vol. 2 (1870 to the Present). Cambridge: Cambridge University Press 2010.

Bronger (2004) = Bronger, Dirk: Metropolen. Megastädte, Global Cities. Die Metropolisierung der Erde. Darmstadt: Wissenschaftliche Buchgesellschaft 2004.

Bronger/Trettin (2011) = Bronger, Dirk/Trettin, Lutz: Megastädte - Global Cities heute: Das Zeitalter Asiens? (Asien, Wirtschaft und Entwicklung 5). Berlin: LIT Verlag 2011.

Buchheim (1994) = Buchheim, Christoph: Industrielle Revolutionen. Langfristige Wirtschaftsentwicklung in Großbritannien, Europa und Übersee. München: Deutscher Taschenbuch-Verlag 1994.

Buchmann (1980) = Buchmann, M.: „Die wirtschaftliche Entwicklung“", in: Hohnholz, Jürgen H. (Hg.): Thailand. Geographie - Geschichte - Kultur - Religion - Staat - Gesellschaft - Wirtschaft (Buchreibe Ländermonographien 13). Tübingen: Erdmann 1980, 416-435.

Buchmann (1980a) = Buchmann, M.: „Die Wirtschaftsstruktur“, in: Hohnholz, Jürgen H. (Hg.): Thailand. Geographie - Geschichte - Kultur - Religion - Staat - Gesellschaft Wirtschaft (Buchreibe Ländermonographien 13). Tübingen: Erdmann 1980, 436-452.

Bulmer-Thomas (1994) = Bulmer-Thomas, Victor: The Economic History of Latin America since Independence. Cambridge: Cambridge University Press 1994.

Cameron/Neal (2003) = Cameron, Rondo/Neal, Larry: A Concise Economic History of the World. From Paleolithic Times to the Present. New York: Oxford University Press 2003 Canada Year Book (1997) = Statistics Canada (Hg.): Canada Year Book 1997. Ottava 1997. 
Cardin/Couture (1997) = Cardin, Jean-François/Couture, Claude. Histoire $d u$ Canada. Espace et différence. Québec: Presses de l’Université Laval 1997.

Cerman (2011) = Cerman, Markus: „Vorindustrielles Gewerbe und ProtoIndustrialisierung“, in: Cerman, Markus u.a. (Hg.): Wirtschaft und Gesellschaft Europa 1000-2000 (VGS Studientexte 2). Wien: StudienVerlag 2011, 211-227.

Chandler/Fox (1974) = Chandler, Tertius/Fox, Gerald: 3000 Years of Urban Growth. New York: Academic Press 1974.

Chapman (1990) = Chapman, S. D.: „The Cotton Industry and the Industrial Revolution“, in: Clarkson, L. A. (Hg.): The Industrial Revolution. A Compendium. London: Macmillan 1990, 1-64.

Cheng (2002) = Cheng, Hung-Chang: International Trade, Productivity and Economic Growth: An Empirical Study on Economic Development of Taiwan. Diss. Innsbruck 2002.

Cheng/Fung (2001) = Cheng, Leonard K./Fung, William K.: „The Globalization of Trade and Production: A Case Study of Hong Kong's Textile and Clothing Industries“, in: Cheng, L. K./Kierzkowski, Henryk (Hg.): Global Production and Trade in East Asia. Boston: Kluwer Academic Publ. 2001, 227-248.

China $(2012 \mathrm{a})=$ China - Bevölkerung nach Provinzen 2012 (de.statista.com $>$ Branchen $>$ Länder $>$ China).

China $(2012$ b) = China - Bruttoinlandsprodukt (BIP) nach Provinzen 2012 (de.statista. com $>$ Branchen $>$ Länder $>$ China).

Chowdhury (1997) = Chowdhury, Anis: „Malaysia in transition“, in: Wahid, Abu N. (Hg.): The ASEAN Region in Transition. Aldershot: Ashgate 1997, 43-64.

Clark (2007) = Clark, Gregor: A Farewell to Alms. A Brief Economic History of the World. Princeton: Princeton University Press 2007.

Clayton/Conniff (1999) = Clayton, Lawrence/Conniff, Michael: A history of modern Latin America. Fort Worth: Harcourt Brace College Publ. 1999.

Collier/Sater (2004) = Collier, Simon/Sater, William F.: A History of Chile, 1808-2000 (Cambridge Latin American Studies). Cambridge: Cambridge University Press 2004

Commander (1995) = Commander, Simon u.a.: „Russia“, in: Commander, Simon/ Coricelli, Fabrizio (Hg.): Unemployment, Restructuring, and the Labor Market in Eastern Europe and Russia. Washington, D.C.: World Bank 1995, 147-191.

Cooper $(2002)=$ Cooper, Frederick: Africa since 1940. The Past of the Present. Cambridge: Cambridge University Press 2002. 
Couturier $(1994)=$ Couturier, Jacques Paul. L’expérience canadienne, des origines à nos jours. Moncton: Éd. d’Acadie 1994

Couturier (1996) = Couturier, Jacques Paul. Un passé composé. Le Canada de 1850 à nos jours. Moncton: Éd. d'Acadie 1996

Delivanis/Sundhausen $(1985)=$ Delivanis, Dimitrios J./Sundhausen, Holm: „Griechenland 1830-1914“, in: Fischer, Wolfram (Hg.): Handbuch der europäischen Wirtschafts- und Sozialgeschichte, Bd. 5 (Europäische Wirtschafts- und Sozialgeschichte von der Mitte des 19. Jahrhunderts bis zum Ersten Weltkrieg). Stuttgart: Klett-Cotta 1985, 649-663. Diamond (1998) = Diamond, Jared: Arm und Reich. Die Schicksale menschlicher Gesellschaften. Frankfurt am Main: S. Fischer 1998.

Donghi (1985) = Donghi, Tulio Halperin: „Economy and Society in post-Independence Spanish America“, in: Bethell, Leslie (Hg.): The Cambridge History of Latin America, vol. 3. Cambridge: Cambridge University Press 1985, 299-345.

Eaton/Newman (1994) = Eaton, Diane F./Newman, Garfield: Canada, a nation unfolding. Toronto: McGraw-Hill Ryerson 1994.

Ehmer (2011) = Ehmer, Josef: „Bevölkerung und historische Demographie“, in: Cerman, Markus u.a. (Hg.): Wirtschaft und Gesellschaft Europa 1000-2000 (VGS Studientexte 2). Wien: StudienVerlag 2011, 134-160.

Eigner (2011) = Eigner, Peter: „Der Weg in die Industriegesellschaft“, in: Cerman, Markus u.a. (Hg.): Wirtschaft und Gesellschaft Europa 1000-2000 (VGS Studientexte 2). Wien: StudienVerlag 2011, 104-133.

Elsenhans $(1982)=$ Elsenhans, Hartmut: „Grundlagen der Entwicklung der kapitalistischen Weltwirtschaft", in: Senghaas, Dieter (Hg.): Kapitalistische Weltökonomie. Kontroversen über ibren Ursprung und ibre Entwicklungsdynamik. Frankfurt am Main: Suhrkamp 1982, 103-148.

Eng $(2002)$ = Eng, Pierre van der: „Indonesia's Growth Performance in the Twentieth Century“, in: Maddison, Angus (Hg.): The Asian Economies in the Twentieth Century. Cheltenham: Elgar 2002, 143-179.

Engelhard (2004) = Engelhard, Karl: Südkorea. Vom Entwicklungsland zum Industriestaat. Münster: Waxmann 2004.

Engerman/Sokoloff (2000) = Engerman, Stanley L./Sokoloff, Kenneth L.: ,,Technology and Industrialization, 1790-1914“, in: Engerman, Stanley L./Gallman, Robert E. (Hg.). The Cambridge Economic History of the United States, vol. 2 (The Long Nineteenth Century). Cambridge: Cambridge University Press 2000, 367-401. 
Escosura (2006) = Escosura, Leandro Prados de la: „The Economic Consequences of Independence in Latin America“, in: Bulmer-Thomas, Victor u.a. (Hg.): The Cambridge Economic History of Latin America, vol. 1 (The Colonial Era and the Short Nineteenth Century). Cambridge: Cambridge University Press 2006, 463-504.

BIP pro Kopf 2010 = Regionales BIP pro Kopf in der EU im Jahre 2010 (http:// ec.europa.eu/eurostat/documents /2995521/5160106/1-21032013-AP-DE. $\mathrm{PDF} / 0 \mathrm{e} 8 \mathrm{a3c} 7 \mathrm{e}-61 \mathrm{ff}-46 \mathrm{bb}-80 \mathrm{ed}-65788 \mathrm{~d} 751 \mathrm{c} 09$ ?version=1.0)

Evans (1996) = Evans, Eric J.: The Forging oft he Modern State. Early Industrial Britain 17831870. London: Longman 1996.

Eversley $(1967)=$ Eversley, D. E. C.: „The Home Market and Economic Growth in England, 1750-1780“, in: Jones, E. L./Mingay, G. E.: Land, Labour and Population in the Industrial Revolution. London: Edward Arnold 1967, 206-259.

Faria $(1989)=$ Faria, Vilmar: „Changes in the Composition of Employment and the Structure of Occupations“, in: Bacha, Edmar L./Klein, Herbert S. (Hg.): Social Change in Brazil, 1945-1985. Albuquerque: University of New Mexico Press 1989, 99-140.

Feinstein (2005) = Feinstein, Charles: An Economic History of South Africa: Conquest, Discrimination and Development. Cambridge: Cambridge University Press 2005.

Fellmeth/Rohde (1999) = Fellmeth, Sebastian/Rohde, Christian: Der Abbau eines Woblfahrtsstaates. Neuseeland als Modell für das nächste Jabrhundert? Marburg: Metropolis 1999.

Fessen/Kubitschek (1984) = Fessen, Helmut/Kubitschek, Hans Dieter: Geschichte Malaysias und Singapurs. Berlin: Deutscher Verlag der Wissenschaft 1984.

Fischer (1968) = Fischer, Ludolph: Afghanistan: eine geographisch-medizinische Landeskunde/A Geomedical Monograph (Medizinische Länderkunde. Beiträge zur geographischen Medizin 2). Berlin: Springer 1968.

Fischer $(1985)=$ Fischer, Wolfram: „Wirtschaft und Gesellschaft 1850-1914“, in: Fischer, Wolfram (Hg.): Handbuch der europäischen Wirtschafts- und Sozialgeschichte, Bd. 5 (Europäische Wirtschafts- und Sozialgeschichte von der Mitte des 19. Jahrhunderts bis zum Ersten Weltkrieg). Stuttgart: Klett-Cotta 1985, 1-207.

Fischer $(1987)=$ Fischer, Wolfram: „Wirtschaft, Gesellschaft und Staat in Europa 1914-1980“, in: Fischer, Wolfram (Hg.): Handbuch der europäischen Wirtschafts- und Sozialgeschichte, Bd. 6 (Europäische Wirtschafts- und Sozialgeschichte vom Ersten Weltkrieg bis zur Gegenwart). Stuttgart: Klett-Cotta 1987, 1-221. 
Fischer (2011) = Fischer, Karin: Eine Klasse für sich: Besitz, Herrschaft und ungleiche Entwicklung in Chile 1830-2010. Baden-Baden: Nomos 2011.

Fischer Weltalmanach (1990) = Der Fischer Weltalmanach '90. Zablen Daten Fakten. Frankfurt am Main: Fischer Taschenbuch 1989.

Fischer Weltalmanach (1992) = Der Fischer Weltalmanach '92. Zablen Daten Fakten. Frankfurt am Main: Fischer Taschenbuch 1991.

Fischer Weltalmanach (1995) = Baratta, Mario von (Hg.):Der Fischer Weltalmanach '95. Zablen Daten Fakten. Frankfurt am Main: Fischer Taschenbuch 1994.

Fischer Weltalmanach (2000) = Baratta, Mario von: Der Fischer Weltalmanach 2000. Zahlen Daten Fakten. Frankfurt am Main: Fischer Taschenbuch 1999

Fischer Weltalmanach $(2005)=$ Der Fischer Weltalmanach 2005. Zablen Daten Fakten. Frankfurt am Main: Fischer Taschenbuch 2004.

Fischer Weltalmanach (2005a) = Ulrich, Volker/Berié, Eva (Hg.): Der Fischer Weltalmanach. Russland und der Kaukasus. Frankfurt am Main: Fischer Taschenbuch 2005.

Fischer Weltalmanach $(2008)=$ Der Fischer Weltalmanach 2008. Zablen Daten Fakten. Frankfurt am Main: Fischer Taschenbuch 2007.

Fischer Weltalmanach $(2011)=$ Der Fischer Weltalmanach 2011. Zablen Daten Fakten. Frankfurt am Main: Fischer Taschenbuch 2010.

Fishlow $(2000)=$ Fishlow, Albert: „Internal Transportation in the Nineteenth and Early Twentieth Centuries“, in: Engerman, Stanley L./Gallman, Robert E. (Hg.). The Cambridge Economic History of the United States, vol. 2 (The Long Nineteenth Century). Cambridge: Cambridge University Press 2000, 543-642.

Fitzpatrick (1969) = Fitzpatrick, Brian: The British Empire in Australia. An Economic History 1834-1939. Melbourne: Macmillan 1969.

Frank (1978) = Frank, Andre Gunder: Dependent Accumulation and Underdevelopment. London: Macmillan 1978.

Frank (1978a) = Frank, Ander Gunder: Weltwirtschaft in der Krise. Verarmung im Norden, Verelendung im Süden. Reinbeck bei Hamburg: Rowohlt Taschenbuch 1978.

Frank (2005) = Frank, Ander Gunder: Orientierung im Weltsystem. Von der Neuen Welt zum Reich der Mitte. Wien: Promedia 2005.

Frank (2005a) = Frank, Rüdiger, „Nordkoreas Wirtschaft“, in: Kern, Thomas/Köllner, Patrick (Hg.): Südkorea und Nordkorea. Einführung in Geschichte, Politik, Wirtschaft und Gesellschaft. Frankfurt am Main: Campus 2005, 235-257. 
Frey (1986) = Frey, Ulrich: Entwicklungsländer im Systemvergleich. Sozialistische Verelendung und marktwirtschaftliches Wachstum. China-Taiwan, Nordkorea-Südkorea, Guinea-Elfenbeinküste, Tansania-Kenia. Kreuzlingen: Edition Erpf bei Neptun 1986.

Galiani/Gerchunoff (2003) = Galiani, Sebastian/Gerchunoff, Pablo: „The labour market", in: Paolera, Gerardo della/Taylor, Alan M. (Hg.): A New Economic History of Argentina. Cambridge: Cambridge University Press 2003, 122-169.

Gallman (2000) = Gallman, Robert E.: „Economic Growth and Structural Change in the Long Nineteenth Century“, in: Engerman, Stanley L./Gallman, Robert E. (Hg.). The Cambridge Economic History of the United States, vol. 3 (The Twentieth Century). Cambridge: Cambridge University Press 2000, 191-247.

Gilboy (1932) = Gilboy E.W.: „Demand as a Factor in the Industrial Revolution“, neu abgedruckt in: Hartwell, R.M. (Hg.): The Causes of the Industrial Revolution in England. London: Methuen 1967.

Gokarn (1995) = Gokarn, Subir V.: „Industrial and Financial Restructuring“, in: Agraval, Pradeep u.a. (Hg.): Economic Restructuring in East Asia and India. Perspectives and Policy Reform. Basingstoke: Macmillan 1995, 22-53.

Gómez-Galvarriato (2006) = Gómez-Galvarriato, Aurora: „Premodern Manufacturing“, in: Bulmer-Thomas, Victor u.a. (Hg.): The Cambridge Economic History of Latin America, vol. 1 (The Colonial Era and the Short Nineteenth Century). Cambridge: Cambridge University Press 2006, 357-394.

Goswin (1996) = Goswin, Thomas u.a.: „Wirtschaftsordung und Wirtschaftspolitik“, in: Wegmann, Konrad (Hg.): Studien zur chinesischen Wirtschaft (Strukturen der Macht. Studien zum politischen Denken Chinas 1). Münster: LIT Verlag 1996, 8-102.

Green $(2000)=$ Green, Alan G.: „Twentieth-Century Canadian Economic History“, in: Engerman, Stanley L./Gallman, Robert E. (Hg.). The Cambridge Economic History of the United States, vol. 2 (The Long Nineteenth Century). Cambridge: Cambridge University Press 2000,

Green $(2003)=$ Green, Duncan: Silent Revolution . The Rise and Crisis of Market Economies in Latein America. New York 2003.

Grondana (2002) = Grondana, Mariano: „Eine kulturelle Typologie der wirtschaftlichen Entwicklung“, in: Huntington, Samuel P./Harrison, Lawrence E. (Hg.): Streit um Werte. Wie Kulturen den Fortschritt prägen. Hamburg: Europa Verlag 2002, 75-89.

Growth Amid Change (2007) = Asian Development Bank (Hg.): Gowth Amid Change in Developing Asia. 2007 
Haber (2006) = Haber, Stephen: „The Political Economy of Industrialization“, in: Bulmer-Thomas, Victor u.a. (Hg.). The Cambridge Economic History of Latin America, vol. 2 (The Long Twentieth Century). Cambridge: Cambridge University Press 2006, 537-586. Hagemann (2004) = Hagemann, Albrecht: Kleine Geschichte Australiens. München: Beck 2004.

Haines (2000) = Haines, Michael R.: „The Population of the United States, 1790-1920“, in: Engerman, Stanley L./Gallman, Robert E. (Hg.). The Cambridge Economic History of the United States, vol. 2 (The Long Nineteenth Century). Cambridge: Cambridge University Press 2000, 143-205.

Harberger $(1988)=$ Harberger, Arnold C.: „Growth, Industrialization and Economic Structure: Latin America and East Asia Compared“, in: Hughes, Helen (Hg.): Achieving Industrialization in East Asia. Cambridge: Cambridge University Press 1988,164-194.

Hasan (1976) = Hasan, Parvez: Korea. Problems and Issues in a Rapidly Growing Economy. Baltimore: Johns Hopkins University Press 1976,

Hauer (1998) = Hauer, Gabriele: Direktinvestitionen im tertiären Sektor. Das Beispiel Sidney, Australien (Kölner Forschungen zur Wirtschafts- und Sozialgeographie 49). Köln: Wirtschaftsund Sozialgeographisches Institut der Universität Köln 1998.

Heim (2000) = Heim, Carol R.: „Structural Changes: Regional and Urban“, in: Engerman, Stanley L./Gallman, Robert E. (Hg.). The Cambridge Economic History oft he United States, vol. 3 (The Twentieth Century). Cambridge: Cambridge University Press 2000, 93-190.

Heimat und Welt (Südasien - Wirtschaft) $=$ Heimat und Welt Weltatlas + Geschichte - Nordrhein-Westfalen - 978-3-14-100267-6, Seite 117 (www.heimatundwelt.de/ kartenansicht.xtp?artId=978-3-14-100267-6)

Helmschrott $(1990)=$ Helmschrott, Helmut/Pilgrim, Eberhard von/Schönherr, Siegfried: Afrika südlich der Sahara: trotz Rohstoffreichtum in die Armut. München: Weltforum-Verlag 1990.

Hentschel $(1986)=$ Hentschel, Volker: Wirtschaftsgeschichte des modernen Japans, 2 Bde. (Wissenschaftliche Paperbacks 22 und 23). Stuttgart: Steiner 1986.

Herrman-Pillath (1995) = Herrmann-Pillath, Carsten: Marktwirtschaft in China. Geschichte - Struktur - Transformation. Opladen: Leske+Budrich 1995.

Hewett (1988) = Hewett, Ed A.: Der neue Mark. Sowjetunion. Effizienz und Perestroika in der sowjetischen Wirtschaft. Landsberg am Lech: Mi-Poller 1988.

Historical Statistics (1960) = Historical Statistics oft he United States, Colonial Times to 1957. Washington, D.C. 1960. 
Hofman $(2000)=$ Hofman, André A.: The Economic Development of Latin America in the Twentieth Century. Cheltenham: Edward Elgar 2000.

Hofmeister (2002) = Hofmeister, Burkhard: „Geographie: Kulturlandschaft“, in: Bader, Rudolf (Hg.): Australien. Eine interdis₹iplinäre Einführung. Trier: WVT 2002, 19-35.

Hossain (1997) = Hossain, Mahabub: „Economic development in the Philippines: a frustrated take-off?“, in: Wahid, Abu N. (Hg.): The ASEAN Region in Transition. Aldershot: Ashgate 1997, 65-86.

Houtte (1980) = Houtte, Jan A. van: „Europäische Wirtschaft und Gesellschaft von den großen Wanderungen bis zum Schwarzen Tod“, in: Houtte, Jan A. (Hg.): Handbuch der europäischen Wirtschafts- und Sozialgeschichte, Bd. 2 (Europäische Wirtschafts- und Sozialgeschichte im Mittelalter). Stuttgart: Klett-Cotta 1980, 1-149.

Hübner-Schmid (2004) = Hübner-Schmid, Katharina: Studien zur länderbezogenen Konfliktanalyse. Pakistan. Berlin: Friedrich-Ebert-Stiftung, Referat Entwicklungspolitik 2004.

Hughes (1988) = Hughes, Helen (Hg.): Achieving Industrialization in East Asia. Cambridge: Cambridge University Press 1988.

Hutchings $(1971)=$ Hutchings, Raymond: Soviet Economic Development. Oxford: Basil Blackwell 1971.

Ingram (1971) = Ingram, James C.: Economic Change in Thailand: 1850-1970. Stanford:

Stanford University Press 1971.

Issawi (1982) = Issawi, Charles: An Economic History of the Middle East and North Africa. New York: Columbia University Press 1982.

Japan (Präfekturen) = Liste der Präfekturen Japans (de.wikipedia.org/wiki/Liste_der_ Präfekturen_Japans)

Japan-Perspektiven (1990) = Frankfurter Allgemeine Zeitung GmbH Informationsdienste (Hg.): Japan-Perspektiven: Wirtschaft, Gesellschaft, Mark.t. Frankfurt am Main 1990.

Johnson/Kaufmann (2001) = Johnson, Simon/Kaufmann, Daniel: „Institution and the Underground Economy“, in: Havrylyshyn, Oleh/Nsouli, Saleh M. (Hg.): A Decade of Transition: Achievements and Challenges. Washington, D.C.: International Monetary Fund 2001, 212-228.

Jones (1981) = Jones, Eric: The European Miracle. Environments, Economies and Geopolitics in the History of Europe and Asia. Cambridge: Cambridge University Press 1981.

Jones (2002) = Jones, Eric: The Record of Global Economic Development. Cheltenham: Edward Elgar 2002. 
Kafle (2007) = Kafle, Agni Prasad: Workforce Development in Nepal. Policies and Practices. Tokio: Asian Development Bank Institute 2007.

Kahan (1985) = Kahan, Arcadius: „Rußland und Kongreßpolen 1860-1914“, in: Fischer, Wolfram (Hg.): Handbuch der europäischen Wirtschafts- und Sozialgeschichte, Bd. 5 (Europäische Wirtschafts- und Sozialgeschichte von der Mitte des 19. Jahrbunderts bis zum Ersten Weltkrieg). Stuttgart: Klett-Cotta 1985, 512-600.

Katzmann (1989) = Katzman, Martin T.: „Urbanization since 1845“, in: Bacha, Edmar L/Klein, Herbert S. (Hg.): Social Change in Brazil, 1945-1985. Albuquerque: University of New Mexico Press 1989, 99-140.

Kerr (1990) = Kerr, Donald u.a. (Hg.): Historical Atlas of Canada, vol. 3. Addressing the Twentieth Century: 1891-1961. Toronto u.a.: University of Toronto Press 1990

Kim $(1990)=$ Kim, Young-Yoon: Die asiatische Pazifikregion. Entstehung eines neuen Weltwirtschaftsraumes (Studien zur Bremer Gesellschaft für Wirtschaftsforschung 1). Frankfurt am Main: Lang 1990.

Kim (2001) = Kim, Hyecheong: The ,Chaebol-Economy'. Its Role and Impact for the Economic Development of South Korea. Dipl. Innsbruck 2001.

Kingston (1988) = Kingston, Beverley: The Oxford history of Australia, vol. 3. (1860-1900: glad, confident, morning). Melbourne: Oxford University Press 1988.

Knapman/Quiggin (1997) = Knapman, Bruce/Quiggin, John: The Australian Economy in the Twentieth Century. Bremen: LIT Verlag1997.

Köllmann (1965) = Köllmann, Wolfgang: Bevölkerung und Raum in Neuerer und Neuester Zeit (Raum und Bevölkerung in der Weltgeschichte. Bevölkerungs-Ploetz 4). Würzburg: A. G. Ploetz 1965.

Kötter (1979) = Kötter, Herbert u.a. (Hg.): Indonesien. Geographie, Geschichte, Kultur, Religion, Staat, Gesellschaft, Bildungswesen, Politik, Wirtschaft. Tübingen: Erdmann 1979.

Kolb (1984) = Kolb, Frank: Die Stadt im Altertum. München: Beck 1984.

Kolb $(2006)=$ Kolb, Frank: „Die ,Hauptstadt der Welt ${ }^{6}-$ Flaniermeilen, Tempel und Wohnquartiere“, in: Ameling, Walter u.a. (Hg.): Antike Metropolen. Darmstadt: Wissenschaftliche Buchgesellschaft 2006, 92-108.

Kratoska (1998) = Kratoska, Paul H.: The Japanese Occupation of Malaya. A Social and Economic History. London: Hurst 1998.

Kraus (1979) = Kraus, Willy: Wirtschaftliche Entwicklung und sozialer Wandel in der Volksrepublik China. Berlin: Springer 1979. 
Kreisel $(2009)=$ Kreisel, Werner: „Die wirtschaftliche Entwicklung der pazifischen Inselländer 1750-2000“, in: Mückler, Hermann u.a. (Hg.): Ozeanien 18. Bis 20. Jahrhundert. Geschichte und Gesellschaft. Wien: Promedia 2009, 246-266.

Kuchis $($ Afghanistan $)=$ http://de.wikipedia.org/wiki/Kuchis

Kuo (1982) = Kuo, Xing-Hu: Freies China. Asiatisches Wirtschaftswunder. Stuttgart: Seewald 1982.

Kwack (1986) = Kwack, Sung Yeung: „The Economic Development of the Republic of Korea“, in: Lau, Lawrence J (Hg.): Models of Development. A Comparative Study of Economic Growth in South Korea and Taiwan. San Francisco: ICS Press 1986, 65-135.

Lal (1988) = Lal, Deepak: „Ideology and Industrialization in India and East Asia“, in: Hughes, Helen (Hg.): Achieving Industrialization in East Asia. Cambridge: Cambridge University Press 1988, 195-240.

Lamoureux $(2003)=$ Lamoureux, Florence: Indonesia. A Global Studies Handbook. Santa Barbara: ABC Clio 2003.

Landes (1969) = Landes, David Saul: The Unbound Prometheus. Technological change and industrial development in Western Europe from 1750 to the present. Cambridge: Cambridge University Press 1969.

Landes (1973) = Landes, David Saul: Der entfesselte Prometheus. Technologischer Wandel und industrielle Entwicklung in Westeuropa von 1750 bis zur Gegenwart. Köln: Kiepenheuer \& Witsch 1973.

Landes (1998) = Landes, David Saul: The Wealth and Poverty of Nations: Why Some Are So Rich and Some So Poor. New York: W. W. Norton 1998.

Landes (2002) = Landes, David Saul: Armut und Woblstand der Nationen. Warum die einen reich und die anderen arm sind. Berlin: Berliner Taschenbuch-Verlag 2002.

Larsen (1996) = Larsen, Sven: „Die demographische Entwicklung der Volksrepublik China“, in: Wegmann, Konrad (Hg.): Studien zur chinesischen Wirtschaft (Strukturen der Macht. Studien zum politischen Denken Chinas 1). Münster: LIT Verlag 1996, 142-187.

Lechleitner $(1972)=$ Lechleitner, Herwig: Die Rolle des Staates in der wirtschaftlichen und sozialen Entwicklung Libanons (Wiener geographische Schriften 36/37). Wien: Hirt 1972.

Linteau/Brown (1988) = Linteau, Paul- André/Brown, Robert Craig: Histoire générale du Canada. Montreal: Boréal 1988.

Lions (2010) = McKinsey Global Institute (Hg.): Lions on the move: The progress and potential of African economies. 2010. 
Lipsey (1972) = Lipsey, Robert. „Foreign Trade“, in: Lance, E. Davis u.a. (Hg.): American Economic Growth. An Economist's History oft he United States. New York: Harper \& Row 1972, 548-581.

Liste der größten Roheisenerzeuger = de.wikipedia.org/wiki/Liste_der_größten_ Roheisenerzeuger

Liste der größten Städte Afrikas = de.wikipedia.org/wiki/Liste_der_größten_Städte_ Afrikas

Liste der Länder (Bruttoinlandsprodukt) = Liste der Länder nach Bruttoinlandsprodukt pro Kopf (de.wikipedia.org/Liste_der_Länder_nach_Bruttoinlandsprodukt_pro_Kopf)

Liste der Städte = de.wikipedia.org/wiki/Liste_der_Städte_in_Albanien bis de.wikipedia. org/wiki/Liste_der_Städte_auf Zypern.

Looney (1977) = Looney, Robert E.: A Development Strategy for Iran through the 1980's. New York: Praeger 1977

Lopez (1971) = Lopez, Robert S.: The Commercial Revolution of the Middle Ages 950-1350. Englewood Cliffs, N.J.: Prentice Hall 1971.

Mabro/Radwan (1978) = Mabro, Robert/Radwan, Samir: The Industrialization of Egypt 1939-1973. Policy and Performance. Oxford: Clarendon Press 1978.

Mackie (1988) = Mackie J. A. C.: „Economic Growth in the ASEAN region: the political underpinnings“, in: Hughes, Helen (Hg.): Achieving Industrialization in East Asia. Cambridge: Cambridge University Press 1988, 283-326.

Maddison (Per Capita GDP) = Statistics on World Population, GDP and Per Capita GDP, 1. www.ggdc.net/maddison/Historical_Statistics/horizontal-file_02_2010.xls

Maddison (Population) $=$ Statistics on World Population, GDP and Per Capita GDP, 1. www.ggdc.net/maddison/Historical_Statistics/horizontal-file_02_2010.xls

Maddison (2001) = Maddison, Angus: The World Economy: A Millenial Perspective. Paris: OECD 2001.

Maddison (2007) = Maddison, Angus: Contours of the World Economy, 1-2030 AD. Oxford: Oxford University Press 2007.

Malanima (2010) = Malanima, Paolo: „Urbanization“, in: Broadberry, Stephen/O’Rourke, Kevin H. (Hg.): The Cambridge Economic History of Modern Europe, vol. 1 (1700-1870). Cambridge: Cambridge University Press 2010, 235-264.

Mansfield (1980) = Mansfield, Peter (Hg.): The Middle East. A Political and Economic Survey. Oxford: Oxford University Press 1980. 
Margo (2000) = Margo, Robert A.: „The Labor Force in the Nineteenth Century“, in: Engerman, Stanley L./Gallman, Robert E. (Hg.). The Cambridge Economic History oft he United States, vol. 2 (The Long Nineteenth Century). Cambridge: Cambridge University Press 2000, 207-243.

Mathieu (2011) = Mathieu, Jon: Die dritte Dimension. Eine vergleichende Geschichte der Berge in der Neuzeit (Wirtschafts-, Sozial- und Umweltgeschichte 3). Basel: Schwabe 2011.

Mathis (2006) = Mathis, Franz: „Insel und Industrialisierung. Japan und Großbritannien im Vergleich“, in: Verband Österreichischer Historiker und Geschichtsvereine (Hg.): Bericht über den 24. Österreichischen Historikertag in Innsbruck. Innsbruck 2006, 222-235.

Mathis (2007) = Mathis, Franz: „Erste Welt und Dritte Welt in einem Land. Zum NordSüd-Gefälle in der Wirtschaft Italiens“, in: Rebitsch, Robert/Taddei, Elena (Hg.): Politik-Konflikt-Gewalt (Innsbrucker Historische Studien 25). Innsbruck: StudienVerlag 2007, 333-341.

Mathis (2011) = Mathis, Franz: „Industrialisierung in der Antike - zum Scheitern verurteilt?", in: Rollinger, Robert/Schwinghammer, Gundula (Hg.): Gegenwart und Altertum. 125 Jahre Alte Geschichte in Innsbruck. Innsbruck 2011, 97-114.

Mathis (2012) = Mathis, Franz: „Wirtschaftliche Entwicklung - ein regionaler statt nationaler Prozess“, in: Hardach, K (Hg.): Internationale Studien zur Geschichte von Wirtschaft und Gesellschaft, Teil 1, Frankfurt am Main: Peter Lang 2012, S. 589-601.

Mathis (2013) = Mathis, Franz: „No Industrialization without Urbanization: The Role of Cities in Modern Economic Development", in: Exenberger, Andreas u.a. (Hg.): Globalization and the City. Two Connected Phenomena in Past and Present. Innsbruck: innsbruck university press 2013, 23-38.

Matis $(1988)$ = Matis, Herbert: Das Industriesystem: Wirtschaftswachstum und sozialer Wandel im 19. Jahrhundert. Wien: Ueberreuter 1988.

Matis/Bachinger (1973) = Matis, Herbert/Bachinger, Karl: „Österreichs industrielle Entwicklung“, in: Brusatti, Herbert (Hg.): Die wirtschaftliche Entwicklung (Die Habsburgermonarchie 1848-1918). Wien: Österreichische Akademie der Wissenschaften 1973, 105-232.

McAuley (1992) = McAuley, Alastair: „The Central Asian economy in comparative perspective“, in: Ellman, Michael/Kontorovich, Vladimir (Hg.): The Disintegration of the Soviet Economic System. London: Routledge 1992, 138-156.

McInnis/Horn (1982) = McInnis, Edgar/Horn, Michiel: Canada: A Political \& Social History. Toronto: Holt, Rinehart \& Winston of Canada 1982. 
McInnis (2000) = McInnis, Marvin: „The Ecomomy of Canada in the Nineteenth Century“, in: Engerman, Stanley L./Gallman, Robert E. (Hg.). The Cambridge Economic History of the United States, vol. 2 (The Long Nineteenth Century). Cambridge: Cambridge University Press 2000, 57-107.

Mauro (1984) = Mauro, Frédéric: Die europäische Expansion (Wissenschaftliche Paperbacks 17). Wiesbaden: Steiner 1984.

Menzel (1985) = Menzel, Ulrich: In der Nachfolge Europas. Autozentrierte Entwicklung in den ostasiatischen Schwellenländern Südkorea und Taiwan. München: Simon \& Magiera 1985.

Menzel (1993) = Menzel, Ulrich: Geschichte der Entwicklungstheorie. Einführung und systematische Bibliographie (Schriften des Deutschen Übersee-Institutwa Hamburg 18). Hamburg: Deutsches Übersee-Institut 1993.

Menzel/Senghaas (1986) = Menzel, Ulrich/Senghaas, Dieter: Europas Entwicklung und die Dritte Welt: Eine Bestandsaufnahme. Frankfurt am Main: Suhrkamp 1986.

Merl (1987) = Merl, Stephan: „Rußland und die Sowjetunion 1914-1980“, in: Fischer, Wolfram (Hg.): Handbuch der europäischen Wirtschafts-und Sozialgeschichte, Bd. 6 (Europäische Wirtschafts- und Sozialgeschichte vom Ersten Weltkerieg bis zur Gegenwart). Stuttgart: KlettCotta 1987, 640-728.

Merrick/Graham (1979) = Merrick, Thomas W./Graham, Douglas H.: Population and Economic Development in Brazil. 1800 to the Present. Baltimore 1979.

Mishra (1995) = Mishra, Veena: „Adjustement in the 1980s“, in: Agraval, Pradeep u.a. (Hg.): Economic Restructuring in East Asia and India. Perspectives and Policy Reform. Basingstoke: Macmillan 1995, 103-133.

Mitchell (1977) = Mitchell, Brian R.: ,Statistischer Anhang 1700-1914“, in: Cipolla, Carlo M./Borchardt, Knut (Hg.): Die Entwicklung der industriellen Gesellschaften (Europäische Wirtschaftsgeschichte 4). Stuttgart: Gustav Fischer 1977, 485-534.

Mitchell (1980) = Mitchell, Brian R.: ,Statistischer Anhang 1920-1970“, in: Cipolla, Carlo M./Borchardt, Knut (Hg.): Die europäischen Volkswirtschaften im zwanzigsten Jahrhundert (Europäische Wirtschaftsgeschichte 5). Stuttgart: Gustav Fischer 1980.

Mitchell (1992) = Mitchell, Brian R.: International Historical Statistics: Europe, 1750-1988. Basingstoke: Macmillan 1992.

Mitchell (1998) = Mitchel, Brian R.: International Historical Statistics: The Americas, 17501993. London: Macmillan 1998.

Mitchell (2003) = Mitchell, Brian. R.: International Historical Statistics: Europe, 1750-2000. Basingstoke: Palgrave Macmillan 2003 
Mitchell (2007) = Mitchell, Brian R.: International Historical Statistics: Africa, Asia \& Oceania, 1750-2005. New York: Palgrave Macmillan 2007.

Mitterauer (2003) = Mitterauer, Michael: Warum Europa? Mittelalterliche Grundlagen eines Sonderweges. München: Beck 2003

Moreno-Brid/Ros (2009) = Moreno-Brid, Juan Carlos/Ros Jamie: Development and Growth in the Mexican Economy: A Historical Perspective. Oxford: Oxford University Press 2009.

Moyo (2011) = Moyo, Dambisa: Dead Aid. Warum Entwicklungshilfe nicht funktioniert und was Afrika besser machen kann. Berlin: Haffmans \& Tolkemitt 2011.

Myers (1986) = Myers, Ramon H.: „The Economic Development oft he Republic of China on Taiwan, 1965-1981“, in: Lau, Lawrence J (Hg.):Models of Development. A Comparative Study of Economic Growth in South Korea and Taiwan. San Francisco: ICS Press 1986, 13-64.

Nadal (1977) = Nadal, Jordi: „Der Fehlschlag der Industriellen Revolution in Spanien 1830-1914“, in: Cipolla, Carlo M./Borchardt, Knut (Hg.): Die Entwicklung der industriellen Gesellschaften (Europäische Wirtschaftsgeschichte 4). Stuttgart: Gustav Fischer 1977, 341-401.

Naya $(1988)$ = Naya, Seiji: „The Role of Trade Policies in the Industrialization of rapidly growing Asian developing countries“, in: Hughes, Helen (Hg.): Achieving Industrialization in East Asia. Cambridge: Cambridge University Press 1988, 64-94.

Newson (2006) = „The Demographic Impact of Colonization“, in: Bulmer-Thomas, Victor u.a. (Hg.): The Cambridge Economic History of Latin America, vol. 1 (The Colonial Era and the Short Nineteenth Century). Cambridge: Cambridge University Press 2006, 143-184.

Niemi (1997) = Niemi, Albert W.: Economic History: A Survey of the Major Issues. Chicago: Rand McNally College Publishing Company 1997.

Noor (1974) = Noor, Abdul Sami: Die Rolle des Außenhandels in der wirtschaftlichen Entwicklung Afghanistans. Diss. Bonn 1974.

North (1961) = North, Douglass C.: The Economic Growth of the United States, 1790-1860. Upper Saddle River, N.J.:, Prentice Hall, 1961

North $(1988)=$ North, Douglass C.: Theorie des institutionellen Wandels. Eine neue Sicht der Wirtschaftsgeschichte. Tübingen: Mohr 1988.

North $(2005)=$ North, Douglass C. : Understanding the Process of Economic Change. Princeton: Princeton University Press 2005..

Nove (1982) = Nove, Alec: An Economic History of the U.S.S.R. Harmindsworth: Penguin Books 1982. 
O’Brien (1982) = O’Brien, Patrick: „European Economic Development: The Contribution of the Periphery“, in: The Economic History Review 35 (1982), 1-18.

Ochel (1978) = Ochel, Wolfgang: Die Industrialisierung der arabischen OPEC-Länder und des Iran. Erdöl und Erdgas im Industrialisierungsprozess (Ifo-Studien zur Entwicklungsforschung 5). München: Weltforum 1978.

OECD Australia = OECD Economic Surveys. Australia . Paris 1976-2001.

OECD (2002) = OECD Economic Surveys 2001-2002. Russian Federation. Paris 2002.

OECD Turkey = OECD Economic Surveys. Turkey. Paris 1990/91-2002.

Osterhammel (2010) = Osterhammel, Jürgen: Die Verwandlung der Welt. Eine Geschichte des 19. Jahrhunderts. München: Beck 2010.

Outlook (2013) = International Monetary Fund (Hg.): Regional Economic Outlook: SubSaharan Africa - Keeping the Pace. 2013 (Regional Economic Outlook, October 2013: Sub-Saharan...https://www.imf.org/external/pubs/.../longres.aspx?s...)

Paolera/Taylor (2003) = Paolera, Gerardo della/Taylor, Alan M. (Hg.): A New Economic History of Argentina. Cambridge: Cambridge University Press 2003.

Pascha (1990) = Pascha Werner: „Dritte Welt im Aufbruch: Ostasiatische Schwellenländer als neue weltwirtschaftliche Entwicklungspole?“, in: Cassel, Dieter (Hg.): Wirtschaftssysteme im Umbruch. Sowjetunion, China und industrialisierte Marktwirtschaften zwischen internationalem Anpassungszwang und nationalem Reformbedarf. München: Vahlen 1990, 92-120.

Pascha (2005) = Pascha, Werner: „Südkoreas Wirtschaft“, in: Kern, Thomas/Köllner, Patrick (Hg.): Südkorea und Nordkorea. Einführung in Geschichte, Politik, Wirtschaft und Gesellschaft. Frankfurt am Main: Campus 2005, 87-120.

Phyllis (1998) = Phyllis, Deane: „Die Industrielle Revolution in Großbritannien“, in: Porter, R./Teich, M. (Hg.): Die Industrielle Revolution in England, Deutschland und Italien. Berlin: Wagenbach 1998, 33-57

Pierenkemper (1996) = Pierenkemper, Toni: Umstrittene Revolutionen. Die Industrialisierung im 19. Jahrbundert. Frankfurt am Main: Fischer Taschenbuch 1996.

Pilat (2002) = Pilat, Dirk: "The Long-Term Performance of the Japanese Economy“, in: Maddison, Angus (Hg.): The Asian Economies in the Twentieth Century. Cheltenham: Edward Elgar 2002, 180-225.

Pockney $(1991)=$ Pockney, Bertram Patrick: Soviet Statistics since 1950. Dartmouth: Aldershot 1991. 
Pollard (1981) = Pollard, Sidney; Peaceful Conquest. The Industrialization 1760-1970. Oxford: Oxford University Press 1981.

Pomeranz, Kenneth (2000): The Great Divergence: China, Europe and the Making of the Modern World Economy. Princeton: Princeton University Press 2000.

Pomfret $(1996)=$ Pomfret, Richard: Asian Economies in Transition. Reforming Centrally Planned Economies. Cheltenham: Edward Elgar 1996.

Quest Trend Magazin = http://www.quest-trendmagazin.de/wirtschaftstrends/china/ industrieproduktion.html

Raffer (1996) = Raffer, Kunibert: „Exportorientierte Entwicklung und Weltmarkt Das Beispiel der asiatischen ,Tiger", “ in: Binderhofer, Edith u.a. (Hg.): Das parifische Jabrbundert? Wirtschaftliche, ökologische und politische Entwicklung in Ost- und Südostasien (Beiträge zur Historischen Sozialkunde 10). Wien: Südwind 1996, 41-58.

Randall (1977a) = Randall, Laura: A Comparative Economic History of Latin America: 15001914, vol. 1 (Mexico). Ann Arbor: University Microfilms International 1977.

Randall (1977b) = Randall, Laura: A Comparative Economic History of Latin America: 15001914, vol. 2 (Argentina). Ann Arbor: University Microfilms International 1977.

Randall $(1977 \mathrm{c})=$ Randall, Laura: A Comparative Economic History of Latin America: 15001914, vol. 3 (Brazil). Ann Arbor: University Microfilms International 1977.

Randall $(1977 \mathrm{~d})=$ Randall, Laura: A Comparative Economic History of Latin America: 15001914, vol. 4 (Peru). Ann Arbor: University Microfilms International 1977.

Ranis (1979) = Ranis, Gustave: „Industrial Development“, in: Galenson, Walter (Hg.): Economic Growth and Structural Change in Taiwan. The Postwar Experience of the Republic of China. Ithaca: Cornell University Press 1979, 206-262.

Raupach (1964) = Raupach, Hans: Geschichte der Sowjetwirtschaft. Reinbeck bei Hamburg: Rowohlt Taschenbuch 1964.

Reichart (1993) = Reichart Thomas: Städte obne Wettbewerb. Eine Untersuchung über die Ursachen der Ballung von Wirtschaft und Bevölkerung in Südkorea und in Kolumbien (Beiträge zur Wirtschaftspolitik. 58). Bern: Haupt 1993.

Resch, Andreas (2011): „Neue Institutionenökonomik und Wirtschaftsgeschichte“, in: Cerman, Markus u.a. (Hg.): Wirtschaft und Gesellschaft Europa 1000-2000 (VGS Studientexte 2). Wien: StudienVerlag, 48-56.

Riedel (2009) = Riedel, James: „Economic Development in East Asia: doing what comes naturally", in: Hughes, Helen (Hg.): Achieving Industrialization in East Asia. Cambridge: Cambridge University Press 1988, 1-38. 
Roberts (1986) = Roberts, A. D.: The Cambridge History of Africa, vol. 7 (c. 1905-c.1940). Cambridge: Cambridge University Press 1986.

Rocchi $(2005)=$ Rocchi, Fernando: Chimneys in the Desert: Industrialization in Argentina During the Export Boom Years, 1870-1930. Stanford: Stanford University Press 2005.

Röpke (1982) = Röpke, Jochen: Die unterentwickelte Freibeit. Wirtschaftliche Entwicklung und unternehmerisches Handeln in Indonesien (Organisation und Kooperation in Entwicklungsländern 20). Göttingen: Vandenhoeck \& Ruprecht 1982.

Roesler (2009) = Roesler, Jörg: Kompakte Wirtschaftsgeschichte Lateinamerikas vom 18. Jahrbundert bis zum 21. Jahrhundert. Leipzig: Leipziger Uni-Verlag 2009.

Ros/Bouillon (2002) = Ros, Jaime/Bouillon, César: „Mexico: trade liberalization, growth, inequality and poverty“, in: Vos, Rob u. a. (Hg.): Economic Liberalization, Distribution and Poverty. Latin America in the 1990s. Cheltenham: Edward Elgar 2002, 347-389.

Rothermund (1985) = Rothermund, Dieter: Indiens wirtschaftliche Entwicklung: von der Kolonialherrschaft bis zur Gegenwart. Paderborn: Schöningh 1985.

Rule, J. (1992): The Vital Century. England's Developing Economy, 1714-1815. London: Routledge 1992.

Sachs (2002) = Sachs, Jeffrey: „Bemerkungen $\mathrm{zu}$ einer neuen Soziologie der wirtschaftlichen Entwicklung“, in: Huntington, Samuel P./Harrison, Lawrence E. (Hg.): Streit um Werte. Wie Kulturen den Fortschrittprägen. Hamburg: Europa Verlag 2002, $57-74$.

Sachs (2005) = Sachs, Jeffrey D.: The End of Poverty. How We Can Make It Happen in Our Lifetime. London: Penguin Books 2005.

Salisbury (1996) = Salisbury, Neal: „The History of Native Americans from Before the Arrival of the Europeans and Africans Until the American Civil War", in: Engerman, Stanley L./Gallman, Robert E. (Hg.). The Cambridge Economic History oft he United States, vol. 1 (The Colonial Era). Cambridge: Cambridge University Press 1996, 1-52.

Salvatore/Nowland (2003) = Salvatore, Ricardo D./Nowland, Carlos: „Between Independence and the golden age: The early Argentine economy“, in: Paolera, Gerardo della/Taylor, Alan M. (Hg.): A New Economic History of Argentina. Cambridge: Cambridge University Press 2003, 19-45.

Salvucci (2006) = Salvucci, Richard: „Export-Led Industrialization“, in: Bulmer-Thomas, Victor u.a. (Hg.). The Cambridge Economic History of Latin America, vol. 2 (The Long Twentieth Century). Cambridge: Cambridge University Press 2006, 249-292.

Sautter (2000) = Sautter, Udo: Geschichte Kanadas. München: Beck 2000. 
Schmid (2013) = Schmid, Dominik: Der ländliche außerlandwirtschaftliche Sektor in Thailand und Vietnam - Struktur, Krisenanfälligkeit und institutionelles Umfeld (Giessener Geographische Schriften 83). Bonn: Scientia Bonnensis 2013

Schmidt (1974) = Schmidt, Waltraud: „Zu den Beziehungen zwischen dem Urbanisierungsprozess und der Herausbildung des inneren Marktes in Indien“, in: Jabrbuch für Wirtschaftsgeschichte 1974, II, 83-97.

Schuman (2009) = Schuman, Michael: The Miracle. The Epic Story of Asia's Quest for Wealth. New York: Harper Business 2009.

Schuster $(1979)=$ Schuster, Wolfgang: Wirtschaftsgeographie Saudi Arabiens mit besonderer Berücksichtigung der staatlichen Wirtschaftslenkung (Dissertationen der Wirtschaftsuniversität Wien 27). Wien: VWGÖ 1979.

Scitovsky $(1986)=$ Scitovsky, Tibor: „Economic Development in Taiwan and South Korea, 1965-1981“, in: Lau, Lawrence J (Hg.): Models of Development. A Comparative Study of Economic Growth in South Korea and Taiwan. San Francisco: ICS Press 1986, 135-195.

Sen $(1995)=$ Sen, Kunal: „Stabilization with Growth“, in: Agraval, Pradeep u.a. (Hg.): Economic Restructuring in East Asia and India. Perspectives and Policy Reform. Basingstoke: Macmillan 1995, 134-158.

Senghaas (1981) = Senghaas, Dieter (Hg.): Peripherer Kapitalismus. Analysen über Abhängigkeit und Unterentwicklung. Frankfurt am Main: Suhrkamp 1981.

Senghaas, Dieter (1982): „Dissoziation und autozentrierte Entwicklung. Eine entwicklungspolitische Alternative für die Dritte Welt“, in: Senghaas, Dieter (Hg.): Kapitalistische Weltökonomie. Kontroversen über ibren Ursprung und ibre Entwicklungsdynamik. Frankfurt am Main: Suhrkamp, 376-412.

Serrao/Thomas $(1985)=$ Serrao, Joel/Thomas, Gerog: „Portugal 1830-1910“, in: Fischer, Wolfram (Hg.): Handbuch der europäischen Wirtschafts- und Sozialgeschichte, Bd. 5 (Europäische Wirtschafts- und Sozialgeschichte von der Mitte des 19. Jahrbunderts bis zum Ersten Weltkrieg). Stuttgart: Klett-Cotta, 687-704.

Siddiqui (1997) = Siddiqui, Shamim A. u.a.: „Economic and social policies of Brunei“, in: Wahid, Abu N. (Hg.): The ASE AN Region in Transition. Aldershot: Ashgate 1997, 1-23. Siew-Yean/Zainal-Abidin (1999) = Siew-Yean, Tham/Zainal-Abidin, Mahani: „Industrial Institution: The Case of Malaysia“, in: Barlow, Colin (Hg.):Institutions and Economic Change in Southeast Asia. The Context of Development from the 1960s to the 1990s. Cheltenham: Edward Elgar 1999, 55-71. 
Shoup (1981) = Shoup, Paul S.: The East European and Soviet Data Handbook. Political, Social, and Developmental Indicators, 1945-1975. New York: Columbia University Press 1981.

Sivasubramonian $(2002)=$ Sivasubramonian, Siva: „Twentieth Century Economic Performance in India“, in:

Skidmore/Smith (2001) = Skidmore, Thomas E./Smith, Peter H.: Modern Latin America. Oxford: Oxford University Press 2001.

Sowjetunion (1992) = Statistisches Bundesamt (Hg.): Sowjetunion 1980-1991. Bilanz der letzten Jahre. Wiesbaden 1992.

Sri Lanka Industry Country Studies = http://countrystudies.us/sri-lanka/52.htm

Stahl (Tabellen und Grafiken) = http://de.wikipedia.org/wiki/Stahl/Tabellen_und_ Grafiken

State of World Population (2010) = United Nations Population Fund (Hg.): State of World Population 2010.

Statistisches Jahrbuch = Statistik Austria (Hg.): Statistisches Jabrbuch Österreichs 1993-2013. Wien: Verlag Österreich GmbH 1993-2013.

Sub-Saharan Africa (1989) = The World Bank (Hg.): Sub-Sabaran Africa. From Crisis to Sustainable Growth. Washington, D.C. 1989.

Suh (1978) = Suh, Sang-Chul: Growth and Structural Changes in the Korean Economy 1910-1940 (Harvard East Asian Monographs 83). Cambridge, Mass.: Harvard University Press 1978

Summerhill (2006) = Summerhill, William R.: „The Development of Infrastructrure“, in: Bulmer-Thomas, Victor u.a. (Hg.). The Cambridge Economic History of Latin America, vol. 2 (The Long Twentieth Century). Cambridge: Cambridge University Press 2006, 293-326. Sutter/Menck (1973) = Sutter, Rolf/Menck, Karl Wolfgang: Investieren in Südostasien. Investitionsbedingungen in Indien, Indonesien, Korea, Malaysia, Philippinen, Singapur, Sri Lanka, Taiwan, Thailand. Hamburg: Verlag Weltarchiv 1973.

Taiwan Data Book (2013) = Council for Economic Planning and Development (Hg.): Taiwan Statistical Data Book. Taipei 2013

Taylor $(2003)=$ Taylor, Jean Gelman: Indonesia. Peoples and Histories. New Haven: Yale University Press 2003.

Textilindustrie in Bangladesch = de.wikipedia.org/wiki/Textilindustrie_in_Bangladesch Thorp (1998) = Thorp, Rosemary: Progress, Poverty and Exclusion: An Economic History of Latin America in the 20th Century. Washington, D.C. 1998.

Tiyambe (1993) = Tiyambe, Zeleza Paul: A Modern Economic History of Africa, vol 1 (The Nineteenth Century). Oxford: CODESRIA 1993. 
Tischner (1981) = Tischner, Helmut: Die wirtschaftliche Entwicklung Indiens in den Jahren 1951-1978 unter besonderer Berücksichtigung der Auslandshilfe (Volkswirtschaftliche Schriften 303). Berlin: Duncker \& Humblot 1981.

Transition report (2003) = European Bank for Reconstruction and Development (Hg.): Transition report 2003. Integration and regional cooperation. London 2003.

Tucher (1999) = Tucher, Mathias von: Die Rolle der Auslandsmontage in den internationalen Wertschöpfungsnetzwerken der Automobilhersteller (Wirtschaft und Raum 5). München: VVFVerlag Florentz 1999.

Uhlig/Lange (1983) = Uhlig, Christian/Lange, Michael: Internationale Produktionskooperation im Vorderen Orient. Joint Ventures und andere Formen unternehmerischer Zusammenarbeit. Tübingen: Erdmann 1983.

Urbanisierung (2011) = Urbanisierung in Afrika Informationen des BMZ (PDF 276 KB) Valmonte $(2007)=$ Valmonte, Ligaya: Workeforce Development in the Philippines. Policies and Practices. Tokio: Asian Development Bank 2007.

Vittinghoff $(1990)=$ Vittinghoff, Friedrich: ,Wirtschaft und Gesellschaft des Imperium Romanum. Gesellschaft“, in: Vittinghoff, Friedrich (Hg.): Handbuch der europäischen Wirtschafts- und Sozialgeschichte, Bd. 1 (Europäische Wirtschafts- und Sozialgeschichte in der römischen Kaiserzeit). Stuttgart: Klett-Cotta 1990), 161-373.

Vorlaufer $(2009)=$ Vorlaufer, Karl: Südostasien. Brunei, Indonesien, Kambodscha, Laos, Malaysia, Myanmar, Osttimor, Philippinen, Singapur, Thailand, Vietnam. Darmstadt: Wissenschaftliche. Buchgesellschaft 2009.

Vos (2002) = Vos, Rob u. a. (Hg.): Economic Liberalization, Distribution and Poverty. Latin America in the 1990s. Cheltenham: Edward Elgar 2002.

Vries (1984) = Vries, Jan de: European Urbanization 1500-1800. London: Methuen 1984. Vries (2011) = Vries, Peter: „Europa und die Welt“, in: Cerman, Markus u.a. (Hg.): Wirtschaft und Gesellschaft Europa 1000-2000 (VGS Studientexte 2). Wien: StudienVerlag 2011, 411-438.

Wagener (1972) = Wagener, Hans-Jürgen: Wirtschaftswachstum in unterentwickelten Gebieten. Ansätze zu einer Regionalanalyse der Sowjetunion (Veröffentlichungen des Osteuropa-Institutes München: Wirtschaft und Gesellschaft 12). Berlin: Duncker \& Humblot 1972.

Wallerstein $(1989)=$ Wallerstein, Immanuel:The Modern World-System, Bd. 3 (The Second Great Expansion of the Capitalist World-Economy, 1730-1840's). San Diego: Academic Press 1989. 
Weber (2006) = Weber, Max: Die protestantische Ethik und der „Geist“ des Kapitalismus. Textausgabe auf der Grundlage der ersten Fassung von 1904/05 mit einem Verzeichnis der wichtigsten Zusätze und Veränderungen aus der zweiten Fassung von 1920. München: FinanzBuch-Verlag 2006.

Weigl (2011) = Weigl, Andreas „Wirtschafts- und Sozialpolitik“, in: Cerman, Markus u.a. (Hg.): Wirtschaft und Gesellschaft Europa 1000-2000 (VGS Studientexte 2). Wien: StudienVerlag 2011, 305-322.

Weitensfelder (2011) = Weitensfelder, Hubert: „Technologische Entwicklungen“, in: Cerman, Markus u.a. (Hg.): Wirtschaft und Gesellschaft Europa 1000-2000 (VGS Studientexte 2). Wien: StudienVerlag 2011, 161-177.

Weitz (1987) = Weitz, Bernd O.: Die Türkei. Soziale, ökonomische und politische Strukturen. Eine Handreichung zum besseren Verständnis türkischer Mitbürger. Essen: Die Blaue Eule 1987.

Welt in Zahlen (Fernsehgeräte) $=$ http://www.welt-in-zahlen.de/laendervergleich. phtml?indicator $=115$.

Welt in Zahlen (Computer) $=$ http://www.welt-in-zahlen.de/laendervergleich. phtml?indicator $=117$.

Welt in Zahlen (Industrieproduktion) = http://www.welt-in-zahlen.de/laendervergleich. phtml?indicator $=64$.

Welt in Zahlen (PKW) = http://www.welt-in-zahlen.de/laendervergleich. phtml?indicator $=126$.

Wikipedia $($ Asien $)$ http://de.wikipedia.org/wiki/Asien

Wikipedia (Bangladesch) = de.wikipedia.org/wiki/Bangladesch

Wikipedia $($ Kanada $)=$ de.wikipedia.org/wiki/Kanada

Wikipedia $($ Kontantinopel $)=$ de.wikipedia.org/wiki/Konstantinopel

Wikipedia (Mongolei) = de.wikipedia.org/wiki/Mongolei

Wikipedia $($ Pakistan $)=$ de.wikipedia.org/wiki/Pakistan

Wikipedia (Papua-Neuguinea) = de.wikipedia.org/wiki//Papua-Neuguinea

Wikipedia (Russland) = de.wikipedia.org/wiki/Russland

Wikipedia $($ Sri Lanka) $=$ de.wikipedia.org/wiki/Sri_Lanka

Wirtschaftszahlen zum Automobil = http://de.wikipedia.org/wiki/Wirtschaftszahlen zum Automobil

WKO Länderprofile $=$ wko.at $/$ statistik/laenderprofile $/$ lp-moldawien.pdf wko.at/statistik/laenderprofile/lp-russland.pdf 
wko.at/statistik/laenderprofile/lp-ukraine.pdf

wko.at/statistik/laenderprofile/lp-weissrussland.pdf

Wolffsohn (1991) = Wolffsohn, Michael: Israel. Grundwissen - Länderkunde. Geschichte Politik - Gesellschaft - Wirtschaft. Opladen: Leske + Budrich 1991.

Wontroba/Menzel (1978) = Wontroba, Gerd/Menzel, Ulrich: Stagnation und Unterentwicklung in Korea. Von der Yi-Dynastie zur Peripherisierung unter japanischer Kolonialherrschaft (Transfines 9). Meisenheim am Glan: Hain 1978.

Woronoff (1992) = Woronoff, Jon: Asia's ,Miracle'Economies. New York: Armonk 1992.

Wu (2002) = Wu, Harry X.: „Industrial Output and Labour Productivity in China 1949-

94: A Reassessment", in: Maddison, Angus (Hg.): The Asian Economies in the Twentieth Century. Cheltenham: Edward Elgar 2002, 82-101.

Zeleza (1993) = Zeleza, Paul Tiyambe: A Modern Economic History of Africa, vol 1 (The Nineteenth Century). Oxford: CODESRIA 1993.

Zimmermann (2003) = Zimmermann, Gerd R.: Indonesien. Eine geographische Landeskunde. Nackenheim am Rhein: Edition Matahari 2003.

Zingel $(1979)$ = Zingel, Wolfgang-Peter: Die Problematik regionaler Entwicklungsunterschiede in Entwicklungsländern: eine theoretische und empirische Analyse, dargestellt am Beispiel Pakistans unter Verwendung der Hauptkomponentenmethode. Stuttgart: Steiner 1979. 


\section{Ortsregister}

\begin{tabular}{|c|c|c|c|}
\hline Aachen & $195 \mathrm{f}$. & Andalusien & 13 \\
\hline Abidjan & 210 & Angers & $195 \mathrm{f}$. \\
\hline Addis Abeba & 210 & Angola & $115,209,211 \mathrm{f}$. \\
\hline Adelaide & 185,221 & Ankara & 133,214 \\
\hline \multirow[t]{2}{*}{ Ägypten } & 107-109, 112-117, & Anshan & 182,220 \\
\hline & $119,209-211$ & Antequera & 196 \\
\hline Äquatorialguinea & 119 & Antwerpen & 197 \\
\hline Äthiopien & 113,118 f., 209-211 & Aostatal & 60 \\
\hline \multirow[t]{2}{*}{ Afghanistan } & $121,139,142,147-$ & Apulien & 60 \\
\hline & $150,215 \mathrm{f}$. & Aquileia & 32 \\
\hline \multirow[t]{3}{*}{ Afrika } & 7, 10, 21 f., 68, 83, & Arabisches Meer & 121 \\
\hline & 105-119, 122, 127, & Arezzo & 195 \\
\hline & $167,209-211$ & Argentinien & 86 f., 89 f., 94-99, \\
\hline Ahmedabad & $139,143,216$ & & 101 f., 135, 204, \\
\hline Aix-en-Provence & 196 & & $206-208$ \\
\hline Al-Khobar & 133 & Arles & 196 \\
\hline Albanien & 59, 63 f., 197 f., 201 & Armenien & $131,135,138,213$ \\
\hline Albany & 72 & & 215 \\
\hline Alberta & $80-82$ & Arras & 195 \\
\hline Alexandria & $105,108,210$ & Aserbaidschan & 131, 135 f., 138, \\
\hline \multirow[t]{2}{*}{ Algerien } & 106-109, 112-116, & & 213,215 \\
\hline & $209-211$ & Asien & $7,10,22,23,121-$ \\
\hline Algier & 105,210 & & 184,212 \\
\hline Alma Ata & 124 & Athen & 49, 195, 199 \\
\hline Alpen & $34 \mathrm{f}$. & Atlanta & 203 \\
\hline \multirow[t]{3}{*}{ Amerika } & $7,10,17,19-22,67-$ & Atlantik & 68 \\
\hline & $103,83,106,163$ & Auckland & 188,221 \\
\hline & 207 & Augsburg & $195 \mathrm{f}$. \\
\hline Amiens & $195 \mathrm{f}$. & Australien & 7, 11, 23-26, 79, 81, \\
\hline Amsterdam & $36,41,197 \mathrm{f}$. & & 154, 171, 185-188, \\
\hline Anaheim & 203 & & 221 \\
\hline
\end{tabular}




\begin{tabular}{|c|c|c|c|}
\hline Avignon & 196 & Bhutan & 149 f., 215 \\
\hline \multirow[t]{2}{*}{ Ayutthaya } & 160 & Bihar & 143 \\
\hline & & Birmingham & 45, 196, $198 \mathrm{f}$. \\
\hline Bagdad & 133,214 & Bischkek & 122 \\
\hline Bahia & 84 & Bogotá & $99,205 \mathrm{f}$. \\
\hline Bahrain & $138,214 \mathrm{f}$. & Bolgar & 195 \\
\hline Baku & 131,214 & Bolivien & $23,98,102,205$ \\
\hline Balkan & 119 & & $207 \mathrm{f}$ \\
\hline Baltikum & 64 & Bologna & $195 \mathrm{f}$. \\
\hline Baltimore & $\begin{array}{l}68,70,74,88,201 \\
203\end{array}$ & Bombay & $\begin{array}{l}\text { 14, } 139,143 \text { f., } 146 \\
\text { f., } 216\end{array}$ \\
\hline Bandung & 164,217 & Bordeaux & 195 f., 198 \\
\hline Bangalore & 143,216 & Bosnien- & \\
\hline Bangkok & 159-161, 217 & Herzegowina & 116,201 \\
\hline Bangladesch & $\begin{array}{l}121,142,145,147- \\
150,215 \mathrm{f} .\end{array}$ & Boston & $\begin{array}{l}\text { 17, 68, } 70 \text { f., 201, } \\
203\end{array}$ \\
\hline Baotou & 220 & Botswana & $118 \mathrm{f}$ \\
\hline Barcelona & 195 f., 198 f. & Bozen & 60 \\
\hline Basilikata & 60 & Bradford & 198 \\
\hline Baskenland & 60 & Brasília & 206 \\
\hline Bayern & 13 & Brasilien & 84, 86-89, 94-99, \\
\hline Beirut & 133,214 & & 101 f., 135, 204, \\
\hline Bekasi & 164 & & $206-208$ \\
\hline Belém & 87,205 & Braunschweig & 196 \\
\hline \multirow[t]{3}{*}{ Belgien } & $25,36,43$ f., 47-49, & $\mathrm{BRD}$ & s. Deutschland \\
\hline & $51-54,57,60,63$ & Bremen & 196 \\
\hline & 79, 197, 199 f., 202 & Brescia & $195 \mathrm{f}$. \\
\hline Belgrad & $195 \mathrm{f}$. & Breslau & 41, 196, 198 \\
\hline Belo Horizonte & 99,206 & Brest & 196 \\
\hline Belutschistan & 149 & Brisbane & 185,221 \\
\hline Bergamo & 196 & Bristol & 196,198 \\
\hline \multirow[t]{2}{*}{ Berlin } & $14,17,36,45,196$ & Britisch-Kolumbien & $80 \mathrm{f}$. \\
\hline & $198 \mathrm{f}$ & Britische Inseln & 31,43 \\
\hline Besançon & 196 & Brügge & 195,197 \\
\hline
\end{tabular}




\begin{tabular}{|c|c|c|c|}
\hline Brüssel & $197 \mathrm{f}$. & Chennai & s. Madras \\
\hline Brunei & 157,218 & Chiba & 165 \\
\hline Budapest & $41,49,196,198 \mathrm{f}$. & Chicago & 17,70 f., 83, 88, \\
\hline \multirow[t]{2}{*}{ Buenos Aires } & $14,83,87-89,93$ & & 201,203 \\
\hline & 98 f., 205 f. & Chile & 86, f., 89 f., 94-97, \\
\hline Buffalo & $72,201,204$ & & $102,204,206-208$ \\
\hline Bukarest & 196,198 & China & $11,13,121,148$ \\
\hline \multirow[t]{2}{*}{ Bulgarien } & 51 f., 54, 60, 64, & & $149,151,163$ \\
\hline & 109, 197, 199, $201 \mathrm{f}$. & & 171 f., 174-176, \\
\hline Burgos & 195 & & 179-184, 219 \\
\hline Burkina Faso & $118,209-211$ & Chittagong & 216 \\
\hline Bursa & 133 & Chon Buri & 160 \\
\hline Burundi & $118 \mathrm{f}$. & Chongqing & $180,183,220$ \\
\hline Busan & 177,220 & Christchurch & 188 \\
\hline Butterworth & 155 & Cincinnati & 201,204 \\
\hline \multirow[t]{2}{*}{ Byzantinisches Reich } & 33 & Clermont-Ferrand & 196 \\
\hline & & Cleveland & 201,203 \\
\hline Cádiz & 32,196 & Colombo & 151 \\
\hline Caen & 196 & Columbus & 201,204 \\
\hline Cagliari & 196 & Córdoba & $34,195 \mathrm{f}$. \\
\hline Calabarzon & 162 & Córdoba (Argent.) & 87,205 \\
\hline Calgary & $81 \mathrm{f}$. & Cornwall & 60 \\
\hline Cali & 99,206 & Costa Rica & 205,208 \\
\hline Caloocan City & 162 & Cremona & $195 \mathrm{f}$. \\
\hline Campinas & 205 & Curitiba & 206 \\
\hline Caracas & 206 & & \\
\hline Cartagena & 196 & Da Nang & 162 \\
\hline Casablanca & 210 & Daegu & 177,220 \\
\hline Celebes & 164 & Dänemark & $44,49,52,54,57$ \\
\hline Central Luzon & 162 & & 197-200, 202 \\
\hline Ceylon & s. Sri Lanka & Dalian & $180,182,220$ \\
\hline Chachoengsao & 160 & Dallas & 203 \\
\hline Changchun & 220 & Damaskus & 214 \\
\hline Changsha & 220 & Dammam & 133 \\
\hline
\end{tabular}




\begin{tabular}{|c|c|c|c|}
\hline Danzig & 198 & Écija & 196 \\
\hline Davao City & 163 & Edinburgh & 196,198 \\
\hline DDR & s. Deutschland & Edmonton & $81 \mathrm{f}$ \\
\hline Delaware & 69 & Edo & s. Tokio \\
\hline Delhi & $143,147,216$ & Ekuador & $98,102,205-208$ \\
\hline \multicolumn{2}{|l|}{ Demokrat. Rep. } & El Salvador & $102,205,208$ \\
\hline Kongo & $119,209-211$ & Elburs-Gebirge & 132 \\
\hline Den Haag & 197 & Elfenbeinküste & $117,209-211$ \\
\hline Denver & 201,203 & England & $11,27,37,42,45 \mathrm{f}$. \\
\hline Detroit & 201,203 & & vgl. Großbritannien, \\
\hline \multicolumn{3}{|l|}{ Deutschland/BRD/ } & Ver. Königreich \\
\hline \multirow[t]{6}{*}{ DDR/Dt. Reich } & $13,18,25,28,31$ & Erfurt & 195 \\
\hline & $36,39,40,42-44$ & Erie-Kanal & 72 \\
\hline & $47-49,51-54,56-$ & Eriesee & 78 \\
\hline & $58,60,79,84,86$ & Eritrea & 119,210 \\
\hline & $114,174,179$ & Espírito Santo & 99 \\
\hline & 196 f., 199 f., 202 f. & Essen & 45 \\
\hline Dhaka & 216 & Estland & $59,61,200,202$ \\
\hline Dharavi & 146 & Europa & 7, 10 f.,16-26, 28, \\
\hline Dijon & 196 & & 29, 31-65, 67 f., 71, \\
\hline Dominik. Republik & $98,102,205,207$ & & 73, 75, 77-79, 83 f., \\
\hline Dortmund & 45 & & 86,94 f., 98, 100, \\
\hline Douai & $195 \mathrm{f}$. & & 102, 106, 113 f., \\
\hline Downpatrick & 196 & & $116,119,122,1$ \\
\hline Dresden & 196 & & 24 f., 127, 149, 151, \\
\hline Dschibuti & 116 & & $165,167,190,192$ \\
\hline Dschidda & 133,214 & & $195-200$ \\
\hline Dublin & $36,196,198$ & Extremadura & 61 \\
\hline Düsseldorf & 45 & & \\
\hline Duisburg & 45 & Faisalabad & 149,216 \\
\hline Durban & 107 & Fall River & 201 \\
\hline \multirow[t]{3}{*}{ Durrës } & 195 & Feodossija & $195 \mathrm{f}$. \\
\hline & & Ferner Osten & 122,125 \\
\hline & & Ferrara & $195 \mathrm{f}$. \\
\hline
\end{tabular}




\begin{tabular}{|c|c|c|c|}
\hline $\mathrm{Fez}$ & 105 & Grenoble & 196 \\
\hline Finnland & $\begin{array}{l}44,47,52,54,56, \\
198-200,202\end{array}$ & Griechenland & $\begin{array}{l}31,51 \text { f., 54, } 59 \text { f., } \\
62,64,109,196 \text { f., }\end{array}$ \\
\hline Florenz & $34,195 \mathrm{f}$ & & 199, $201 \mathrm{f}$ \\
\hline Florida & 69 & Groningen & 197 \\
\hline Fort Lauderdale & 204 & Großbritannien & 21 f., 24, 37-40, 42- \\
\hline Fortaleza & 206 & & $44,49,51-53,56$ \\
\hline Frankfurt am Main & 196 & & $60,73,79,84,86$ \\
\hline \multirow[t]{5}{*}{ Frankreich } & 11, 25, 31, 36, 39, & & 139, 149, 167, 196, \\
\hline & $40,42-44,47-49$ & & 200; vgl. England, \\
\hline & 51 f., 54, 56-58, 60, & & Ver. Königreich \\
\hline & $79,84,114,161$ & Guadalajara & $205 \mathrm{f}$ \\
\hline & 196 f., 199 f., 202 & Guangzhou & s. Kanton \\
\hline Fukuoka & 170,220 & Guatemala & $98,102,205,207$ \\
\hline Fushun & 220 & Guatemala City & 205 \\
\hline \multirow[t]{2}{*}{ Fuzhou } & 220 & Guayaquil & 206 \\
\hline & & Guinea & $119,209,211$ \\
\hline Gabun & 114,116 & Guinea Bissau & 119 \\
\hline Gambia & 116 & Guiyang & 220 \\
\hline Gaza & 213 & Gujranwala & 149 \\
\hline Genf & 196 & Gyeonggi-do & 177 \\
\hline Gent & 195, 197 f. & Gyeongsangbuk-do & 177 \\
\hline Genua & $\begin{array}{l}\text { 18, } 34 \text { f., 41, 46, } \\
195 \text { f., } 198\end{array}$ & Gyeongsangnam-do & 177 \\
\hline \multirow[t]{2}{*}{ Georgien } & $131,135,138,213$ & Haarlem & 197 \\
\hline & 215 & Habsburgermonarchie & s. Österreich-Ungarn \\
\hline \multirow[t]{2}{*}{ Ghana } & 111-113, 116, 209- & Haiderabad & 216 \\
\hline & 211 & Haifa & 131 \\
\hline Gizeh & 210 & Haiphong & 162 \\
\hline Glasgow & $45,49,196,198 \mathrm{f}$. & Haiti & 205,207 \\
\hline Gouda & 196 & Hamburg & 14, 196, $198 \mathrm{f}$. \\
\hline Granada & $34,195 \mathrm{f}$ & Hamilton & 81 \\
\hline Graz & 197 & Hangzhou & 182,220 \\
\hline Great Lakes & $72,76,78,204$ & Hanoi & 161 f., 217 \\
\hline
\end{tabular}




\begin{tabular}{|c|c|c|c|}
\hline Harbin & $180,183,220$ & Israel & 131, 133 f., 136, \\
\hline Havanna & $205 \mathrm{f}$. & & $138,213-215$ \\
\hline Himalaya & 150 & Istanbul & 130 f., 133, 214 \\
\hline Ho-Chi-Minh-Stadt & s. Saigon & Italien & $13,18,25$ f., 28,31 , \\
\hline Honduras & $102,205,207$ & & 35, 44, 46-49, 51 f., \\
\hline \multirow[t]{2}{*}{ Hongkong } & 153, 180, 182 f., & & 54, 57 f., 60 f., 64, \\
\hline & 220 & & 196 f., 199 f., 202 \\
\hline Houston & 203 & Izmir & 133 \\
\hline Huainan & 220 & & \\
\hline Hyderabad & 149 & Jaén & 196 \\
\hline \multirow[t]{2}{*}{ Hyōgo } & 165 & Jakarta & 164,217 \\
\hline & & Jamaika & 205,208 \\
\hline Iaşi & s. Jassy & Japan & $11,17,23-26,121$ \\
\hline Ibadan & 105 & & $153,165-172,174-$ \\
\hline Iberische Halbinsel & 31,35 & & $177,181,184,219$ \\
\hline Illinois & $72 \mathrm{f}$. & Jassy & 196 \\
\hline Incheon & 177,220 & Java & 164 \\
\hline Indiana & $72 \mathrm{f}$ & Jekaterinburg & $122-124$ \\
\hline Indianapolis & 201,204 & Jemen & $136-138,213,215$ \\
\hline \multirow[t]{4}{*}{ Indien } & $9,21,26,121,139$ & Jerez de la Frontera & 196 \\
\hline & 141-145, 147-150, & Jersey City & 201 \\
\hline & 179, 181, 184, & Jerusalem & 131 \\
\hline & $215 \mathrm{f}$. & Jilin & 220 \\
\hline Indochina & 161 & Jinan & 220 \\
\hline \multirow[t]{2}{*}{ Indonesien } & $21,121,153,157-$ & Johannesburg & $105,107,210$ \\
\hline & $159,162-164,217 \mathrm{f}$. & Johor & 155 \\
\hline Innsbruck & 32 & Johor Bahru & 155 \\
\hline Ipoh & 155 & Jordanien & $138,213,215$ \\
\hline \multirow[t]{2}{*}{ Irak } & 132 f., 136-138, & Jugoslawien & 51, 54, 57, 59, 197, \\
\hline & 213,215 & & 199 f., 203 \\
\hline Iran & $131-138,213-215$ & & \\
\hline \multirow[t]{2}{*}{ Irland } & 39, 44, 54, 57 f., 81, & Kabul & 150 \\
\hline & 196,198 f., 202 & Kairo & 105,107 f., 210 \\
\hline Island & 200 & Kalabrien & 60 \\
\hline
\end{tabular}




\begin{tabular}{|c|c|c|c|}
\hline Kalifornien & 74 & Kirgisistan & 121, 124, 126-129, \\
\hline Kaliningrad & 196 & & $212 \mathrm{f}$ \\
\hline \multirow[t]{2}{*}{ Kalkutta } & 139-141, 143, 147, & Kitakyūshū & 170,220 \\
\hline & 216 & Kitchener & 81 \\
\hline Kambodscha & 158 f., 161 f., 217 f. & Kōbe & $166,168,220$ \\
\hline Kamerun & $209-211$ & Kocaeli & 133 \\
\hline Kampanien & 60 & Köln & 34 f., 195 f., 198 \\
\hline Kampur & 139,216 & Kolumbien & 94-99, 101 f., 204, \\
\hline \multirow[t]{4}{*}{ Kanada } & 7, 11, 23 f., 26, 68, & & 206-208 \\
\hline & 71, 77-83, 86, 89, & Konstantinopel & $32 \mathrm{f}$. \\
\hline & $97,100,114,119$ & Kopenhagen & 41, 49, 197-199 \\
\hline & $\begin{array}{l}\text { 165, 171, 184, 188, } \\
\text { 192, } 207 \mathrm{f} .\end{array}$ & Korea & $\begin{array}{l}\text { 121, 173, 177; } \\
\text { vgl. Südkorea und }\end{array}$ \\
\hline Kanagawa & 165 & & Nordkorea \\
\hline Kansas & 69 & Korinth & 195 \\
\hline Kansas City & 201,204 & Kosovo & 196 \\
\hline Kantō & 165 & Krakau & 196 \\
\hline Kanton & $180,182,220$ & Kroatien & $62,200,202$ \\
\hline Kaohsiung & 178 & Kuala Lumpur & 155 f., 217 \\
\hline Kapstadt & $105,107,210$ & Kuba & $90,95,98,102$ \\
\hline Karatschi & $139,142,149,216$ & & 205,207 \\
\hline Karibische Inseln & 205 & Kunming & 220 \\
\hline Kasachstan & $121,123-129,212 \mathrm{f}$. & Kusnezk & 124 \\
\hline Kasan & 196 & Kuwait & $132,138,214 \mathrm{f}$. \\
\hline Katalonien & 13,46 & Kyoto & $165,168,220$ \\
\hline Katar & $132,138,214 \mathrm{f}$. & & \\
\hline Kathmandu & 150 & L'Aquila & 195 \\
\hline Kaukasus & 121 & La Paz & 205 \\
\hline Kawasaki & 220 & La Plata & 87,205 \\
\hline Kenia & $209-211$ & La Valletta & 196 \\
\hline Kibera & 112 & Lagos & 210 \\
\hline Kiew & 196 & Lahore & $139,142.149,216$ \\
\hline Kinki & 165 & Lanzhou & 220 \\
\hline Kinshasa & 210 & Laon & 195 \\
\hline
\end{tabular}




\begin{tabular}{|c|c|c|c|}
\hline Laos & 159, 161 f., 217 f. & Lucca & 196 \\
\hline \multirow[t]{3}{*}{ Lateinamerika } & 7, 24 f., 68, 82-103, & Lübeck & $195 \mathrm{f}$. \\
\hline & $106,167,204-206$ & Lüta & s. Dalian \\
\hline & 208 & Lüttich & 197 \\
\hline Leeds & 198 & Luxemburg & $54,59,154,199 \mathrm{f}$. \\
\hline Leiden & 197 & Lyon & 32, 36, 195 f., 198 \\
\hline Leipzig & 196 & & \\
\hline Lemberg & 196 & Macau & 183 \\
\hline Leningrad & s. Sankt Petersburg & Madagaskar & $119,209-211$ \\
\hline León & 195 & Madras & $139,143,147,216$ \\
\hline Lettland & $61,200,202$ & Madrid & $14,36,49,60,196$, \\
\hline Levante & 21,26 & & $198 \mathrm{f}$ \\
\hline Liaoning & 182 & Madura & 164 \\
\hline \multirow[t]{2}{*}{ Libanon } & $133,136,138,213$ & Madurai & 139 \\
\hline & 215 & Maharashtra & $143 \mathrm{f}$. \\
\hline Liberia & 119 & Mailand & $18,32,34-36,46$ \\
\hline \multirow[t]{2}{*}{ Libyen } & $107,109,112,114$ & & 49, 195 f., 198 f. \\
\hline & $117,211 \mathrm{f}$. & Maine & 69 \\
\hline Ligurien & 46 & Mainz & $195 \mathrm{f}$. \\
\hline Lille & $195 \mathrm{f}$. & Makassar & 164 \\
\hline Lima & $87,99,205 \mathrm{f}$. & Málaga & $195 \mathrm{f}$. \\
\hline Lissabon & 36, 195 f., 198 & Malawi & 113, 119, 209 f., \\
\hline Litauen & $61,196,200,202$ & & 212 \\
\hline Liverpool & 196 & Malaysia & $153,155,157-159$, \\
\hline Livorno & 196 & & $161,217 \mathrm{f}$. \\
\hline Löwen & 195 & Malediven & 215 \\
\hline Lombardei & 46,60 & Mali & $9,209,211 \mathrm{f}$. \\
\hline \multirow[t]{3}{*}{ London } & $14,17,35-37,40$ & Malta & 196,200 \\
\hline & 45 f., 190, 195, & Manchester & 45 f., 198 \\
\hline & $198 \mathrm{f}$ & Mandschurei & 181 \\
\hline London (Kanada) & 81 & Manila & 163, 217; vgl. \\
\hline Lorca & 196 & & Metro Manila \\
\hline Los Angeles & 74, 201, 203 & Manitoba & $80 \mathrm{f}$. \\
\hline Louisville & 201 & Mannheim & 196 \\
\hline
\end{tabular}




\begin{tabular}{|c|c|c|c|}
\hline \multirow{3}{*}{$\begin{array}{l}\text { Mantua } \\
\text { Marokko }\end{array}$} & \multicolumn{2}{|l|}{$195 \mathrm{f}}$. & \multirow{3}{*}{$\begin{array}{l}\text { 43, 46-65, 70, 76, } \\
84,90,97,99 \text { f., } \\
\text { 119, 125, 127, }\end{array}$} \\
\hline & \multirow{2}{*}{\multicolumn{2}{|c|}{$\begin{array}{l}107,111-117,209- \\
211\end{array}$}} & \\
\hline & & & \\
\hline Marseille & \multicolumn{2}{|l|}{ 41, 195 f., 198} & 130 f., 134-136, \\
\hline Mauritius & \multicolumn{2}{|l|}{$109,111,119$} & 139, 147, 157, \\
\hline Mazedonien & \multicolumn{2}{|l|}{$62-64,201,203$} & 167 f., 174,177 \\
\hline \multicolumn{3}{|l|}{ Mecklenburg- } & $184,188,195,199$ \\
\hline Vorpommern & 13 & Mittelmeer & $10,31,33,35,59$, \\
\hline Medan & \multicolumn{2}{|l|}{164,217} & $67,105,107,121$ \\
\hline Medellín & \multicolumn{2}{|l|}{99,206} & 135 \\
\hline Medina & 133 & Mittlerer Westen & 69, 73 f., 83, 203 \\
\hline Medina del Campo & 195 & Modena & 196 \\
\hline Mekka & 133 & Modica & 196 \\
\hline Melbourne & 185 f., 221 & Moldawien & 59, 63 f., 201, 203 \\
\hline Memphis & 201 & Mongolei & 121 f., 125-129, \\
\hline Messina & 195 & & $212 \mathrm{f}$ \\
\hline Metro Manila & 162 & Monterrey & $88,98,206$ \\
\hline Metz & $195 \mathrm{f}$. & Montevideo & $87,89,99,205$ f. \\
\hline México & 98 & Montpellier & $195 \mathrm{f}$. \\
\hline \multirow[t]{2}{*}{ Mexico City } & \multirow{2}{*}{$\begin{array}{l}83,87,89,98 \text { f., } \\
205 \text { f. }\end{array}$} & Montreal & $68,77-80,82$ f., 88 \\
\hline & & Mosambik & $118,209-211$ \\
\hline \multirow[t]{3}{*}{ Mexiko } & 21,67 f., 84, 86-90, & Moskau & $36,42,45$ f., 49, \\
\hline & \multicolumn{2}{|l|}{ 94-98, 101 f., 135, } & 195 f., 198 f. \\
\hline & & München & 196 \\
\hline Miami & 203 & Mukden & s. Shenyang \\
\hline Michigan & 72 & Multan & 149 \\
\hline Middelburg & 197 & Mumbai & s. Bombay \\
\hline Mideast (USA) & 69 f., 72, 76, 204 & Murcia & 196 \\
\hline Milwaukee & 201,204 & Myanmar & 121, 153, 158 f., \\
\hline Minas Gerais & 99 & & 161 f., $217 \mathrm{f}$ \\
\hline Mindanao & 163 & & \\
\hline Minneapolis & 201,203 & Nagoya & $166,168,170,220$ \\
\hline Mittelamerika & 205 & Nagpur & 143,216 \\
\hline Mitteleuropa & $18,24,26,35,40$ f., & & \\
\hline
\end{tabular}




\begin{tabular}{|c|c|c|c|}
\hline Naher Osten & $\begin{array}{l}\text { 21, 132; vgl. West- } \\
\text { asien, Vorderer } \\
\text { Orient }\end{array}$ & $\begin{array}{l}\text { Niger } \\
\text { Nigeria }\end{array}$ & $\begin{array}{l}119,209 \mathrm{f} . \\
21,105,113,118, \\
209-211\end{array}$ \\
\hline Nairobi & 112 & Nîmes & 196 \\
\hline Namibia & 109, 116, 119 & Nonthaburi & 159 \\
\hline Nanchang & 220 & Nordafrika & $10,111,116$ \\
\hline Nancy & 196 & Nordamerika & $17,19,22,29,67$ \\
\hline Nanjing & s. Nanking & & 88, 94 f., 97 f., 100, \\
\hline Nanking & $180,182,220$ & & 102, 113 f., 127, \\
\hline Nantes & 196 & & 190 \\
\hline Narbonne & 195 & Nordasien & 7, 121-129, 212 \\
\hline Navarra & 60 & Nordeuropa & $24,31,35$ f., 41, 53- \\
\hline Neapel & $\begin{array}{l}\text { 18, 34, 36, 46, } \\
195 \text { f., } 198 \text { f. }\end{array}$ & & $\begin{array}{l}55,58-65,76,97 \\
100,119,127,136,\end{array}$ \\
\hline Nepal & $\begin{array}{l}\text { 142, 147, 149-151, } \\
215 \mathrm{f} .\end{array}$ & & $\begin{array}{l}\text { 139, 147, 184, 188, } \\
199\end{array}$ \\
\hline Neu-Taipeh & 178 & Norditalien & 13, 18, 60; vgl. \\
\hline Neubraunschweig & 77 & & Oberitalien \\
\hline Neuengland & 69 f., 72, 76, 204 & Nordkorea & 173 f., 219; vgl. \\
\hline Neuschottland & 77 & & Korea \\
\hline Neuseeland & $7,79,185-188,221$ & Nordosten (USA) & 69-75, 82 f., 203 \\
\hline New Jersey & 69 & Norfolk & 204 \\
\hline New Orleans & $71,201,204$ & North Dakota & 69 \\
\hline New South Wales & 185 & Norwegen & $44,49,52,54,64$ \\
\hline New York & $69,72 \mathrm{f}$. & & $81,151,198-200$ \\
\hline \multirow[t]{2}{*}{ New York City } & $14,17,68,70,201$ & & 202 \\
\hline & 203 & Norwich & 196 \\
\hline Newark & 201,203 & Nova Iguaçu & 206 \\
\hline \multicolumn{2}{|c|}{ Newcastle upon Tyne 196} & Novgorod & 195 \\
\hline Newcastle (Austr.) & 185 & Novosibirsk & 122,124 \\
\hline Nicaragua & 205 f., 208 & Nürnberg & 196 \\
\hline Niederlande & $\begin{array}{l}11,36,44,47,49, \\
52,54,56,60,153, \\
197,199 \text { f., } 202\end{array}$ & Nueva León & 98 \\
\hline
\end{tabular}




\begin{tabular}{|c|c|c|c|}
\hline Oberitalien & $\begin{array}{l}\text { 25, } 35 \text { f., 46; vgl. } \\
\text { Norditalien }\end{array}$ & Pakistan & $\begin{array}{l}121,142,145,147- \\
151,215 \mathrm{f} .\end{array}$ \\
\hline Odessa & 198 & Palembang & 164 \\
\hline Odisha & s. Orissa & Palermo & 34, 36, 46, 195 f., \\
\hline \multirow[t]{3}{*}{ Österreich } & $25,28,49,52,54$ & & 198 \\
\hline & $56,58,160,197-$ & Palma di Mallorca & 196 \\
\hline & 200,202 & Panama & 205 f., 208 \\
\hline Österreich-Ungarn & $42-44,46-48$ & Papua-Neuguinea & 185 \\
\hline Ohio & $72 \mathrm{f}$ & Paraguay & $98,102,205,208$ \\
\hline Omaha & 201 & Paris & $17,34-37,40,45$ \\
\hline Oman & $138,213,215$ & & 195 f., 198 f. \\
\hline Omsk & 122,124 & Parma & $195 \mathrm{f}$ \\
\hline Ontario & $78,80-82$ & Paterson & 201 \\
\hline Ontariosee & 78 & Pavia & $195 \mathrm{f}$. \\
\hline Orient & 67 & Peking & 180,182 f., 220 \\
\hline Orissa & 143 & Pennsylvania & 69,73 \\
\hline Orléans & 196 & Perlfluss-Delta & 182 \\
\hline \multirow[t]{2}{*}{ Osaka } & 14, 17, 165 f., 168 & Perlis & 155 \\
\hline & 170,220 & Persien & 21 \\
\hline Oshawa & 81 & Persischer Golf & 135,157 \\
\hline Osmanisches Reich & 21 & Perth & 185,221 \\
\hline Ostasien & $\begin{array}{l}\text { 7, 121, 165-184, } \\
219 \mathrm{f} .\end{array}$ & Peru & $\begin{array}{l}67 \text { f., } 84,87,95, \\
97 \text { f., } 101 \text { f., 204, }\end{array}$ \\
\hline \multirow[t]{5}{*}{ Osteuropa } & $24,31,35,41,49-$ & & $206-208$ \\
\hline & $60,62-65,81,90$ & Perugia & 195 \\
\hline & 96 f., 99 f., 102. & Petaling Jaya & 155 \\
\hline & 109, 114 f.. 128, & Philadelphia & $17,68,70,201,203$ \\
\hline & 138, 157, 195, 199 & Philippinen & 121, 153, 157-159, \\
\hline Ostküste (USA) & 69 & & $162-164,217 \mathrm{f}$. \\
\hline Ottawa-Gatineau & 82 & Phnom Penh & 161 \\
\hline \multirow[t]{2}{*}{ Ozeanien } & $7,10,22,185-188$ & Phoenix & 204 \\
\hline & & Piacenza & $195 \mathrm{f}$. \\
\hline Padang & 164 & Piemont & 46 \\
\hline Padua & $32,195 \mathrm{f}$. & Piöngjang & 220 \\
\hline
\end{tabular}




\begin{tabular}{|c|c|c|c|}
\hline Pisa & 195 & Québec & $77-82$ \\
\hline Pittsburgh & 70, 201, 203 & Queensland & 185 \\
\hline Plains (USA) & 76,204 & Quezon City & 162 f., 217 \\
\hline Plowdiw & 195,197 & & \\
\hline Polazk & 195 & Rangun & 161,217 \\
\hline \multirow[t]{3}{*}{ Polen } & $44,51,54,57$ f., 60 & Rawalpindi & 149 \\
\hline & 62, 109, 196 f., & Rayong & $160 \mathrm{f}$. \\
\hline & 199 f., 202 & Recife & $87,99,205 \mathrm{f}$. \\
\hline Port Elizabeth & 107 & Regensburg & 196 \\
\hline Port Louis & 111 & Reims & 196 \\
\hline Port Said & 108 & Rennes & 196 \\
\hline Portland & 204 & Réunion & 109 \\
\hline Porto & 196 & Riad & 133,214 \\
\hline Porto Alegre & $87,205 \mathrm{f}$. & Rio de Janeiro & 84, 87-89, 98 f., \\
\hline \multirow[t]{3}{*}{ Portugal } & 11, 44, 51 f., 54, & & $205 \mathrm{f}$ \\
\hline & 59-61, 63 f., 109, & Rio Grande & 67,83 \\
\hline & 196 f., 199 f., 202 & Rischon LeZion & 133 \\
\hline Posen & 106 & Rochester & 201 \\
\hline Potosí & 23 & Rocky Mountains & 76,204 \\
\hline Prag & 60, 195 f., 198 & Römisches Reich & $31-33$ \\
\hline Preslav & 195 & Rom & 32 f., 35 f., 195 f., \\
\hline Pressburg & 60,196 & & $198 \mathrm{f}$. \\
\hline Pretoria & 107 & Rosario & $87,99,205$ \\
\hline Prinz-Edward-Insel & 77 & Rotterdam & 197 \\
\hline Prizren & 197 & Rouen & 41, 195 f., 198 \\
\hline Providence & 201 & Ruanda & $118,209,211$ \\
\hline Pskow & 195 & Ruhrgebiet & $18,28,45$ \\
\hline Puebla & 84,88 & Rumänien & 51 f., 54, 57, 59 f., \\
\hline Puerto Rico & 205,208 & & 62-64, 135, 196 f., \\
\hline Pune & 143,216 & & 199 f., 202 \\
\hline \multirow[t]{2}{*}{ Punjab } & 143,149 & Russe & 197 \\
\hline & & Russland/ & \\
\hline Qingdao & 220 & Russ. Föderation & $42,44,46$ f., 56-60, \\
\hline Qiqihar & 220 & & 63 f., 121-129, 135, \\
\hline
\end{tabular}




\begin{tabular}{|c|c|c|c|}
\hline \multirow{4}{*}{ 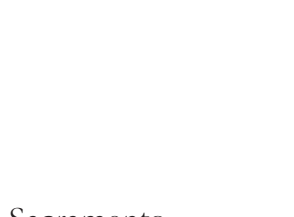 } & 174, 196, 199-202, & Sapporo & 170,220 \\
\hline & \multirow{3}{*}{$\begin{array}{l}\text { 212, vgl. Sowjet- } \\
\text { union }\end{array}$} & Saragossa & 196 \\
\hline & & Saskatchewan & $80-82$ \\
\hline & & Saudi-Arabien & 132 f., 136-138, \\
\hline Sacramento & 204 & & 213,215 \\
\hline Sahara & $105,111,113$ & Schottland & 140 \\
\hline Saigon & 161 f., 217 & Schumen & 197 \\
\hline \multirow[t]{2}{*}{ St. Louis } & 70 f., 83, 88, 201, & Schwarzes Meer & 133 \\
\hline & 203 & Schweden & $44,47-49,52,54$ \\
\hline Saint-Étienne & 196 & & $56-59,154,197-$ \\
\hline Saint-Omer & 195 & & 200,202 \\
\hline St. Paul & 201 & Schweiz & 9, 11, 25 f., 28, \\
\hline Saitama & 165 & & 43 f., 47-49, 51 f., \\
\hline Saloniki & $195 \mathrm{f}$. & & 54, 57 f., 59, 154, \\
\hline Salvador & $87,99,205 \mathrm{f}$. & & $196,198-200,202$ \\
\hline \multirow[t]{2}{*}{ Sambia } & 116, 119, 209, & Seattle & 203 \\
\hline & $211 \mathrm{f}$. & Semarang & 164,217 \\
\hline Samut Prakan & 159 & Senegal & $113,115,117,209$, \\
\hline San Antonio & 204 & & $211 \mathrm{f}$. \\
\hline San Bernardino & 203 & Seoul & 177,220 \\
\hline San Diego & 203 & Serbien & $63,196,201$ \\
\hline San Francisco & $74,201,203$ & Serbien-Montenegro & $201 \mathrm{f}$. \\
\hline San José & 204 & Sevilla & 34, 195 f., 198 \\
\hline San Juan & 206 & Seychellen & 109 \\
\hline Sankt-Lorenz-Strom & 77 & Shanghai & $180,182,220$ \\
\hline \multirow[t]{2}{*}{ Sankt Petersburg } & $40,42,45$ f., 49, & Sheffield & 198 \\
\hline & $196,198 \mathrm{f}$. & Shenyang & $180,182,220$ \\
\hline Santa Fe & 87,98 & Shenzhen & 182 \\
\hline Santiago de Chile & $87-89,99,205$ f. & Sherbrooke & 78 \\
\hline Santiago de Comp. & 196 & Shijiazhuang & 220 \\
\hline Santo Domingo & 206 & Shkodra & 197 \\
\hline Santos & 205 & Sian & s. Xi'an \\
\hline \multirow[t]{2}{*}{ São Paulo } & 84, 87-89, 98 f., & Sibirien & 122 f., 125 \\
\hline & $205 \mathrm{f}$ & Siena & 195 \\
\hline
\end{tabular}




\begin{tabular}{|c|c|c|c|}
\hline Sierra Leone & 119 & Südafrika & 105-109, 111-117, \\
\hline Silistra & 197 & & $119,135,209-211$ \\
\hline \multirow[t]{2}{*}{ Simbabwe } & 108 f., 113-115, & Südamerika & $22,67 \mathrm{f}$ \\
\hline & 117, 119, 209, 211 & Südasien & 7, 121, 139-151, \\
\hline \multirow[t]{3}{*}{ Singapur } & 24 f. , 151-154, 157, & & $215 \mathrm{f}$ \\
\hline & 159, 179, 217 f., & Südeuropa & $24,35,41,49-56$ \\
\hline & 217 & & $58-60,62,65,81$ \\
\hline Sizilien & 60 & & $90,97,99,102$ \\
\hline Skandinavien & $49,52,56,64$ & & 109, 138, 157, 195, \\
\hline \multirow[t]{2}{*}{ Slowakei } & 57, 60, 63 f., 196, & & 199 \\
\hline & 200 & Süditalien & $13,18,46,60$ \\
\hline Slowenien & 59 f., 64, 200, 202 & Südkorea & $24-26,170-174-$ \\
\hline Smolensk & 195 & & 179, 184, 219; vgl. \\
\hline Sofia & 195,197 & & Korea \\
\hline Solapur & 139 & Südostasien & $7,121,151-164$ \\
\hline Somalia & 119 & & $217 \mathrm{f}$. \\
\hline South Australia & 185 & Südosteuropa & 128,151 \\
\hline \multirow[t]{4}{*}{ Sowjetunion } & 31, 49-58, 63 f., & Südrhodesien & 108 \\
\hline & 122-126, 131, & Südstaaten (USA) & $69-76,82,203,204$ \\
\hline & 135 f., 197, 199 f., & Suez & 108 \\
\hline & 202; vgl. Russland & Sulawesi & 164 \\
\hline \multirow[t]{4}{*}{ Spanien } & $11,13,31,34$ f., 44, & Sumatra & 164 \\
\hline & 46 f., 51 f., 54, 56- & Surabaya & 164,217 \\
\hline & 61, 63 f., 109, 163, & Swasiland & 116 \\
\hline & 196 f., 199 f., 202 & Swerdlowsk & s. Jekaterinburg \\
\hline Speyer & 35,195 & Sydney & 185 f., 221 \\
\hline \multirow[t]{2}{*}{ Sri Lanka } & $139,142,145,147-$ & Syracuse & 201 \\
\hline & $149,151,215$ f. & Syrien & 133 f., 136-138, \\
\hline Stockholm & 197 & & $213-214$ \\
\hline Straßburg & 196 & & \\
\hline Suceava & 195 & Tadschikistan & 124-129, $212 \mathrm{f}$. \\
\hline Sudak & 195 & Taichung & 178 \\
\hline Sudan & $113,209-211$ & Tainan & 178 \\
\hline Sudetenländer & 46 & Taipeh & 178,220 \\
\hline
\end{tabular}




\begin{tabular}{|c|c|c|c|}
\hline \multirow[t]{3}{*}{ Taiwan } & $24-26,121,170-$ & Tschad & $119,209,211 \mathrm{f}$. \\
\hline & 172, 175 f., 178 f., & Tscheljabinsk & 122,124 \\
\hline & 184,219 & Türkei & $131,133-138,213-$ \\
\hline Taiyuan & 220 & & 215 \\
\hline Tamil Nadu & 143 & Tunesien & 107 f., 112-117, \\
\hline Tampa & 203 & & $119,209,211 \mathrm{f}$. \\
\hline Tangerang & 164 & Tunis & 105 \\
\hline Tangshan & 210 & Turin & 18, 46, 196, 198 \\
\hline Tansania & 118 f., 209-211 & Turkmenistan & $121,124,126-129$ \\
\hline Taschkent & 124 & & $212 \mathrm{f}$. \\
\hline Teheran & $131 \mathrm{f}, 214$ & Twer & 195 \\
\hline Tel Aviv & 131,133 & & \\
\hline Texas & 69 & Uganda & $118,209-211$ \\
\hline Thailand & $153,157-161,217 \mathrm{f}$. & Ukraine & 59 f., 63 f., 201, 203 \\
\hline Tianjin & s. Tientsin & Ungarn & 51-54, 59 f., 196 f., \\
\hline Tientsin & 180, 182 f., 220 & & 199 f., 202 \\
\hline Tiflis & 131,214 & Ural & $121-125,212$ \\
\hline Togo & 115 f., 119 & Uruguay & 89 f., 94 f., 98, 205- \\
\hline Tokio & 14, 17, 165 f., 168 & & 208 \\
\hline & 170,220 & USA & 7, 11, 17 f., 21-26, \\
\hline Toledo & $195 \mathrm{f}$. & & $32,68-79,81-84$ \\
\hline Toledo (USA) & 201 & & $86,89,97,100$ \\
\hline Toronto & $78-80,82$ & & 119, 151, 153 f., \\
\hline Toulon & 197 & & $163,165-169,171$ \\
\hline Toulouse & 195,197 & & 174, 184, 201, \\
\hline Tournai & 195,197 & & 203 f., 207 f. \\
\hline Tours & 195 & Usbekistan & 124-129, $212 \mathrm{f}$. \\
\hline Trentino & 28 & Utrecht & 197 \\
\hline Trier & 32 & & \\
\hline Trinidad und Tobago & 205 & Valencia & $195 \mathrm{f}$. \\
\hline Troyes & 195 & Valenciennes & 195 \\
\hline Tschech. Republik & 59 f., 64, 196, 200 & Valladolid & 195 \\
\hline Tschechoslowakei & $51-54,57,197,199$ & Valparaíso & 205 \\
\hline & f., 202 & Vancouver & $80-82$ \\
\hline
\end{tabular}




\begin{tabular}{|c|c|c|c|}
\hline Venedig & $\begin{array}{l}34-36,41,195 \text { f., } \\
198\end{array}$ & & $\begin{array}{l}\text { Osten, Vorderer } \\
\text { Orient }\end{array}$ \\
\hline Venezuela & 21, 94-98, 101 f., & Westbengalen & 143 \\
\hline & $204,206-208$ & Western Australia & 185 \\
\hline Ver. Königreich & $\begin{array}{l}39 \text { f., } 42 \text { f., } 47-49 \text {, } \\
51 \text { f., } 54,57 \text { f., 63, } \\
\text { 153, 171, 197, } \\
199 \text { f., 202; vgl. } \\
\text { England, Großbri- } \\
\text { tannien }\end{array}$ & Westeuropa & $\begin{array}{l}18,24,26,31,35 \text { f., } \\
40 \text { f., 43, 46-61, 63- } \\
65,70,76,84,90, \\
99 \text { f., 109, 119, 125, } \\
127,130 \text { f., 134- } \\
136,138,147,157,\end{array}$ \\
\hline Vereinigte Arab. & & & 167 f., 174, 177, \\
\hline Emirate (VAE) & $132,138,213,215$ & & 184, 188, 195, 199 \\
\hline Verona & 195 & Westjordanland & 213 \\
\hline Versailles & 197 & Westküste (USA) & $73-76,82,203 \mathrm{f}$. \\
\hline Vicenza & $195 \mathrm{f}$. & Westsibirien & 123 \\
\hline Victoria & 185 & Wien & $14,17,36,45$ f., \\
\hline Vientiane & 161 & & $195,197-199$ \\
\hline Vietnam & 158 f., 161 f., 217 f. & Windsor & 81 \\
\hline Villa Miseria & 93 & Winnipeg & 81 \\
\hline Vilnius & $195 \mathrm{f}$. & Wisconsin & 72 \\
\hline Visayas & 163 & Wladimir & 195 \\
\hline Vorarlberg & $19,28,46$ & Worcester & 201 \\
\hline Vorderer Orient & 189, vgl. Westasien, & Worms & 105 \\
\hline & Naher Osten & Wuhan & 180,220 \\
\hline Vorderasien & s. Westasien & & \\
\hline & & Xi'an & 183,220 \\
\hline Wales & 60 & & \\
\hline Warschau & 196,198 & Yangtse-Delta & 182 \\
\hline Washington, D.C. & $71,74,83,201,203$ & Yangtsekiang & 180,182 \\
\hline Weißrussland & $56,64,200,202$ & Yokohama & $166,168,220$ \\
\hline Weliko Tarnowo & 195 & Ypern & 195 \\
\hline Wellington & 188 & & \\
\hline Westasien & $7,121,130-139$ & Zaire & 113 \\
\hline & 213-215; vgl. Naher & Zentralafrikanische & \\
\hline
\end{tabular}




$\begin{array}{ll}\text { Republik } & 119 \\ \text { Zentralasien } & 7,121-129,212 \\ \text { Zhengzhou } & 220 \\ \text { Zibo } & 220 \\ \text { Zypern } & 200\end{array}$

